UNIVERSIDADE FEDERAL DE JUIZ DE FORA

FACULDADE DE MEDICINA

MESTRADO PROFISSIONAL EM SAÚDE DA FAMÍLIA

Ana Paula Vilas Boas Wheberth

EDUCAÇÃO PERMANENTE PARA MÉdICOS DA ESTRATÉGIA DE SAÚdE DA FAMÍLIA DE UM MUNICÍPIO POLO DE MINAS GERAIS

Juiz de Fora - MG 
Ana Paula Vilas Boas Wheberth

\title{
EDUCAÇÃO PERMANENTE PARA MÉDICOS DA ESTRATÉGIA DE SAÚDE DA FAMÍLIA DE UM MUNICÍPIO POLO DE MINAS GERAIS
}

\begin{abstract}
Dissertação apresentada ao Programa de Pósgraduação do Mestrado Profissional em Saúde da Família, área de concentração Educação e Saúde: tendências contemporâneas da educação, competência e estratégias de formação profissional. Núcleo de Assessoria, Treinamento e Estudos em Saúde, da Universidade Federal de Juiz de Fora, como requisito parcial para a obtenção do grau de Mestre.
\end{abstract}

Orientadora: Prof ${ }^{\mathrm{a}} \mathrm{Dr}^{\mathrm{a}}$ Beatriz Francisco Farah

Juiz de Fora - MG 
Ficha catalográfica elaborada através do programa de geração automática da Biblioteca Universitária da UFJF,

com os dados fornecidos pelo(a) autor(a)

Wheberth, Ana Paula Vilas Boas.

Educação Permanente para médicos da Estratégia de Saúde da Família de um município polo de Minas Gerais / Ana Paula Vilas Boas Wheberth. -- 2021.

$159 \mathrm{f}$. : il.

Orientadora: Beatriz Francisco Farah

Dissertação (mestrado profissional) - Universidade Federal de Juiz de Fora, Faculdade de Medicina. Programa de Pós-Graduação em Saúde da Família, 2021.

1. Educação Permanente para médicos. 2. Estratégia de Saúde da Família. 3. Aprendizagem significativa. 4. Atenção Primária à Saúde. I. Farah, Beatriz Francisco, orient. II. Título. 


\title{
EDUCAÇÃO PERMANENTE PARA MÉDICOS DA ESTRATÉGIA DE SAÚdE DA FAMÍLIA DE UM MUNICÍPIO POLO DE MINAS GERAIS
}

\begin{abstract}
Dissertação apresentada ao Programa de Pósgraduação do Mestrado Profissional em Saúde da Família, área de concentração Educação e Saúde: tendências contemporâneas da educação, competência e estratégias de formação profissional. Núcleo de Assessoria, Treinamento e Estudos em Saúde, da Universidade Federal de Juiz de Fora, como requisito parcial para a obtenção do grau de Mestre.
\end{abstract}

Aprovada em 24 de junho de 2021.

BANCA EXAMINADORA

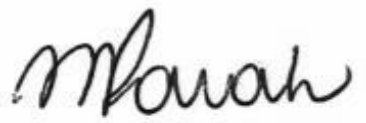

Prof Dr $^{\mathrm{a}}$ Beatriz Francisco Farah - Orientadora

Universidade Federal de Juiz de Fora

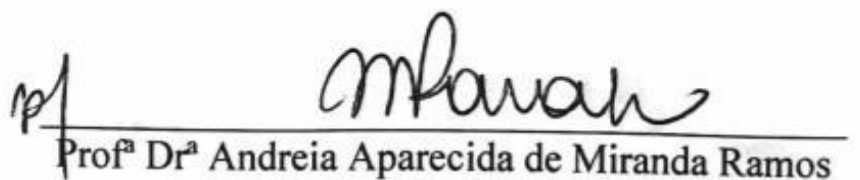

Universidade Federal de Juiz de Fora

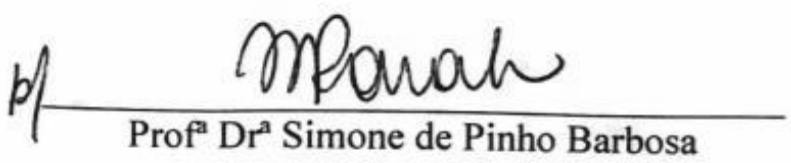

Universidade Federal de Juiz de Fora/Campus Governador Valadares 


\section{AGRADECIMENTOS}

Em 2015, tive três ou quatro sonhos que retornava à sala de aula na faculdade de medicina, exatamente como nas manhãs e tardes que passei nos primeiros anos da graduação. Assim, intrigada, perguntava a Deus em minhas orações: "meu Deus, por que estou tendo esta sequência de sonhos estudando em sala de aula, já com mais de dez anos de prática médica?" No ano seguinte, resolvi entrar na residência de Medicina de Família e Comunidade, estimulada por colegas e amigos próximos, reiniciando minha caminhada de estudo e processos educacionais, assim como este mestrado, que me possibilitaram ser preceptora da residência em que me formei e professora do curso de medicina da Universidade Federal de Juiz de Fora, campus Governador Valadares. Dessa forma justifico meu agradecimento a Deus, meu Fiel Companheiro e Amigo. Ao meu esposo Dhennis e filha Ana Luíza, os quais abriram mão de meus cuidados a fim de que eu pudesse realizar as viagens por $500 \mathrm{~km}$ para cumprir meus estudos neste mestrado. Também agradeço à minha mãe, educadora dedicada, pelo apoio e orações, às minhas irmãs, Valeska e Vanessa, pelo carinho e incentivo e aos meus colegas preceptores na residência. Este trabalho também é dedicado a vocês. Agradeço à Secretaria Municipal de Saúde de Governador Valadares pela autorização da pesquisa nas unidades de saúde e aos colegas do Departamento de Atenção à Saúde. Aos meus colegas do mestrado pela parceria e amizade. Externo meus fiéis agradecimentos à minha professora e orientadora Dra. Beatriz, que de forma dedicada, graciosa e competente, lançou luz sobre meus passos nesta pesquisa, também lembrando sobre os cuidados de se realizar uma pesquisa de campo, em plena pandemia. À professora doutora Simone, pelo apoio e pelo gentil e honroso consentimento em

participar da banca de qualificação e defesa. Aos professores e doutores das bancas de qualificação e defesa e todos os professores deste singular curso de mestrado profissional, obrigada por tanta gentileza e aprendizado dispensados à nossa turma. 


\section{RESUMO}

A Educação Permanente em Saúde (EPS) se apresenta como uma proposta de aprendizagem no trabalho, em que o aprender e o ensinar tornam-se inerentes ao cotidiano das organizações. A EPS se baseia na aprendizagem significativa e na possibilidade de transformar as práticas profissionais. Para a Atenção Primária à Saúde (APS), a efetiva EPS é desejável e está inserida na última Política Nacional da Atenção Básica (PNAB), na qual concerne acerca da responsabilidade do Estado, na disponibilização para os municípios de instrumentos técnicos e pedagógicos que facilitem o processo de formação e educação permanente dos membros das equipes de gestão e de atenção. Ressalta-se a importância da institucionalização desse processo nos municípios, pois se espera pela melhoria do desenvolvimento das práticas da Estratégia de Saúde da Família (ESF), já que tem sido o modelo prioritário de reorganização da APS no Brasil. Esta pesquisa tem como objetivo geral analisar as necessidades de educação permanente em saúde dos médicos da ESF, de um município polo de Minas Gerais. O estudo foi realizado nas UBS com ESF, no referido município, com a participação de 52 médicos da APS, lotados nessas ESF. A coleta de dados foi realizada em duas etapas: $1^{\mathrm{a}}$ - aplicou-se questionário com perguntas fechadas e abertas; $2^{\mathrm{a}}$ - realizou-se entrevista semiestruturada. Na etapa quantitativa os dados foram processados por análise descritiva e, na qualitativa, por meio da análise de conteúdo, do tipo análise temática, utilizando-se de software IRAMUTEQ. Na etapa quantitativa, foram construídas 4 categorias: 1. Caracterização sociodemográfica, de formação e trabalho dos médicos da ESF; 2. Educação permanente e continuada dos médicos da ESF; 3. Atributos da APS, princípios e ações desenvolvidas na ESF pelos médicos; 4. Satisfação, reconhecimento e valorização do trabalho médico na ESF. 98\% dos participantes informaram realizar educação permanente, porém, verificou-se que há dificuldade de entendimento entre educação permanente (EP) e continuada. Observou-se que a educação continuada é uma prática importante e muito presente na educação desses profissionais A modalidade mais citada de EP foi a educação a distância (83\%). Dentre as atividades diárias realizadas pelos médicos, as de participação com a comunidade foi a mais referida $(21,4 \%)$. Na etapa qualitativa emergiram duas categorias: 1. Habilidades e competências para o médico da ESF; 2. Importância da EP na prática médica na ESF. Na primeira, o perfil médico necessário coaduna com o currículo baseado em competências na Sociedade Brasileira de Medicina de Família e Comunidade; a relação médico-paciente, a sinergia e harmonia do trabalho em equipe, além da competência clínica e a importância de um olhar mais humanizado, são características destacadas nesse perfil. Na segunda, quanto à EPS, apesar de não se haver um total entendimento, sendo 
confundida com a EC, apresentou-se importante em aproximar-se à origem do exercício profissional a fim de promover as transformações pertinentes. Este estudo é inovador no município até esta data e objetiva-se com este contribuir para um futuro projeto de educação permanente dos médicos da ESF e favorecer o modelo assistencial de saúde da ESF.

Palavras-chave: Educação Permanente para Médicos. Estratégia de Saúde da Família. Aprendizagem Significativa. Atenção Primária à Saúde 


\begin{abstract}
Permanent Education in Health (PEH) presents itself as a proposal for learning at work, in which learning and teaching become inherent to the daily lives of organizations. PEH is based on meaningful learning and the possibility of transforming professional practices. For Primary Health Care (PHC), the effective PEH is desirable and is included in the latest National Policy for Primary Care (NPPC), in which it concerns the State's responsibility, in providing technical and pedagogical instruments that facilitate the process of training and permanent education of the members of the management and care teams. The importance of institutionalizing this process in the municipalities is emphasized, as it is expected to improve the development of the practices of the Family Health Strategy (FHS), since it has been the priority model for PHC reorganization in Brazil. This research has as general objective to analyze the needs of permanent education in health of the doctors of the FHS, of a city pole of Minas Gerais. The study was carried out in BHU with FHS, in that municipality, with the participation of 52 PHC doctors, assigned to these FHS. Data collection was carried out in two stages: 1st - a questionnaire was applied with closed and open questions; 2nd - semi-structured interview was carried out. In the quantitative stage, the data were processed by descriptive analysis and, in the qualitative one, through content analysis, of the thematic analysis type, using IRAMUTEQ software. In the quantitative stage, 4 categories were built: 1. Sociodemographic characterization, training and work of FHS doctors; 2. Permanent and continuous education of FHS doctors; 3. PHC attributes, principles and actions developed in the FHS by doctors; 4. Satisfaction, recognition and appreciation of medical work in the FHS. $98 \%$ of the participants informed that they had a permanent education, however, it was found that there is difficulty in understanding between permanent (PE) and continuing education. It was observed that continuing education is an important practice and very present in the education of these professionals. The most cited modality of PE was distance education (83\%). Among the daily activities performed by doctors, participation in the community was the most mentioned (21.4\%). In the qualitative stage, two categories emerged: 1 . Skills and competences for the FHS physician.; 2. Importance of PE in medical practice in the FHS. In the first, the necessary medical profile is consistent with the competency-based curriculum at the Brazilian Society of Family and Community Medicine; the doctor-patient relationship, the synergy and harmony of teamwork, in addition to clinical competence and the importance of a more humanized look, are characteristics highlighted in this profile. In the second, regarding $\mathrm{PEH}$, although there is no total understanding, being confused with $\mathrm{CE}$, it was important to get closer
\end{abstract}


to the origin of professional practice in order to promote the relevant transformations. This study is innovative in the municipality to date and aims to contribute to a future permanent education project for FHS doctors and to promote the FHS health care model.

Descriptors: Permanent Education for Doctors. Family Health Strategy. Meaningful learning. Primary Health Care 


\section{LISTA DE QUADROS}

Quadro 1 - Síntese propostas e elaboradas nas oficinas regionais .........................................28

Quadro 2 - As Conferências Nacionais de Saúde e a educação dos trabalhadores da saúde ...34

Quadro 3 - Método do Arco ou Arco de Maguerez................................................................... 46

Quadro 4 - Unidades Básicas de Saúde do município polo com modelo de Estratégia de Saúde

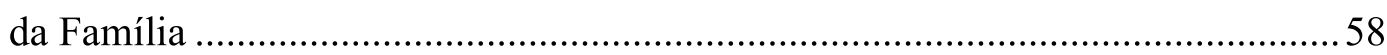

Quadro 5 - Composição das categorias de análise ................................................................. 90 


\section{LISTA DE FIGURAS}

Figura 1 - Mapa conceitual da Trajetória do Desenvolvimento da Educação Permanente ......24

Figura 2 - Método do Arco ou Arco de Maguerez .................................................................. 45

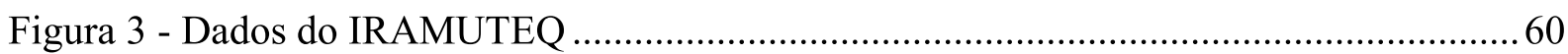

Figura 4 - Dendrograma da Classificação Hierárquica Descendente realizado pelo software

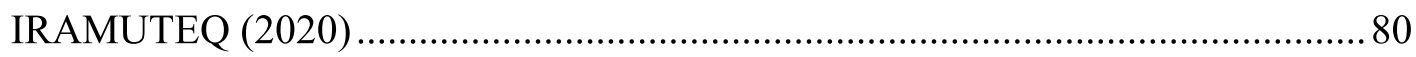

Figura 5 - Representação da Análise Fatorial de correspondência fornecida pelo software

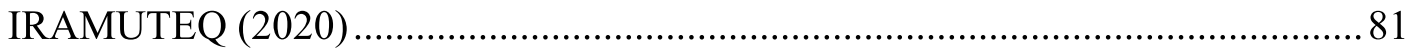

Figura 6 - Árvore de similitude gerada pelo software IRAMUTEQ (2020) ........................... 84

Figura 7 - Nuvem de palavras gerada pelo software IRAMUTEQ (220) .............................. 88 


\section{LISTA DE TABELAS}

Tabela 1 - Características sociodemográficas de formação e trabalho dos médicos da Estratégia de Saúde da Família, (N=52), 2020)

Tabela 2 - Aspectos educativos autorreferidos pelos médicos na Estratégia de Saúde da Família, (N=52), 2020)

Tabela 3 - Atributos da APS, princípios e ações desenvolvidas na Estratégia da Saúde da Família, $(\mathrm{N}=52), 2020)$.

Tabela 4 - Percepção dos médicos relacionada à satisfação, reconhecimento e valorização do trabalho médico na Estratégia de Saúde da Família, $(\mathrm{N}=52), 2020$. 


\section{LISTA DE SIGLAS}

APS

ACS

CHD

CIES

CIR

CIB

CONASS

CONASEMS

CES

CLS

$\mathrm{DCN}$

DEGES

DF

EAD

EC

EP

EPS

ES

ESF

ESP

ESP-MG
Atenção Primária à Saúde

Agente Comunitário de Saúde

Classificação Hierárquica Descendente

Comissão de Integração Ensino Serviço

Comissões Intergestores Regionais

Comissão Intergestores Bipartite

Conselho Nacional de Secretários de Saúde

Conselho Nacional de Secretarias Nacionais de Saúde

Conselho Estadual de Saúde

Conselho Local de Saúde

Diretrizes Curriculares Nacionais

Departamento de Gestão da Educação na Saúde

Distrito Federal

Educação a Distância

Educação Continuada

Educação Permanente

Educação Permanente em Saúde

Educação em Saúde

Estratégia de Saúde da Família

Escola de Saúde Pública

Escola de Saúde Pública do Estado de Minas Gerais 


$\begin{array}{ll}\text { E-SUS AB } & \text { Sistema de Informação da Atenção Básica } \\ \text { FIOCRUZ } & \text { Fundação Oswaldo Cruz } \\ \text { GAP } & \text { Grupo de Aperfeiçoamento Profissional } \\ \text { HIPERDIA } & \text { Hipertensão e Diabete } \\ \text { IRAMUTEQ } & \begin{array}{l}\text { Interface de R pour les Analyses Multidimensionnelles de Textes et de } \\ \text { Questionnaires }\end{array} \\ \text { MCCP } & \text { Método Clínico Centrado na Pessoa } \\ \text { MFC } & \text { Medicina de Família e Comunidade } \\ \text { MS } & \text { Ministério da Saúde } \\ \text { NASF } & \text { Núcleo Ampliado de Saúde da família } \\ \text { PACS } & \text { Programa agentes comunitários de saúde } \\ \text { PDR } & \text { Plano Diretor de Regionalização } \\ \text { PEP } & \text { Programa de Educação Permanente } \\ \text { PEPS } & \text { Polos de Educação Permanente em saúde }\end{array}$

PMAQ-AB Programa Nacional de Melhoria do Acesso e da Qualidade da Atenção Básica (PMAQ-AB)

PMM Programa Mais Médicos

PNAB Política Nacional de Atenção Básica

PNEPS Política Nacional Educação Permanente em Saúde

PNFP Plano Nacional de Formação de Preceptores

PNS Plano Nacional de Saúde

PSF Programa de Saúde da Família

PRO EPS-SUS Programa para o Fortalecimento das Práticas de Educação Permanente em Saúde no SUS 
RUTE

SBMFC

SES/MG

SGTES

ST

SUS

OPAS

TIC

UBS

UNA - SUS

UNESCO

UNICEF

WONCA
Rede Universitária de Telemedicina

Sociedade Brasileira de Medicina de Família e Comunidade

Secretaria de Estado de Saúde de Minas Gerais

Secretaria de Gestão do Trabalho e da Educação em Saúde

Segmento de Texto

Sistema Único de Saúde

Organização Pan-Americana da Saúde

Tecnologia da informação e Comunicação

Unidade Básica de saúde

Universidade Aberta do Sistema Único de Saúde

Organização das Nações Unidas para a Educação, Ciência e Cultura

Fundo das Nações Unidas para a Infância

World Organization of Family Doctors 


\section{SUMÁRIO}

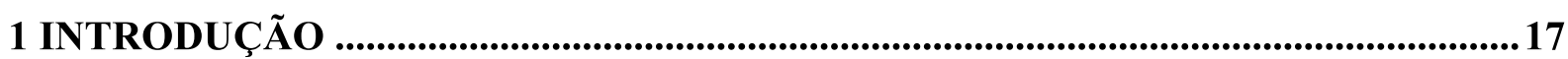

2 JUSTIFICATIVA ……............................................................................................................22

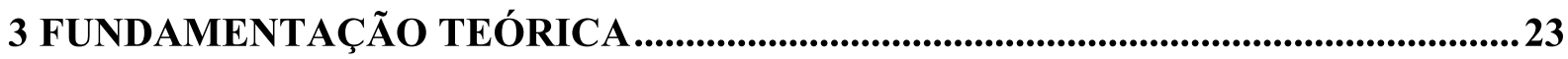

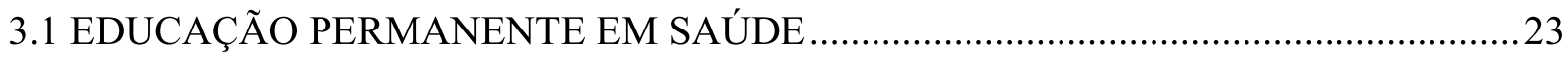

3.1.1. Breve contextualização das Conferências Nacionais de Saúde e a Educação

Permanente em Saúde.....................................................................................................33

3.1.2 A educação permanente em saúde como dispositivo de transformação na formação médica.............................................................................................................................38

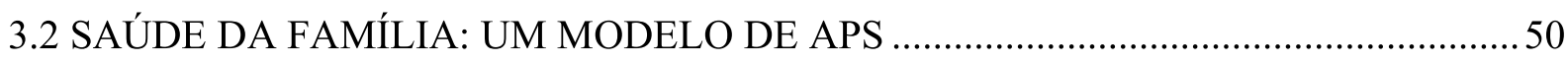

4 OBJETIVOS GERAIS ........................................................................................................56

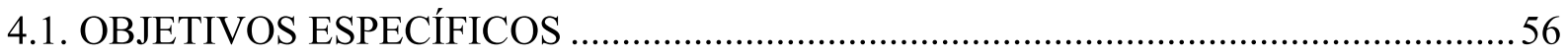

5 PERCURSO METODOLÓGICO.....................................................................................57

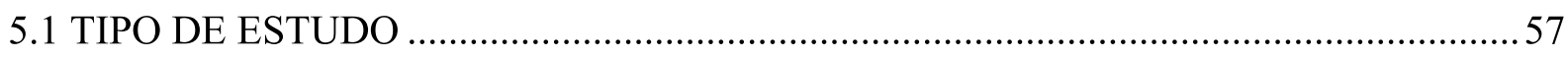

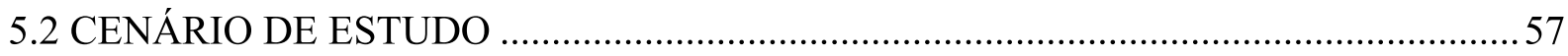

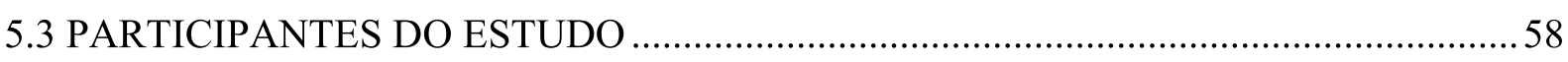

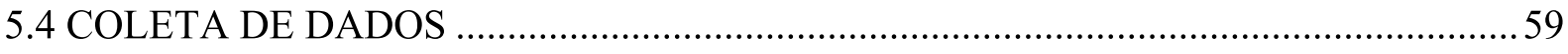

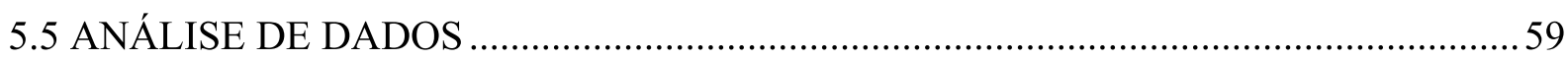

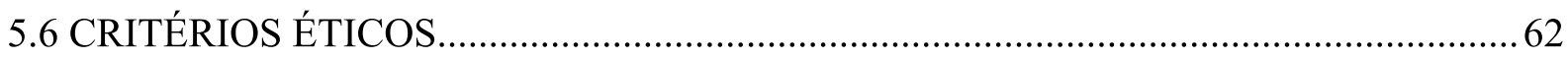

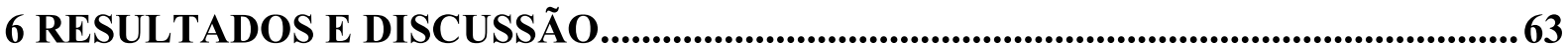

6.1 CARACTERIZAÇÃO SOCIODEMOGRÁFICA, DE FORMAÇÃO E TRABALHO DOS MÉDICOS DA ESTRATÉGIA DE SAÚDE DA FAMÍLIA ………………………......... 63

6.2 EDUCAÇÃO PERMANENTE E EDUCAÇÃO CONTINUADA DOS MÉDICOS DA

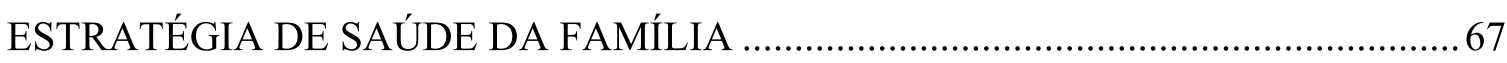

6.3 ATRIBUTOS DA APS, PRINCÍPIOS E AÇÕES DESENVOLVIDAS NA

ESTRATÉGIA DE SAÚDE DA FAMÍLIA PELOS MÉDICOS …………………….......73

6.4 SATISFAÇÃO, RECONHECIMENTO E VALORIZAÇÃO DO TRABALHO MÉDICO

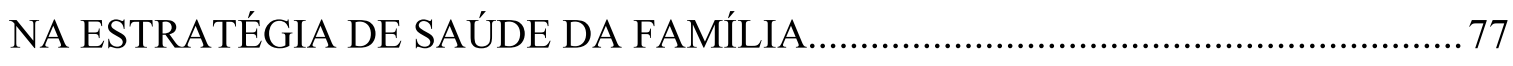

6.5 RESULTADOS DA ANÁLISE TEXTUAL DO SOFTWARE IRAMUTEQ …………....79

6.6 CATEGORIA 1:AS HABILIDADES E COMPETÊNCIAS NECESSÁRIAS PARA SER

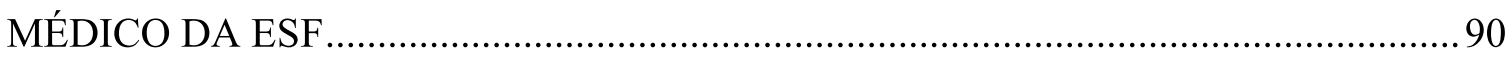


6.7 CATEGORIA 2: A IMPORTÂNCIA DA EDUCAÇÃO PERMANENTE NA PRÁTICA PROFISSIONAL MÉDICA NA ESTRATÉGIA DE SAÚDE DA FAMÍLIA..................99

6.8 DIRETRIZES PARA UM PROGRAMA DE EDUCAÇÃO PERMANENTE EM

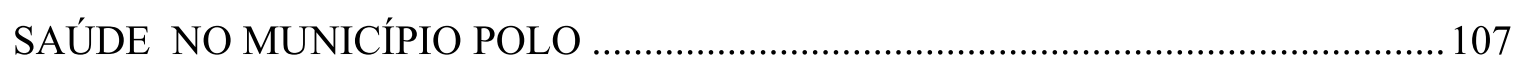

7 CONSIDERAÇÕES FINAIS........................................................................................110

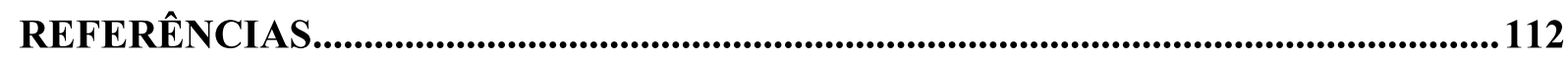

APÊNDICE A - TERMO DE CONSENTIMENTO LIVRE E ESCLARECIDO............132

APÊNDICE B - TERMO DE CONSENTIMENTO LIVRE E ESCLARECIDO ............133

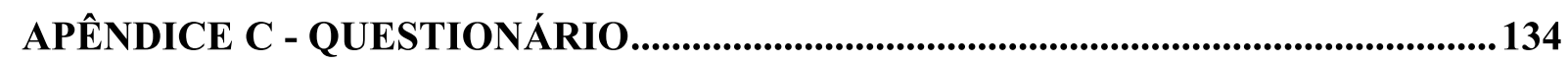

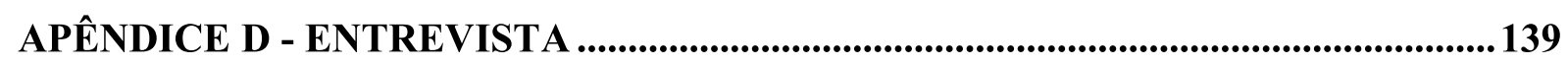

ANEXO A - DADOS DO PROJETO DE PESQUISA ………………………........................... 140

ANEXO B - DADOS DO QUESTIONÁRIO DA PESQUISA COMPILADOS NO

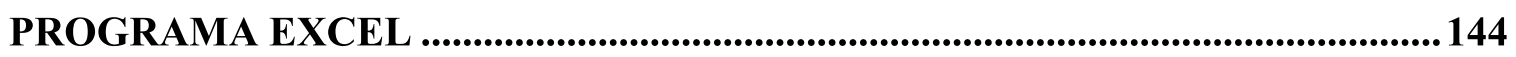




\section{INTRODUÇÃO}

A insuficiência da formação de profissionais para a área de saúde para atender as necessidades de saúde da população brasileira é referida desde as primeiras conferências nacionais do setor, demonstrando que a formação andava em descompasso com as demandas tocantes a essa esfera da realidade brasileira (GONZÁLEZ et al., 2010).

A premência de um novo perfil profissional para atuar no Sistema Único de Saúde (SUS) objetivando a implementação e consolidação do modelo assistencial de saúde proposto, tornou-se uma das atribuições do SUS. O artigo 200, inciso III da Constituição Federal de 1988, informa que a ordenação da formação dos profíssionais de saúde é de competência do SUS, pois se deseja que esses estejam capacitados para atenderem à realidade de saúde da população brasileira (BRASIL, 1988).

Para observar e efetivar essa tarefa, o Ministério da Saúde tem desenvolvido diversas estratégias e políticas voltadas para a adequação da formação e qualificação dos trabalhadores de saúde às necessidades de saúde da população e ao desenvolvimento do SUS (BRASIL, 2018d).

Porém, a formação médica flexneriana ainda presente em diversas escolas, que privilegia o modelo assistencial hospitalocêntrico, com foco no indivíduo, na doença e no tratamento, tem sido constantemente debatida nos diversos espaços da educação médica. A mudança na formação foi lenta e vivenciada por vários projetos que tinham como objetivo aproximar a academia dos serviços de saúde do SUS, com intuito de estimular as mudanças curriculares. Todos os esforços de mudanças culminaram em 2001 com as Diretrizes Curriculares Nacionais (DCN) para a área de saúde que propunham um novo profissional de saúde para que pudessem atuar na prevenção de doenças, promoção, cura e reabilitação da saúde, focando o indivíduo, família e comunidade e estivesse preparado para atuar em diversos cenários da saúde. Em 2014, as DCN foram reformuladas e atualmente as escolas de medicina têm pautado suas mudanças curriculares para a adequação (ALMEIDA et al., 2010).

Com o advento do SUS, um grande contingente de profissionais de saúde, em particular, os médicos, inseridos em seus cenários de prática, teve que se adequar às propostas do modelo assistencial de saúde. A Educação Permanente para os profissionais, assim, foi proposta como uma ferramenta que estivesse apta a contribuir para a adequação e transformação desses profissionais.

A Educação Permanente em Saúde (EPS) se apresenta como uma proposta de aprendizagem no trabalho, em que o aprender e o ensinar tornam-se inerentes ao cotidiano das organizações. Isso porque a EPS se baseia na aprendizagem significativa e na possibilidade de transformar as práticas profissionais (BRASIL, 2018d). Além disso, oportuniza uma prática reflexiva, mediada pela capacidade de crítica e pela necessidade de transformação a partir dos processos desencadeados no 
trabalho. Seus pressupostos priorizam os problemas cotidianos dos serviços de saúde e das equipes, buscando a transformação das práticas, as relações entre os sujeitos e a compreensão do trabalho em saúde, na tentativa de superar a lógica das capacitações, aperfeiçoamentos e atualizações (SILVA K. M. et al., 2015).

Desde meados da década de 1980, a EPS vem sendo amplamente divulgada e disseminada como um novo instrumento de formação para a transformação das práticas em saúde, levando em consideração as necessidades sociais e não apenas qualificando os serviços, mas tornando os profissionais dotados de segurança em si (BARTH et al., 2014; LEMOS, 2016).

A concepção de EPS vai além do "aprender a aprender" e da responsabilidade de gerações futuras de profissionais. "A EPS é entendida, ao mesmo tempo, como uma prática de ensinoaprendizagem e como uma política de educação na saúde.” (CECCIM; FERLA, 2009, p. 1). Segundo Ceccim et al. (2009), a EPS como "prática de ensino-aprendizagem" está relacionada à produção de conhecimentos no cotidiano das instituições de saúde, a partir da realidade vivida pelos sujeitos envolvidos, tendo como base de interrogações os problemas enfrentados no dia a dia do trabalho e as experiências desses sujeitos. Como "política de educação na saúde", a EPS representa a contribuição do ensino à construção do Sistema Único de Saúde (SUS), na medida em que tanto as políticas de saúde, quanto as diretrizes curriculares nacionais para a formação dos profissionais da área, buscam inovar na proposição de articulações entre o ensino, o trabalho e a cidadania.

A EPS tal como concebida pelos gestores do Ministério da Saúde adota como pressuposto pedagógico a noção de aprendizagem significativa: aprendizado de algo que faça sentido para os sujeitos envolvidos de modo que os processos de capacitação sejam estruturados a partir da problematização dos processos de trabalho (VENTURELLI, 2006).

Para que se tenha uma EPS como aprendizado transformador, é preciso superar a prática domesticada, tecnicista e acrítica de executar suas funções, com segmentação de ideias ancoradas em ação automática do processo. É necessário instituir novas maneiras de pensar e de agir na educação no trabalho, trazendo consigo a proposta da transformação pessoal, profissional e institucional (SILVA et al., 2014). Caracteriza-se, portanto, como uma robusta vertente educacional com potencialidades ligadas a mecanismos e temas que possibilitam gerar reflexão acerca do processo de trabalho, autogestão, mudança institucional e transformação das práticas em serviço, por meio da proposta do aprender a aprender, de trabalhar em equipe, de construir realidades diárias e eles mesmos tornarem-se como objeto de aprendizagem individual, coletiva e institucional (BRASIL, 2018d).

No que se refere à Atenção Primária à Saúde (APS), que tem a Estratégia da Saúde da Família (ESF) como modelo prioritário de reorganização, a EPS é desejável e está inserida na última Política Nacional da Atenção Básica (PNAB) segundo a portaria nº 2.436 de 21 de setembro de 2017. 
Nessa política destaca-se a necessidade de implantação da EPS para os profissionais de saúde e que é responsabilidade do Estado a disponibilização aos municípios de instrumentos técnicos e pedagógicos que facilitem o processo de formação e educação permanente dos membros das equipes de gestão e de atenção (BRASIL, 2009a).

A EPS se apresenta como uma estratégia de educação na saúde que tem um olhar sobre as necessidades do médico, equipe, território e gestão, configurando-se como um processo de direção participativa e transformadora, que inclui instituições de ensino, trabalhadores, gestores e usuários, conformando o "quadrilátero da formação" (CUNHA, 2009; PESSOA et al., 2013; SILVA, 2013). A articulação do quadrilátero do SUS (ensino - serviço - gestão - controle social) ganha relevância porque a formação na área da saúde deve considerar, para além das exigências do mercado de trabalho, que demanda cada vez mais trabalhadores treinados para a produção do capital; é preciso interagir com os diversos atores que têm interseção nos serviços de saúde, pois essa interação é determinante da qualidade da resposta assistencial (CECCIM et al., 2004).

A implementação da educação permanente favorece o princípio da alteridade, pois o trabalhador é também transformado, ao passo em que programa condutas que visem à transformação da realidade em saúde de determinada comunidade. Os desafios impostos pela APS, especialmente por meio da ESF, para a realização de novas práticas que reorientem o quadro sanitário nacional, convergem com a edificação de métodos e práticas democratizantes e inovadoras de gestão do trabalho no SUS. A EPS, na APS, contribui para aprimorar o processo de análise da realidade social e subsidiar a tomada de decisão, bem como aumentar a resolubilidade e qualificar os processos de longitudinalidade do cuidado, promover a humanização da assistência, a competência pedagógica e cultural coletiva (TESSER et al., 2011).

Comumente, a deficiência do médico não está no conhecimento. A matriz de competência desde a formação acadêmica envolve além do conhecimento, habilidades e atitudes mais acertadas que necessitem ser desenvolvidas pelo futuro médico ou no presente exercício profissional, para um desempenho qualificado e resolutivo. A construção de habilidades, principalmente as ligadas à comunicação, requer reforço, tendo como objetivo qualificar a relação médico-paciente. Desenvolver o hábito da aprendizagem autoinduzida de longo prazo e de avaliação da prática profissional, com mensuração de desfechos e induzir uma cultura de transformação e renovação, são aspectos importantes nas intervenções de educação permanente para médicos (SILVÉRIO, 2008).

É sugerido que a educação permanente seja desenvolvida por meio da aprendizagem colaborativa em pequenos grupos de médicos, centrada em dados da realidade dos pares, que se apresentem como um cenário potente para melhorar a prática profissional e devendo ser realçada. Mudar a prática profissional de um médico não é simples: é um processo complexo. Na maioria das 
vezes a aquisição de novos conhecimentos, habilidades e atitudes apresentam-se insuficientes para empreender novas práticas. A aquisição de competências e capacidade de fazer são fatores predisponentes. $\mathrm{O}$ estabelecimento da mudança na prática depende muito de agentes facilitadores que se encontram no contexto de trabalho, seja de estrutura física, material e logística, seja no contexto social de organização, motivação e postura da equipe de saúde. Quando o médico adquire nova competência e encontra ambiente favorável no trabalho, ele pode modificar sua prática (SILVÉRIO, 2008).

Em Minas Gerais foi instituída a resolução da Secretaria Estadual de Saúde - SES/MG no 3.229, de 18 de abril de 2012, que dispôs acerca das normas gerais do Programa de Educação Permanente (PEP) para médicos de família. Esse considerou, dentre alguns requisitos, o Plano Estadual de Saúde e a necessidade de organizar a APS no Estado. Expôs, também, os objetivos do Programa, o método educacional, as competências do Estado, parceria universitária, deveres dos médicos participantes e outros (MINAS GERAIS, 2012).

O Programa de Educação Permanente (PEP)foi implantado em 29 municípios do Estado de Minas Gerais, com ação descentralizada e parcerias estratégicas da Secretaria de Estado da Saúde de Minas Gerais (SES/MG) com a Escola de Saúde Pública de Minas Gerais, Universidade Federal dos Vales do Jequitinhonha e Mucuri (UFVJM), Associação Mineira de Medicina de Família e Comunidade, gestores municipais de saúde e médicos das Equipes da ESF (MINAS GERAIS, 2012). Em um estudo foi verificado que médicos que participavam do programa de educação permanente mostraram-se satisfeitos, com relatos de mudança da prática, não só por parte desses, mas também dos usuários e dos gestores de saúde. Assim, pode-se inferir que o programa nesses municípios é efetivo, promovendo mudança na prática profissional, perceptíveis aos médicos, gestores e usuários do SUS. O programa contribuiu capacitando os médicos para utilização do método clínico centrado na pessoa em suas consultas, reduzindo o isolamento profissional, criando vínculo, não só com a população, mas com outros profissionais de cidades vizinhas e aumentando a fixação profissional nos municípios (CRUZ et al., 2018).

O presente trabalho, assim, propõe a transformação da prática profissional médica em um município polo de Minas Gerais contemplando os aspectos e metodologias mencionados e introduzindo a EPS no cotidiano laboral dos médicos da APS do município.

A EPS em um município polo de Minas Gerais caminha de forma incipiente. Há relatos de tentativa de instituição do Programa de Educação Permanente (PEP) para médicos em 2009, porém, não houve êxito. No final de abril de 2019 houve uma oficina na Regional de Saúde desse município, acerca da EPS para representantes de 20 municípios da região leste do Estado. Tal ação faz parte das 
atividades de implantação do Programa para fortalecimento das práticas de Educação Permanente no SUS (BRASIL, 2018).

As práticas de educação para médicos na APS do referido município têm se baseado em capacitações frequentes, com temas variados, conformadas na modalidade da Educação Continuada (EC), todavia, com temas escolhidos de forma verticalizada, em horários de trabalho protegidos às tardes, em datas mensais, de acordo com a disponibilidade do palestrante e com o cuidado de não desamparar a assistência médica nas Unidades (procura-se chamar um médico de cada unidade por vez). Em abril de 2019, iniciou-se o Programa de Matriciamento em Saúde Mental, com reuniões mensais divididas em dois grupos de médicos da APS liderados pelo psiquiatra dos Centros de Referência em Saúde Mental (atenção secundária). O Matriciamento em Saúde Mental é uma das atividades da EPS, pois objetiva modificar as práticas desses profissionais em suas equipes, já que produz um aprendizado contextualizado e significativo. A discussão dos casos clínicos vivenciados por eles pode transformar suas atuações no território, ajudando na condução e resolução do tratamento de usuários em sofrimento mental na própria atenção primária. 


\section{JUSTIFICATIVA}

Em virtude das dificuldades enfrentadas para a implementação e consolidação do SUS, sendo uma delas a formação dos profissionais de saúde e, nesse caso, a dos médicos, ao modelo de saúde proposto para o sistema, foi instituída a Política Nacional de Educação Permanente em Saúde (PNEPS) por meio da portaria $\mathrm{n}^{\circ} 1.996$, de 20 de agosto de 2007, na qual dispunha a respeito das diretrizes para a implementação da PNEPS (BRASIL, 2007a).

Para o funcionamento da PNEPS é necessária a elaboração de Plano de Ação Regional de Educação Permanente em Saúde, que esteja articulado e integrado com o Plano Regional de Saúde e coerente com a portaria GM/MS n ${ }^{\circ}$. 3.332, de 28 de dezembro de 2006. Dentre as orientações, destacam-se: identificação do (s) problema (s) de saúde, isto é, identificar os principais problemas enfrentados pela gestão e pelos serviços daquela região, assim como seus descritores; a caracterização da necessidade de formação em saúde; a identificação das carências de determinadas categorias profissionais e; o desenvolvimento dos profissionais dos serviços a partir do perfil epidemiológico da população e dos processos de organização do cuidado em saúde de uma dada região. Também, quanto ao funcionamento adequado da PNEPS, há a necessidade de atualização dos problemas e necessidades de educação permanente para que se atinjam os propósitos dessa política. Portanto verifica-se aderência deste projeto de pesquisa com a portaria referida.

Atuo na APS do município desta pesquisa há 14 anos, acompanhando a trajetória das equipes quanto à sua expansão, interação, deficits de conhecimento e cumprimento dos atributos da APS, problemas nas relações de trabalho, alta rotatividade dos profissionais, sobretudo de médicos que apresentam práticas fragmentadas. Percebem-se fragilidades na prática clínica dos médicos na ESF, em virtude do pouco conhecimento quanto aos protocolos, Medicina Baseada em Evidências, Prevenção Quaternária e princípios da Medicina de Família e Comunidade. Também se verifica pouco envolvimento desses profissionais com o trabalho em equipe, recusa em acolher e facilitar o acesso da população aos serviços de saúde (um dos princípios essenciais da Atenção Primária em Saúde).

Nessa perspectiva, essa pesquisa tem como finalidade traçar diretrizes para a elaboração de um projeto de intervenção de educação permanente para médicos, pois é uma ação importante para organizar e qualificar o trabalho médico nas equipes de APS, tendo como foco principal a ESF e a promoção da saúde para os usuários da APS. 


\section{FUNDAMENTAÇÃO TEÓRICA}

\subsection{EDUCAÇÃO PERMANENTE EM SAÚDE}

A educação permanente em saúde está evoluindo com o passar do tempo e atualmente ela pode ser entendida enquanto "prática de ensino-aprendizagem" (embasada na problematização do cotidiano de trabalho e produção de conhecimento para solução dos problemas identificados) e como "política de educação na saúde" (contribuição do ensino para a construção do SUS) (CECCIM; FERLA, 2008). Os referidos autores endossam o caráter político da EPS quando dizem que não é um processo didático-pedagógico, mas, sim, político-pedagógico. Como política, a EPS objetiva promover o ensino e a aprendizagem no cotidiano de trabalho dos profissionais que atuam nas unidades de saúde, visando à transformação de suas práticas de saúde de acordo com os princípios e diretrizes do SUS. Por isso, é de extrema importância que os profissionais que atuam no SUS, compreendam esse conceito e proponham processos de EPS, que, de fato, atendam às demandas reais de suas práticas de trabalho e contribuam para a sua reflexão (PINTO et al., 2016).

A EPS para ser desenvolvida se estrutura no ensino problematizado e na aprendizagem significativa. Pinto et al. (2016) também apontam que a EPS deve se fazer na dialogicidade e problematização da realidade e na construção conjunta e criativa de soluções pensadas por sujeitos que se desenvolvem e se emancipam durante o processo, enfatizando o caráter político e de gestão da EPS.

A Política Nacional de Educação Permanente em Saúde (BRASIL, 2009) e a Portaria ${ }^{\circ}$ 278/2014 (BRASIL, 2014) reforçam esses dois aspectos:

A Educação Permanente é a aprendizagem no trabalho, onde o aprender e o ensinar se incorporam ao cotidiano das organizações e ao trabalho. A educação permanente se baseia na aprendizagem significativa e na possibilidade de transformar as práticas profissionais. A educação permanente pode ser entendida como aprendizagemtrabalho, ou seja, ela acontece no cotidiano das pessoas e das organizações (...). Propõe que os processos de educação dos trabalhadores da saúde se façam a partir da problematização do processo de trabalho, e considera que as necessidades de formação e desenvolvimento dos trabalhadores sejam pautadas pelas necessidades de saúde das pessoas e populações. Os processos de educação permanente em saúde têm como objetivos a transformação das práticas profissionais e da própria organização do trabalho. (BRASIL, 2009, p. 20; BRASIL, 2014, p. 20).

Silva et al. (2011) enfatizam que a finalidade da EPS necessita de ações mais amplas e menos burocráticas para que essa seja colocada em prática. Afirmam que a EPS tem o objetivo de constituir uma rede de ensino-aprendizagem no exercício do trabalho no SUS com a sua recomposição na 
direção das necessidades da população/usuários como cidadãos de direitos. Afinal, no setor da saúde ocorre uma concentração do saber em áreas técnicas de profissionais específicos, que minimizam as realidades locais em prol do conhecimento técnico, que impõe uma linha de prescrições ao trabalho. Portanto, faz-se necessário ampliar as possibilidades de respostas para além do normatizado, por meio da interação intersubjetiva, em direção às necessidades de saúde dos usuários/população.

Este trabalho, dessa forma, coaduna com os autores acima referidos e enfatiza a EPS como política, que incentiva e facilita o aprendizado no trabalho de forma estimulante e significativa, problematizador, além de qualificar a assistência à saúde aos usuários e promover satisfação aos profissionais em suas práticas.

Para melhor entendimento da trajetória do desenvolvimento da EPS até a construção da PNEPS, esquematizou-se um mapa conceitual (Figura 1). Segundo Novak et al. (2010, p.10), "mapas conceituais são ferramentas gráficas para a organização e representação do conhecimento".

Figura 1 - Mapa conceitual da Trajetória do Desenvolvimento da Educação Permanente

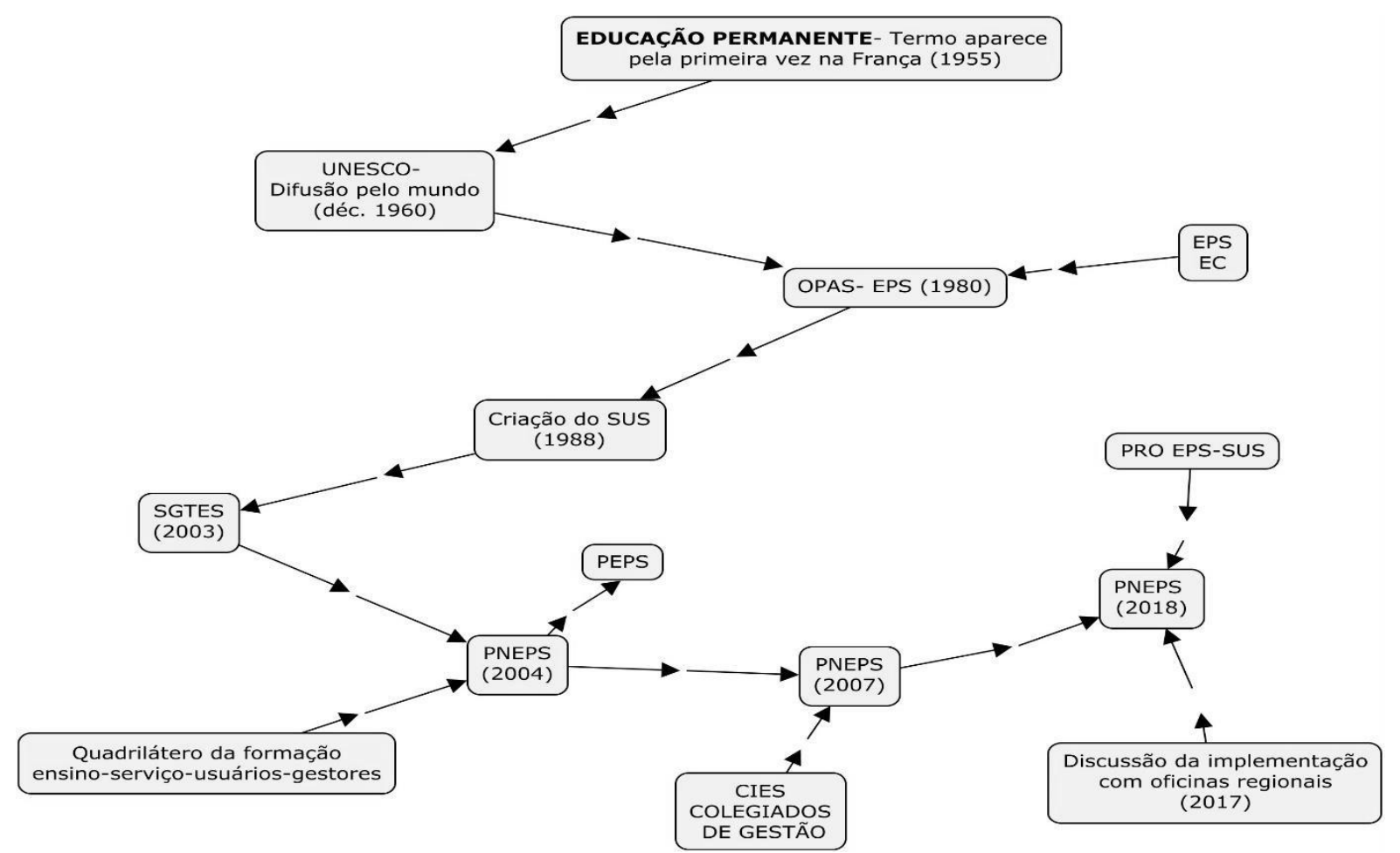

Fonte: Elaborado pela autora (2020).

O termo Educação Permanente aparece pela primeira vez na França em 1955 e foi oficializado no ano seguinte em um documento do Ministro Educacional referente ao prolongamento da escolaridade obrigatória e da reforma do ensino público (GADOTTI, 1988). No final da década de 1960, passa a ser difundido pela Organização das Nações Unidas para a Educação, Ciência e Cultura (UNESCO), fundamentado na teoria do capital humano (SCHULTZ, 1985), que compreende 
a qualificação do trabalhador como um dos mais importantes meios para a produtividade econômica e o desenvolvimento do país. A nomenclatura derivada, Educação Permanente em Saúde (EPS) é difundida em meados da década de 1980, pelo Programa de Desenvolvimento de Recursos Humanos da Organização Pan Americana de Saúde (OPAS). (ROVERE et al., 1994).

Em 1978, a Organização Pan-Americana de Saúde (OPAS) conceituou a EPS como um processo dinâmico de ensino e aprendizagem, ativo e contínuo, com a finalidade de análise e aprimoramento da capacitação de pessoas e grupos frente à evolução tecnológica assim como às necessidades sociais e aos objetivos e metas institucionais (LINO et al., 2007).

Os termos educação continuada e educação permanente, para muitos, são sinônimos, entretanto, há muito tempo são utilizados nas áreas da saúde e educação cujos conceitos são distintos. (ANDRADE et al., 2018).

Em virtude dessa dificuldade de entendimento e de confusão dos termos, a Organização Pan-americana de Saúde descreve a Educação Continuada (EC) como um processo dinâmico, ativo e permanente que se inicia após a formação básica e está destinado a atualizar e qualificar os processos de trabalho de uma pessoa ou grupo, frente às evoluções tecnológicas e científicas e às necessidades sociais, aos objetivos e metas institucionais (SILVA et al., 2011). Posteriormente, em 1982, a Organização Mundial da Saúde (OMS) conceitua a EC como um processo que inclui as experiências posteriores ao treinamento inicial, que ajudam o pessoal a aprender competências importantes para o seu trabalho. Essa também é conceituada como algo que envolveria as atividades de ensino após o curso de graduação com finalidades mais restritas de atualização, aquisição de novas informações, com atividades de duração definida e por meio de metodologias tradicionais (SILVA et al., 2014).

No Brasil, com o SUS e os novos desafios assumidos, a formação dos trabalhadores da saúde passa a ter maior ênfase. No texto da Constituição Federal (Artigo 200), fica estabelecido que "ao sistema único de saúde compete, além de outras atribuições, nos termos da lei, ordenar a formação de recursos humanos na área da saúde" (BRASIL, 2019). A formação profissional passou a ser reconhecida como fator essencial para o processo de consolidação da Reforma Sanitária Brasileira. Em 2003, é criada no Ministério da Saúde a Secretaria de Gestão do Trabalho e da Educação em Saúde (SGTES), que assumiu a responsabilidade de formular políticas orientadoras da gestão, formação, qualificação e regulação dos trabalhadores da saúde no Brasil.

Em 2004, foi implantada a Política Nacional de Educação Permanente em Saúde (PNEPS) pela Portaria 198, na qual o Ministério da Saúde assume a responsabilidade constitucional de ordenar a formação de seus recursos humanos. Com a PNEPS criou-se Polos de Educação Permanente em Saúde (PEPS) que foram eficazes na difusão da proposta da EPS pelos diferentes municípios brasileiros. É importante situar que no ano de 2005 houve alterações no quadro de trabalhadores e 
gestores SGTES e, em agosto de 2007, a PNEPS foi alterada pela Portaria GM/MS nº 1996. Com isso, em 2007 iniciou-se a segunda fase da PNEPS com mudanças conceituais e metodológicas em relação à condução dessa política. As Comissões de Integração Ensino Serviço (CIES) e os Colegiados de Gestão substituíram os PEPS na gestão da EPS (BRASIL, 2009a).

As CIES foram criadas como instâncias intersetoriais e interinstitucionais permanentes que participam da formulação, condução e desenvolvimento da Política de Educação Permanente em Saúde previstas no Artigo 14 da lei 8080/90 e na NOB/RH - SUS. São compostas pelos gestores de saúde municipais, estaduais e do Distrito Federal e ainda, conforme as especificidades de cada região, com atribuições como: apoiar e cooperar tecnicamente com os Colegiados de Gestão Regional para a construção dos Planos Regionais de Educação Permanente em Saúde da sua área de abrangência; articular instituições para propor, de forma coordenada, estratégias de intervenção no campo da formação e desenvolvimento dos trabalhadores, sob conceitos e princípios da EPS, da legislação vigente e do Plano Regional para a Educação Permanente em Saúde; incentivar a adesão cooperativa e solidária de instituições de formação e desenvolvimento dos trabalhadores de saúde aos princípios, à condução e ao desenvolvimento da EPS, ampliando a capacidade pedagógica em toda a rede de saúde e educação; contribuir com o seguimento, monitoramento e avaliação das ações e estratégias de EPS implementadas; e apoiar os gestores na discussão acerca da EPS, na proposição de intervenções nesse campo e no planejamento e desenvolvimento de ações que contribuam para o cumprimento das responsabilidades assumidas nos respectivos Termos de Compromisso de Gestão (BRASIL, 2007b).

Após essas primeiras iniciativas, novas ações foram se estabelecendo. Com o intuito de participar da proposição e do acompanhamento da educação dos profissionais de saúde e da PNEPS no SUS, a partir do reconhecimento da necessidade de prover cooperação, tanto do ponto de vista técnico, quanto financeiro para a implementação da EPS. Em 2018, o Departamento de Gestão da Educação na Saúde (DEGES) lança o Programa para o Fortalecimento das Práticas de Educação Permanente em Saúde no SUS - PRO EPS-SUS. O PRO EPS-SUS foi lançado com o propósito de fortalecer as ações de EPS no território brasileiro, dar prioridade aos processos de gestão da PNEPS na lógica do modelo de atenção à saúde e reconhecer as contribuições dos principais atores nesse processo. Além disso, prover aos estados e DF com o incentivo de custeio para a elaboração de Planos Estaduais de Educação Permanente em Saúde; e aos municípios e DF com o incentivo para a execução de ações de EPS pelas equipes de APS. O DEGES considerou que após 14 anos da publicação da portaria que criou a PNEPS no SUS, muito se alcançou, porém, um árduo caminho ainda há que ser trilhado, principalmente no âmbito da gestão pública federal (BRASIL, 2018). 
Considerando-se os problemas que incidem em relação à efetiva consolidação do SUS - a exemplo do subfinanciamento (PAIM, 2014), recomposição das relações entre público e privado, mudanças na gestão de unidades complexas e reorientação de políticas e estratégias prioritárias, constatou-se a necessidade de ajustes em vários âmbitos da gestão do trabalho e da educação em saúde (SCHEFFER, 2015a). Especificamente à PNEPS, identificou-se a necessidade de uma reflexão acerca das estratégias a serem adotadas para garantia de sua efetiva implementação, levando-se em conta as especificidades regionais, estaduais e locais (GONÇALVES et al., 2019).

Nessa perspectiva, o MS em 2017, por meio do DEGES, vinculado à SGTES, em parceria com o CONASS, CONASEMS, CNS, Escolas Técnicas do SUS, Escolas de Saúde Pública (ESP), IES, Organização Pan-Americana da Saúde (OPAS) e demais secretarias do MS, deu-se

início ao processo de discussão a respeito à PNEPS com o objetivo de debater coletivamente estratégias para atualizar a Portaria GM/MS nº 1.996/07.

Assim, acordou-se a realização de Oficinas Regionais, envolvendo estados e municípios, para avaliação do processo de implementação da Política, cuja organização foi construída coletivamente envolvendo o DEGES/SGTES, com a cooperação técnica das equipes do Instituto de Saúde Coletiva da Universidade Federal da Bahia (ISC/UFBA), do Instituto de Medicina Social da Universidade do Estado do Rio de Janeiro (IMS/UERJ), Faculdade de Medicina da Universidade Federal de Minas Gerais (UFMG), Fundação Oswaldo Cruz (FIOCRUZ) e a participação do CONASS e do CONASEMS.

Foram realizadas seis oficinas, reunindo gestores e técnicos das regiões Nordeste, Norte, Centro-Oeste, Sudeste e Sul, com o objetivo de debater acerca de ações em torno da PNEPS, constituindo o ponto de partida para a elaboração de propostas que geraram iniciativas no âmbito do MS, bem como nos estados.

O debate nas Oficinas Regionais teve como objetivos: a) identificar os principais problemas enfrentados no âmbito estadual e municipal para a implementação da PNEPS; b) identificar "nós críticos" que demandem apoio institucional da DEGES/SGTES/MS; c) elaborar propostas para o aperfeiçoamento da PNEPS com base nas necessidades identificadas ao nível estadual e municipal (BRASIL, 2017).

A metodologia adotada nas oficinas possibilitou aos participantes, por meio de análises e debates, reconstruir uma imagem compartilhada da realidade em que operava a PNEPS em seus territórios. Foi possível ainda mapear as relações institucionais e uma reflexão acerca das práticas, complexidades, problemas, fortalezas, processos de gestão e de métodos pedagógicos da EPS, segundo suas próprias e singulares necessidades e possibilidades. Aponta-se que, para além dos seus objetivos iniciais, essas oficinas foram vivenciadas e percebidas como uma atividade de EPS, ou seja, 
transformaram-se em um momento de aprendizagem significativa, constituindo-se em importante instrumento de monitoramento e acompanhamento, uma vez que permitiram examinar o desenvolvimento, os instrumentos utilizados para a gestão, os problemas, os objetivos e os resultados alcançados na sua implementação nos estados, sob a ótica dos alicerces conceituais e organizacionais da PNEPS (GONÇALVES et al., 2019).

No que se refere ao conteúdo do debate no interior das oficinas, cabe enfatizar, em primeiro lugar, a problematização da pertinência da revisão do marco regulatório da PNEPS, considerando-se que os princípios e diretrizes da Política continuam ativos, bastando realizar algumas adaptações no texto, levando em conta o contexto atual da política de saúde. Dessa forma, considerou-se que o principal problema com relação à PNEPS não é o conteúdo da política e, sim, as dificuldades enfrentadas no processo de implementação, que contribuem, inclusive, para a existência de grande heterogeneidade e desigualdade na situação verificada em cada unidade federada (GONÇALVES et al., 2019).

A identificação dos "nós críticos" propiciou a elaboração de um conjunto de propostas em cada uma das oficinas, as quais foram sistematizadas em uma matriz (quadro 1), com base na semelhança e aproximação temática.

Quadro 1 - Síntese propostas e elaboradas nas oficinas regionais

\begin{tabular}{|c|l|}
\hline Área-problema & Proposta \\
\hline Gestão da & • apoio do MS para fomentar a elaboração dos Planos estaduais de EPS e \\
de Planos de ação regional; \\
• vincular instrumentos de gestão e planejamento do SUS à EPS; \\
• implantar sistema de informação/gerenciamento das ações de EPS; \\
• criar a função de apoiadores regionais na área de EPS; \\
• incluir e articular as ações de formação promovidas pelo Ministério da \\
Saúde na PNEPS, por exemplo: COAPES, Programa de Formação de \\
Profissionais de Nível Médio para a Saúde etc.
\end{tabular}




\begin{tabular}{|c|c|}
\hline & $\begin{array}{l}\text { - realizar seminários a partir de experiências exitosas; } \\
\text { - articular melhor as instituições de ensino no processo de implementação } \\
\text { da PNEPS. Pensar mecanismos para reforçar a participação da IES dentro } \\
\text { da CIES; } \\
\text { • estabelecer estratégias para que gestores e instituições de ensino se } \\
\text { comprometam em construir e participar efetivamente das ações de EPS } \\
\text { - reconhecer a preceptoria nos processos de progressão funcional dos } \\
\text { servidores; } \\
\text { - definir as contrapartidas na articulação ensino serviço; } \\
\text { - qualificar processos/desenhos estratégicos pedagógicos voltados para } \\
\text { problematização, transformação da realidade e qualificação para o SUS; } \\
\text { - implantar sistema de regulação das práticas de formação e EPS nos } \\
\text { serviços. }\end{array}$ \\
\hline $\begin{array}{l}\text { Infraestrutura } \\
\text { da CIES }\end{array}$ & $\begin{array}{l}\text { - estimular a criação de espaços nas Secretarias Estaduais e Municipais } \\
\text { para a EPS e CIES; } \\
\text { - garantir que o setor responsável pela Educação Permanente em Saúde } \\
\text { (EPS) esteja presente no organograma oficial da Secretaria Estadual de } \\
\text { Saúde (SES) e que disponha de estrutura física própria; } \\
\text { - Fortalecer as Regiões de Saúde através das CIES. }\end{array}$ \\
\hline Conceito EPS & $\begin{array}{l}\text { - promover o alinhamento conceitual sobre a PNEPS, especialmente a } \\
\text { concepção de EPS; } \\
\text { - realizar oficinas de trabalho com gestores e técnicos para alinhamento } \\
\text { conceitual em torno da EPS; } \\
\text { - fortalecer as equipes das Escolas do SUS e membros da CIES para } \\
\text { facilitarem a discussão sobre o conceito de EPS; } \\
\text { - incluir a discussão sobre o conceito de EPS nas Comissões Intergestores } \\
\text { Regionais (CIR). }\end{array}$ \\
\hline $\begin{array}{l}\text { Monitoramento } \\
\text { e avaliação das } \\
\text { ações de EPS }\end{array}$ & $\begin{array}{l}\text { - estabelecer mecanismos de monitoramento e avaliação da execução dos } \\
\text { planos estaduais e regionais de EPS com indicadores de processo e } \\
\text { resultados; } \\
\text { - estimular que as áreas técnicas registrem e divulguem as ações de EPS; } \\
\text { - dimensionar /mapear os pontos de educação da rede estadual. }\end{array}$ \\
\hline $\begin{array}{c}\text { Articulação } \\
\text { interfederativa } \\
\text { (MS/SES/SMS) }\end{array}$ & $\begin{array}{l}\text { - maior articulação MS/MEC; } \\
\text { - fomentar dentro da PNEPS a organização das CIES regionais; } \\
\text { - sensibilização das instâncias colegiadas sobre a importância dos } \\
\text { processos de EPS; } \\
\text { - promover melhora articulação entre a CIR e as CIES regionais; } \\
\text { - recompor as CIES Regionais e Estadual; } \\
\text { - incluir na agenda da gestão estadual do SUS a EPS como pauta } \\
\text { permanente da CIR, Comissão Intergestores Bipartite (CIB), Conselho } \\
\text { Estadual de saúde (CES); } \\
\text { - promover a qualificação dos membros da CIES em EPS; } \\
\text { - discutir a importância do COAPES para articulação entre as diferentes } \\
\text { instâncias; } \\
\text { - Instituir a CIES regional como membro do comitê gestor local do } \\
\text { COAPES; }\end{array}$ \\
\hline
\end{tabular}




\begin{tabular}{|l|l|}
\hline • potencializar a Rede de Educação em Saúde Coletiva/Educação \\
Permanente em Saúde; \\
• garantir espaços de diálogos entre os diversos atores da PNEPS, por \\
meio de fóruns, oficinas, seminários, entre outros; \\
• formar Núcleos municipais e/ou microrregionais de EPS e \\
Humanização. Manter editais (pesquisa e/ou estruturação da política de \\
EPS) e portarias que valorizem esta articulação.
\end{tabular}

Fonte: Ministério da Saúde. Relatório Consolidado Sobre o Processo de Implementação da Política Nacional de Educação Permanente em Saúde (BRASIL, 2018).

Diante das avaliações e desafios levantados com a realização das oficinas regionais, o DEGES/SGTES iniciou, durante o ano de 2018, uma série de atividades voltadas ao atendimento das necessidades dos estados, buscando dar respostas imediatas a alguns dos principais problemas identificados.

Quanto ao financiamento, os problemas de repasses de recursos do MS aos Estados e municípios trilharam caminhos que resultaram na publicação da Portaria $n^{\circ} 3.194$, de 28 de novembro de 2017, que dispõe a respeito do Programa para o Fortalecimento das Práticas de Educação Permanente em Saúde no Sistema Único de Saúde (PRO EPS-SUS). Tinha como propósito estimular, acompanhar e fortalecer a qualificação profissional dos trabalhadores da área para a transformação das práticas de saúde em direção ao atendimento dos princípios fundamentais do SUS. Destaca-se que todo esse processo deve ser desenvolvido a partir da realidade local e da análise coletiva dos processos de trabalho (BRASIL, 2017). Com isso, foram repassados aos municípios e estados aproximadamente $\mathrm{R} \$ 70$ milhões para o planejamento e execução de ações educativas que respondessem às necessidades de saúde, respeitando a realidade regional/local.

Paralelamente, tratou-se de incentivar a implementação dos processos de Integração EnsinoServiço-Comunidade. Nesse sentido, como estratégia para alavancar o processo de contratualização no país, investimentos foram feitos para qualificar o processo de negociação permanente em defesa da organização do cuidado e da formação.

Buscando dar visibilidade às experiências inovadoras, o DEGES/SGTES/MS, em parceria com a OPAS/Organização Mundial da Saúde (OMS), lançou em 2018 o Edital do Laboratório de Inovações em Educação na Saúde com ênfase na Educação Permanente em Saúde, tendo recebido 251 inscrições, que passaram por uma comissão de avaliadores, resultando em uma primeira seleção de 45 experiências que foram apresentadas em seminário nacional. Destas, 30 foram selecionadas para visitação in loco, tendo sido premiadas 15 finalistas que compuseram uma publicação específica do MS/OPAS, organizada em três eixos temáticos: Integração Ensino-Serviço-Comunidade; Educação e Práticas Interprofissionais; e Gestão da Política de Educação Permanente em Saúde (BRASIL, 2018). 
Para apoio técnico ao processo de planejamento e programação das ações de EPS nos estados, foi elaborado um manual intitulado "Orientações para o planejamento das ações de Educação Permanente em Saúde no SUS", encaminhado a todas as SES e Secretarias Municipais de Saúde (SMS) para subsidiar a elaboração dos Planos de Educação Permanente (GONÇALVES et al., 2019).

Também foi organizada uma publicação específica intitulada "Política Nacional de Educação Permanente em Saúde: o que se tem produzido para o seu fortalecimento?”, estruturada em quatro capítulos e que aborda aspectos relevantes do atual movimento em torno da implementação da PNEPS, como integração ensino-serviço; COAPES; programa para fortalecimento da EPS; reconhecimento de experiências de EPS; incorporação de novas abordagens nos processos de EPS, como a educação interprofissional em saúde e incentivo ao planejamento ascendente, participativo e regionalizado das ações de EPS nos estados. Finalmente, em novembro de 2018, foi realizada em Brasília, a Oficina Nacional, reunindo cerca de 120 participantes, para validação do Relatório Final das Oficinas Regionais e apresentação da proposta preliminar relativa ao sistema de monitoramento e avaliação das ações de EPS, que será desenvolvido no próximo ano (GONÇALVES et al., 2019).

Em Minas Gerais, com a publicação da Portaria GM/MS nº1996/2007 e da Deliberação CES/MG Nº 002/2010, em abril de 2010, a SES/MG definiu as diretrizes para a implementação da Política de Educação Permanente em Saúde em Minas Gerais. Em junho de 2010, aconteceu a primeira reunião da CIES Estadual, na qual se constituiu como um espaço de articulação entre gestores municipais e estaduais das áreas da saúde e educação, instituições formadoras e o controle social. No primeiro momento, as reuniões foram direcionadas para a discussão, redação e aprovação do Regimento Interno, tendo sido publicado por meio da Resolução no 2579 de 24 de novembro de 2010 (BRASIL, 2018).

A partir da primeira reunião da CIES Estadual foram instituídas as setenta e sete Comissões Técnicas Regionais de Educação Permanente, as treze Comissões Permanentes de Integração Ensino e Serviço das Regiões Ampliadas - CIES/RA e a Comissão Permanente de Integração Ensino e Serviço Estadual - CIES Estadual. Essas comissões são instâncias intersetoriais e interinstitucionais permanentes que participam da formulação, condução e desenvolvimento da Política de Educação Permanente em Saúde. Após a instituição dessas comissões, em 2011, em parceria da CIES Estadual foi realizada a Oficina de Planejamento Estratégico em Educação Permanente em Saúde, na qual foi apresentado o diagnóstico situacional acerca da Educação Permanente em Saúde, o levantamento de necessidades de ações educacionais e a verificação a respeito do desenvolvimento de competências na implantação das redes prioritárias de atenção à saúde (BRASIL, 2018).

Em 2013, o Núcleo de Educação Permanente da SES-MG passou a integrar a estrutura interna da Subsecretaria de Gestão Regional. O Núcleo e os componentes da CIES perceberam a 
necessidade de readequação da Deliberação CES/MG n ${ }^{\circ}$ 002/2010 em função da publicação do Decreto $\mathrm{n}^{\circ} 7.508$ de 28 de junho de 2011, que regulamenta a Lei n 8.080, de 19 de setembro de 1990, a fim de dispor em relação à organização do Sistema Único de Saúde - SUS, o planejamento da saúde, à assistência à saúde e à articulação Interfederativa (BRASIL, 2018).

Em 5 de dezembro de 2018, a Secretaria de Saúde de Minas Gerais deliberou a aprovação e divulgação do Plano Estadual de Educação Permanente em Saúde em atendimento à Portaria GM/MS $\mathrm{n}^{\circ} 3.194 / 2017$. O documento tem como objetivo apresentar o caminho percorrido para elaboração do Plano Estadual de Educação Permanente em Saúde (PEEPS), assim como as diretrizes e estratégias para a implementação da Política Estadual de Educação Permanente em Saúde no Estado de Minas Gerais. O PEEPS foi elaborado por meio do desenvolvimento de 15 oficinas em todas as Regiões Ampliadas de Saúde, sob a coordenação do Grupo de Trabalho Estadual (GTE) com apoio financeiro do Ministério da Saúde, conforme disposto na Portaria 3.194/20171. O incentivo financeiro de custeio para a elaboração do Plano Estadual de Educação Permanente encontra-se no Fundo Estadual de Saúde desde 04/04/2018 e está sob a responsabilidade da Secretaria de Estado de Saúde de Minas Gerais (SES/MG) para o planejamento e elaboração desse Plano Estadual de Educação Permanente para o quadriênio 2019-2022 (BRASIL, 2018).

O plano organiza-se nos seguintes tópicos: a) contextualização breve acerca dos aspectos históricos da educação permanente em saúde no país e sua construção no Estado de Minas Gerais; b) descrição do processo de elaboração do PEEPS; c) sentidos da educação permanente em saúde pelos diferentes atores nos territórios de Minas Gerais e principais desafios para desenvolvê-la; e, d) diretrizes e estratégias para a implementação de ações e processos de educação permanente em saúde (BRASIL, 2018).

A política estadual confirma o objetivo central da política nacional, como apontar princípios, estratégias e diretrizes para o desenvolvimento e valorização dos processos de educação permanente em saúde no Estado com e entre os trabalhadores que atuam nos diversos serviços que compõem o SUS, com vistas à transformação de práticas de atenção à saúde, gestão, educação e participação social (BRASIL, 2018).

Desde o ano de 2018, é viável identificar em atuação os seguintes espaços de governança da EPS no Estado: CIES Estadual e Comissões Temáticas vinculadas às Comissões Intergestores Regionais (CIR) e Câmara Técnica de Educação Permanente do Conselho Estadual de Saúde (CES). Além disso, as referências técnicas de EPS das Unidades Regionais têm um importante papel na governança regional da EPS, atuando na articulação entre os diversos atores da gestão, serviço, ensino e comunidade e entre os municípios. Ressalta-se que nos últimos anos a CIES Estadual tem discutido as prioridades em fortalecer a EPS em Minas Gerais e de repensar a sua própria forma de trabalho. 
Os debates realizados têm versado a respeito das inúmeras faces relacionadas às concepções de EPS, acerca das fragilidades e insuficiências do modelo adotado pelo Estado para a gestão regional dessa Política, entre outras questões pertinentes. É importante destacar ainda seu protagonismo na condução da política estadual quanto às discussões e no desenvolvimento de ações de fortalecimento da EPS nos territórios mineiros. Esses movimentos foram ampliados a partir de 2015, com a incorporação da Política de EPS no âmbito estadual como uma estratégia da gestão apoiada pela Escola de Saúde Pública de Minas Gerais (ESP-MG) (BRASIL, 2018).

O plano mineiro reconhece que para a EPS acontecer é necessário reinventar os processos de formação dos trabalhadores, rompendo com os modelos tradicionais de capacitação que abordam os processos de trabalho de forma fragmentada e descontextualizada, baseada na transmissão de conhecimentos (NESPOLI et al., 2011). Compreende a EPS como uma ferramenta que privilegia o diálogo, a cooperação e a integralidade entre os espaços de gestão, assistência, formação e controle social, ampliando a capacidade do SUS (BRASIL, 2007). Desse modo, não se trata apenas de uma dimensão pedagógica, mas de um processo político pedagógico capaz de transformar os processos de trabalho em saúde, tornando os profissionais de saúde, gestores e usuários, em atores protagonistas do seu processo de aprendizagem (YAKAMOTO et al., 2015).

O processo de análise dos resultados das oficinas para construção do referido plano sistematizou os problemas existentes, mediante a identificação das facilidades e dificuldades enfrentadas para a efetiva operacionalização das diretrizes de implementação da PNEPS, dispostas na Portaria GM/MS nº 1996/2007. As avaliações referentes à realização das oficinas convergiram para a pertinência e relevância da EPS e constituíram-se em grande oportunidade para propor caminhos para o fortalecimento e institucionalização da PNEPS no Estado.

\subsubsection{Breve contextualização das Conferências Nacionais de Saúde e a Educação Permanente em Saúde}

A responsabilidade da gestão do SUS com a formação e o desenvolvimento de recursos humanos em saúde está formalizada tanto nos textos legais de institucionalização do sistema como nos relatórios das Conferências Nacionais de Saúde (CECCIM et al., 2004). As conferências nacionais de saúde, apesar de constituírem-se lócus de definição de políticas públicas desde 1941, somente a partir de 1963 atuaram como espaço privilegiado de discussão relativo à EPS. Observa-se, após análise dos relatórios das conferências, que, até o início da década de 1960, a questão do desenvolvimento de recursos humanos em saúde não fazia parte da agenda política, pois o foco estava em sanar a precária situação sanitária do país. Dos anos 1960 a 1980, as discussões se voltaram para 
aspectos relativos à qualificação profissional dos trabalhadores da saúde, principalmente os de baixa escolaridade (MORAES, 2012).

A VIII Conferência Nacional de Saúde realizada em 1986 é considerada um marco na reformulação da Política Nacional de Saúde. Com relação à política de pessoal, foi sugerida a adoção dos seguintes princípios: capacitação e reciclagem permanente de recursos humanos e; formação de profissionais de saúde integrada ao sistema regionalizado e hierarquizado de atenção à saúde. A partir dessa, o desenvolvimento de recursos humanos para a saúde passou a se constituir pauta para a construção de políticas públicas, incluindo as questões relativas às condições laborais, iniciando as preocupações a respeito das relações rudimentares de trabalho e da necessidade de uma política de recursos humanos que também considerasse a gestão do trabalho no SUS. Em 2001, o Ministério da Saúde (MS) estabeleceu as diretrizes para a instituição da PNEPS, ratificando a responsabilidade do SUS na ordenação da formação de recursos humanos para o setor (BRASIL, 2012).

Quadro 2 - As Conferências Nacionais de Saúde e a educação dos trabalhadores da Saúde

\begin{tabular}{|c|c|c|c|}
\hline Ano & Conferência & Tema Central & $\begin{array}{l}\text { Educação dos trabalhadores da } \\
\text { saúde }\end{array}$ \\
\hline 1963 & III CNS & $\begin{array}{l}\text { Descentralização na área de } \\
\text { saúde: dez anos após a criação } \\
\text { do Ministério da Saúde. }\end{array}$ & $\begin{array}{l}\text { Surgem discussões sobre educação } \\
\text { para o trabalho entendidas como } \\
\text { educação em serviço. }\end{array}$ \\
\hline 1967 & IV CNS & $\begin{array}{l}\text { Recursos humanos para as } \\
\text { atividades em saúde. }\end{array}$ & $\begin{array}{l}\text { Educação para o trabalho: ainda } \\
\text { incipiente. }\end{array}$ \\
\hline 1975 & V CNS & $\begin{array}{l}\text { Constituição do } \text { Sistema } \\
\text { Nacional de Saúde e a sua } \\
\text { institucionalização. }\end{array}$ & $\begin{array}{l}\text { Educação para o trabalho: ainda } \\
\text { incipiente. }\end{array}$ \\
\hline 1977 & VI CNS & $\begin{array}{l}\text { Controle das grandes } \\
\text { endemias e interiorização dos } \\
\text { serviços de saúde. }\end{array}$ & $\begin{array}{l}\text { Educação para o trabalho: ainda } \\
\text { incipiente. Usa-se o termo Educação } \\
\text { continuada (EC). }\end{array}$ \\
\hline 1980 & VII CNS & $\begin{array}{l}\text { Extensão das ações de saúde } \\
\text { por meio dos serviços básicos. }\end{array}$ & $\begin{array}{l}\text { Educação para o trabalho: ainda } \\
\text { incipiente. Usa-se o termo Educação } \\
\text { continuada (EC). }\end{array}$ \\
\hline 1986 & VIII CNS & $\begin{array}{l}\text { Saúde como direito: } \\
\text { reformulação do Sistema } \\
\text { Nacional de Saúde e } \\
\text { financiamento setorial. }\end{array}$ & $\begin{array}{l}\text { Reconhece a importância da área de } \\
\text { recursos humanos no interior das } \\
\text { políticas de saúde. Capacitação e } \\
\text { reciclagem permanente de recursos } \\
\text { humanos e formação de profissionais } \\
\text { de saúde integrada ao sistema } \\
\text { regionalizado e hierarquizado de } \\
\text { atenção à saúde. A Educação } \\
\text { Permanente em Saúde se destaca } \\
\text { (EPS). }\end{array}$ \\
\hline
\end{tabular}




\begin{tabular}{|c|c|c|c|}
\hline 1992 & IX CNS & Municipalização da Saúde. & $\begin{array}{l}\text { Os gestores devem assegurar uma } \\
\text { política de formação e capacitação de } \\
\text { recursos humanos articulada com } \\
\text { órgãos formadores. Valoriza a } \\
\text { educação voltada para o trabalho. }\end{array}$ \\
\hline 1996 & $\mathrm{X}$ CNS & $\begin{array}{l}\text { Construção de modelo de } \\
\text { atenção à saúde. }\end{array}$ & $\begin{array}{l}\text { O tema EPS é ampliado e } \\
\text { aprofundado quanto às propostas } \\
\text { anteriores. }\end{array}$ \\
\hline 2000 & XI CNS & $\begin{array}{l}\text { Efetivando o SUS: acesso, } \\
\text { qualidade e humanização na } \\
\text { atenção à saúde com controle } \\
\text { social. }\end{array}$ & $\begin{array}{l}\text { A articulação dos serviços de saúde } \\
\text { com os aparelhos formadores e os } \\
\text { mecanismos de controle social do } \\
\text { SUS reaparece com riqueza de } \\
\text { proposições. }\end{array}$ \\
\hline 2003 & XII CNS & $\begin{array}{l}\text { Saúde: um direito de todos e } \\
\text { um dever do Estado. A saúde } \\
\text { que temos, o SUS que } \\
\text { queremos. }\end{array}$ & $\begin{array}{l}\text { Regularização dos Vínculos e } \\
\text { Desprecarização do Trabalho em } \\
\text { Saúde; Relações de Trabalho e } \\
\text { Saúde do Trabalhador da Saúde; } \\
\text { Formação dos Profissionais de } \\
\text { Saúde; e Gestão da Educação em } \\
\text { Saúde e Educação Permanente e } \\
\text { Educação em Serviço, }\end{array}$ \\
\hline 2007 & XIII CNS & $\begin{array}{l}\text { Saúde e qualidade de vida: } \\
\text { Políticas de Estado e de } \\
\text { Desenvolvimento. }\end{array}$ & $\begin{array}{l}\text { Discute as políticas de financiamento } \\
\text { para a gestão do trabalho em saúde } \\
\text { com recursos das esferas federais e } \\
\text { estaduais. }\end{array}$ \\
\hline 2011 & XIV CNS & $\begin{array}{l}\text { Todos usam o SUS: o SUS na } \\
\text { Seguridade Social, Política } \\
\text { Pública e patrimônio do povo } \\
\text { brasileiro. }\end{array}$ & $\begin{array}{l}\text { Valorização dos trabalhadores e } \\
\text { investimento em EPS. }\end{array}$ \\
\hline 2015 & XV CNS & $\begin{array}{l}\text { "Saúde pública de qualidade } \\
\text { para cuidar bem das pessoas: } \\
\text { direito do povo brasileiro" }\end{array}$ & $\begin{array}{l}\text { Combate a precarização das relações } \\
\text { de trabalho, evitando a transferência } \\
\text { ou terceirização de serviços públicos } \\
\text { para o setor privado. Propôs políticas } \\
\text { de gestão do trabalho e de educação } \\
\text { que estimulem a fixação dos } \\
\text { profissionais, fortaleçam a carreira } \\
\text { pública, valorizem o trabalho e } \\
\text { atendam às necessidades de saúde da } \\
\text { população. }\end{array}$ \\
\hline 2019 & XVI CNS & $\begin{array}{l}\text { "Democracia e Saúde". Os } \\
\text { eixos temáticos são: Saúde } \\
\text { como Direito, Consolidação } \\
\text { dos Princípios do SUS e } \\
\text { Financiamento do SUS. }\end{array}$ & $\begin{array}{l}\text { Financiar e Incentivar a educação } \\
\text { permanente e continuada de acordo } \\
\text { com os princípios do SUS, } \\
\text { priorizando as necessidades de saúde } \\
\text { vigente, com aumento de aporte } \\
\text { financeiro federal para os estados e } \\
\text { municípios, ampliando }\end{array}$ \\
\hline
\end{tabular}




\begin{tabular}{|l|l|l|}
\hline & & $\begin{array}{l}\text { fortalecendo as tecnologias / } \\
\text { informatização em Saúde visando à } \\
\text { interação da rede de Saúde. }\end{array}$ \\
\hline
\end{tabular}

Fonte: Gigante et al. (2016); atualizado e adaptado pela autora (2020).

A IX Conferência Nacional de Saúde - realizada em 1992, a primeira após a promulgação da lei orgânica da saúde - recomenda que, quanto à consolidação do SUS, os gestores devem assegurar uma política de formação e capacitação de recursos humanos estruturada com órgãos formadores; garantirem escolas de formação para os trabalhadores da saúde, atribuírem recursos orçamentários para desenvolvimento e formação de pessoal; criarem núcleos de recursos humanos com atividades administrativas e de desenvolvimento de pessoal, além de manterem e ampliarem vagas para residência médica e de outros profissionais de saúde (multiprofissional). As recomendações da IX Conferência tiveram como ênfase o desenvolvimento dos trabalhadores e deveriam estar inseridas na gestão de recursos humanos de cada esfera de governo, valorizando, assim, a educação voltada para o trabalho (GIGANTE et al., 2016).

A X e a XI Conferência Nacional de Saúde, que ocorreram respectivamente em 1996 e 2000 , foram profundas em recomendações em relação à EPS ampliando e discutindo propostas das conferências anteriores. As propostas avançaram no sentido da construção de mecanismos de consolidação da política de desenvolvimento e formação de pessoal por meio de estratégias como: reforçar a estreita relação entre processo formativo e processo de trabalho em saúde, de modo a valorizar a formação de profissionais mediante as necessidades concretas de saúde da população; consolidar investimentos financeiros com repasses específicos para essas atividades, inclusive instando as secretarias de saúde estaduais e municipais a manter técnica e financeiramente escolas de formação, com autonomia e integradas aos respectivos conselhos de saúde, bem como às respectivas secretarias de Educação e às universidades. A articulação dos serviços de saúde com os aparelhos formadores e os mecanismos de controle social do SUS reapareceu com riqueza de proposições (BRASIL, 2001).

A XII Conferência Nacional de Saúde, inicialmente programada para ser realizada em 2004, foi antecipada para dezembro de 2003, com a finalidade de produzir orientações para a formulação do Plano Nacional de Saúde (PNS). Segundo o seu relatório, “a participação popular no governo federal deixou de ser mera formalidade, tornou-se uma ação política concreta". Nessa conferência nacional, sem negar os avanços apontados pelas anteriores, a gestão da educação aparecia estreitamente vinculada à necessidade de mudança no modelo de atenção à saúde, enfatizando a interdependência entre a qualidade da assistência prestada e a adesão e qualidade do trabalho do profissional de saúde, a qual depende das condições de trabalho e da capacitação para seu exercício. 
Nesse sentido, as propostas foram apresentadas segundo os seguintes eixos: Regularização dos Vínculos e Desprecarização do Trabalho em Saúde; Relações de Trabalho e Saúde do Trabalhador da Saúde; Formação dos Profisssionais de Saúde; e Gestão da Educação em Saúde e Educação Permanente e Educação em Serviço, com recomendações exaustivas em todos os eixos considerados (GIGANTE et al., 2016).

A XIII Conferência, diferentemente da anterior, não foi estruturada em diversas temáticas, englobando apenas três grandes eixos gerais, com destaque para o de políticas públicas para a saúde e qualidade de vida, o SUS na seguridade social e o Pacto pela Saúde. O Pacto havia sido publicado no ano anterior ao de realização da conferência e teve grande importância para a gestão, para o planejamento e para a organização do cuidado e dos serviços de saúde. Essa foi a conferência com o maior número de resoluções (total $=857$ ) e uma singularidade, com a divisão no relatório, entre deliberações inéditas (quase 40\%) e aquelas vindas das discussões dos municípios e estados (RICARDI et al., 2017).

A XIV Conferência resultou em um número menor de propostas (total $=343$ ) que as Conferências XII e a XIII. O plano de saúde, sobretudo, apresentou peculiaridade daquele momento em que a gestão passava a priorizar a organização do cuidado em redes de atenção à saúde. Quanto a $\mathrm{XV}$ CNS, as temáticas foram distribuídas em oito eixos, sendo sete diretamente referentes à política de saúde e um eixo transversal, acerca de reformas democráticas e populares do Estado, apresentado como uma inovação nas Conferências, em meio ao contexto de início de uma importante crise política no país. Houve, também, bastante destaque às questões de acesso com qualidade e valorização do trabalho e da educação em saúde; ocorreu grande mobilização ao redor do tema do financiamento, que havia sido reduzido pouco tempo antes da Conferência. No total, a XV resultou em 560 propostas aprovadas. O PNS 2016-2019 não apresenta importantes inovações, tendo grande similaridade com os eixos do plano anterior, porém, aparentemente, com menor evidência de integração ao planejamento do governo federal para além do setor saúde (RICARDI et al., 2017).

No relatório final da XVI Conferência na Diretriz Eixo III há o comprometimento em financiar e estimular a educação permanente e continuada de acordo com os princípios do SUS, priorizando as necessidades de saúde vigente, com postura proativa do governo federal, para os Estados e municípios, ampliando e fortalecendo as tecnologias/informatização em Saúde visando à interação da rede de Saúde.

As Conferências Nacionais de Saúde somam esforços para um trabalho de participação social forte e denso, mobilizado pelo debate de ideias e concepções de como fortalecer o SUS, também em promoção à efetiva EPS. Os relatórios demonstram a síntese das melhores posições e orientações para defender e consolidar o SUS, qualificar a saúde de cada indivíduo e fortalecer 
relações de trabalho mais saudáveis e democráticas no interior de sistemas e serviços de saúde e na sociedade como um todo.

Ao se buscar destacar as relações entre as propostas emitidas nos relatórios das CNS com a expressão dos documentos oficiais em relação à formação e ao desenvolvimento de recursos humanos para a saúde, é possível estabelecer correlação entre as reivindicações próprias dos interesses sociais e as propostas inscritas nas legislações pertinentes, indicando o crescimento da importância do assunto para a consolidação do SUS. A PNEPS reafirma a necessidade de alteração de ordem metodológica nos processos de formação em saúde. Ao explicitar princípios pedagógicos como a aprendizagem significativa, o processo de aprender a aprender e a eleição dos problemas do cotidiano como fonte de aprendizagem, se inscreve na lógica das metodologias ativas de ensino-aprendizagem, como referenciais pedagógicas inovadores e necessárias para a promoção de mudanças com objetivo às práticas integradoras e democráticas. Os processos educativos estipulados estão imersos em contexto profundo, com práticas gestoras e de cuidado nem sempre inclusivas e democráticas.

\subsubsection{A educação permanente em saúde como dispositivo de transformação na formação médica}

A educação permanente em saúde tem sido aplicada como prática pedagógica para os profissionais médicos. Ela surge como possibilidade de ação educativa inovadora. Tem como proposta incorporar o ensino-aprendizagem no cotidiano dos serviços médicos, modificando estratégias educativas nas quais o processo de trabalho é revalorizado como centro privilegiado da aprendizagem e o profissional como ator reflexivo e construtor de saber (FIGUEIREDO, 2012).

Ao dissertar a respeito da formação com recurso de mobilização do sujeito e do trabalho em saúde, Figueiredo destaca que o ensino problematizador visa produzir uma postura ativa na construção do conhecimento, destacando que o sucesso de projetos de educação permanente “dependem de uma profunda imbricação entre processos educativos e processos de intervenção institucional, que contemplem a complexidade dos vetores que incidem na coprodução dos modos de fazer saúde" (FIGUEIREDO, 2012, p. 98).

Para entender a proposta da educação problematizadora, recorremos ao educador Paulo Freire que concebeu uma epistemologia inovadora da educação em termos mundiais (FREIRE, 2011). A proposta de Paulo Freire da educação da libertação (ou educação problematizadora) se baseia na indissociabilidade dos contextos e das histórias de vida na formação de sujeitos, que ocorre por meio do diálogo e da relação entre alunos e professores. Freire enfatiza que ambos, professores e alunos, são transformados no processo da ação educativa e aprendem ao mesmo tempo em que ensinam, 
sendo que o reconhecimento dos contextos e histórias de vida nesse diálogo se desdobram em ação emancipadora (CHIARELLA et al., 2015).

A educação problematizadora busca estimular a consciência crítica da realidade e a postura ativa de alunos e professores no processo ensino-aprendizagem, de forma que não haja uma negação ou desvalorização do mundo que os influencia. Sendo assim, a educação é entendida como um ato político, e as relações estabelecidas entre alunos e professores devem ser embasadas em interações de respeito entre sujeitos e cidadãos, de modo a construir conhecimento crítico e centrado na busca pela autonomia (CHIARELLA et al., 2015).

A educação problematizadora aparece na PNEPS sendo um dos sustentáculos para a EPS, pois se espera que os trabalhadores de saúde possam, de acordo com sua realidade, construir seus próprios conhecimentos e serem capazes de transformar suas práticas de saúde, conforme as necessidades de qualificação para uma melhor atuação.

Há intenso debate na literatura em educação médica acerca da necessidade de articular a formação de profissionais médicos para o sistema de saúde, ajustando a graduação e o ambiente acadêmico com a realidade local de cada país (FRENK et al., 2010).

No contexto brasileiro, com a promulgação da Constituição da República Federativa do Brasil de 1988 e a consolidação do SUS, no qual a saúde passou a ser encarada como um direito universal, a formação de médicos é considerada de extrema importância. Para viabilizar as novas demandas do SUS, o Ministério da Saúde elaborou diversas políticas públicas com o objetivo de efetivar o direito da população brasileira à saúde encontrando consonância na concepção problematizadora de educação de Paulo Freire, entre elas a Política Nacional de Humanização, a Política Nacional de Atenção Básica e a Política Nacional de Promoção à Saúde (BRASIL, 2012). Os princípios norteadores da Política Nacional de Humanização apontam que os profissionais de saúde devem "valorizar a dimensão subjetiva e social dos indivíduos e coletivos nas práticas assistenciais e de gestão, além de estimular a realização de processos comprometidos com a produção de saúde e de sujeitos, com forte estímulo à autonomia, participação popular e gestão participativa" (BRASIL, 2004, p. 9). Já a Política Nacional de Promoção à Saúde se baseia numa concepção ampliada do processo saúde-doença e propõe "ampliar a autonomia e corresponsabilização de sujeitos e coletividades, inclusive do poder público, no cuidado integral à saúde e minimizar e/ou extinguir as desigualdades de toda e qualquer ordem [...]" (BRASIL, 2010, p.17). Portanto, a necessidade de qualificar os profissionais da saúde, em especial os médicos, torna-se premente.

As políticas encontram-se em forte consonância com os ideais pedagógicos de Paulo Freire, uma vez que ressaltam a necessidade de construir coletivamente processos de empoderamento de cidadãos, tomando como horizonte o respeito às diferenças e considerando os múltiplos contextos e 
histórias de vida dos sujeitos (FREIRE, 2011). No entanto, a implementação de políticas públicas no nível da gestão do trabalho em saúde, estando desarticulada à reformulação dos processos de ensinoaprendizagem das escolas médicas, não resulta numa efetiva transformação das práticas médicas do país. É necessário adotar metodologias que permitam uma aprendizagem ativa dos profissionais médicos desde a academia, além de reavaliar a lógica prioritária de transmissão de conteúdos técnicos e a integração entre ensino e serviços de saúde (FRENK et al., 2010).

A pertinência da educação problematizadora na formação médica encontra-se em consonância com a construção do paradigma da integralidade no ensino da Medicina e com as Diretrizes Curriculares Nacionais para o Curso de Graduação em Medicina (DCN), promulgadas em 2014, que preconizam a formação de médico humanista, crítico e reflexivo, que atue com responsabilidade social e cidadania (BRASIL, 2014).

Assim, a EPS também para médicos, apresenta-se como uma estratégia de educação na saúde que tem um olhar sobre as necessidades do médico, equipe, território e gestão, configurando-se como um processo de direção participativa e transformadora, que inclui instituições de ensino, trabalhadores, gestores e usuários, conformando o "quadrilátero da formação" (CUNHA, 2009; SILVA, 2013; PESSOA et al., 2013). Nesse contexto, a EPS como instrumento viabilizador de análise crítica e constituição de conhecimentos em relação à realidade local, precisa ser pensada e implementada na lógica da regionalização e ser adaptada, portanto, às situações de saúde em cada nível local do sistema de saúde (MICCAS et al., 2014).

A implementação da EPS favorece o princípio da alteridade, pois o trabalhador é, também, amadurecido, ao passo em que consolida condutas que visem à transformação da realidade em saúde de determinada comunidade. Os desafios impostos pela APS, especialmente por meio da Estratégia de Saúde da Família (ESF), para a realização de novas práticas que reorientem o quadro sanitário nacional, convergem com a edificação de métodos e práticas democratizantes e inovadoras de gestão do trabalho no SUS. A EPS, na APS, contribui para aprimorar o processo de análise da realidade social e subsidiar a tomada de decisão, bem como aumentar a resolubilidade e qualificar os processos de longitudinalidade do cuidado, promover a humanização da assistência e a competência pedagógica e cultural coletiva (TESSER et al., 2011).

Para que ocorra a efetivação da compreensão conceitual da EPS no campo da saúde e, mais especificamente na atenção primária, torna-se necessário, primeiramente, seu reconhecimento e legitimação como movimento e política educativa pelos trabalhadores da saúde no cenário de suas práticas. Entre as iniciativas de EPS realizadas na APS citadas em 13 (48,1\%) das 27 publicações selecionadas por Ferreira L. et al. (2019), estão, principalmente, as relacionadas com os recursos tecnológicos, como educação a distância e Telessaúde; as aproximações entre ensino e serviço, como 
o Pró e Pet-Saúde; e as relacionadas com o cotidiano do trabalho, como as rodas de conversa e reuniões de equipe (FERREIRA L. et al., 2019).

Ao verificar as estratégias utilizadas para efetivação da PNEPS na APS, um estudo identificou o desenvolvimento das seguintes iniciativas: uso de tecnologias inovadoras, como a internet; a educação a distância e o Telessaúde (FUZISSAKI et al., 2014). Afirma-se que as práticas de EPS devem estar embasadas no uso de metodologias ativas para construção do conhecimento e não no repasse de informações, em que o educando não é aquele que escuta e decora, mas aquele que constrói para si o saber que foi emitido nos debates. Corroborando com o pensamento de Ceccim (2005), a EPS consiste na atualização diária das práticas pelos profissionais de saúde de acordo com a aprendizagem significativa e por meio da utilização de metodologias ativas e de avanços científicos e tecnológicos (SCHWEICKARDT et al., 2015).

Essas tecnologias dispensam a figura do professor, instigando a autoaprendizagem (metacognição) por meio de materiais pedagógicos disponibilizados e a troca de experiências e saberes entre os profissionais. Essa linha metodológica é, em grande medida, utilizada como uma das possibilidades da Educação a Distância (EAD), por meio de Tecnologias da Informação e Comunicação (TIC), que conectam unidades básicas de saúde a centros de referência, possibilitando a capacitação pela internet dos profissionais e gestores, evitando deslocamentos desnecessários e oferecendo apoio à tomada de decisões (SILVA, 2013).

A utilização de TIC na saúde encontra incentivo numa resolução da OMS, que oportuniza seus Estados-Membros a formularem uma política de ensino pautada na EPS, orientada para a transformação das práticas de saúde vigentes (SILVA, 2013). Facilitam a disseminação da informação e do desenvolvimento profissional, num processo dialógico de aprendizagem entre os profissionais, docentes, pesquisadores e população. Por meio das TIC, inúmeras possibilidades se apresentam: cursos de especialização; discussão on-line por meio de fóruns, videoconferências e troca de experiências. Nessa esteira, tem-se o Programa Telessaúde, instituído pelo MS, objetivando, fundamentalmente, a capacitação e a educação permanente de trabalhadores da atenção básica (BRASIL, 2013), almejando a ampliação da autonomia e da capacidade resolutiva de quem as solicita.

As TIC ou o Programa Telessaúde baseiam-se nas melhores evidências científicas disponíveis, adaptadas para as realidades locorregionais e seguindo os princípios do SUS (BRASIL, 2013). Outro exemplo é a Rede Universitária de Telemedicina (RUTE) que integra todos os hospitais públicos universitários e de ensino e cria núcleos formais de Telemedicina, subsidiando a realização de $w e b$ e videoconferências e processos de educação a distância (MESSINA et al., 2013). É preciso ressaltar que as diferentes propostas metodológicas não se anulam entre si, pelo contrário, são 
complementares e estimulam os atores envolvidos no processo de EPS a buscar diferentes formas de conhecimento alinhadas às necessidades pessoais, do serviço e da população que atende. Preconizase, então, a utilização de metodologias dinâmicas, ativas e de fluxo contínuo de conhecimento, que se distancia da lógica tradicional de educação de transmissão de saberes.

A EPS para médicos também pode abranger o uso de metodologias que incorporem tais tecnologias, seguindo princípios éticos e eficazes para estimularem a aprendizagem significativa.

A Educação Permanente na APS é considerada importante por estar associada à busca pela garantia de princípios básicos do SUS como a universalidade e integralidade, pois, além de compreender o ambiente de saúde a partir do enfoque familiar e comunitário, ela é considerada como espaço de construção coletiva, em que os diversos sujeitos estão envolvidos nos cuidados em saúde, desde os profissionais que atuam na assistência em saúde, aos pacientes/clientes que são assistidos por esses profissionais (HEIMANN et al., 2011).

Algumas experiências de EPS na APS são relatadas em trabalhos na literatura com o intuito de consolidar a PNEPS, entre eles, o Programa de Educação Permanente (PEP) para médicos de Saúde da Família de um Estado da região sudeste. O PEP, lançado em 2004, é financiado integralmente com recursos do tesouro estadual e está presente em todas as 13 regiões ampliadas de saúde do Estado investigado, tendo como parceiras 17 instituições (16 universidades e a prefeitura da capital do Estado). A opção desse programa em contemplar, inicialmente, somente os médicos da Saúde da Família, relaciona-se à baixa adesão desses profissionais à ESF, com curta permanência nas equipes e à frágil formação do médico no campo da APS, assim como à pequena participação desses trabalhadores em qualificações pertinentes a esse nível de atenção (SILVÉRIO, 2008).

De acordo com Silvério, o objetivo da instituição do PEP foi qualificar o exercício da prática médica de maneira a reconstruí-la, de forma duradoura, de acordo com as necessidades em saúde, enfatizando o cuidado. Entre as suas metas, encontram-se a qualificação da prática; o fortalecimento da autoestima; a minimização do isolamento; o estabelecimento de protocolos; a ampliação da efetividade e resolutividade da APS e a redução dos diagnósticos e prescrições incorretas e da rotatividade dos médicos na ESF (SILVÉRIO, 2008). Em relação metodologia, o PEP tem como núcleo a consulta médica centrada no paciente e é organizado a partir dos Grupos de Aperfeiçoamento Profissional (GAP), compostos por 8 a 12 médicos que integram a ESF de uma mesma região de saúde. As atividades desses grupos, nas publicações, são desenvolvidas em encontros mensais ou quinzenais, com a orientação de um professor da Universidade parceira, ou de um médico de família pertencente à rede de um dos municípios da região. Esse professor/médico de família é chamado de supervisor e é responsável por direcionar e acompanhar as discussões dos GAP, de acordo com a metodologia preconizada pelo programa, sem aulas expositivas. 
Quanto à infraestrutura do programa, recomenda-se que seja disponibilizado nos municípios um espaço educativo constituído por salas de educação permanente, com capacidade e qualidade adequadas. Ainda, o PEP é operacionalizado por meio de quatro estratégias educacionais, sendo que para cada, devem ser dedicadas quatro horas mensais no horário de trabalho, organizadas de acordo com as necessidades de cada grupo. Essas estratégias educacionais englobam: a) Plano de Desenvolvimento Profissional (PDP) - ferramenta para promover a autoaprendizagem e a identificação das fragilidades profissionais individuais, sobre as quais são traçadas estratégias; b) Módulos de Capacitação - reuniões em torno de um eixo temático constituído a partir do estabelecimento de prioridades, identificadas pelos gestores e médicos do GAP; c) Treinamento de Habilidades Clínicas - acompanhamento e avaliação de um preceptor/facilitador quanto ao atendimento clínico; e, d) Ciclo de Aperfeiçoamento de Prática Profissional (CAPP) - pilar da ação educacional, constituindo um espaço permanente de discussão e de proposição crítica da prática, por meio da análise das consultas, dos eventos, dos prontuários, dos mecanismos de auditoria clínica e operacional, da discussão de casos clínicos e de protocolos externos e internos (SILVÉRIO, 2008).

De acordo com as falas de profissionais de saúde de um município da região metropolitana de Belo Horizonte (MG), as iniciativas de EPS proporcionaram identificar diferentes ferramentas que orientam a prática na APS, oportunizando mudanças na organização dos processos de trabalho e na qualificação dos profissionais. Provocam, assim, reflexões acerca do trabalho na APS, principalmente no que diz respeito à prática das equipes e a discussão dos elementos do processo de trabalho (SILVA et al., 2012). A existência de propostas que integram o ensino e serviço, como, por exemplo, o Pró e Pet-Saúde e/ou a existência de políticas de educação nas instituições de saúde, de rodas de discussão e de oficinas, na visão de alguns dos autores, constituem-se em importantes e relevantes iniciativas para consolidação da EPS (CARDOSO, 2012).

As rodas de EPS configuram-se em importantes espaços de aprendizado. Para Costa et al. (2015), a instituição desses espaços coletivos pode propiciar a interação de diferentes atores para a reflexão em relação à realidade dos serviços de saúde nos quais estão inseridos e para a elaboração de projetos, tarefas e ações, com o fortalecimento da autonomia e do protagonismo. Tais espaços coletivos de aprendizado seguem na mesma lógica que o Método da Roda, conhecido como Método Paideia, desenvolvido por Campos (2000) e entendido como um método crítico à racionalidade gerencial hegemônica que propõe novas formas de reconstrução da cogestão de instituições, a partir da instauração de espaços coletivos com a integração dos diferentes atores, diretrizes e práticas em saúde (CUNHA et al., 2010).

Na visão dos profissionais da equipe de saúde da família, participantes da pesquisa realizada no município do Rio de Janeiro por Silva J. F. A. et al. (2015), os espaços coletivos, como a reunião 
de equipe, apresentam-se como importantes para a produção de saberes, tornando-se o cotidiano de trabalho, um dispositivo para a estruturação, organização, estabelecimento de diretrizes e espaço de tomada de decisões (SILVA J. F. A. et al., 2015).

Foram relatadas as avaliações de oficinas nos anos de 2011 e 2012 em um município do Estado do Ceará. Nesse período, o município contava com dez (10) equipes da Estratégia Saúde da Família (ESF), duas (02) equipes do Programa Agentes Comunitários de Saúde (PACS) e um (01) Núcleo Ampliado de Saúde da Família (NASF). Este último era composto pelos seguintes trabalhadores da saúde: médico pediatra, fisioterapeuta, psicólogo, educador físico, nutricionista e agente administrativo. A coleta de informações foi realizada utilizando-se exclusivamente os registros das atas das reuniões, as quais são de domínio público, das oficinas da APS com os trabalhadores da saúde. A análise desses documentos ocorreu durante os meses de janeiro a fevereiro de 2015 e as informações foram recorridas de uma avaliação coletiva descrita em cada ata de oficina de capacitação das equipes multiprofissionais. Não houve a aplicação de instrumento de avaliação individual por profissional nessas oficinas. Nessas avaliações continham os questionamentos levantados pela Coordenadora da APS em cada temática abordada nos encontros das EPS. Dessa forma, descreveu-se os eixos norteadores abordados nas sessões de EPS, nos quais foram divididos em: a) Soluções para problemas que impediam a implantação das linhas de cuidado em saúde da criança (puericultura), saúde mental, saúde da mulher (gestantes), atendimento aos hipertensos e diabéticos no município; b) Significado da educação em saúde na prática de trabalho; c) Estratégias de educação em saúde para estabelecer as linhas de cuidado em saúde da criança, saúde mental, prénatal (gestantes), hipertensão e diabetes, por meio das experiências de grupos de ESF e NASF; d) Existência da prática da educação em saúde nas equipes de ESF ou PACS, anteriores às oficinas de EPS (SANTOS et al., 2016).

Realizadas as discussões em reuniões e oficinas, foram identificados problemas comuns existentes nas equipes da APS do município e propagadas diretrizes para reorganização das políticas, relatadas de forma consensual em cada ESF, PACS e NASF.

Os discursos encontrados nas atas de reuniões mostraram que as sessões de educação permanente realizadas em dois anos com todos os profissionais da APS foram relevantes no sentido de redirecionar as práticas dos serviços executadas em diferentes unidades existentes no município. O trabalho conjunto promoveu a melhoria dos indicadores de saúde e a aproximação dos profissionais, por meio da troca de experiências e conhecimentos para a reconstrução de uma gestão local em saúde solidificada objetivando a organização do atendimento proporcionado aos usuários (SANTOS et al., 2016). 
As evidências expostas permitem refletir que, na proposta de EPS, a capacitação da equipe, os conteúdos dos momentos presenciais e as tecnologias a serem utilizadas devem ser determinados a partir da observação dos problemas e o enfoque problematizador é uma resposta inovadora frente a desafios presentes na formação de profissionais da saúde para que os serviços prestados ganhem qualidade e os usuários fiquem satisfeitos com a atenção prestada (LEITE et al., 2012).

A importância da educação permanente na Atenção Primária em Saúde está associada à busca pela garantia da universalidade e integralidade do SUS, uma vez que, além de compreender um território adscrito a partir do enfoque familiar e comunitário, a APS é considerada espaço de construção coletiva, em que os diversos sujeitos estão envolvidos nos cuidados em saúde (STARFIELD, 2002, p.28).

Em consonância com a proposta da PNEPS (BRASIL, 2018) a metodologia a ser desenvolvida na proposta de EPS no município do estudo será a da problematização. Como estratégias para desenvolvimento da EPS, na proposta da problematização, citam-se os treinamentos baseados em discussões problematizadoras com foco nas demandas do território e dos profissionais do serviço de saúde; reuniões de equipe que permitam o compartilhamento de informações, discussão de casos clínicos e tomada de decisão coletiva para cada caso, pois constituem-se como espaços de troca, negociação e busca de consensos; rodas de conversa; exposições dialogadas; estudos dirigidos em grupos; relatos de experiência e narrativas; e atividades com uso de mapa conceitual (JUZWIAK et al., 2013).

Como metodologia de aprendizagem, a EPS requer a organização de estratégias de educação embasadas nas questões emanadas da realidade do trabalho dos atores envolvidos. Ela se alicerça na proposta de educação problematizadora de Paulo Freire, a qual parte de experiências de quem educa e de quem é educado, numa lógica dialógica, compartilhada e horizontal (JUZWIAK et al., 2013). Com base nessa metodologia, propõe-se o Método do Arco ou Arco de Maguerez (figura 2), que retrata a realidade numa escala de cinco etapas: observação da realidade social; identificação dos pontos-chaves a serem estudados; análise dos pontos-chaves; hipóteses de solução e; aplicação à realidade prática. De acordo com tal concepção, é na realidade que se encontram os problemas e é também nela que devem ser aplicadas as possibilidades de solução (PRADO et al., 2012).

Figura 2 - Método do Arco ou Arco de Maguerez 


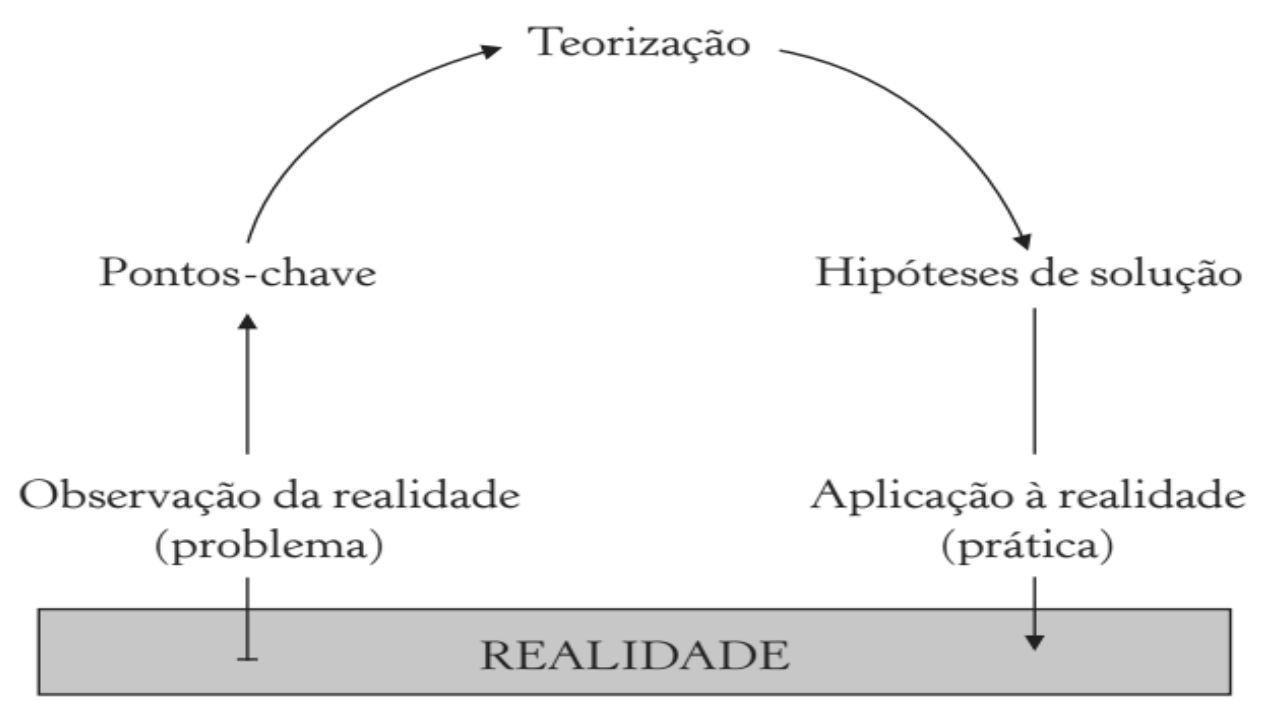

Fonte: Villardi et al. (2015. p. 46).

Os responsáveis por trazer a público o método do Arco de Maguerez foram Juan Diaz Bordenave e Adair Martins Pereira, no livro Estratégias de ensino-aprendizagem (primeira edição em 1977. O arco foi um dos primeiros referenciais teóricos que auxiliaram na fundamentação que Berbel (1995; 1998; 2012a; 2012b) passou a desenvolver e denominou, de metodologia da problematização (VILLARDI et al., 2015). São cinco etapas (Quadro 3) que se desenvolvem a partir de um recorte da realidade e que para ela retornam: a observação da realidade e a identificação do problema, os pontoschave, a teorização, as hipóteses de solução e a aplicação à realidade (VILLARDI et al., 2015).

Quadro 3 - Método do Arco ou Arco de Maguerez

\begin{tabular}{|l|l|}
\hline Etapas & Características \\
\hline $\begin{array}{l}\text { Observação da } \\
\text { realidade concreta }\end{array}$ & $\begin{array}{l}\text { Observação da realidade percebida pelo educando; o aprendiz identifica } \\
\text { as dificuldades, conflitos etc. que podem configurar-se como problemas. } \\
\text { Problematiza a realidade, articulando os conhecimentos prévios com } \\
\text { aqueles com que se depara; formula um problema e, nessa etapa, espera- } \\
\text { se que assuma uma postura crítica frente à realidade, que se envolva } \\
\text { intelectual e politicamente com ela. }\end{array}$ \\
\hline $\begin{array}{l}\text { Determinação de } \\
\text { pontos-chaves }\end{array}$ & $\begin{array}{l}\text { O educando define o aspecto do problema que será objeto de pesquisa. } \\
\text { Inicia com uma reflexão acerca dos possíveis fatores associados ao } \\
\text { problema e que afetam a sua ocorrência; reflete também a respeito dos } \\
\text { possíveis determinantes maiores, contextuais, tais como os aspectos } \\
\text { político, econômico e ético que podem se associar ao problema e aos } \\
\text { próprios fatores já registrados. Assim, nessa dinâmica, são estabelecidos } \\
\text { os aspectos essenciais para compreender mais profundamente o } \\
\text { problema e encontrar maneiras de interferir na realidade. São eleitos os } \\
\text { pontos considerados prioritários, os quais indicarão caminhos para } \\
\text { chegar a uma solução para ele. Nesse momento de análise reflexiva, o }\end{array}$ \\
\hline
\end{tabular}




\begin{tabular}{|c|c|}
\hline & $\begin{array}{l}\text { educador deve orientar a elaboração de uma síntese, apontando o } \\
\text { conjunto dos tópicos a serem investigados. }\end{array}$ \\
\hline Teorização & $\begin{array}{l}\text { É a etapa investigativa, em que se busca conhecimentos e informações } \\
\text { acerca do problema em diferentes fontes, usando estratégias ou formas } \\
\text { de coleta de informações (pesquisa bibliográfica, entrevistas, consultas } \\
\text { a especialistas etc.). O estudo deve subsidiar a transformação da } \\
\text { realidade. O educando deve organizar, analisar e avaliar as informações } \\
\text { obtidas e o quanto podem contribuir para chegar a uma resolução para } \\
\text { o problema. Também deve verificar sua validade e pertinência, } \\
\text { interligando teoria e prática, por meio de discussão e análise. Nessa } \\
\text { etapa, o educando adquire maior consciência do problema e de sua } \\
\text { influência acerca do meio social. }\end{array}$ \\
\hline $\begin{array}{l}\text { Hipóteses } \\
\text { solução }\end{array}$ & $\begin{array}{l}\text { Etapa em que o potencial criativo e o reflexivo são mobilizados para o } \\
\text { educando pensar de modo renovador. Algumas questões podem surgir: } \\
\text { como desfazer o "nó crítico"? Quais são as ações viáveis e necessárias? } \\
\text { Com base na teorização, os alunos projetam ideias que poderão se } \\
\text { transformar em ações concretas para solucionar o problema ou apontar } \\
\text { caminhos para isso. A formulação das hipóteses de solução deve ser } \\
\text { norteada pela percepção do problema e pela compreensão teórica } \\
\text { alcançada pelo educando. O estudo deverá fornecer subsídios para que } \\
\text { se elaborem alternativas de solução. }\end{array}$ \\
\hline $\begin{array}{l}\text { Aplicação prática } \\
\text { à realidade }\end{array}$ & $\begin{array}{l}\text { Nessa etapa devem ser analisadas e escolhidas as propostas de soluções } \\
\text { mais exequíveis e ajudarão a superar o problema total ou parcialmente, } \\
\text { contribuindo para a transformação da realidade investigada. É o } \\
\text { momento de planejamento e de execução, de desenvolvimento de um } \\
\text { compromisso social, profissional e político. Permite que o educando } \\
\text { pratique o conhecimento adquirido no meio estudado, percebendo-se } \\
\text { como sujeito ativo e exercendo a sua cidadania. Nessa etapa ele toma e } \\
\text { executa decisões, adicionando um componente social e político à sua } \\
\text { formação e ajudando-o a ter consciência do seu compromisso com a } \\
\text { transformação da realidade. É necessário e importante garantir alguma } \\
\text { forma de aplicação concreta do que foi estudado, mesmo que se limite } \\
\text { à ação de socializar o conhecimento adquirido. }\end{array}$ \\
\hline
\end{tabular}

Fonte: Villardi et al. (2015, p. 45-48); adaptado pela autora (2020).

Nessa direção, a EPS é tomada como um dispositivo para a problematização a respeito do processo de trabalho, partindo de uma situação existente em busca de mudá-la, transformá-la e superá-la. Assim o movimento de problematização deve envolver o questionamento constante do sujeito em relação ao seu processo de trabalho (COLLAR et al., 2015). Contudo, para que isso ocorra, é preciso que as ações em saúde sejam realizadas de acordo com as necessidades de saúde das populações, o que exige que gestores, trabalhadores e usuários estejam integrados ao cotidiano do trabalho em saúde, com possibilidade de exercício crítico das suas liberdades (COLLAR et al., 2015). 
A EPS encontra-se em um movimento dialético, cercada por contradições, mas que ao mesmo tempo invoca um novo pensar em saúde. Essa perspectiva remove os profissionais do papel de agentes passivos e os coloca como protagonistas no processo de ensino-aprendizagem, importante dispositivo da EPS (DAVINI, 2009). Dessa forma, vê-se a produção de mudanças no campo da saúde, que pressupõe que as antigas formas de praticar educação em saúde eram insuficientes para promover reflexões, de forma permanente, acerca do processo de trabalho.

A inserção da problematização no cotidiano proporciona a percepção dos profissionais referente aos benefícios da EPS para a população. Evidencia-se que os profissionais desenvolvem uma escuta mais aguçada, capaz de entender as questões trazidas pelos usuários e estabelecer com eles uma comunicação mais eficaz. Nesse momento, o usuário também se torna protagonista, proporcionando ao profissional o contato com a prática social. Trata-se de compreender que a EPS não está restrita a momentos pontuais ou palestras isoladas proferidas por especialistas, todavia ela incita um processo de mudança no trabalho em saúde, com abertura para maior participação social. A própria PNEPS enfatiza a necessidade de que o trabalhador participe dessas práticas educativas, sejam elas em modo de palestras, cursos ou outros eventos dessa natureza, cuja finalidade seja capacitar os profissionais de saúde, bem como instrumentalizá-lo para enfrentar os problemas do seu cotidiano de trabalho (CUNHA et al., 2014). Do ponto de vista da gestão, essa melhoria se traduz como diminuição dos encaminhamentos para serviços especializados e internação, aumentando a resolutividade do serviço (ERDMANN, 2013).

O médico é um importante agente para a consolidação da APS, pois, como membro da equipe da ESF, pode exercer sua função no cuidado dos usuários da população sob sua responsabilidade sanitária. Também como integrante da equipe tem um importante papel como agente proativo na promoção da EPS no trabalho, devendo estar apto a mudar sua prática assistencial, seu relacionamento intra e interdisciplinar, de acordo com as necessidades do próprio meio laboral (equipe), da comunidade e da gestão a que se submete.

O profissional médico incentivado pela prática de educação permanente ao assumir uma postura de reflexão, pode aprender, a partir de sua expertise, a problematizar a natureza dos conflitos, compreender os "nós críticos" como condicionantes, levantar diagnósticos e soluções, redimensionados pelo trabalho em equipe (inerente à APS) que faz circular informações, saberes e valores, ajudando a construir os pactos que organizam as ações referentes à realidade de modo proveitoso e ético.

Um estudo brasileiro de revisão integrativa a respeito dos pontos frágeis e dificuldades na realização das iniciativas de EPS na Atenção Primária à Saúde, apontaram inadequações no cotidiano de trabalho, como sobrecarga de trabalho e quadro de pessoal aquém do necessário, falta de 
planejamento para realização das iniciativas de EPS, a não valorização das iniciativas de EPS pela gestão e as características inadequadas das iniciativas de EPS desenvolvidas (FERREIRA L. et al., 2019).

Os profissionais de saúde da APS expõem que a pouca participação dos trabalhadores em saúde nas iniciativas de EPS está, muitas vezes, relacionada com o diminuto quadro de pessoal e com a dificuldade de liberação do trabalho (SILVA L. A. A. et al., 2017), com o não cumprimento de horários expostos, com a realização de atividades em horários inadequados e com a sobrecarga da equipe (RADDATZ, 2014). Outro estudo realizado por Mishima et al. (2015) considerou que há um predomínio de um modelo formativo baseado em cursos esporádicos e fragmentados, no qual a educação profissional encontra-se desenvolvida por meio da oferta de capacitações e treinamentos, apoiada no saber biomédico e fundamentada em abordagem metodológica de transmissão unidirecional de informação, cujo principal propósito é o da atualização de procedimentos, protocolos e rotinas, em geral baseando-se nas recomendações estabelecidas pelo Ministério da Saúde ou Secretaria Estadual de Saúde.

Para Fuzissaki et al. (2014), a falta de planejamento das iniciativas de EPS, com frequência, se tornam superficiais. Os autores destacaram que, na percepção dos gestores, as iniciativas de EPS são iniciais e as ferramentas da PNEPS são apresentadas de forma incipiente e insuficiente para a alteração do quadro de problemas levantados nos serviços, estando ainda distantes do cotidiano dos serviços da APS. Nota-se um papel importante da gestão na realização das iniciativas de EPS, principalmente no que tange à organização do trabalho, ao planejamento das atividades atreladas às dificuldades locais, às comunicações e à tomada de decisões, visto que os gestores são peças-chave na contínua organização e no aperfeiçoamento das estruturas e, sobretudo, dos processos (FERREIRA L. et al., 2019).

Corroborando com os autores acima referidos, Araújo et al. (2013) destacam dificuldades para realização das iniciativas de EPS em estudos com profissionais de saúde da ESF: a utilização de metodologias inapropriadas; a falta de habilidade do palestrante; a repetição de temas; a abordagem temática não contextualizada com os serviços; e a utilização de linguagem inadequada. Outros elementos que obstruem a realização de tais ações são o desconhecimento e/ou a não valorização pelos gestores municipais de saúde das iniciativas de educação permanente e o perfil despreparado dos gestores, além da sua falta de experiência e desconhecimento das especificidades do SUS e de suas diretrizes (FERREIRA L. et al., 2019).

Para além das dificuldades e desafios relacionados com a EPS na APS, medidas são necessárias para o enfrentamento das barreiras que impedem a efetivação das propostas de EPS. Nessa esteira de pensamento, Lemos (2016) cita acerca da necessidade de ações voltadas para a 
avaliação desses processos de EPS e da permanente conscientização dos gestores enquanto protagonistas, no que diz respeito à maleabilidade das ações educativas no campo de prática. Desse modo, faz-se necessária a realização de procedimentos avaliativos para consolidação da qualidade nas práticas de EPS, por meio de instrumentos que avaliem a EPS no âmbito da atenção primária. Um estudo brasileiro de revisão integrativa referente a pontos frágeis e dificuldades na realização das iniciativas de EPS na Atenção Primária à Saúde apontou inadequações no cotidiano de trabalho, como sobrecarga de trabalho e quadro de pessoal aquém do necessário, falta de planejamento para realização das iniciativas de EPS, a não valorização das iniciativas de EPS pela gestão e as características inadequadas das iniciativas de EPS desenvolvidas (FERREIRA L. et al., 2019).

A prática médica na APS encontra na EPS forte aliada para a transformação de ações com a finalidade de promover, primeiramente, aprendizagem para o trabalho (aprendizagem significativa), auxílio no processo de aprender a aprender e a sistematizar os problemas do cotidiano como fonte de aprendizagem. Certamente, a EPS é um dispositivo capaz de promover satisfação profissional intra e interdisciplinar, melhor qualificação na prestação de serviços médicos em saúde e confiança aos usuários.

\subsection{SAÚDE DA FAMÍLIA: UM MODELO DE APS}

No Brasil, a principal estratégia prática de reorganização da APS implementada em 1994 consistiu no Programa de Saúde da Família (PSF), denominado posteriormente de Estratégia Saúde da Família (ESF) (OLIVEIRA, 2013).

A Atenção Primária à Saúde (APS) é o primeiro nível de atenção dos sistemas de saúde, de forma contínua, organizada e sistematizada por meio do fornecimento de cuidados ao longo da vida das pessoas, das famílias e das comunidades (STARFIELD, 2002). Quando bem desenvolvida, é capaz de suprir as necessidades curativas e preventivas da população. Países com melhores resultados em saúde são aqueles que têm uma APS forte em todos os seus atributos essenciais: acesso (primeiro contato), longitudinalidade, integralidade e boa coordenação do cuidado na rede (STARFIELD, 2002).

Após a Constituição Federal de 1988 e a Lei 8.080/90, o município passou a ter um lugar privilegiado no desenvolvimento de ações e serviços de saúde. Visando a reorganização da APS, no Brasil foi instituída a Política Nacional de Atenção Básica (PNAB) em 2006, que tinha como objetivo ampliar a concepção e disposição da atenção básica ao incorporar seus atributos da atenção de maneira abrangente, reconhecendo a Saúde da Família como modelo substitutivo e de reorganização. Posteriormente, duas versões revisando a PNAB foram publicadas pelo Governo Federal, uma em 
2011 e outra, em setembro de 2017, adaptando-se às necessidades e ao contexto político de saúde. Todas mencionam a EPS por meio das portarias $n^{\circ}$ 648/06, 2.488/11 e 2.436/17(BRASIL, 2017).

A APS no Brasil embasou seu fortalecimento no Programa de Saúde da Família (MENDES, 2011). O programa sofreu modificações e converteu-se em uma agenda estruturante dos sistemas municipais de saúde. A ESF passou, assim, a assumir papel importante na coordenação da rede de atenção à saúde e determina por vezes a melhoria dos indicadores de vida de uma população, por reorganizar e atuar nas ações de prevenção de agravos, promoção, reabilitação e assistência à saúde (MENDES, 2011).

A consolidação da APS nas últimas décadas representa um dos avanços mais relevantes do SUS enquanto política pública de saúde e sistema de saúde universal no Brasil. Tal avanço está ancorado na abrangência da Estratégia de Saúde da Família (ESF), seu principal modelo assistencial, que ultrapassou a marca de 40 mil equipes em todo o território nacional em 2016 (BRASIL, 2018).

A significativa expansão e manutenção da cobertura da ESF nos últimos 20 anos provocaram o aumento da oferta de ações e serviços de amplo espectro econômico para efeitos positivos importantes em relação à saúde da população. Destacam-se aqui a redução da mortalidade infantil e de menores de cinco anos de idade nos municípios brasileiros (CECCON et al., 2014), mesmo quando controlada a ação de outros fatores determinantes. Também em relação às internações por causas sensíveis à APS, vários estudos têm destacado o papel da ESF na redução dessas hospitalizações (PINTO et al., 2018). Destaca-se o estudo de Alfradique et al. (2009) que atribui à APS a capacidade de evitar internações desnecessárias por meio de ações efetivas. A superioridade do modelo da ESF em relação ao modelo tradicional tornou-se consenso nacional e internacional na última década.

Macinko et al. (2010) concluíram que a evidência é clara de que a ESF é uma abordagem poderosa e eficaz para a organização da atenção primária à saúde no Brasil. Em um estudo, a adesão aos atributos da APS de Starfield foi mais marcante na ESF, nas dimensões de acesso no primeiro contato, abrangência, enfoque familiar e orientação para a comunidade. Acrescenta-se, ainda, a participação no planejamento e na organização do processo de trabalho da equipe (MACINKO et al., 2010). Segundo a Portaria GM/MS 2.488 de 21/10/2011, a ESF é composta por equipes multiprofissionais de médicos, enfermeiros, cirurgiões-dentistas, auxiliar em saúde bucal ou técnico em saúde bucal, auxiliar de enfermagem ou técnico de enfermagem e agentes comunitários da saúde, dentre outros profissionais (ESCOREL et al., 2007).

Os profissionais compõem a equipe em função da realidade epidemiológica, institucional e das necessidades de saúde da população. Há de se considerar que as atribuições e competências previstas pelo Ministério da Saúde para os médicos da ESF coincidam também com a proposição do modelo de atenção centrado na pessoa e na comunidade. 
Nesse modelo vigente de saúde da família cabe ao médico, junto aos demais membros da equipe de saúde, desenvolver ações de assistência e educação em níveis individuais, coletivos e comunitários. O médico ainda deve ser capaz de desenvolver habilidades para atender à demanda de forma programada e ter a capacidade em estabelecer fluxos de encaminhamento que ofereçam resolubilidade. Deve, ainda, integrar numa relação comunicativa, realizar novos procedimentos voltados para o atendimento de grupos de risco e para os problemas sócio-sanitários da comunidade sob sua responsabilidade (GIOVANELLA et al., 2009).

Além disso, o papel do médico na APS, sobretudo no modelo da ESF, abrange a avaliação das necessidades de saúde da população e o envolvimento no planejamento e na organização de um processo de trabalho multiprofissional, para a oferta de uma atenção integral, constituída de ações de saúde diversas, no âmbito individual e coletivo, além da consideração do contexto emocional, familiar e social do usuário (VASCONCELOS et al., 2011).

Embora apoiado por grande acreditação, a ESF apresenta há tempos alguns entraves para seu pleno desenvolvimento. Merece destaque a escassez de médicos com perfil adequado para atuar nesse serviço, a grande rotatividade do médico generalista e ainda a heterogeneidade de competências desses profissionais. A rotatividade profissional pode comprometer a efetividade do modelo brasileiro, uma vez que este se fundamenta no vínculo entre profissionais da equipe e a população e só pode ser gerado com a permanência do profissional na ESF (CAMPOS C. V. et al., 2008).

Esse cenário aponta as dificuldades para a formação dessa categoria profissional para desempenho da função. Os desafios de inserção do ensino na rede de serviços da APS, o surgimento recente de especialidades na área, os problemas para consolidação de um Plano de Carreira, Cargos e Salário, constituem algumas dessas dificuldades. Restam ainda os cuidados necessários, nesse empreendimento, para não comprometer a imagem da medicina nos âmbitos da academia e da sociedade (MELLO et al.,2009).

Quanto aos avanços e desafios da APS no Brasil, diferentes estudos têm apontado "nós críticos" que necessitam ainda ser transpostos. Citam-se as condições heterogêneas e, em sua maioria, inadequadas da infraestrutura das UBS, o subfinanciamento, a dificuldade de integração com a atenção secundária (atenção especializada) e terciária (hospitais e outros serviços de maior complexidade) e fracos investimentos em qualificação de recursos humanos. Entretanto, salienta ter havido, por parte dos governos, principalmente federal e municipal, ações relevantes direcionadas para ampliação da capacidade resolutiva dos serviços de APS, entre as quais podemos citar: Programa Mais Médicos (PMM); Sistema de Informação (E-SUS AB); Programa Nacional de Melhoria do Acesso e da Qualidade da Atenção Básica (PMAQ-AB). Sabe-se que os avanços alcançados em ampliação do acesso e melhoria da qualidade na atenção primária ainda estão longe do que se poderia 
almejar para esse nível de atenção em um sistema de saúde universal. Contudo, a reforma na atenção primária, desde final dos anos 1990, indubitavelmente, tem avançado na maior inclusão da população na assistência à saúde no SUS (SILVA et al., 2018).

Pode-se salientar o primeiro programa citado no parágrafo anterior, Programa Mais Médicos (PMM), como um importante avanço da APS no Brasil quanto ao acesso da população ao profissional médico. Lançado em 2013, o PMM procurou minimizar a carência histórica de médicos para atender a população e é a mais abrangente intervenção para ampliação do acesso à atenção médica na ESF mediante provisão emergencial em larga escala (cerca de 18 mil médicos em seu pico) associada com intervenções na melhoria da infraestrutura dos serviços e na formação e educação de médicos. A presença dos profissionais em 4058 municípios beneficiou cerca de 63 milhões de pessoas, fortalecendo as práticas e ações em saúde, impactando positivamente a redução de internações por condições sensíveis à APS (FACCHINI et al., 2018). Atualmente, o PMM continua em vigor, porém, com anúncio de nova política e título, Médicos pelo Brasil, todavia na mesma direção: que o acesso à assistência médica continue a ser ampliado no país. A gestão da ESF e a prática profissional de suas equipes padecem quanto a um conflito sistêmico de incompletude das ofertas de ações e de cuidados em saúde, apesar da disponibilidade de padrões de referência, diretrizes, metas e protocolos clínicos e de programas advindos de ações políticas (FACCHINI et al., 2018).

Em um estudo brasileiro, quanto ao pré-natal, apenas $15 \%$ das gestantes realizaram todos os exames e receberam as orientações preconizadas. Sendo que o exame de mamas foi referido por $56 \%$, enquanto os exames ginecológicos e odontológicos sequer foram executados em metade delas (TOMASI et al., 2017). Em novo estudo, para o controle do câncer uterino, 11\% das usuárias dos serviços de APS estavam com exames atrasados e 19\% deixaram de receber orientações (BARCELOS et al., 2017). Considerando a atenção aos portadores de diabetes, menos da metade dos entrevistados em uma UBS, afirmou ter recebido educação em saúde para o cuidado com os pés e apenas 30\% referiram ter seus pés examinados no ano anterior à entrevista. Apenas 14,3\% dos usuários referiram o recebimento do conjunto completo dos cuidados para diabetes (TOMASI et al., 2017a). Em análise ajustada, ao considerar o conjunto de itens preconizados, observou-se que a prevalência de cuidados completos aumentou significativamente em UBS em função da adequação da estrutura, da organização e gestão de serviços e da prática clínica (BRASIL, 2012).

Um estudo realizado por Barbosa, S. P. et al. (2019) no mesmo município polo deste trabalho apresentou os aspectos do perfil profissional dos médicos assistentes da ESF local. Os médicos citaram as vantagens de trabalhar na ESF. A maioria afirmou a identificação com a proposta de trabalho, seguida da autonomia e valorização profissional, à boa remuneração, sendo a maioria vinculada ao programa federal Mais Médicos. Também foram referidos, de forma mais pontual, atuar 
com a população mais necessitada, sendo uma positiva oportunidade de agir na prevenção de doenças e ter maior proximidade com o usuário. Em relação às desvantagens encontradas ao trabalhar na ESF, alguns apontaram o vínculo empregatício instável, desamparo da gestão local e oferta de locais de difícil atuação. Alguns relataram vínculo empregatício instável, desamparo da gestão, locais de difícil atuação, excesso de cobrança, carga horária de 40 horas semanais, falta de medicamentos, falta de recursos diversos, dificuldade na integração entre os níveis de atenção primário e secundário, referência e contra referência, amplo território adscrito, instabilidade de emprego e baixa resolutividade.

A oferta de cuidados de saúde na APS e, especificamente na ESF, depende profusamente de processos organizacionais e das práticas dos profissionais. Paralelamente aos desafios relacionados com a melhoria da estrutura dos serviços, a qualificação e organização planejada da gestão do cuidado por equipes interdisciplinares, são essenciais para qualificar a efetividade da ESF, tendo em vista o seu efeito mediador na atenção à saúde. Para promover o acesso à integralidade e à resolutividade, é necessário aprimorar os fluxos dos usuários no interior do serviço, desde à recepção até a sua saída ao término do atendimento. O agendamento, o acolhimento, o vínculo, a demanda espontânea e a demanda programada, a atribuição de cada profissional da equipe, as relações do serviço com outras atribuições da rede de atenção e com serviços de apoio diagnósticos e terapêuticos, demandam preciosa discussão e pactuação com as equipes e com a gestão municipal (RAMOS et al., 2015).

No dia 11 de março de 2020 a Organização Mundial da Saúde (OMS) declarou estado de pandemia da doença Covid-19, confirmando-se mais de 820 mil casos e mais de 40 mil mortes em decorrência da infecção pelo SARS-CoV-2, até o dia $1^{\circ}$ de abril de 2020 (OMS, 2020). A pandemia iniciada na província de Hubei, na China, causada por uma nova cepa viral da família Coronaviridae (SARS-CoV-2) e que provoca a doença Covid-19, está sendo disseminada rapidamente por todos os continentes. No momento inicial, Estados Unidos, Itália, Espanha e China eram os países com maior número de casos, porém, houve rápida expansão para muitos países incluindo o Brasil, demonstrando que o vírus se dissemina agressivamente em locais com distintas características sociais e econômicas (OMS, 2020).

A Atenção Primária à Saúde (APS) tem papel fundamental no enfrentamento à pandemia, uma vez que os estudos indicam que cerca de $80 \%$ dos casos são leves e grande parte dos portadores de condições moderadas, procura a rede básica como primeiro acesso na busca de cuidados (DUNLOP, 2020). Desse modo, a APS deve ser considerada um importante pilar frente às situações emergenciais, tais quais as epidemias de dengue, zika, febre amarela, Chikungunya e, também agora, a Covid-19 (DUNLOP, 2020). 
Com a pandemia do Covid-19 amplia-se o leque de responsabilidades e novos problemas como aqueles oriundos do isolamento social prolongado e da precarização da vida social e econômica, transtornos mentais, alcoolismo, violência doméstica e descompensação ou desenvolvimento de agravos crônicos, cujas consequências são de difícil previsão, exigindo cuidados integrados longitudinais. Tudo isso se soma ao conjunto de conflitos já vivenciados pela população e que se apresentam no cotidiano dos serviços (SARTI et al., 2020).

Lançar mão daquilo que é o cerne da atenção primária, como o conhecimento do território, o acesso, o vínculo entre o usuário e a equipe de saúde, a integralidade da assistência, o monitoramento das famílias vulneráveis e o acompanhamento aos casos suspeitos e leves, é estratégia fundamental tanto para a contenção da pandemia, quanto para o não agravamento das pessoas com a Covid-19.

É imprescindível de forma rápida e competente, forjar esforços em relação aos desafios impostos à APS, no que se refere às necessidades da Covid-19, garantindo investimentos e capacitação necessários, reconhecendo a singularidade do trabalho executado por essas equipes e o tipo de densidade tecnológica que essas operam e quais recursos têm sido mantidos para esses serviços e profissionais, facilitando atuação de forma técnica, científica, digna e humanitária (BARBOSA et al., 2020).

Considera-se um grande desafio para a APS, já que possui a tarefa de lidar com tantos doentes das mais variadas complexidades e diante dos problemas crônicos sociais, financeiros e políticos que perduram em sua história e se acentuam dia a dia. O médico, integrante das equipes da APS, deve ser um agente profissional capacitado para responder com qualidade às necessidades das pessoas neste momento de pandemia. A ESF neste momento torna-se fundamental para subsidiar a prática dos profissionais de saúde e nesse caso a dos médicos. O Ministério da Saúde disponibilizou na internet o protocolo de manejo clínico ao coronavírus (BRASIL, 2020) com atualizações periódicas, mas o conhecimento específico dos territórios e das pessoas (como vivem, moram, trabalham) é importante para a definição das estratégias a serem tomadas pelos profissionais da APS. Muita literatura tem sido produzida e acentua-se a esperança de tratamento específico e vacina eficazes ao combate à Covid-19. 


\section{OBJETIVOS GERAIS}

Analisar as necessidades de educação permanente em saúde dos médicos da Estratégia de Saúde da Família, em um município polo de Minas Gerais.

\subsection{OBJETIVOS ESPECÍFICOS}

- Conhecer a percepção dos médicos das equipes de Saúde da Família acerca da educação permanente em saúde;

- Compreender a percepção dos médicos das equipes de Saúde da Família em relação à importância do desenvolvimento da educação permanente;

- Identificar quais são as necessidades de educação permanente dos médicos que atuam nas equipes de Saúde da Família em um município polo de Minas Gerais;

- Traçar diretrizes para um processo de educação permanente para médicos das equipes da Estratégia de Saúde da Família em um município polo de Minas Gerais. 


\section{PERCURSO METODOLÓGICO}

\subsection{TIPO DE ESTUDO}

Foi realizado um estudo descritivo e exploratório com abordagem quanti-qualitativa. As pesquisas descritivas têm como objetivo primordial a descrição das características de determinada população ou fenômeno ou, então, o estabelecimento de relações entre variáveis. Essas pesquisas têm como propósito proporcionar maior familiaridade com o problema, com vistas a torná-lo mais explícito ou a constituir hipóteses. As pesquisas exploratórias têm como meta principal o aprimoramento de ideias ou a descoberta de intuições. Seu planejamento é, portanto, bastante flexível, de modo que possibilite a consideração dos mais variados aspectos relativos ao fato estudado (GIL, 2002).

As pesquisas descritivas têm como objetivo primordial a descrição das características de determinada população ou fenômeno ou, então, o estabelecimento de relações entre variáveis. Essas pesquisas têm como objetivo proporcionar maior familiaridade com o problema, com vistas a tornálo mais explícito ou a constituir hipóteses. As pesquisas exploratórias têm como meta principal o aprimoramento de ideias ou a descoberta de intuições. Seu planejamento é, portanto, bastante flexível, de modo que possibilite a consideração dos mais variados aspectos relativos ao fato estudado (GIL, 2002).

\subsection{CENÁRIO DE ESTUDO}

O estudo foi realizado nas UBS com ESF em um município polo de Minas Gerais. Localizado ao leste do Estado, na região do Vale do Rio Doce; ocupa uma área de 2.342,319 km², sendo que $24,4 \mathrm{~km}^{2}$ estão em perímetro urbano e sua população em 2018 era de 278.685 habitantes (IBGE, 2018). Possui uma APS cujo modelo principal é a ESF com atuais 61 equipes, gerando uma cobertura de $75 \%$ da população e 10 equipes nas sub regiões do município desenvolvendo ações de APS em modelo convencional de assistência à saúde. Em algumas UBS em modelo de atenção da ESF, há o desenvolvimento da residência médica em Medicina de Família e Comunidade (MFC), sendo 16 equipes neste período.

A APS do município conta 71 equipes distribuídas nas 10 sub-regiões do município, sendo 61 equipes desenvolvendo o modelo assistencial da ESF e 10 equipes desenvolvendo ações de APS em modelo convencional de assistência em saúde. Em algumas UBS de ESF, há o desenvolvimento 
da residência médica em Medicina de Família e Comunidade (MFC), com 16 equipes de ESF com essa residência.

O município aderiu ao programa Requalifica UBS em 2011 e realizou reforma, construção e ampliação programadas das UBS próprias. Conforme o quadro 4, o município possui 37 UBS, que comportam 61 ESF. Das 37 UBS, 25 são próprias e 12 são alugadas.

Quadro 4 - Unidades Básicas de Saúde do município polo com modelo de Estratégia de Saúde da Família

\begin{tabular}{|c|c|}
\hline \multicolumn{2}{|c|}{37 UBS com modelo ESF } \\
\hline \multirow[t]{4}{*}{25 UBS próprias } & - 13 UBS com 2 ESF \\
\hline & - $1 \mathrm{UBS}$ com $3 \mathrm{ESF}$ \\
\hline & - $1 \mathrm{UBS}$ com $4 \mathrm{ESF}$ \\
\hline & $\begin{array}{l}10 \text { UBS com } 1 \text { ESF (5 } \\
\text { ESF rurais) }\end{array}$ \\
\hline \multirow[t]{2}{*}{12 UBS alugadas } & - 6 UBS com 2 ESF \\
\hline & $\begin{array}{l}\text { - } 6 \text { UBS com } 1 \text { ESF (1 } \\
\text { ESF rural) }\end{array}$ \\
\hline Total & 61 equipes \\
\hline
\end{tabular}

Fonte: Elaborado pela autora (2021).

\subsection{PARTICIPANTES DO ESTUDO}

Participaram desta pesquisa os médicos da APS, lotados nas UBS com o modelo de atenção ESF e os preceptores da residência de MFC (também lotados nas UBS com ESF), totalizando 52 médicos.

Foram incluídos na pesquisa aqueles médicos inseridos nas unidades com ESF e que estavam trabalhando num período mínimo de um ano, mesmo que este período fosse em Unidades de ESF diferentes sem restrição de idade, sexo ou nacionalidade. Foram excluídos os médicos inseridos nas UBS que não estavam exercendo as atividades assistências nas unidades de ESF.

Com a finalidade de preservar o anonimato dos participantes, esses foram identificados pela letra $\mathrm{M}$, seguida pelos números arábicos consecutivos, em ordem crescente, de acordo com o número de entrevistados (M1, M2, M3, M4...). 


\subsection{COLETA DE DADOS}

A coleta de dados foi realizada em duas etapas: na primeira aplicou-se questionário composto de questões fechadas e abertas para caracterizar o perfil dos participantes e a identificação das necessidades de educação permanente (Apêndice C). Foram convidados a participar dessa fase todos os 61 médicos atuantes do modelo de ESF, respeitando os critérios de inclusão e exclusão, tendo aceitação de 52 médicos.

O questionário foi entregue aos participantes na reunião mensal de Matriciamento em Saúde Mental do programa da APS do município. Aproveitou-se esse momento para explicar a pesquisa, seus objetivos e sua importância. Vale ressaltar que esse momento antecedeu à pandemia da COVID19.

Na segunda etapa, realizou-se entrevista semiestruturada (Apêndice D) com os participantes, por sorteio aleatório e que aceitaram responder a entrevista. As perguntas versavam a respeito do entendimento e da importância da educação permanente, acerca das habilidades e competências para ser médico da ESF, bem como os desafios e potencialidades para desenvolver o modelo da ESF. Por se tratar de uma pesquisa qualitativa, as entrevistas foram realizadas até se obter a saturação em relação ao conteúdo manifesto pelos participantes. Após essa constatação, foram efetuadas outras três entrevistas para confirmação da saturação dos dados (MINAYO, 2013), totalizando 20 entrevistas.

As entrevistas foram realizadas nas UBS, em salas reservadas, para preservar o sigilo das informações, seguindo todos os cuidados em relação à pandemia da COVID-19, com o uso de equipamentos de proteção individual, álcool gel e distanciamento de 1,5 metros.

As entrevistas foram gravadas e totalizaram 90 minutos de gravação, obtendo-se a média de 4 minutos e trinta segundos por entrevista.

\subsection{ANÁLISE DE DADOS}

Para a análise de dados foi realizada a análise de conteúdo do tipo análise temática (MINAYO, 2013) para a etapa qualitativa e análise descritiva, com cálculo de frequências absolutas e relativas médias para a etapa quantitativa.

A análise dos dados qualitativos foi apoiada com a utilização dos recursos do software IRAMUTEQ (Interface de R pour les Analyses Multidimensionnelles de Textes et de Questionnaires), desenvolvido por Pierre Ratinaud em 2009. Consiste em um programa informático que permite diferentes formas de análises estatísticas acerca de corpus textuais e de tabelas de indivíduos por palavras (CAMARGO, 2016). 
O IRAMUTEQ realiza os seguintes tipos de análises: estatísticas textuais clássicas; pesquisa de especificidades de grupos; Classificação Hierárquica Descendente (CHD); análises de similitude e nuvem de palavras (CAMARGO, 2016). A utilização desse programa corroborou para a construção do corpus de dados, constituído por meio do conjunto de todas as respostas oriundas das entrevistas.

Para que o corpus textual seja consistente e confira confiabilidade para a análise, é necessário haver uma retenção mínima de 75\% dos segmentos textuais (CAMARGO, 2016). Nessa pesquisa a confiabilidade do corpus textual foi de $84,54 \%$. Para tanto, foram realizadas as seguintes análises:

1) Método da Classificação Hierárquica Descendente (CHD): visa obter classes de segmentos de texto que, ao mesmo tempo, apresentam vocabulário semelhante entre si, e vocabulário diferente dos segmentos de texto das outras classes. A partir dessas análises em matrizes, o software organiza a análise dos dados em um dendrograma da CHD, que ilustrará as relações entre as classes (CAMARGO, 2016);

2) A Análise de similitude: fundamenta-se na teoria dos grafos. Possibilita identificar as coexistências entre as palavras e seu resultado traz indicações da conexão entre as palavras, ajudando na identificação da estrutura da representação (CAMARGO, 2016);

3) A nuvem de palavras: agrupa e organiza os vocábulos graficamente em função da frequência. É uma análise lexical mais simples, porém, graficamente bastante interessante, na medida em que possibilita rápida identificação das palavras-chave de um corpus (CAMARGO, 2016);

Nesta pesquisa o corpus geral para a análise do conteúdo no software IRAMUTEQ foi separado em 194 segmentos de texto (ST), com aproveitamento de 164 STs (84,54\%) dos vocábulos do corpus. Emergiram 6.920 ocorrências (palavras ou vocabulários), sendo 6.112 distintas e 493 com uma única ocorrência.

A figura 3 apresenta os dados processados e apresentados pelo IRAMUTEQ:

Figura 3 - Dados do IRAMUTEQ

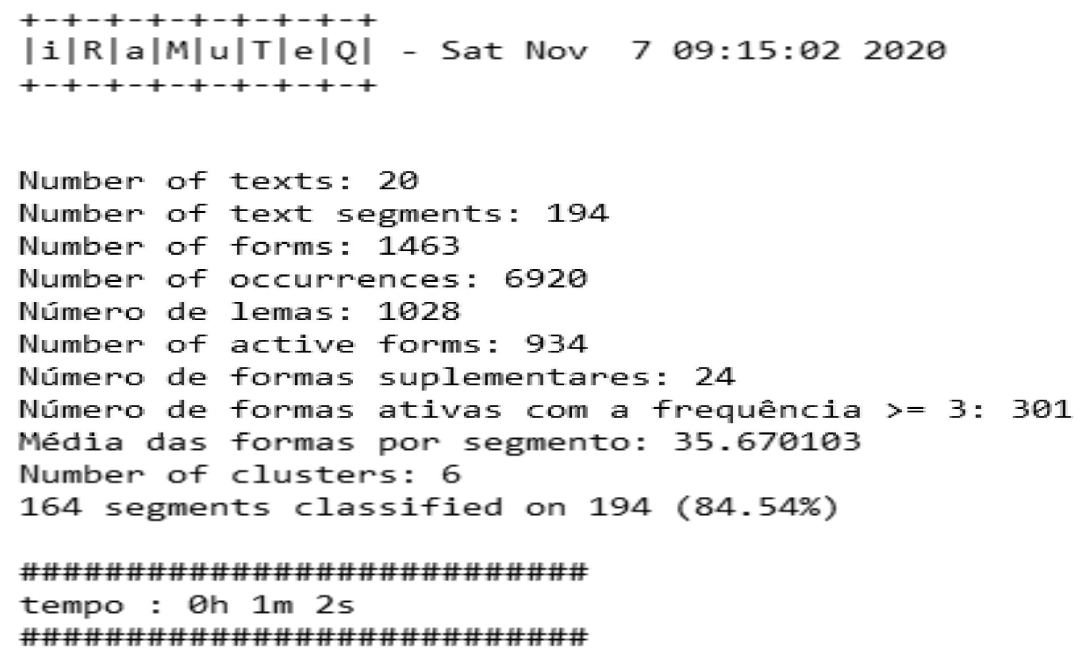




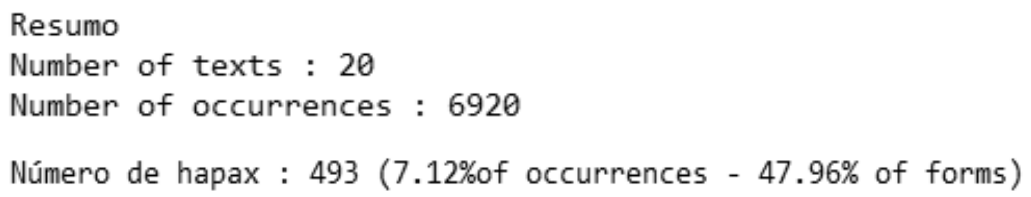

O conteúdo analisado originou 6 classes: Classe 1 com 24 ST (14,63\%); Classe 2 com 29 ST (17,68\%); Classe 3 com 28 ST (17,07\%); Classe 4 com 27 ST (16,46\%); Classe 5 com 28 ST 28 ST (17,07\%) e; Classe 6 com 28 ST $(17,07)$.

Após a operacionalização e análise dos dados pelo IRAMUTEQ, procedeu-se a análise dos dados pelo método da análise de conteúdo, do tipo análise temática (MINAYO, 2013). Essa se desdobra em três etapas:

1) A pré-análise que consiste na escolha dos documentos a serem analisados na retomada das hipóteses e dos objetivos iniciais da pesquisa, reformulando-as frente ao material coletado e na construção de indicadores que orientem a interpretação final. Pode ser dividida nas seguintes tarefas: leitura flutuante do conjunto das comunicações, constituição do corpus e formulação de hipóteses e objetivos.

Na primeira deve-se tomar contato exaustivo com o material deixando-se impregnar pelo seu conteúdo. Na segunda tarefa há a organização do material de tal forma que possa responder a algumas normas de validade: exaustividade (que contempla todos os aspectos descritos no roteiro), representatividade (que contenha a representação do universo almejado), homogeneidade (que obedeça a critérios precisos de escolha em termos de temas) e pertinência (os documentos analisados devem ser adequados aos objetivos do trabalho). A terceira e última tarefa citada, segundo Minayo (2013), há necessidade de se estabelecer hipóteses iniciais, pois a realidade não é evidente: responde a questões que teoricamente são colocadas. Todavia, esses pressupostos iniciais têm de ser de tal forma maleáveis que permitam hipóteses emergentes a partir de procedimentos exploratórios.

Nessa fase pré-analítica determinam-se a unidade de registro (palavra-chave ou frase), a unidade de contexto (a delimitação do contexto de compreensão da unidade de registro), os recortes, a forma de categorização, a modalidade de codificação e os conceitos teóricos mais gerais que orientarão a análise.

2) A Exploração do Material é a que compreende em sua essência na operação de codificação e realiza-se a manipulação dos dados ainda não lapidados com vistas a alcançar o centro de entendimento do texto. A análise temática tradicional constrói essa fase, primeiro com o recorte do texto em unidades de registro que podem ser uma palavra, frase, um tema, um personagem, um fato ocorrido tal como determinado na pré-análise. Em segundo lugar, escolhe-se as regras de contagem, uma vez que tradicionalmente ela constrói índices que permitem alguma forma de 
quantificação. Em terceiro lugar, ela realiza a classificação e a agregação dos dados, escolhendo as categorias teóricas ou empíricas que comandarão a especificação dos temas.

3) Na terceira etapa da análise temática, Tratamento dos Resultados Obtidos e Interpretação, em que os resultados brutos são submetidos a operações estatísticas simples (percentagem) ou complexas (análise fatorial) que evidenciem colocar em destaque as informações obtidas.

A partir daí, pode-se propor inferências e realizar interpretações previstas no quadro teórico ou pode-se abrir outras pistas em torno de dimensões teóricas sugeridas pela leitura do material.

A etapa quantitativa utilizou-se de análise descritiva para a caracterização da amostra. Segundo Gil (2010, p.27-28), a análise descritiva tem dentre os objetivos estudar as características de um grupo, tais como: sua distribuição por idade, sexo, procedência, nível de escolaridade, estado de saúde física e mental e outros. Baseou-se nos dados e informações coletados nos questionários compilados com o apoio do programa Microsoft Excel 2019, demonstrada por meio de números percentuais e absolutos distribuídos de forma descritiva, com cálculo de frequência absoluta e relativa. Buscou-se descrever as características dos médicos quanto ao perfil demográfico e formativo, aspectos relacionados ao trabalho como carga horária semanal, tempo de atuação na APS e especificamente na ESF e modalidade contratual vigente. Também se procurou especificar informações em relação à educação autorreferida dos profissionais como cursos realizados, modalidade de EP que participavam e se receberam capacitação em ESF para atuação, até a satisfação e valorização laboral (Anexo B).

\subsection{CRITÉRIOS ÉTICOS}

Conforme determina a Resolução nº. 466/2012 e a Norma Operacional nº. 001/2013 do CNS, o projeto de pesquisa foi submetido ao Comitê de Ética em Pesquisa (CEP) da Universidade Federal de Juiz de Fora (UFJF) e aprovado sob o parecer consubstanciado $\mathrm{n}^{\mathrm{o}}$. 3.824.788, em 06 de fevereiro de 2020 (Anexo A). Foi assegurado o anonimato dos participantes da pesquisa. Todos os participantes foram voluntários e, após explicação acerca dos objetivos do estudo e a concordância em participar, assinaram em duas vias (uma foi entregue ao médico e a outra devolvida à pesquisadora) de igual teor o Termo de Consentimento Livre e Esclarecido (TCLE) (Apêndice A e B). 


\section{RESULTADOS E DISCUSSÃO}

Os resultados são decorrentes da análise dos questionários e das entrevistas que compuseram as etapas quantitativa e qualitativa da pesquisa.

Foram construídas 4 categorias: 1. Caracterização sociodemográfica, de formação e trabalho dos médicos da Estratégia de Saúde da Família; 2. Educação permanente e continuada dos médicos da Estratégia de Saúde da Família; 3. Atributos da APS, princípios e ações desenvolvidas na Estratégia de Saúde da Família pelos médicos; 4. Satisfação, reconhecimento e valorização do trabalho médico na Estratégia de Saúde da Família.

$\mathrm{Na}$ etapa qualitativa, as entrevistas foram processadas no software IRAMUTEQ e analisadas por meio da análise de conteúdo, tipo análise temática. Emergiram duas categorias: 1. Percepção dos médicos referente às habilidades e competências necessárias para ser médico da ESF; 2. Entendimento e importância da EP na prática profissional médica na ESF.

\subsection{CARACTERIZAÇÃO SOCIODEMOGRÁFICA, DE FORMAÇÃO E TRABALHO DOS MÉDICOS DA ESTRATÉGIA DE SAÚDE DA FAMÍLIA}

Para caracterizar os 52 profissionais participantes da pesquisa foi elaborada a tabela 1.

Tabela 1 - Características sociodemográficas, de formação e trabalho dos médicos da Estratégia de Saúde da Família, (N=52), 2020

\begin{tabular}{l|l|l}
\hline Sexo & N & \% \\
\hline Feminino & 24 & 46 \\
\hline Masculino & 28 & 54 \\
\hline Idade & & \\
\hline $25-30$ & & \\
\hline $31-35$ & 10 & 19 \\
\hline $36-40$ & 13 & 25 \\
\hline $41-45$ & 11 & 21 \\
\hline $46-50$ & 09 & 17 \\
\hline $51-55$ & 03 & 06 \\
\hline $56-59$ & 02 & 04 \\
\hline 60 ou + & 00 & 00 \\
\hline \multicolumn{2}{|l|}{04} & 08 \\
\hline Tempo de Formatura & \multicolumn{2}{|l}{} \\
\hline 1 a 10 anos & 38 & 73 \\
\hline 11 a 20 anos & 08 & 15 \\
\hline 21 a 30 anos & 03 & 6 \\
\hline
\end{tabular}




\begin{tabular}{l|l|c}
\hline 31 ou + & 03 & 6 \\
\hline Formação Profissional & & \\
\hline Apenas graduação & 09 & 17 \\
\hline Residência Médica & 11 & 21 \\
\hline Pós-Graduação Lato Sensu & 35 & 67 \\
\hline Pós-Graduação Stricto Sensu & 01 & 2 \\
\hline & & \\
\hline Modalidade Contratual & & 2 \\
\hline Estatutário & 01 & 20 \\
\hline CLT & 10 & 58 \\
\hline Bolsista Mais Médicos & 30 & 20 \\
\hline Bolsista Preceptor & 11 & \\
\hline & & 6 \\
\hline Carga horária na ESF & & 23 \\
\hline 20h semanais & 03 & 71 \\
\hline 30h semanais & 12 & \\
\hline 40h semanais & 37 & \\
\hline & & 17 \\
\hline Incentivo financeiro da prefeitura: & & 23 \\
\hline Função gratificada & 9 & 20 \\
\hline Incentivo produtividade & 0 & 65 \\
\hline Incentivo ESF & 7 & \\
\hline Plano de carreira, cargos e salários & 1 & \\
\hline Insalubridade & 10 & \\
\hline Outros & 34 & \\
\hline
\end{tabular}

Fonte: Elaborada pela autora (2020).

De acordo com os dados apresentados na tabela 1, pode-se observar a prevalência dos homens, sendo 54\% médicos (28). Apesar desta prevalência, estudos apontam que a população médica vem sofrendo uma mudança no perfil quanto ao gênero e idade, acentuando-se processos de feminização e juvenilização da categoria no mundo. Não se evidenciou o fenômeno da feminização neste estudo, porém, na medicina brasileira, tal fato tem se confirmado, com a presença de mulheres de forma crescente e expressiva (CONSELHO FEDERAL DE MEDICINA, 2018).

Em 2014, os homens eram maioria, $57,5 \%$, dos médicos no país e as mulheres, $42,5 \%$. No cenário em 2015, entre os médicos com 29 anos ou menos, as mulheres se tornaram a maioria, com $56,2 \%$ contra $43,8 \%$ dos homens. Entre 30 e 34 anos, eram 49,9\% de mulheres e 50,1\% de homens. Daí para frente, o percentual de homens é maior, passando de 55,6\% no grupo com 50 a 54 anos e chegando a 77,6\% entre os médicos com idade entre 65 e 69 anos (SCHEFFER, 2015).

Ainda quanto à faixa etária no município, sobressaem médicos jovens, entre 25 e 45 anos, com menos de 10 anos de profissão (82\%), informação que se confirma à juvenilização profissional na medicina. A idade média do médico brasileiro, hoje de 45,7 anos, vem caindo, revelando uma profissão jovem, reflexo da abertura de novos cursos e da ampliação de vagas de graduação. Isso 
coloca o Brasil em posição oposta aos países em que ocorre o fenômeno de "envelhecimento" da profissão, com número maior de saídas (por aposentadoria e óbito) do que de entradas de recémformados, com consequente diminuição global da força de trabalho médico disponível (SCHEFFER, 2015, p.138).

Nota-se que $21 \%$ possuem residência médica, sendo que a maioria $(67 \%)$ confirma ter outra pós-graduação latu sensu. São 30 médicos (58\%) bolsistas do programa federal Mais Médicos e 11 profissionais $(20 \%)$ que recebem bolsa como médicos preceptores do Programa de Residência de Medicina de Família e Comunidade pertencente à Secretaria Municipal de Saúde, cumprindo carga horária de 40 horas na semana. Os bolsistas do PMM cumprem 32h de assistência e 8h de estudo, correspondendo a 71\% dos médicos. Em dezembro de 2012, foi publicada a Portaria $\mathrm{n}^{\circ} 3.147 / 2012$ do Ministério da Saúde para incentivar os municípios a desenvolverem o Programa de Residência de Medicina de Família e Comunidade na Rede de Atenção à Saúde objetivando qualificar as Estratégias de Saúde da Família, com acompanhamento de preceptoria (STORTI et al., 2017). O Plano Nacional de Formação de Preceptores (PNFP) foi implementado como parte integrante do eixo de qualificação da APS, com o objetivo central de subsidiar e assegurar instrumentos para o processo de expansão de vagas de residência de Medicina de Família e Comunidade (CONASS, 2015). O Programa de Residência Médica de Medicina de Família e Comunidade pertencente à Secretaria Municipal de Saúde local foi fundado no ano de 2010, com progressivo aumento de vagas, inicialmente 2, 4, 6 e atualmente 12 vagas anuais, serviço este, que tem impactado positivamente à assistência em saúde na APS local.

Com relação ao incentivo financeiro é importante registrar que o município polo aderiu ao PMM desde sua criação e implementação. Muitos já trabalhavam como médicos contratados da prefeitura antes de aderirem ao programa e já conheciam seu território de atuação, apenas permanecendo na função após adesão ao programa. As vantagens para o bolsista do PMM permeiam considerações de ganho financeiro (a bolsa federal é o dobro do salário local do médico contratado para exercer mesma função), horário protegido para $8 \mathrm{~h}$ de estudo na semana, quando alguns fazem plantões extras ou pós-graduações concomitantes, além de cursos nas plataformas online e têm a vantagem de isenção de imposto de renda. Quanto a outros ganhos financeiros (65\%), recebem bolsa alimentação e moradia como contrapartida municipal prevista no edital do PMM. Todavia o médico não recebe direitos trabalhistas relacionados ao regime CLT, não tem possibilidade de obter plano de carreira ou exercer cargo por concurso público, além de não receber o benefício de insalubridade. Outra desvantagem é que ao terminar o PMM (três anos inicialmente, com possível prorrogação por mais 3 anos, sendo 6 anos no máximo), muitos, desestimulados pela diminuição de renda mensal, 
desistem de pedir contratação da prefeitura e perdem o vínculo com a população e território de atuação.

Verificou-se que $20 \%$ dos médicos recebiam insalubridade, pois eram médicos contratados ou efetivos da prefeitura, $17 \%$ eram de função gratificada e $13 \%$ recebiam incentivo da ESF. Destacase que apenas $2 \%$ estavam inseridos no plano de carreira, cargos e salários da prefeitura (efetivos por concurso público).

Os profissionais que atuam em municípios sem planos de cargos, carreiras e salários apresentam maior média de remuneração mensal. Esse achado pode ser atribuído à consequente restrição dos gastos com pessoal na administração direta determinada pela Lei de Responsabilidade Fiscal, que se reflete nos planos de cargos, carreiras e salários, restrição esta que não se aplica da mesma forma nos gastos com contratações intermediadas de pessoal para o serviço público (VIEIRA, 2014). Segundo Vieira, essa realidade se aplica particularmente aos profissionais médicos, que, pelo caráter de profissão liberal e busca de autonomia no trabalho, tendem a escolher melhores salários, os quais, na maioria dos municípios, não são contemplados nos planos de carreira pelas restrições da Lei de Responsabilidade Fiscal.

O município deste estudo realiza concurso público para médico de $20 \mathrm{~h}$ semanais, com quantitativo de vagas pequeno (5 vagas por concurso) e com intervalos muito longos, pois verificouse que os dois últimos concursos aconteceram em 2009 e 2020 e não houve cargo médico específico para ESF.

Um estudo realizado no Norte de Minas Gerais (BARBOSA, S. P. et. al., 2019) demonstrou que a maioria dos profissionais não contavam com incentivos financeiros pelo trabalho na ESF. Esse resultado condizia com o contexto apresentado em que prevaleciam vínculos precários e ausência de plano de carreira, o que certamente confirmou a inexistência de políticas de incentivos baseadas em resultados por meio da contratualização de metas. Em contramão a esses resultados, deve-se destacar o esforço do Ministério da Saúde, por meio da indução financeira, de reorientar a atenção à saúde dos municípios, priorizando a APS. Uma forma de indução foi o já extinto Programa Nacional de Melhoria do Acesso e da Qualidade da Atenção Básica (PMAQ-AB), criado em 2011 pelo Ministério da Saúde, que vinculava a contratualização, por adesão espontânea, das equipes de saúde da família a repasse de recursos federais para implantação e alcance dos padrões de acesso e de qualidade na APS (POLI et al., 2016).

O processo de fortalecimento da ESF está relacionado à valorização dos profissionais de saúde, atores essenciais para efetivar as ações necessárias para a reorientação da APS (SEIDL et al., 2014). Porém, tem-se observado, ao longo dos anos, a fragilização do trabalho em saúde, sustentáculo central dos sistemas de saúde, com ausência de efetivas políticas do governo federal 
(GIOVANELLA, 2018). Isso porque a valorização dos profissionais da APS com desprecarização do trabalho em saúde, com política de pessoal única para o SUS e estabelecimento de carreira SUS de dedicação exclusiva, certamente contribuiria para uma APS robusta e competente (GIOVANELLA, 2018). Para valorização e melhoria do desempenho dos profissionais de saúde que atuarem na APS, são fundamentais medidas tais como: qualificação e capacitação do profisssional de saúde, remuneração adequada, novas formas de contratos de trabalho que garantam mais estabilidade e fortaleçam o vínculo empregatício, além da melhoria das condições de trabalho e infraestrutura dos serviços e unidades (MOTTA et al., 2015).

\subsection{EDUCAÇÃO PERMANENTE E EDUCAÇÃO CONTINUADA DOS MÉDICOS DA ESTRATÉGIA DE SAÚDE DA FAMÍLIA}

A educação nos serviços de saúde vem sendo realizada por meio da educação permanente, a partir das necessidades do processo de trabalho e tem demonstrado ser um importante dispositivo potencializador para a transformação do modelo de atenção à saúde no SUS, sendo catalisador da promoção de autoanálise e mudanças no cotidiano dos serviços de saúde. Ademais, a educação permanente estimula novas práticas e consciência crítica, além de encorajar novos caminhos para se produzir saúde, formação profissional, gestão e controle social. A educação continuada ainda muito presente no cotidiano dos profissionais possibilita a atualização e aplicação de prescrições seguras, ao incorporar protocolos e diretrizes clínicas na prática médica e possibilitar a abordagem clínica individual, familiar ou comunitária (CAMPOS et al., 2017).

Destarte, procurou-se conhecer como os participantes da pesquisa desenvolviam seus processos educativos. Foi elaborada uma tabela sintetizando as diversas maneiras de realizarem seus processos (Tabela 2):

Tabela 2 - Aspectos educativos autorreferidos

pelos médicos da Estratégia de Saúde da Família, (N=52), 2020

\begin{tabular}{l|l|l}
\hline Participa de atividades de EP & N & \% \\
\hline Sim & 51 & 98 \\
\hline Não & 01 & 02 \\
\hline & & \\
\hline Modalidade de EP que participa * & & \\
\hline Promovida pela gestão da ESF & 41 & 79 \\
\hline Educação a distância & 43 & 83 \\
\hline Na equipe & 11 & 21 \\
\hline Outras & 02 & 04 \\
\hline & & \\
\hline Atividades de educação que participa * & & \\
\hline
\end{tabular}




\begin{tabular}{|c|c|c|}
\hline Reuniões & 46 & 88 \\
\hline Cursos & 33 & 63 \\
\hline Capacitações & 47 & 90 \\
\hline Palestras & 38 & 73 \\
\hline Treinamentos & 27 & 52 \\
\hline Especialização & 33 & 63 \\
\hline \multicolumn{3}{|c|}{ Recebeu capacitação para atuar na ESF? } \\
\hline Sim & 38 & 73 \\
\hline Não & 14 & 27 \\
\hline \multicolumn{3}{|c|}{ Cursos de atualização nos últimos 5 anos } \\
\hline Nenhum & 11 & 21 \\
\hline 1 a 5 cursos & 30 & 58 \\
\hline 6 a 10 cursos & 07 & 13 \\
\hline $11 \mathrm{ou}+$ & 04 & 08 \\
\hline \multicolumn{3}{|c|}{ Ferramenta que utiliza para se atualizar * } \\
\hline Livros & 33 & 63 \\
\hline Artigos científicos & 32 & 61 \\
\hline Congressos & 17 & 32 \\
\hline Seminários & 14 & 27 \\
\hline Cursos presenciais & 26 & 50 \\
\hline EAD & 39 & 75 \\
\hline Internet & 28 & 54 \\
\hline Webpalestras & 23 & 44 \\
\hline Telessaúde & 17 & 33 \\
\hline \multicolumn{3}{|c|}{ Temas necessários para estudo (serviço) * } \\
\hline Organização do serviço & 24 & 46 \\
\hline Prontuário Eletrônico & 13 & 25 \\
\hline Trabalho em equipe e interdisciplinar & 14 & 27 \\
\hline Gestão do serviço & 19 & 36 \\
\hline Sistemas de Informação & 17 & 33 \\
\hline Outros & 04 & 08 \\
\hline \multicolumn{3}{|c|}{ Temas necessários para estudo (prestação cuidado) * } \\
\hline Desempenho clínico & 28 & 54 \\
\hline Habilidades de comunicação & 18 & 34 \\
\hline Gestão da clínica & 19 & 37 \\
\hline Saúde da Mulher & 16 & 30 \\
\hline Saúde do Homem & 17 & 33 \\
\hline Saúde da Criança & 18 & 35 \\
\hline Saúde do Adolescente & 23 & 44 \\
\hline Saúde do Idoso & 24 & 46 \\
\hline Abordagem individual & 11 & 21 \\
\hline Abordagem familiar & 23 & 44 \\
\hline
\end{tabular}

Fonte: Elaborada pela autora (2020).

Legenda: * mais de uma resposta

Analisando a tabela 2, observa-se que os médicos em sua maioria, 98\%, afirmaram ter participação em atividades de Educação Permanente, sendo o matriciamento uma dessas atividades. 
O Departamento de Atenção à Saúde local promove o matriciamento em saúde mental mensal, momento em que os médicos discutem com o psiquiatra da atenção secundária, casos clínicos de usuários de suas áreas de abrangência, os quais julgam pertinentes à continuidade exclusiva do cuidado na ESF. Ressalta-se que o Programa Mais Médicos, criado em 2013, está fundamentado pelas diretrizes pedagógicas da Educação Permanente (BRASIL, 2015).

Resgatando as concepções da PNEPS (BRASIL, 2009; BRASIL, 2014, p. 20) acerca da educação permanente como prática pedagógica apta para gerar aprendizagem durante as ações do trabalho e absorvendo o entendimento da aprendizagem significativa transformadora, os médicos do estudo realizavam a educação permanente em saúde, ao discutirem as histórias clínicas de seus territórios de atuação com o especialista opinando em relação aos casos entre si, desenvolvendo a aprendizagem real ao considerar cada especificidade de seu território. Nesse contexto, o apoio matricial constitui um importante recurso de trabalho e um mecanismo nobre de educação permanente em saúde. $\mathrm{O}$ apoio matricial apoia-se na interprofissionalidade, neste caso, interespecialidade médica, trabalho em redes, atuação em território definido, compartilhamento de saberes, deliberação conjunta e cogestão. Além desses, também apresenta componente educador e formativo, uma vez que cria espaços de discussão, troca de saberes e reflexão para a prática (OLIVEIRA et al., 2015).

Notou-se que a maioria dos participantes, 83\%, referiram que realizavam a educação permanente pela modalidade de Educação a Distância (EAD). A expansão dos cursos na modalidade EAD foi impulsionada a partir do fim da década de 1980, considerando a informatização e utilização de novas tecnologias. Essa modalidade de ensino tem tido seu uso incrementado, exponencialmente, por representar uma possibilidade de educação com vistas a superar a carência de formação em diversas áreas de conhecimento e por favorecer o acesso ao ensino nas regiões mais longínquas (RANGEL et al., 2012).

As atividades educacionais presentes no questionário são todas importantes práticas do grupo e $73 \%$ receberam alguma capacitação para atuação na ESF. O ensino a distância (EAD) é a ferramenta mais utilizada (75\%). Thumé et al. (2016), em um estudo qualitativo, analisaram o processo de aprendizagem de médicos integrantes do PMM durante o curso de especialização a distância em Saúde da Família e consideraram a metodologia do curso baseada na problematização, uma vigorosa aliada à formação dos médicos do Programa, o que coaduna com os princípios da educação permanente em que se transpõe a tradicional transmissão de informação com foco sistêmico e integral na realidade cotidiana da atenção primária à saúde. Os médicos participantes ainda pontuaram que a metodologia de educação a distância foi uma nova maneira de se aprender agregando vantagens como a flexibilidade de horários com tempo hábil para a organização dos estudos de acordo com a disponibilidade individual. 
Para Silva, K. M. et al. (2015), a EAD tem se mostrado bastante útil para a EPS, uma vez que rompe com as barreiras físicas e permite que o aprendiz escolha a hora e local de estudos, além de propiciar uma interação em tempo real entre estudantes e professores, o que gera um acesso mais democrático ao conhecimento. Nesse sentido, uma das iniciativas do Ministério da Saúde foi criar o Sistema Universidade Aberta do Sistema Único de Saúde (UNA-SUS) pelo Decreto n⿳ํㅜ 7.385, de 8 de dezembro de 2010, em parceria com as demais esferas governamentais, instituições públicas de ensino superior e unidades internacionais para a formação continuada dos profissionais da área. $\mathrm{O}$ (UNA-SUS) ofertou cursos de pós-graduação e de extensão universitária a distância fortalecendo a educação continuada para a APS (BARBOSA, S. P. et al., 2019).

Em um estudo realizado por Coelho et al., (2017) houve relato da construção e disponibilização de módulo a distância do "Curso de Capacitação em Ações de Eliminação da Hanseníase em Minas Gerais". Elaborado pelos integrantes do Núcleo de Estudos e Pesquisa em Hanseníase da Escola de Enfermagem da Universidade Federal de Minas Gerais em parceria com a Secretaria de Estado da Saúde de Minas Gerais, em modalidade presencial e a distância, foram utilizadas estratégias de ensino apoiadas em tecnologia virtual logo após o treinamento presencial, permitindo aprofundar os conhecimentos teóricos relativos à doença e acompanhar o desempenho das equipes nas ações de eliminação da hanseníase. Utilizou-se recursos como fórum de discussão, momento de interação dos participantes e facilitadores do curso, promovendo troca de saberes e experiências, além da possibilidade de relatar os casos e fatos vivenciados por cada participante, quanto à sua realidade.

Além dessa forma, foi citado neste estudo que $79 \%$ dos profissionais participavam de educação permanente, quando esta era promovida pela gestão da ESF. As ações educativas eram organizadas vislumbrando atendimento de novas diretrizes, normas estaduais, federais, informes de novas ações e atualizações de programas, ou de alguma temática específica para o atendimento de eventos e agravos à saúde. Todos os médicos integrantes da pesquisa participavam do matriciamento em saúde mental, realizado mensalmente e organizado pela gestão.

Também se discutiu em outros encontros mensais protocolos e diretrizes clínicas, nos mais diversos temas de saúde mental (tabagismo, ansiedade, depressão, manejo de alcoolismo e abuso de drogas ilícitas e outros). Praticavam a EC como um processo dinâmico e integrado à EPS, pois as atualizações que eram geradas mudavam ou transformavam as práticas médicas locais de cada profissional, além de levarem os casos clínicos de suas unidades para esclarecimento de dúvidas com o especialista. As ações de educação permanente na equipe foram relacionadas por $21 \%$ dos participantes. 
Os momentos dessas ações eram em reuniões de equipe e matriciamento com o NASF nas unidades locais. As equipes enviavam um consolidado à coordenação todo fim do mês, incluindo o relatório com a ata das atividades e temas trabalhados semanalmente em EPS. Elegiam por sorteio ou escala, um profissional da equipe ou NASF como líder responsável por conduzir o tema com a equipe. Constatou-se que foi prática incipiente com descontinuidade após o início da pandemia de COVID19.

Dentre as atividades educativas apontadas pelos profissionais, verificou-se a predominância de atividades de educação continuada por meio de cursos, capacitações, palestras e treinamentos, obtendo a participação acima de 52\% nessas atividades, podendo inferir ser um meio educativo de importância significativa para esses médicos. Assim, em consonância a essa proposta de educação continuada, na qual o profissional individualmente procura se capacitar em assuntos de seu interesse, foram citadas várias ferramentas para se atualizarem. As mais apontadas pelos participantes foram: EAD 75\%; livros 63\%; artigos científicos 61\%; Internet 54\%.

A educação médica tem perpassado por alterações, inclusões e novas perspectivas em relação ao ensino-aprendizagem. O uso de Tecnologias da Informação e Comunicação (TIC) em saúde tem crescido nas últimas décadas. É consenso a necessidade de avanço para uma aprendizagem construtivista e, nesse sentido, a EAD (com o uso da internet é mais comum) pode contribuir para este fim. Essa modalidade de ensino deve ser considerada não apenas como uma alternativa, mas também como uma nova metodologia de ensinar e aprender, tendo em vista que não se restringe a transmissão de conhecimento (VARGAS et al., 2016). Os autores ainda afirmam que a proposta da EAD, em contextos atuais, se sustenta em um modo de ensinar e aprender globalizado, multidimensional, considerando a complexidade dos sujeitos e da sociedade.

O ensino presencial frequentemente está centrado no docente, em um unidirecionamento da linha de ensino, com comprometimento da capacidade crítica do aprendiz, que aprende o que lhe foi entregue, sem levantar indagações. Verificou-se na EAD que o estudante participa de forma ativa na construção de seu conhecimento de forma mais produtiva do que aquela restrita aos pensamentos do professor (MARIZ et al., 2017).

Ao serem questionados com relação aos cursos de atualização realizados nos últimos 5 anos, a maioria, $58 \%$, realizou de 1 a 5 cursos, porém, $21 \%$ não fizeram nenhum. Isso ratifica as ferramentas adotadas acima referidas como as melhores para os participantes da pesquisa.

Dos 52 participantes da pesquisa identificou-se que $27 \%$ dos médicos que compõem as equipes de ESF não foram capacitados ao se inserirem nas equipes acerca da proposta da ESF. Os médicos, assim como todos os profissionais da ESF, devem estar capacitados para os desafios que a 
prática exige e preparados para buscar respostas às indagações advindas dessa ação (VASCONCELOS et al., 2015).

Os bolsistas do PMM são a maioria dos médicos da ESF no município de estudo e o ingresso é por seleção federal. Os médicos bolsistas preceptores possuem residência em MFC, ou seja, possuem capacitação no modelo de ESF. Porém, a gestão local não realiza capacitação para o trabalho em ESF e tão pouco orienta previamente, quanto à rede de saúde local.

Quanto às necessidades de educação permanente, os participantes informaram temas relativos ao funcionamento e organização do serviço e à prestação do cuidado. Com relação ao serviço, todas as temáticas relacionadas são importantes para o bom desenvolvimento da ESF, tais como: a organização do serviço; gestão do serviço; sistema de informação, trabalho em equipe e interdisciplinar; prontuário eletrônico que retratam a proposta do bom funcionamento da ESF.

O trabalho na ESF deve ser em equipe interdisciplinar, sendo desenvolvido de forma colaborativa e integrada. Nesse sentido, surge a ideia da cooperação, de que, mesmo com a divisão do trabalho, existe uma relação de dependência entre as ações profissionais, fundamentadas na confiança no outro (SANTOS et al., 2016). O trabalho em equipe se configura como um processo em que as ações são orientadas a um fim específico e comum, alcançado por meio da colaboração. A relação é marcada pela reciprocidade na comunicação e interação social, a qual pode assumir diferentes formas, conforme o nível de articulação das ações e da interação dos agentes (PEDUZZI et al., 2020). As equipes potencializam os processos de trabalho, na medida em que permitem a interação e a troca de saberes e percepções diferentes em relação a um mesmo problema. Além disso, possibilitam a divisão das tarefas, reduzindo a carga de trabalho individual e compartilhando recursos (PEDUZZI et al., 2016).

As temáticas de educação permanente referidas como necessárias para o desenvolvimento da prestação do cuidado perpassam por todos os ciclos de vida e também os específicos de habilidades de comunicação, desempenho clínico, abordagem individual e familiar. O levantamento de tais temáticas suscita importantes reflexões em relação à formação dos profissionais médicos: estaria, ela, adequada para atender as necessidades do SUS/ESF?

Conforme bem delimitado nas DCN de 2014 do Curso de Graduação em Medicina, ora vigentes, a ESF tem sido considerada um cenário oportuno para a formação médica. A formação, o desempenho e a gestão dos recursos humanos afetam consideravelmente a qualidade dos serviços prestados e o grau de satisfação dos usuários. Assim, a formação e a educação dos profissionais para abordagem do processo saúde-doença - com enfoque na saúde da família - são um dos desafios para o êxito do modelo sanitário proposto pelo SUS (MOTTA et al., 2015). A saúde da família e especificamente, a área médica, têm potencial transformador tanto no âmbito da prática do médico e 
no desenvolvimento de pesquisas, contribuindo para maior efetividade desses temas, inspiradas em bases mais humanas e comunitárias. A saúde da família, tem assumido papel relevante principalmente na promoção da Atenção Integral à Saúde. Os médicos de família desempenham um papel importante na integração e cuidados de coordenação, fornecidos aos pacientes e suas famílias (VASCONCELOS et al., 2015).

Portanto, a educação permanente a ser organizada para o município deverá se pautar nas necessidades apontadas pelos profissionais, que estão em consonância com os princípios e diretrizes do modelo da APS/ESF.

\subsection{ATRIBUTOS DA APS, PRINCÍPIOS E AÇÕES DESENVOLVIDAS NA ESTRATÉGIA DE SAÚDE DA FAMÍLIA PELOS MÉDICOS}

Com base nas definições de Starfiel (2002) procurou-se conhecer e identificar quais eram os atributos essenciais e derivados da APS e princípios da ESF presentes na prática das equipes e as ações desempenhados pelos profissionais médicos, uma vez que se interpreta que a ESF se alicerça nos atributos e princípios da APS que se harmonizam com o SUS. Além disso, a autora define como atributos essenciais: integralidade, longitudinalidade, coordenação da atenção, primeiro contato e derivados, competência cultural e abordagem comunitária da APS. Os princípios da ESF: territorização, caráter substitutivo, planejamento e programação, intersetorialidade e espaço de construção da cidadania (BRASIL, 2006). As ações desenvolvidas foram diversas e serão apresentadas na tabela 3 .

Tabela 3 - Atributos da APS, princípios e ações desenvolvidas

na Estratégia de Saúde da Família pelos médicos, (N=52), 2020

\begin{tabular}{l|l|l}
\hline Atributos realizados em sua ESF * & N & \% \\
\hline Primeiro contato & 44 & 84 \\
\hline Equidade & 44 & 84 \\
\hline Longitudinalidade & 36 & 70 \\
\hline Universalidade & 40 & 77 \\
\hline Encaminhamentos & 42 & 80 \\
\hline Coordenação do cuidado & 33 & 63 \\
\hline Competência cultural & 13 & 25 \\
\hline Abordagem comunitária & 32 & 62 \\
\hline Conselho local & 32 & 62 \\
\hline Integralidade & 34 & 65 \\
\hline & & \\
\hline Princípios da ESF desenvolvidos na sua UBS * & & \\
\hline Territorização & 40 & 77 \\
\hline
\end{tabular}




\begin{tabular}{l|l|l}
\hline Planejamento e programação & 41 & 79 \\
\hline Caráter substitutivo & 04 & 08 \\
\hline Intersetorialidade & 27 & 52 \\
\hline Espaço de construção da cidadania & 22 & 42 \\
\hline & & \\
\hline Ações desenvolvidas no cotidiano do trabalho * & & \\
\hline Consultas individuais & 52 & 100 \\
\hline Preventivo ca colo & 21 & 40 \\
\hline Pré-natal & 49 & 94 \\
\hline Puericultura & 41 & 79 \\
\hline Matriciamento com o NASF & 48 & 92 \\
\hline Atendimento DM/HAS & 41 & 79 \\
\hline Consultas compartilhadas & 48 & 92 \\
\hline Visitas Domiciliares & 51 & 98 \\
\hline Ferramentas de abordagem familiar como ecomapa e & 14 & 27 \\
genograma & & \\
\hline Cadastramento & 15 & 29 \\
\hline Reuniões com a equipe & 45 & 86 \\
\hline Mapa de área de abrangência & 14 & 27 \\
\hline Planejamento das ações da equipe & 32 & 61 \\
\hline Notificação compulsória de agravos e doenças & 41 & 79 \\
\hline Busca ativa & 39 & 75 \\
\hline Atividades nas escolas & 25 & 48 \\
\hline Grupos educativos & 46 & 88 \\
\hline Salas de espera & 26 & 50 \\
\hline Reuniões Cons. Local & 35 & 67 \\
\hline Reuniões com a comunidade & 28 & 54 \\
\hline Diagnóstico de saúde local & 29 & 54 \\
\hline & & \\
\hline Atividades mais realizadas cotidianamente & & $\%$ relativa \\
\hline Assistenciais & & 20,4 \\
\hline Administrativas e gerenciais & & 19,6 \\
\hline Educativas & & 19,8 \\
\hline Pesquisa & & 18,8 \\
\hline Participação com a comunidade & 21,4 \\
\hline Fonte: Elaborada pela autora (2020). & \\
Legenda: * mais de uma resposta & & \\
\hline & & \\
\hline & & \\
\hline & & \\
\hline & & \\
\hline
\end{tabular}

A maioria dos atributos era praticada pelos profissionais das equipes de ESF, porém, destaca-se a competência cultural, $25 \%$ no cotidiano das práticas, ainda pouco desenvolvida. Esse atributo consiste na capacidade das ESF de comunicar-se de forma efetiva com as pessoas, adaptandose às suas características culturais e permitindo que a comunicação com as pessoas continue efetiva. A compreensão gera confiança do paciente no profissional e maior adesão ao tratamento (ALVES, 2020). Para a efetividade da assistência e do modelo da ESF, torna-se imprescindível que haja mudança e incorporação no processo de trabalho desse atributo. Dessa forma, a educação permanente das equipes deve abordar a importância da competência cultural. 
Em decorrência das suas potencialidades, a ESF é reconhecida pela sua capacidade em reorientar a organização do sistema de saúde, buscar respostas para todas as necessidades de saúde da população e contribuir na mudança do modelo assistencial vigente com seu caráter substitutivo, que nesta pesquisa foi citado por apenas $8 \%$ dos participantes. O entendimento da ESF como modelo complementar e não substitutivo, desconsidera a ESF como um importante indutor de mudanças no modelo assistencial. A ESF baseia-se em princípios norteadores para o desenvolvimento das práticas de saúde, como a centralidade na pessoa/família, o vínculo com o usuário, a integralidade e a coordenação da atenção, a articulação à rede assistencial, a participação social e a atuação intersetorial (GIOVANELLA et al., 2009).

Quanto aos princípios da ESF, a intersetorialidade ainda é pouco praticada: 52\%, além do espaço de construção da cidadania: 42\%. Em um estudo, as autoras Barra et al. (2016) analisam que a intersetorialidade permanecia com um longo caminho a avançar, tanto no campo da gestão quanto do cotidiano das práticas das equipes de saúde da família. Descrevem que a intersetorialidade é um importante desafio, cuja superação envolve gestores, profissionais e usuários na construção de uma gestão democrática e comprometida com a integralidade da assistência.

As atividades desenvolvidas pelos profissionais foram classificadas em atividades assistenciais (20,4\%); administrativas e gerencias (19,6\%); educativas $(19,8 \%)$; pesquisa $(18,8 \%)$ e participação com a comunidade $(21,4 \%)$. Demonstraram equilíbrio no seu desenvolvimento, uma vez que na ESF espera-se que todos os profissionais se envolvam com todas as atividades para o cumprimento das diretrizes e princípios da ESF.

A gestão do trabalho pode ser compreendida apenas sob o formato administrativo, pautado em situações de comandar demandas ou delegar execuções e no controle prescritivo da organização dos processos de trabalho, no campo da macropolítica, mas também pode ser uma ação cotidiana do trabalhador, no espaço da micropolítica, a partir do reconhecimento de que todos os trabalhadores são gestores do seu próprio trabalho, exercendo graus de liberdade na organização e execução de suas práticas (GALAVOTE et al., 2016). Na ESF são estimuladas ações não somente praticadas pelo médico, todavia, que sejam compartilhadas em equipe, que se consubstanciem numa clínica ampliada e centrada nas demandas dos usuários e na promoção de seu cuidado. Para tanto, necessita-se que a ESF cumpra um papel indutor, podendo garantir na prática tais ações (SANTOS et al., 2015). Segundo Campos, C. V. et al. (2008) seriam: trabalho em equipe interdisciplinar; responsabilidade sanitária por um território e construção de vínculo entre equipe e usuários; abordagem do sujeito, da família e do seu contexto; reformulação do saber e da prática tradicional em saúde; articulação da ESF em uma rede de serviços de saúde que assegure apoio e amplie a capacidade de resolver problemas. Nessa perspectiva, a ESF tenta superar o modelo hegemônico centrado na figura do 
médico e propõe uma diferenciada forma de assistir à população, colocando como ponto-chave o trabalho interprofissional (OLIVEIRA et al., 2011).

Um estudo verificou que quanto à assistência médica, as consultas individuais eram citadas como a principal atividade dos médicos. Ainda pontuou que haviam queixas desses por sentirem dificuldades para exercer outras atividades na ESF. O modelo hegemônico centrado na figura do médico ainda vigorava nas equipes, dificultando o trabalho médico em outras práticas na ESF (GONÇALVES et al., 2009).

O município polo também aponta o modelo hegemônico assistencial centrado no médico. Os enfermeiros assumem a maior parte da assistência gerencial e administrativa (as unidades básicas não possuem gerentes formais). Tal fato é um importante fator para que o médico priorize a demanda e necessidade assistenciais e pouco se envolva com as questões administrativas, educativas e de controle social.

As ações que obtiveram maior percentual foram às relativas à participação com a comunidade: 21,4\%; as mais apontadas foram reuniões com o conselho local de saúde: $67 \%$ e reuniões com a comunidade: 54\%. Referente às atividades "assistenciais", 20,4\% estiveram com percentual muito próximo das de controle social, sendo as mais pontuadas as consultas individuais: 100\%; pré-natal: 94\%; consultas compartilhadas: 92\% e matriciamento com o NASF: $92 \%$.

A Constituição da República Federativa do Brasil, de 1988, estabeleceu, no inciso III, do artigo 198, seção II (da saúde), a "participação da comunidade” como uma das diretrizes do SUS. Criaram-se, a partir de então, conselhos e Conferências de Saúde como espaços privilegiados de discussão e controle das ações do setor. A participação da população, legitimada como direito e princípio do SUS, só adquire sentido quando é percebida como divisão de responsabilidades, colaboração, envolvimento com a construção das políticas de saúde, implicação com o SUS, conquista, união e mobilização pela saúde (LIMA et al., 2016). A participação popular confere maior transparência e legitimidade às políticas de saúde, além de um comprometimento coletivo com a gestão do SUS (BRASIL, 2009).

Desta forma, constatou-se que além da abordagem assistencial, os médicos do município precisam se envolver com as questões administrativas e educativas, além de participação em ações com a comunidade. $\mathrm{O}$ fato de não haver um gerente administrativo nas UBS, é um fator deflagrador da sobrecarga administrativa do enfermeiro, somado ao modelo hegemônico assistencial centrado no médico, colaborando para que falte a interação do mesmo com as demais atividades específicas da ESF. Também se averiguou que os médicos precisam desenvolver os atributos da APS como competência cultural, desenvolver os princípios da ESF como caráter substitutivo, contribuindo para consolidação da ESF como modelo prioritário. Necessitam de atuar nos territórios praticando a 
intersetorialidade e quanto ao espaço de construção da cidadania, valioso princípio da ESF, torna-se importante a participação ativa médica no conselho local, na administração da UBS, nas decisões interdisciplinares, nas atividades educativas junto à equipe e comunidade. A gestão da clínica deve ser praticada também por esses profissionais, para que contribua para promoção de saúde no território, pois ela compreende ações que caracterizam o processo de trabalho na ESF.

A EPS é uma estratégia que os profissionais médicos devem adotar na sua equipe, pois o processo de educação permanente possibilita principalmente a análise coletiva da dinâmica do trabalho, já que qualifica o processo de trabalho na assistência para a produção do cuidado em saúde (BRASIL, 2014).

\subsection{SATISFAÇÃO, RECONHECIMENTO E VALORIZAÇÃO DO TRABALHO MÉDICO NA ESTRATÉGIA DE SAÚDE DA FAMÍLIA}

A satisfação, o reconhecimento e a valorização do trabalho são algumas das características que os trabalhadores esperam obter na realização do serviço (DEJOURS, 2011). Várias são as características que permeiam o processo de trabalho de saúde, neste caso, dos médicos da ESF, que podem interferir na qualidade do trabalho desenvolvido e na saúde do trabalhador (ABRAMO, 2019).

Para este estudo considerou-se que a satisfação no trabalho se consolida quando se obtém o reconhecimento da utilidade e da qualidade do trabalho. O reconhecimento pode ser entendido como uma retribuição simbólica, proveniente de julgamentos relacionados ao fazer das pessoas (DUARTE et al., 2015). Considera-se o reconhecimento do trabalho, nas práticas cotidianas, no lócus de atuação do trabalhador (DEJOURS, 2015). E a valorização está associada à apreciação social, ao status que a profissão ocupa na sociedade, ao sentimento de importância que o profissional exerce no contexto social (DUARTE et al., 2016). As perguntas contidas no questionário aplicado aos participantes da pesquisa foram respondidas de acordo com a autopercepção deles (tabela 4):

Tabela 4 - Percepção dos médicos relacionada à satisfação, reconhecimento e valorização do trabalho médico na Estratégia de Saúde da Família, (N=52), 2020

\begin{tabular}{l|l|l}
\hline Satisfação com o trabalho na ESF & N & \% \\
\hline Sim & 47 & 90 \\
\hline Não & 05 & 10 \\
\hline Reconhecimento da gestão pelo trabalho na ESF & & \\
\hline Sim & 39 & 75 \\
\hline Não & 13 & 25 \\
\hline Valorização com o trabalho na ESF & & \\
\hline Sim & & \\
\hline
\end{tabular}




\begin{tabular}{l|l|l}
\hline Não & 10 & 19 \\
\hline Fonte: Elaborada pela autora $(2020)$ &
\end{tabular}

Fonte: Elaborada pela autora (2020).

De acordo com a tabela 4, observa-se que os profissionais se sentem mais satisfeitos (90\%) e valorizados (81\%) com o trabalho desempenhado do que se sentem reconhecidos $(75 \%)$.

O trabalho deve ser fonte de bem-estar, auto realização e prazer (NEVES et al., 2018), dessa forma os profissionais ao se sentirem satisfeitos, reconhecidos e valorizados com o trabalho desenvolvido, sentem-se motivados e estabelecem alicerces para a promoção da saúde dos trabalhadores e maior produtividade para a instituição (SILVA, L. A. A. et al., 2016).

Neste estudo processou-se que $25 \%$ dos médicos referiram não haver reconhecimento da gestão pelo trabalho desenvolvido. Vários são os possíveis fatores que podem influenciar nesta resposta: os baixos salários, a carga horária inflexível e a prática incipiente de educação permanente.

Verificou-se que $71 \%$ cumpriam carga-horária de $40 \mathrm{~h}$ semanais. Em estudo de Soratto et al. (2017), constatou-se que a insatisfação dos profissionais que atuavam na ESF possuía uma forte ligação com a gestão do trabalho em saúde na APS. Ressaltou-se, assim, que a jornada de 40 horas semanais era considerada como excessiva e se apresentou como elemento insatisfatório para os profissionais que agiam na ESF, colaborando para um aumento da sobrecarga de trabalho. Cabe reforçar que para alguns a jornada era ainda maior devido ao duplo e até triplo vínculo. Concluiu-se que, o tempo dedicado ao trabalho ocupava grande espaço na vida desses profissionais (SORATTO et al., 2017). O salário, que não corresponde ao nível de exigência e de complexidade das profissões, foi considerado em um estudo como um dos principais motivos de insatisfação. Uma das alternativas para reversão dessa situação seria a implantação de um plano de cargos e salários, como um aspecto importante a ser considerado para a satisfação profissional. A ausência de planos de carreira é um dos fatores que levam à desmotivação e à rotatividade dos profissionais atuantes na ESF (MILANEZ et al., 2018).

Em outro estudo, identificou-se que o frágil vínculo entre a gestão e os médicos do Programa Mais Médicos também pode ser um determinante fator para o menor reconhecimento. Um dos objetivos do PMM desde sua implementação em 2013 é fortalecer a política de educação permanente com a integração ensino e serviço (MOTA et al., 2016). O que se percebe no município polo é que o Programa requer dos médicos bolsistas o cumprimento de cursos EAD com metas pré-estabelecidas por período de tempo, diante da apresentação de certificados on-line (cursos UNA-SUS). Porém, a EPS que se concebe como o aprendizado diante da problematização no trabalho com seus "nós críticos" e próprios de cada local, ainda é incipiente.

Os profissionais indicaram que estão satisfeitos com o desenvolvimento de seu trabalho na ESF (90\%). Soratto et al. (2020), após analisarem a satisfação no trabalho dos profissionais de saúde 
que atuavam na ESF, destacaram que a satisfação era um fenômeno complexo de dimensão subjetiva, mas com contumaz relação com elementos do próprio processo de trabalho, como esse é organizado e sob que condições e relações ele se constrói. Considerou-se que uma atuação multiprofissional que se articule em uma ação coletiva de reciprocidade e interação entre os diferentes profissionais, as relações que se estabelecem no local de trabalho e a possibilidade de desenvolver um trabalho coletivo e integrado com os demais membros da equipe, são elementos centrais na produção de satisfação nos profissionais que atuam na ESF. Ainda se acrescentou que a satisfação está vinculada à identificação com o trabalho na ESF e os atributos da APS, implicando em estabelecer uma concepção mais ampla de saúde e de entendimento do processo saúde-doença. Considerou-se a importância da interação entre saberes técnicos e oriundos da população e a mobilização de recursos institucionais e comunitários para o enfrentamento dos problemas de saúde, como fortes fatores que contribuíam para essa satisfação (SORATTO et al., 2020).

Soratto et al. (2020) citaram que a valorização do gestor pode favorecer a satisfação do médico em seu trabalho, quando compreende que o trabalho do profissional deve ser considerado além de cobranças de metas ou aspectos técnicos quantitativos, mas, também, a dimensão subjetiva, ou seja, nos resultados de abordagem qualitativa em todos os aspectos do trabalho na ESF: assistencial, administrativo, educacional, multiprofissional e outros (SORATTO et al., 2020).

Quanto à satisfação com o trabalho na ESF, 90\% se sentiam satisfeitos e 75\%, reconhecidos pela gestão e $81 \%$ se sentiam valorizados com o trabalho na ESF. A gestão local usava aplicativo de mensagem para transmitir elogios aos médicos, oriundos da população à ouvidoria municipal, de outros membros da equipe ou de redes sociais, com manifestação pública (grupo de WhatsApp) e pessoal ao profissional. A prática de valorização e reconhecimento desses profissionais médicos publicamente, concordando com os autores referenciados, torna-se uma importante ação geradora de satisfação desses no município polo, não somente por externar o reconhecimento do gestor, mas também pela possibilidade de parceria das equipes e da população assistida.

\subsection{RESULTADOS DA ANÁLISE TEXTUAL DO SOFTWARE IRAMUTEQ}

Os resultados obtidos da análise do corpus do software IRAMUTEQ serão apresentados a seguir. A figura 4 representa a divisão final das classes com os vocábulos mais frequentes, contidos em cada uma delas, por meio do Dendrograma.

Figura 4 - Dendrograma da Classificação Hierárquica Descendente

Realizado pelo software IRAMUTEQ (2020) 


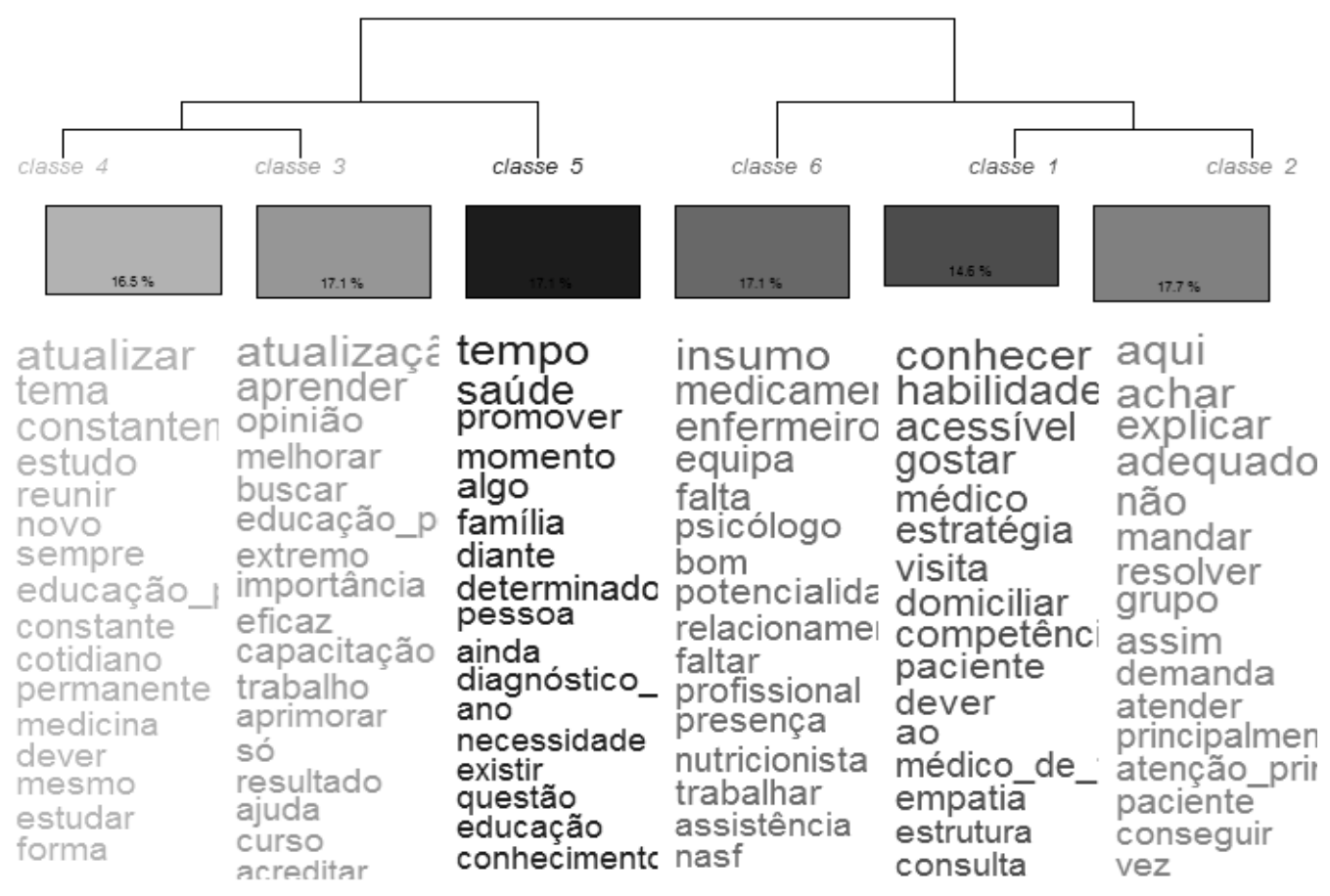

Fonte: software IRAMUTEQ 7.2.

A figura 4 demonstra o dendrograma da CHD com as divisões do corpus textual. O corpus foi dividido em dois subcorpus. No primeiro obteve-se a classe 5, com 28 segmentos de texto (ST), que corresponde a $17,1 \%$ dos ST. Houve nova subdivisão nesse subcorpus, emergindo a classe 4, com 27 ST, concentrando $16,5 \%$ dos ST. A classe 3, com 28 ST, correspondeu a 17,1\% do corpus total. Do outro subcorpus, obteve-se a classe 6 , com 28 ST, que correspondeu a $17,1 \%$ do total. Nesse mesmo subcorpus houve uma segunda subdivisão, que englobou a classe 1 com 24 ST correspondendo a $14,6 \%$, e a classe 2 , com 29 ST, sendo $17,7 \%$ do total.

Com esse dendrograma foi possível visualizar as palavras que obtiveram maior porcentagem quanto à frequência média entre si e diferente entre elas.

Figura 5-Representação da Análise Fatorial de correspondência fornecida pelo software IRAMUTEQ (2020) 


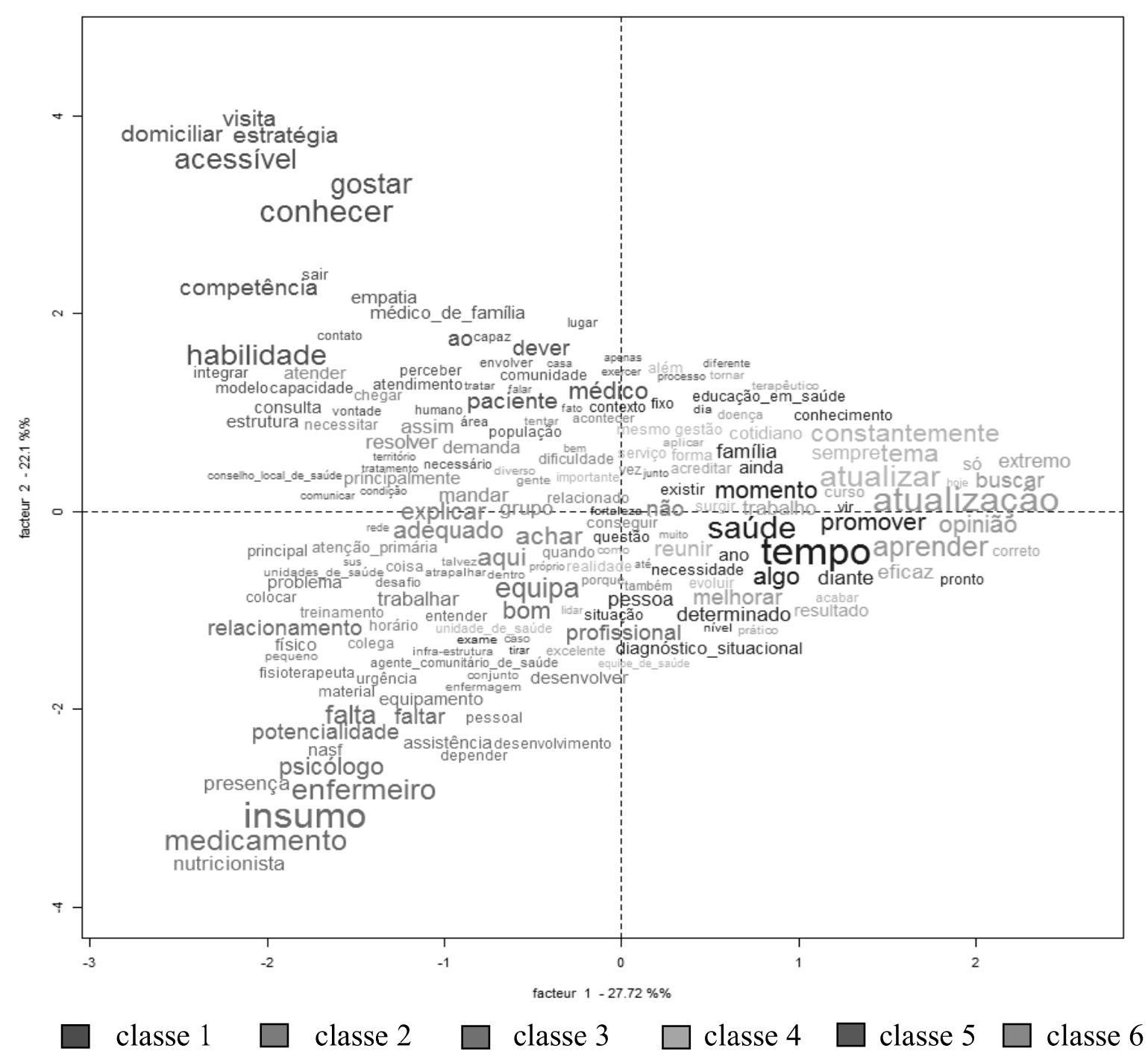

Fonte: software IRAMUTEQ 7.2.

A análise fatorial exposta na figura 5 possibilitou a comparação da produção textual das classes permitindo visualizar a correspondência dos conteúdos e das relações entre as classes (CAMARGO et al., 2016).

Analisando a figura 5, percebeu-se que as classes 1 e 2 comunicam entre si, expondo graficamente as semelhanças e proximidade pelas palavras que as contêm. As principais palavras que emergiram nas classes foram habilidade, conhecer, competência, acessível, gostar e médico (classe 1), as quais sinalizam as potencialidades e características do médico para exercer o modelo assistencial na ESF. Os vocábulos: dificuldade, resolver, necessitar, atender, tentar e explicar (classe 2) relacionam-se aos desafios que eles encontram para exercer o modelo assistencial preconizado pela ESF. Dessa forma, verificou-se a proximidade e a ligação entre essas classes, pois os desafios são barreiras que devem ser transpostas para a execução de um trabalho médico gratificante e pleno na ESF. Segundo Milanez et al. (2018), a satisfação dos profissionais envolve o reconhecimento do 
trabalho (usuário satisfeito e trabalho reconhecido), o processo de trabalho (equipe, identificação e organização) e aspectos institucionais (jornada de trabalho e estabilidade). A gestão do trabalho em saúde é o ponto central para potencializar aspectos associados à satisfação e suprimir elementos vinculados à insatisfação dos profissionais na Estratégia Saúde da Família, concluíram os autores.

À classe 6 destacam-se: potencialidade, equipe, trabalhar, relacionamento, profissional e assistência, as quais salientam-se o conhecimento do território, a importância do trabalho em equipe e da qualidade do cuidado. O médico é um dos integrantes da ESF, que tem caráter multiprofissional e interdisciplinar, sendo responsável pelo processo de cuidado da população (GARCIA et al., 2018). Faz-se necessário que os médicos e todos os profissionais envolvidos reflitam acerca do que é trabalho em equipe e como podem converter sua prática individualista em um modelo interdisciplinar com sinergia e efetividade para transformar o processo de trabalho na ESF (JACOVISKI et al., 2016).

À classe 5 destacam-se as palavras saúde, tempo, promover, diagnóstico situacional, conhecimento, família e contexto, que correspondem aos elementos necessários para que o médico possa trabalhar no modelo da ESF e requerem uma atitude médica com abordagem individual, familiar e comunitária.

A classes 4 e 3 apresentam-se estreita relação entre si, também expondo graficamente as semelhanças e proximidade e pelas palavras que as integram. As palavras centrais que emergiram nas classes foram quanto à classe 4: atualizar, constante, estudo, reunir, cotidiano e educação permanente. A classe 3 emergiram-se, principalmente: atualização, aprender, melhorar, capacitação, aprimorar, resultado e curso. A Organização Mundial da Saúde anunciou, como diretriz, que $80 \%$ dos problemas de saúde da população devem ter resolutividade na APS. Isto implica profissionais e diretrizes de ação que pressupõem contato com um robusto e contundente número de variáveis, remetidas a um campo de complexidade, acolhidas por uma clínica ampliada, que comporte aspectos biomédicos, subjetivos e sociais dos sujeitos (PEREIRA et al., 2009). Nessas classes as palavras relacionadas ao estudo, estar atualizado, ter aprimoramento clínico no trabalho, além do aspecto conjunto com a palavra "reunir" no trabalho, estão presentes em destaque nas colocações dos médicos entrevistados. Referindo-se à expressão educação permanente (codificada como palavra pelo software, pois foi formatada intencionalmente como "educação permanente"), Cruz et al. (2018) afirmaram que quanto à percepção em relação aos médicos, no referido estudo, verificou-se a necessidade de desenvolver uma abordagem adequada e efetiva de transformação com a utilização da educação permanente com a finalidade de melhorar o nível de resolubilidade da APS.

$\mathrm{Na}$ área da saúde a educação permanente se apresenta como forma de transformar as práticas nos territórios, incluindo todos os indivíduos envolvidos, oferecendo subsídios para que consigam resolver seus problemas e estabeleçam estratégias que possam suprir, inclusive, as necessidades de 
sua comunidade. Almeja-se qualificar o método educacional em saúde, tendo o processo de trabalho como seu objeto de transformação, buscando aprimorar as ações em serviço, tendo em vista alcançar equidade no cuidado, tornando-os mais competentes para o atendimento das necessidades da população (CRUZ et al., 2018).

Outra forma de análise foi a de Similitude (figura 7) em que se observou a apresentação gráfica das palavras. É realizada com base na coocorrência de palavras dos segmentos do corpus, demonstrando que tiveram semelhanças entre si e a ligação entre os vocábulos de uma mesma classe e entre as demais classes, permitindo a identificação de coexistência entre aqueles e seus resultados (CAMARGO et al., 2016). 
Figura 6 - Árvore de similitude gerada pelo software IRAMUTEQ

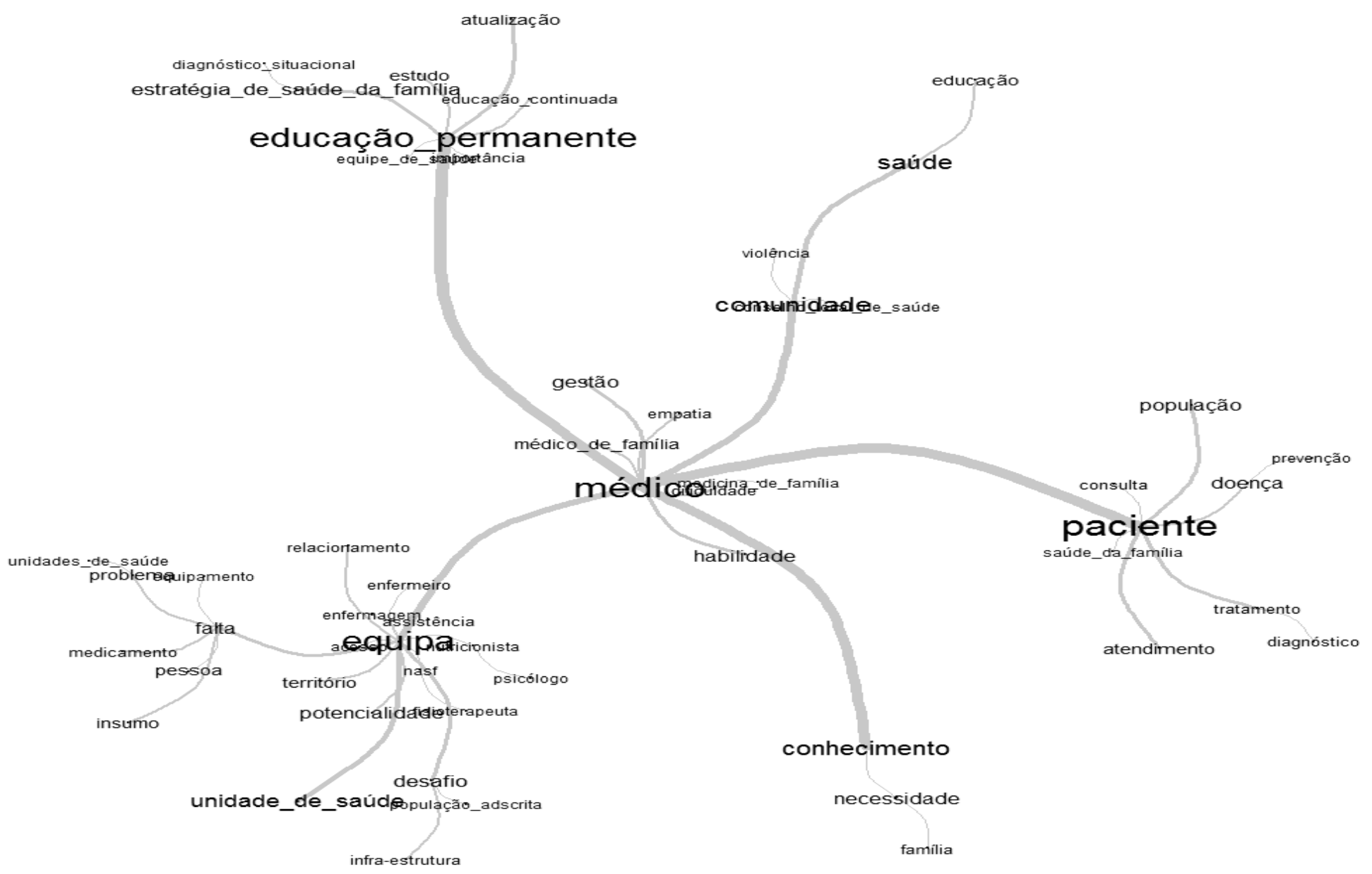


A árvore de similitude apresentou a interface dos resultados identificando as coocorências entre os vocábulos e a conexidade entre as palavras: médico, equipe, conhecimento, paciente, educação permanente, comunidade. São vocábulos identificados como essenciais para o desenvolvimento do processo de trabalho na ESF.

As coocorrências visualizadas a partir do vocábulo central, "médico", estão relacionadas às habilidades e competências necessárias ao profissional para desenvolver suas atividades na ESF, sendo essas, relacionadas à assistência e abordagem clínica individual, familiar e comunitária, relativas à gestão da ESF local, práticas educativas e de participação com a comunidade. Os vocábulos fortemente ligados ao "médico" são: "gestão", "médico de família, "empatia", "dificuldade" e "habilidade". Para exercer suas atividades na ESF o médico precisa adquirir habilidades e competências para identificar as "necessidades" de saúde da "família". Vasconcelos et al. (2015) afirmaram que o médico na ESF deve realizar uma abordagem com ênfase clínica e também desenvolver, de forma integrada e integradora, práticas de promoção, proteção e recuperação da saúde, dirigidas a pessoas, famílias e comunidades. Esses atributos podem favorecer um novo significado às bases estruturais da própria profissão médica, adquirindo papel fundamental na constituição dos novos parâmetros em saúde. A expressão "medicina de família" liga-se à "médico".

Ao vocábulo "conhecimento" conectam-se "necessidade" e "família", sendo esse último, alvo de abordagem médica no contexto teórico e prático do modelo assistencial ESF. Para o desenvolvimento da ESF espera-se que o médico junto com a equipe, tenham conhecimentos que possam vislumbrar o modelo voltado para a centralidade da pessoa inserida em uma família, da determinação social do processo saúde-doença, para o atendimento das necessidades de saúde com vistas a integralidade da assistência. A educação permanente em saúde é capaz de contribuir para a construção do saber médico e da equipe, qualificando as ações na APS por meio desse modelo assistencial prioritário.

Para o desenvolvimento de suas atividades quer clínicas, quer de gestão na ESF, de educação e controle social na saúde, o médico precisa conhecer a "comunidade", outro vocábulo em conexão. As ações desenvolvidas na ESF são de base territorial, com foco no indivíduo, inserido em uma família, que está dentro de uma "comunidade". Assim permitirá a compreensão das necessidades de saúde, como aquela comunidade em que vive, mora, adoece, se diverte etc., possibilitando o diagnóstico do território, permitindo conhecer a determinação social da saúde. Para Melo et al. (2017) o cuidado centrado na pessoa, prática estimulada na ESF, favorece a abordagem integral e longitudinal do indivíduo, considerando o sujeito em sua singularidade, mas também considerando sua inserção familiar e comunitária. Dessa forma, esse conhecimento do diagnóstico permitirá o 
planejamento de ações, que o médico junto com a equipe, possam atuar na promoção da "saúde" por meio de ações de "educação" em saúde, prevenção e recuperação das doenças.

O vocábulo "paciente" possui forte conexão com o vocábulo "médico". O paciente é o objeto de trabalho, o centro de sua abordagem e para produzir o cuidado necessita de forte relação interpessoal entre eles. Apareceram palavras mais destacadas como "população" e "doença" e também de forma expressiva, surgiram "consulta", "atendimento", "tratamento", "diagnóstico" e "prevenção". Os vocábulos suscitados reforçam as atividades assistenciais desenvolvidas pelo médico no modelo biologicista, que ainda é presente em algumas equipes, ao contrário do preconizado pela ESF que cabe ao profissional "realizar assistência integral (promoção e proteção da saúde, prevenção de agravos, diagnóstico, tratamento, reabilitação e manutenção da saúde) aos indivíduos e famílias em todas as fases do desenvolvimento humano: infância, adolescência, idade adulta e terceira idade" (JUNQUEIRA, 2008, p. 156). O médico em seu trabalho na ESF assiste indivíduos em seu contexto familiar e comunitário, tratando das mais diversas patologias ou doenças e abordando, além do diagnóstico e tratamento, também a prevenção. A abordagem aos pacientes por intermédio da medicina centrada na pessoa é fundamental, pois cumpre o papel de contribuir para promoção à saúde, ao incorporar a perspectiva do paciente e torná-lo sujeito de sua própria saúde (FEUERWERKER, 2007). Pendleton e colaboradores (2011) também afirmaram que a prática médica deve considerar duas perspectivas: a do médico e a do paciente, dessa forma, centrando no paciente a sua abordagem.

A expressão "educação permanente" aparece em conectividade com as expressões "estratégia de saúde da família" e "educação continuada" e as palavras "atualização" e "diagnóstico situacional" e "importância". Nesse núcleo visualiza-se que na ESF é importante ter EPS, pois ela é fundamental para a efetivação do modelo de saúde que preconiza com qualidade. Portanto é necessária a compreensão do processo de trabalho para o desenvolvimento das competências e habilidades para atuar no território de contextos socioculturais variados (ALMEIDA et al., 2016).

Os médicos entendem que a EPS é uma importante forma de atualização e que deve partir também do diagnóstico situacional para identificarem as necessidades de saúde do território e, dessa forma, verificarem as necessidades de EPS. Emerge o vocábulo "educação continuada", sendo esta modalidade de atualização fortemente realizada pelos médicos por meio de plataformas, devido à facilidade de acesso em qualquer horário e local. A utilização do dispositivo "educação permanente" na ESF possui crucial importância, pois permite contribuir com a qualidade dos serviços de saúde e da educação em serviço, fortalecendo e favorecendo os processos de trabalho em saúde (CARDOSO et.al., 2017; LEMOS, 2016). 
Considera-se que o trabalho em equipe com base na cogestão e que valoriza os espaços permanentes de diálogo é mais eficiente na condução de um processo problematizador que abranja uma maior diversidade de olhares, na busca por conhecimentos que façam sentido, na identificação de necessidades educacionais pertinentes e no planejamento de intervenções resolutivas, que possam de fato qualificar as práticas e avançar no cuidado integral à saúde (COLLAR et al., 2015; PINTO, 2016; SILVA K. L., et al., 2017). As equipes que praticam EPS passam a desenvolver uma escuta mais aguçada, capaz de entender as questões trazidas pela comunidade e estabelecer com ela uma comunicação mais eficaz.

O termo de uma das ramificações foi "equipe", fortemente ligado a "médico". O trabalho em saúde é coletivo e na ESF é um dos princípios da organização do processo de trabalho, ser em equipe e interdisciplinar. Destacam-se os vocábulos "fisioterapeuta", "psicólogo", "nutricionista", profissionais presentes nas equipes do "NASF". O termo "relacionamento" tem conexão com os profissionais da enfermagem, muito próximos aos médicos no cotidiano do trabalho em equipe na ESF. Ao aparecerem esses vocábulos, ressaltou-se que o processo de trabalho na ESF é em equipe multidisciplinar desvinculando a ideia de que o médico é o centro do processo de trabalho e, para vislumbrarmos o desenvolvimento do conceito ampliado de saúde, é necessário a todos os profissionais. Dessa forma a palavra "potencialidade" está ligada a equipe informando a positividade do trabalho em equipe.

Na outra ramificação a palavra "unidade de saúde" está relacionada à "falta" e "desafio" apontando a conexão com "população adscrita". É um desafio trabalhar de forma integrada e articulada com a população para o atendimento das necessidades de saúde, como preconiza a ESF. Portanto, vários são os desafios a serem enfrentados como: a "infraestrutura" às vezes inadequada da UBS para o atendimento à "falta" de "equipamento", "insumo", "medicamento", para atender às necessidades de saúde da "pessoa" ou de um "problema" específico ao procurar a UBS. Essas "faltas" transformam-se em "nós críticos" externados pelos participantes, como desafios para exercer o modelo assistencial da ESF.

A oferta de cuidados de saúde na rede básica e, particularmente, na ESF depende intensamente de processos organizacionais e das práticas interprofissionais. Ao lado dos desafios relacionados com a melhoria da estrutura dos serviços, a qualificação de processos de organização e gestão do cuidado por equipe multiprofissional é essencial para aumentar a efetividade da ESF, considerando seu efeito mediador na atenção à saúde (FACCHINI et al., 2018). O médico é um importante agente do cuidado na APS e precisa se comportar nessa prática interprofissional não somente como um clínico reconhecido, todavia, como um colega de trabalho, que saiba se relacionar em equipe e com seu paciente. Nessa perspectiva é necessário o desenvolvimento da educação permanente. 
Figura 7 - Nuvem de palavras gerada pelo software IRAMUTEQ (220)

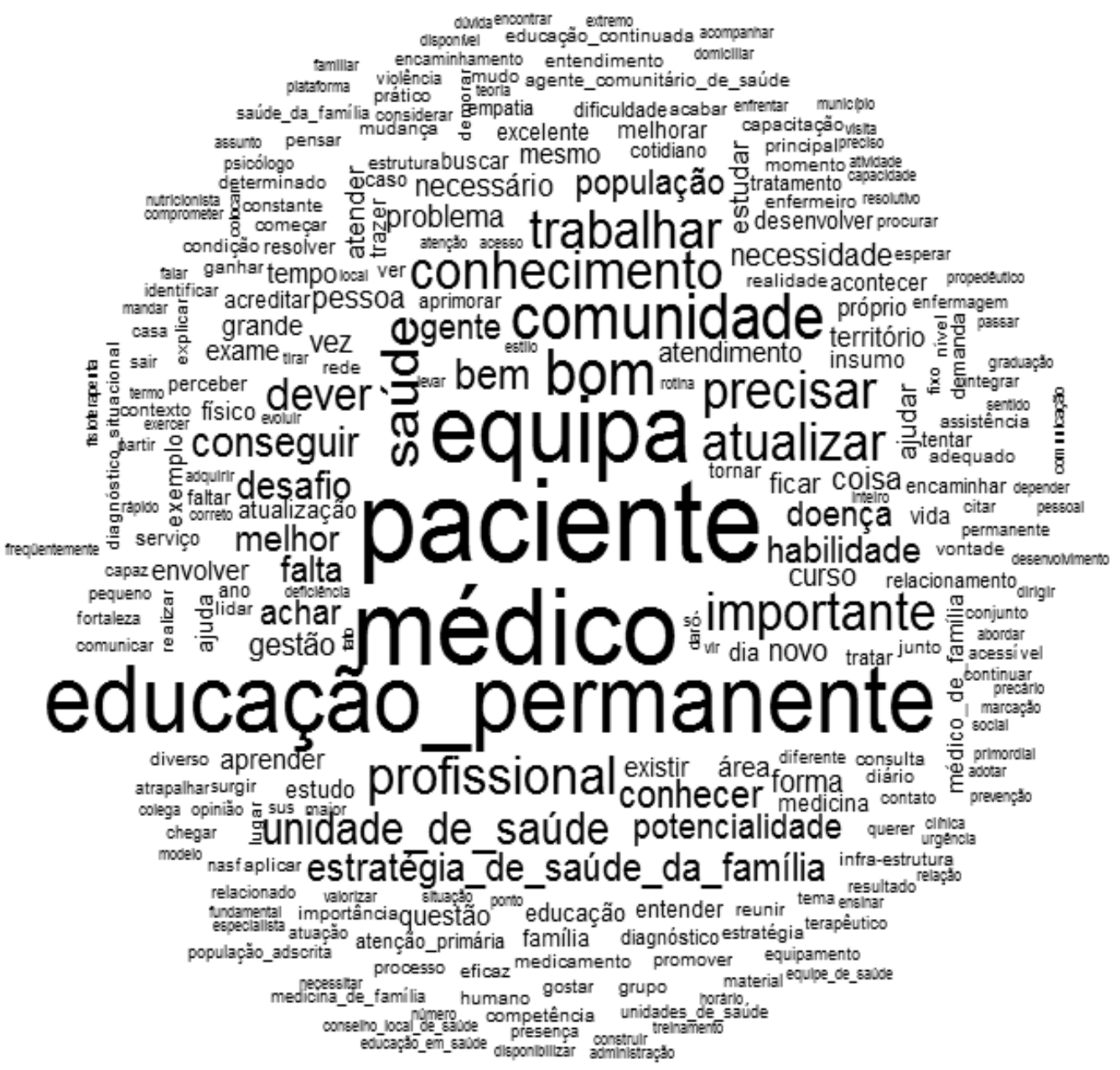

Fonte: software IRAMUTEQ 7.2.

Um importante resultado proveniente foi a "Nuvem de Palavras", que possibilitou a rápida identificação das palavras-chaves do corpus. Reuniu os vocábulos de acordo com a frequência e graficamente foi demonstrada pelo tamanho proporcional da frequência. Tal análise propicia a identificação das palavras-chaves do corpus (CAMARGO et al., 2016).

No centro da nuvem se destacaram os termos paciente, médico, educação permanente, equipe, os quais estão intimamente ligados para o desenvolvimento do processo de trabalho médico, sendo o primeiro, objeto central do processo de trabalho e, o último, dispositivo modificador e transformador da prática médica. As palavras principais que emergiram foram: paciente, médico, equipe, educação permanente, atualizar, profissional, habilidade, saúde, conhecimento, comunidade, precisar, importante, conseguir, desafio, trabalhar, potencialidade e dever. Dessa forma, pode-se constatar que na nuvem de palavras o resultado explicitado corrobora com os da árvore de similitude já analisados anteriormente. 
Mas, reforça-se que a importância das relações médico-paciente, médico-equipe, equipepaciente e médico-paciente-equipe, requerem harmonia e sinergia no trabalho na ESF (DUARTE et al., 2015). O médico por meio da abordagem centrada no paciente pode alcançar sucesso no desenvolvimento de seus projetos terapêuticos conjuntos e focando na equipe de ESF e NASF, nos projetos terapêuticos singulares, já que o trabalho interdisciplinar necessita de coesão para ser aplicado e concretizado.

Embora a prática médica no Brasil já apresente uma postura mais humanizada e integral ao tratar dos problemas das pessoas, de modo geral ainda não se conseguiu romper com o método de abordagem aos problemas de saúde baseado no modelo biomédico tradicional, que tem como características principais ser centrado na doença e no médico. Mesmo com todo o progresso trazido pelo desenvolvimento tecnológico e do conhecimento, o evento central da vida profissional do médico e, especialmente, do médico de família, continua sendo a consulta e, por consequência, tornase o ato principal do seu processo de trabalho. Há ainda um desafio para a medicina contemporânea, que é integrar dentro do processo de produção de cuidado a medicina baseada em evidências, o atendimento centrado na pessoa e o trabalho em equipe (LOPES et al., 2015).

O dispositivo EPS é caracterizado como um processo educativo imprescindível para o desenvolvimento do trabalho na ESF. A EPS tem seu cerne nas necessidades e problemas identificados pelos coletivos (no contexto, equipes de ESF e pacientes) no espaço da micropolítica do trabalho em saúde. Pode-se proporcionar aprendizagem significativa e transformação das práticas do médico e equipes com vistas à integralidade da atenção ao paciente. A prática da EPS está diretamente vinculada à forma como as equipes organizam seu processo de trabalho e às bases epistemológicas que o fundamentam (LEMOS, 2016). Os médicos deste estudo valorizam a EPS como dispositivo importante para atualização de temas médicos necessários ao aprimoramento de suas práticas.

Após as análises do corpus textual acima apresentado, emergiram categorias compostas pelas respectivas classes por afinidade dos vocábulos. Cada classe recebeu sua denominação de acordo com os vocábulos mais frequentes e mais significativos, conforme quadro 5: 
Quadro 5 - Composição das categorias de análise

\begin{tabular}{|c|c|c|}
\hline CATEGORIAS & CLASSES & DENOMINAÇÃO \\
\hline \multirow[t]{3}{*}{$\begin{array}{l}\text { 1-Habilidades e } \\
\text { competências para o médico } \\
\text { da ESF }\end{array}$} & Classe 6 & $\begin{array}{l}\text { Trabalho em equipe e sua } \\
\text { importância no cuidado na } \\
\text { ESF: uma percepção médica }\end{array}$ \\
\hline & Classe 1 & $\begin{array}{l}\text { As potencialidades e } \\
\text { características do médico } \\
\text { para exercer o modelo } \\
\text { assistencial na ESF }\end{array}$ \\
\hline & Classe 2 & $\begin{array}{l}\text { Desafios que os médicos } \\
\text { encontram para exercer o } \\
\text { modelo assistencial } \\
\text { preconizado pela ESF. }\end{array}$ \\
\hline \multirow[t]{3}{*}{$\begin{array}{l}\text { 2-A importância da EP na } \\
\text { prática médica na ESF }\end{array}$} & Classe 5 & $\begin{array}{l}\text { Fatores necessários ao } \\
\text { trabalho médico qualificado } \\
\text { na ESF }\end{array}$ \\
\hline & Classe 4 & $\begin{array}{l}\text { A EP na prática profissional } \\
\text { do médico }\end{array}$ \\
\hline & Classe 3 & $\begin{array}{l}\text { O entendimento na } \\
\text { percepção dos médicos sobre } \\
\text { EP }\end{array}$ \\
\hline
\end{tabular}

Fonte: Elaborado pela autora com os dados da entrevista (2021).

\subsection{CATEGORIA 1:AS HABILIDADES E COMPETENCIAS NECESSÁRIAS PARA SER MÉDICO DA ESF}

As classes que compõem esta categoria são a classe 6 "Trabalho em equipe e sua importância no cuidado na ESF: uma percepção médica"; classe 1 "As potencialidades e características do médico para exercer o modelo assistencial na ESF" e a classe 2 "Desafios que os médicos encontram para exercer o modelo assistencial preconizado pela ESF". Nessa categoria os vocábulos mais visíveis foram: potencialidade, equipe, trabalhar, relacionamento, profissional, assistência (classe 6), habilidade, conhecer, competência, acessível, gostar, médico (classe 1), dificuldade, resolver, necessitar, atender, tentar e explicar (classe 2).

Para ser um médico da ESF muitas são as habilidades, competências e atitudes que se esperam desse profissional, uma vez que atuará num modelo assistencial de saúde oposto ao modelo hegemônico, o qual o considerava o centro do processo de trabalho. 
O médico da ESF tem o fundamental papel de trabalhar em equipe, colaborando no processo de territorialização e mapeamento da área de atuação. Necessita ter a capacidade de identificar os aspectos determinantes sociais da saúde da população; conhecer as famílias e os grupos (comunidade) da área adscrita, zelando por cuidados no âmbito tanto da unidade de saúde, quanto do domicílio. Além disso, deve realizar ações de atenção à saúde de acordo com o perfil populacional, em busca da integralidade por meio de ações de promoção, proteção e recuperação da saúde (BARBOSA, S. P. et al.,2019). Todavia, para que sua função seja efetiva, é preciso romper com o modelo hegemônico de formação, sustentado pela abordagem biologicista, medicalizante e centrado em procedimentos (FERTONANI et al., 2015).

É função do médico realizar atenção à saúde aos usuários adscritos no território de sua responsabilidade; consultas clínicas, procedimentos e educação em saúde em grupo; praticar ações em saúde de acordo com as necessidades da comunidade; encaminhar usuários aos diferentes níveis de atenção, respeitando referência e contra referência e garantindo o acompanhamento do plano terapêutico; deve colaborar para a educação permanente dos demais profissionais da equipe; e, ainda, participar do gerenciamento de insumos (BRASIL, 2017).

O médico de família e comunidade é o profissional formado para atender na APS. É um coordenador do cuidado, responsável por articular o usuário nos diversos níveis de atenção, e garantir seu acesso aos serviços de saúde. A Sociedade Brasileira de Medicina de Família e Comunidade (SBMFC) criou um currículo baseado em competências, que busca determinar as habilidades esperadas do médico de família e comunidade considerando os princípios da medicina de família e comunidade e os atributos da APS. Dentre essas competências, trata da abordagem médica ao indivíduo, às famílias e comunidade, das habilidades clínicas e de comunicação, ética médica, acerca da educação permanente e outras (SBMFC, 2015).

No presente estudo, constatou-se que a relação médico-paciente, a sinergia e harmonia do trabalho em equipe e a competência clínica, além de um olhar mais humano, são características valiosas para parte dos entrevistados, como M8 expõe:

"[...] o médico integrante da equipe de saúde da família deve ser um médico comunicativo, paciente e um médico disposto a escutar e avaliar um doente em todo o seu contexto biopsicossocial, isto é, de acordo com a medicina centrada na pessoa e não apenas no aspecto biológico e técnico [...]”. (M8).

A coordenação do cuidado, atributo essencial da APS, necessita do trabalho em equipe, interação entre profissionais e integração em rede e também participação dos cidadãos, corresponsáveis pela própria saúde, nos canais participativos de inclusão nos processos decisórios. 
Embora o papel do médico seja central, prevalece a compreensão de um agir compartilhado entre os profissionais e com a rede, a ser apreendido pelos profissionais desde a sua formação (LAPÃO et al., 2017).

Com o objetivo de remodelar a formação médica, o Ministério da Saúde instituiu, em 2001, as Diretrizes Curriculares Nacionais (DCN), que buscavam definir uma formação geral humanista, crítica, reflexiva e ética, preparando os graduandos para enfrentar os desafios da transformação profissional e das condições de trabalho construídas numa formação básica sólida e capaz de associar conhecimentos e habilidades para beneficiar a saúde pública (GOMES et al.,2017). Em 2014, o Conselho Nacional de Educação, diante de novas diretrizes da área da saúde no Brasil, traçou o perfil de competência do médico a ser formado, analisando sua aplicação, diferentes abordagens e implicações no campo de formação de trabalhadores de saúde e, dessa forma, instituiu a partir de 2014, as atuais DCN dos cursos de Medicina (BURSZTYNL, 2015).

O modelo humano, acessível, empático e competente proposto pela SBMFC e pelas DCN (2014) foi visto pelos entrevistados como aspecto importante, como demonstram as falas a seguir:

"[...] o médico na ESF deve ter contato com seu paciente e demonstrar empatia e buscar a confiança dele, criando vínculo com o paciente ao traçar um plano terapêutico. Sem este vínculo o tratamento pode ser comprometido [...]”. (M19).

"[...] O médico deve ter a competência de saber fazer bem uma anamnese ao entrevistar o paciente com conhecimento cientifico das patologias que vai tratar e ter habilidades de comunicação, entendendo que deve prescrever e se comunicar de forma acessível ao paciente [...]". (M1).

"[...], além disso, ele deve conhecer o território em que está trabalhando e conhecer a sua equipe o que possibilita traçar as melhores estratégias para atendimento daquela população [...]”.'. (M11).

"[...] as habilidades do médico são empatia, conhecer sobre territorização, conhecer a população adscrita, saber trabalhar em equipe, conhecer $e$ aplicar o método clínico centrado na pessoa, sempre se colocar no lugar de seu paciente ou colega. Deve conhecer a rede de saúde e gostar de fazer visita domiciliar [...]”. (M3).

“[...] temos que ser estudiosos e termos habilidade técnica durante a abordagem ao paciente na atenção primária com prudência para diferenciar o que pode ser resolvido ali ou o que necessita ser encaminhado a outro nivel de atenção [...]”. (M3).

"[...] tem que trabalhar como gestor da clínica na unidade de saúde, já que o médico é uma das cabeças mais pensantes profissionais dentro da estratégia de saúde da família. Portanto, tem que trabalhar com essa gestão, 
com uma agenda aberta e organizada e fazer um diagnóstico situacional da sua área de abrangência [...]”. (M2).

Analisando as falas dos entrevistados, notou-se que coadunam com o currículo baseado em competências na SBMFC. Citaram as habilidades de comunicação como empatia e capacidade de gerar confiança ( $4^{\circ}$ princípio da Medicina de Família e Comunidade que é a relação médico paciente), abordagem familiar e comunitária (conhecer a população, territorização, traçar melhores estratégias de abordagem, dentre outras). M3 enfatizou a importância de habilidades clínicas e a capacidade resolutiva para discernir o que seja necessário encaminhar a outro nível de atenção. A gestão da clínica deve ser outra habilidade médica a ser desenvolvida e aplicada pelo médico de família, como expôs M2.

Uma atuação centrada na pessoa (Método Clínico Centrado na Pessoa ou MCCP) é considerada fundamental para um bom desempenho de qualquer profissional da área da saúde, porém, ao médico de família e comunidade ela é imprescindível (LOPES et al., 2015). Ainda que a prática médica no Brasil já apresente uma abordagem mais humanizada e integral ao tratar dos conflitos das pessoas, de modo geral, ainda não se conseguiu romper com o método de abordagem aos problemas de saúde baseado no modelo biomédico tradicional, que tem como características principais ser centrado na doença e no médico. Mesmo com todo o progresso trazido pelo desenvolvimento tecnológico e do conhecimento, a ferramenta central da vida profissional do médico continua sendo a consulta e, por consequência, ela torna-se a ação principal do seu processo de trabalho. Surge então o desafio para a medicina contemporânea de integrar dentro do processo de produção do cuidado, a medicina baseada em evidências, o atendimento centrado na pessoa e o trabalho em equipe (LOPES et al., 2015).

Mendes (2011, p. 368) definiu gestão da clínica como

uma atenção à saúde de qualidade; centrada nas pessoas; efetiva; estruturada com base em evidências científicas; segura, que não cause danos aos pacientes e profissionais; eficiente, provida com os custos ótimos; oportuna, prestada no tempo certo; equitativa, de modo a reduzir as desigualdades injustas; e ofertada de forma humanizada.

Segundo Padilha et al. (2018), a gestão da clínica tem como foco central a produção de uma atenção integral à saúde, com qualidade e segurança, que se oriente de acordo com às necessidades de saúde das pessoas e populações, por meio da transformação de práticas de atenção, gestão e educação. Para ser um bom gestor da clínica, alguns médicos opinaram: 
"[...] para que tudo isto aconteça ele precisa ter o conhecimento dos princípios de medicina de familia e comunidade e deve trabalhar esses princípios dentro de seu território de atuação, sabendo sempre reconhecer quais são os problemas e as dificuldades que pode solucionar para beneficiar seus pacientes [...]”. (M15).

"[...] a educação permanente ajuda a lidar com o paciente em longo prazo, pois você vai saber fazer as alterações na terapêutica quando for preciso e vai te ajudar a pedir os exames corretos nos tempos precisos [...]". "Na gestão e administração, saber administrar sua unidade de saúde, identificar os insumos necessários para se ter o melhor trabalho [...]" (M18).

Os médicos e todos os profissionais da APS necessitam desenvolver e exercer suas competências e habilidades na atenção à saúde dos indivíduos, com foco na comunidade e em seus territórios de atuação, contemplando um atributo essencial da APS, a integralidade, assim como os profissionais de outros níveis de atenção precisam atuar. Suas ações devem ser norteadas por condutas sólidas baseadas em evidências científicas, boa interação com o usuário, liderança proativa no trabalho multiprofissional, na administração e gestão da força do trabalho e se qualificar em sua prática por meio da educação continuada e permanente (MAHMUD et al., 2018).

Por meio das falas dos médicos verificou-se a importância de se desenvolver competências gerais das DCN dos cursos da área da Saúde que é administrar e gerenciar. Dotar os profissionais com tais habilidades e competências promove a capacidade de serem gestores não só da força de trabalho, mas de recursos materiais e físicos, da informação, promovendo o desenvolvimento dos princípios da APS e do modelo assistencial da ESF (BRASIL, 2001).

A visita domiciliar é uma das vertentes da atenção domiciliar (cuidado domiciliar) e propicia conhecimento do contexto familiar e comunitário do usuário do sistema. A atenção domiciliar pode ser definida como um modelo de assistência que envolve promoção, prevenção, tratamento, reabilitação e paliação da saúde, no âmbito domiciliar. Sendo ofertados serviços que incluem: visitas domiciliares, atendimento domiciliar e internação domiciliar (PROCÓPIO et al., 2019). Na ESF o médico, generalista ou médico de família, assume um modelo de cuidado amplo, cuja essência seja a prevenção e promoção da saúde, sempre atuando de forma multidisciplinar, almejando avaliar o paciente de maneira independente e ir agregando atendimentos de outros profissionais geralmente coordenados por ele e, interdisciplinar, em que a equipe de profissionais colabora com o mesmo alvo e todos compartilhando a coordenação do cuidado do paciente. $\mathrm{O}$ atendimento não se limita somente à Unidade de Saúde, mas também ao domicílio do paciente, conhecendo a dinâmica familiar e realizando um cuidado direcionado ao seu contexto (MAHMUD et al., 2018). 
Os médicos do estudo atribuíram à visita domiciliar, o exercício de uma prática ora como competência, ora como habilidade do médico:

"[...] a atenção em saúde é o contato direto com os próprios pacientes, onde o médico vai atender as demandas da população e trabalhar com consultas de rotina, com consultas agendadas e com visitas domiciliares [...]”. (M3).

"Temos que estar sempre com habilidade em dia, ter um bom relacionamento com o paciente, atender com pontualidade, conversando bem com o paciente, com seus familiares, fazendo as visitas domiciliares nas datas marcadas [...]". (M14).

"[...] a habilidade é ter empatia, conhecer sobre territorização, conhecer a população adscrita, saber trabalhar em equipe, conhecer e aplicar o método clínico centrado na pessoa, sempre se colocar no lugar do outro, conhecer a rede de saúde e gostar de fazer visita domiciliar [...]". (M19).

A atenção domiciliar é uma das competências do médico de família (presente no currículo baseado em competências) e o estímulo e orientação ao paciente e cuidador são abordados e incentivados. As habilidades precisam ser desenvolvidas como realizar entrevista clínica e exame físico em ambiente domiciliar, avaliando estado orgânico, mental, funcional e social; avaliar os fatores do processo saúde-doença no espaço domiciliar e estabelecer um plano de assistência domiciliar sob a lógica do trabalho em equipe e outras (SBMFC, 2015, p. 51).

Os médicos entrevistados apontaram as potencialidades no dia a dia do serviço da ESF no município polo:

"[...] temos boas potencialidades como uma boa infraestrutura aqui na unidade e boa equipe”. (M21).

"[...] a residência em medicina de família e comunidade é uma grande potencialidade, com médicos especialistas em atenção primária e a equipe tem um grande interesse em ajudar a população fazendo um ótimo atendimento, tentando organizar o serviço [...]". (M6).

"[...] as potencialidades são a presença do NASF com profissionais que nos ajudam no cuidado como educador físico, fisioterapeuta, psicólogo, farmacêutico e assistente social. O salário sem atrasos também é muito bom e há uma boa interação da população adscrita com a nossa equipe. [...]". (M19).

"[...] as potencialidades que observo aqui são o bom espaço físico da unidade e a excelente equipe que faço parte, pois trabalhamos em conjunto $[\ldots]$ '. (M12). 
“[...]a potencialidade é que temos profissionais na equipe capacitados e temos medicamentos de urgência disponíveis, como um anti-hipertensivo ou material para curativo [...]”. (M14).

"[...] as potencialidades eu diria quanto ao SUS com sua rede é que conseguimos encaminhar o paciente para outros especialistas ou outros níveis de atenção. [...]”. (M11).

"[...] as potencialidades são a equipe que é excelente, a gente trabalha bem e sempre que falta algo, fazemos reuniões e conseguimos nos juntar e tentar reverter às deficiências, os exames que pedimos estão saindo rápido e os encaminhamentos também não estão demorando. [...]”. (M16).

Quanto às potencialidades, os efetivos trabalhos em equipe e multidisciplinar ganharam valor nas falas, sendo dessa forma, destaques nas entrevistas. O NASF possui papel sinérgico à atuação médica e da equipe, quanto à assistência em saúde dos territórios de atuação. O entrosamento das equipes do NASF e da ESF é o que deve acontecer para a ocorrência da prática de apoio matricial, e que, para tal, precisam ser considerados os princípios profissionais que a sustentam: a interprofissionalidade, o vínculo, a integralidade no cuidado, a acessibilidade, a resolutividade e a longitudinalidade (HIRDES, 2015). De igual modo, as políticas públicas preveem que as equipes de profissionais do NASF e das ESF organizem seus processos de trabalho priorizando o atendimento compartilhado e interdisciplinar, superestimando a troca de saberes e a capacitação, mantendo sempre foco na integralidade, na humanização e na promoção de saúde, no território sob a responsabilidade delas (SANTOS et al., 2017).

A residência em MFC, certamente, é apresentada como potencialidade pelos médicos preceptores e ratificada como fortalecedora da APS em muitos estudos e políticas citados anteriormente.

A coordenação do cuidado foi potencialidade apontada por M11 e M16 quanto ao acesso do usuário à rede do SUS no município e como desafio por M19 (pág.97), quanto à demora no acesso à rede secundária e à propedêutica complementar. A APS é considerada a principal estratégia de reorientação do modelo assistencial, apontada como centro de comunicação das redes e coordenadora do cuidado. Deve ser, assim, a porta de entrada preferencial do SUS, não seletiva, capaz de assumir a coordenação do cuidado dos usuários como um atributo fundamental na organização de sistemas de saúde, promotora de equidade, acesso, qualidade e continuidade da atenção (ALELUIA et al., 2016).

Ressalta-se que um bom relacionamento em equipe é uma potencialidade citada por boa parte dos entrevistados. Em um estudo realizado na ESF de um município brasileiro de grande porte, demonstrou-se que profissionais vivenciavam rotineiramente situações que desencadeavam insatisfação no trabalho, como baixo salário, mau relacionamento entre a equipe, equipes 
incompletas, sobrecarga de serviço, entre outros. Por outro lado, também existiam elementos que proporcionavam a satisfação, a saber: o trabalho em equipe, o gosto pelo que faziam e outros (SORATTO et al., 2017).

A satisfação no trabalho em equipe promove o desenvolvimento de um ambiente saudável e estímulo para o desenvolvimento das ações e enfrentamentos decorrentes das situações precariedade e dificuldades vivenciadas pela população usuária e que culmina na atenção à saúde pelas equipes.

Os desafios apontados no dia a dia do serviço da ESF foram:

"[...] os desafios são a falta de medicamentos aqui na farmácia e também faltam alguns profissionais como o dentista, psicólogo e nutricionista que fazem falta para o território daqui [...]”. (M20).

"[...] os desafios são a infraestrutura da unidade de saúde, que é péssima, pois somos três médicos aqui e temos disponivel apenas um consultório e temos que estar dividindo horários na mesma sala, falta de consultório adequado para realizarmos procedimentos médicos. Com a pandemia não temos uma sala adequada para o atendimento de pacientes com síndrome gripal e temos que atender fora da unidade de saúde. Também temos um território com violência e tráfico de drogas [...]”. (M16).

"[...] e de desafio que observo é que a nossa população é um pouco violenta $[\ldots]$ '. (M12).

"[...] os desafios são a falta de insumos e ter uma população adscrita muito numerosa. Precisamos melhorar a infraestrutura e há falta de medicamentos. Temos alguns problemas de relacionamento na equipe, atraso na marcação de exames propedêuticos [...]”. (M19).

"[...] faltam medicamentos e precisamos estar reunidos com a gestão pra ver se pode melhorar essa situação [...]”. (M14).

Um estudo brasileiro descritivo-exploratório de 2020 demonstrou que precárias condições de trabalho, como falta de estrutura física, insumos e material humano, eram elencados como fatores que poderiam desmotivar um futuro médico a escolher a ESF como área de atuação pós-formação (ROTTA et al., 2020). M6, M19 e M16 citaram a má infraestrutura das unidades em que atuavam.

Em 2011, o Ministério da Saúde instituiu o Programa de Requalificação de UBS (Requalifica UBS) como estratégia para a estruturação e o fortalecimento da APS. Por meio do programa, houve proposta de uma estrutura física para as unidades básicas de saúde que facilitasse a mudança das práticas das equipes de saúde. Também objetivou-se criar incentivo financeiro para a reforma, a ampliação e a construção de UBS, provendo condições adequadas para o trabalho em saúde e promovendo melhoria do acesso e da qualidade da APS (BRASIL, 2016). A infraestrutura das 
unidades básicas foi um "nó crítico" importante para os médicos no estudo, os quais apontaram necessitar de melhorias. Constatou-se que tal insatisfação é predominante entre os médicos que atuavam nas UBS alugadas, sendo essas, casas adaptadas pela prefeitura, ainda sem benfeitorias ou reformas como as já realizadas nas unidades próprias.

A falta de insumos foi pontuada pelos médicos e se destacou nas falas de M20, M19, M14. Um estudo realizado em Pernambuco avaliou o acesso a medicamentos pela ESF. Entre os hipertensos, $37 \%$ compravam medicamentos; e entre os diabéticos, $30 \%$, com desembolso direto mensal de, em média, $\mathrm{R} \$ 20,00$. Constatou-se um acesso baixo a médio e a necessidade de alguns usuários para comprar os medicamentos (BARRETO et al., 2015).

Uma pesquisa exploratória descritiva, com abordagem qualitativa realizada no município de Campina Grande (PB), em 2015, concluiu-se que havia inúmeros entraves para a adequada atenção às urgências na ESF, comprometendo a resolubilidade e, consequentemente, o princípio da integralidade à saúde. Dentre eles, destacaram-se a falta de uma equipe profissional capacitada, escassez de insumos e medicamentos mínimos de urgência, ausência de um local adequado para realizar o acolhimento e de uma sala de observação equipada para proporcionar atendimento de baixa gravidade/complexidade, além da deficiente integração da APS com os demais serviços da rede de assistência (FARIA et al., 2015). Soratto et al. (2017) concluíram em um estudo que os aspectos geradores de insatisfação relacionados a condições de trabalho, diziam respeito a deficits na estrutura física e instrumentos de trabalho encontrados nas unidades básicas de saúde onde atuavam as ESF's (SORATTO et al., 2017).

Soratto et al. (2017) também consideraram a respeito da ausência de segurança para o exercício profissional, seja dentro da UBS ou fora dela. As competências de trabalho na ESF exigiam do profissional atuação externa à UBS em locais com maior incidência de criminalidade. Esses motivos fizeram os profissionais, em alguns momentos, terem medo de trabalhar. $\mathrm{O}$ avanço da criminalidade foi motivo de preocupação dos mais diversos setores. As ações criminosas que outrora estavam mais restritas às localidades periféricas, na época do estudo, agiam sem esse critério, não respeitando classe social ou grupos, de modo que a sociedade como um todo vivia com insegurança. Esse medo da insegurança proporcionou perda da satisfação e demonstrou capacidade de gerar sofrimento (SORATTO et al., 2017).

O participante da pesquisa M16 queixou-se de ausência de sala adequada para o atendimento de pacientes com síndrome gripal, o que foi contrário às recomendações para a pandemia. As orientações para o manejo de pacientes com COVID-19 indicam que se deve manter o ambiente de atendimento arejado e, caso haja ventiladores, ajustar o fluxo de ar na direção contrária ao profissional de saúde durante a assistência ao paciente e atentar para a limpeza frequente desses dispositivos. 
Além disso, que haja também sinalização dos ambientes, áreas e espaços destinados ao atendimento de pacientes com COVID-19 (BRASIL, 2020).

A insatisfação dos profissionais que atuam na ESF é desencadeada pelas condições do trabalho, pela fragilidade na gestão e por problemas nas relações que se constroem durante o processo de trabalho em saúde (MILANEZ et al.,2018). Para que haja o cuidado individual, familiar, de um território ou comunitário em um trabalho em equipe e que possa fruir a cooperação mútua em harmonia, é fundamental que se consolide a interação, comunicação e capacidade para colocar-se no lugar do outro, compreendendo os diferentes saberes em cada um de seus membros (DUARTE et al., 2015).

Um modelo de atenção à saúde deve ter como centro de atuação o conteúdo do sistema de saúde representado pelas práticas e não apenas interesse pela infraestrutura, gestão e financiamento. Essa designação refere-se essencialmente às formas de organização dos serviços, com base em tecnologias estruturadas para a resolução de problemas e atendimento das necessidades de saúde (GALAVOTE et al., 2016). Dessa forma, não apenas a infraestrutura deve ser fortalecida pelos gestores, mas, todo um aporte tecnológico, disponibilidade de insumos e recursos humanos qualificados, precisam ser ofertados aos serviços em saúde.

Portanto, verificou-se que os desafios a serem enfrentados pelas equipes de ESF deste estudo

coadunam com os estudos apresentados na discussão acima. É fato que para uma APS/ESF tornar-se forte são necessários investimentos em infraestrutura, insumos, contratação de força de trabalho em quantidade e qualidade suficientes, implantar uma EPS sólida nas equipes e ter vontade política de instituir a mudança no modelo proposto pela ESF. Essas são importantes atitudes para fortalecer o modelo assistencial, no qual não só os médicos, mas toda a equipe possa ter condições de ofertar assistência integral e de qualidade a todos os usuários que procuram atendimentos nas UBS.

A categoria formada a partir das 3 classes evidenciou o perfil esperado do médico integrante da equipe de ESF e sua contribuição para abordagem interdisciplinar. Elencou as potencialidades reconhecidas por esses profissionais no ambiente do trabalho e destacou os desafios encontrados em sua caminhada na APS.

\subsection{CATEGORIA 2: A IMPORTÂNCIA DA EDUCAÇÃO PERMANENTE NA PRÁTICA PROFISSIONAL MÉDICA NA ESTRATÉGIA DE SAÚDE DA FAMÍLIA}

A classe 5 "Fatores necessários ao trabalho médico qualificado na ESF"; a classe 4 "A EP na prática profissional médica" e a classe 3 "O entendimento na percepção dos médicos sobre EP" formaram essa categoria. Na classe 5 os vocábulos que mais apareceram foram: saúde, tempo, 
promover, diagnóstico situacional, conhecimento, família e contexto. Atualizar, constantemente, estudo, reunir, cotidiano e educação permanente destacaram na classe 4; e atualização, aprender, melhorar, capacitação, aprimorar, resultado e curso na classe 3 (FIGURA 5).

Sabe-se que o trabalho em saúde traz especificidades que o diferencia de outros trabalhos, não se realiza sobre objetos e sim sobre o homem. Tem como finalidade a produção do cuidado, por meio de ações de promoção, prevenção, cura ou reabilitação, para indivíduos, famílias e comunidade. É desenvolvido de forma coletiva multidisciplinar e interdisciplinar (GOMES et al., 2016; GONÇALVES, 1992; MERHY, 2007).

O trabalho na ESF, dessa forma, pressupõe a utilização de instrumentos diferenciados e objetos de trabalho que ultrapassam o limite do sujeito individual, ou seja, amplia sua atenção para a compreensão do ambiente sociocultural, a vinculação e participação da comunidade como objeto/sujeito coletivo de sua ação. Uma ferramenta importante citada na classe 5 dessa categoria é o diagnóstico situacional em saúde, que se constitui elemento preliminar fundamental ao planejamento em saúde. É resultado de um processo de coleta, tratamento e análise dos dados colhidos no local onde se deseja realizá-lo. O diagnóstico pode ser considerado como uma das mais importantes ferramentas de gestão, constituído por "pesquisa" das condições de saúde e risco de uma determinada população, para posteriormente planejar e programar ações (SANT’ANNA et al., 2011). Diante de um diagnóstico de saúde no território de atuação, o médico e equipe podem planejar intervenções que promovam melhorias nas condições de doença mais prevalentes.

A manutenção das diretrizes e princípios do SUS, bem como o impacto favorável nas condições de saúde da população adscrita, devem ser as preocupações básicas da ESF. É fundamental que a equipe trabalhe com vistas a conhecer a sua área de abrangência, ampliando o vínculo com a comunidade, a qualidade e o acesso aos serviços prestados, bem como elabore ações estratégias e de intervenções que desencadeiem melhorias na saúde da população (BRASIL, 2015).

É exigência aos profissionais da área da saúde estarem atualizados e acompanhando a evolução tecnológica possibilitando ampliar sua atuação. Pode-se verificar nas falas dos profissionais essa necessidade associada ao vocábulo tempo que é citado por eles, relacionando-o à atualização médica, como algo inerente ao seu cotidiano, na realização de cursos e estudos:

"[..] tem que estudar todo o tempo, a parte clínica $[\ldots] "$.
(M20). "[...] ele precisa sempre estudar melhor a cada dia [...]". (M8)

"[...] a cada tempo e a cada mudança na prática diária de uma comunidade, o médico tem que estar buscando uma capacitação [...]”. (M3). 
A EPS é uma construção dinâmica na formação dos profissionais de saúde, a partir do entendimento de que formação ocorre por toda uma vida (MOREIRA et al., 2017). Para Ceccim et al. (2009), a EPS deve ser uma estratégia para que os profissionais de saúde cheguem à sua condição de autores da própria história, na resolução das questões oriundas do cotidiano do trabalho, a partir da reflexão crítica.

Durante as entrevistas percebeu-se que a maioria dos médicos entendia a educação permanente como aquela que se constrói ao realizar atualizações e estudos rotineiros e justificava a importância dessa prática, pois a tornaria apta a oferecer a melhor assistência intelectual e científica em prol dos seus pacientes como demonstrado nas falas:

"[...] a educação permanente é de extrema importância no meu trabalho na ESF para minha atualização e ajuda muito, facilitando um diagnóstico assertivo e terapêutica eficaz, já que em medicina tudo é muito dinâmico e o que hoje é padrão ouro, amanhã já pode ter mudado [...]". (M17).

"[...] educação permanente é estar sempre aprimorando tanto o conhecimento adquirido e consolidado, como se abrindo para novas perspectivas e novas possibilidades tanto de aprendizagem quanto de ensino. É uma atualização constante, em que se está buscando aprimorar e melhorar em qualquer ambiente de trabalho [...]". (M7).

"[...] a educação permanente é primordial, pois nós temos um "bum” de informações todos os dias com várias pesquisas e estudos, muita coisa nova, tecnologias e se não nos atualizarmos diariamente, acabamos nos perdendo nesse caminho [...]”. (M4).

"[...] a educação permanente vem ajudar não somente o médico, mas toda a equipe da estratégia de saúde da familia, para que eles possam adquirir mais conhecimentos sobre uma determinada questão em saúde [...] os médicos bem como todos os profissionais têm que entender que eles devem estar em estudo constante [...] para que não só o médico como toda a equipe, possam estar capacitados em oferecer melhor saúde, a partir do momento que procuram adquirir mais conhecimento sobre uma determinada situação $[\ldots] ” .(M 3)$.

Pinheiro et al. (2018), ao refletirem em relação à ocorrência de atividades educativas no cotidiano dos serviços de saúde, constataram o benefício de tal inserção, para que os serviços estejam preparados para prestar assistência de forma adequada aos diferentes públicos que necessitem de cuidado. Sendo assim, concluíram que os instrumentos, o conhecimento e as relações são essenciais para que o processo de trabalho se efetive na produção de cuidado e na organização da assistência à saúde. Recordando os conceitos de Freire (2015), a EPS ao se tornar real exige alguns ajustes no que 
diz respeito aos processos educativos, como por exemplo, a superação da cultura da educação bancária (consiste no depósito de informações e exige que o educando absorva os conhecimentos transferidos pelo educador), por meio da pedagogia da problematização, que segundo o autor, situa o indivíduo como protagonista e não como mero espectador da construção do conhecimento.

Segundo as falas dos médicos, o entendimento de EPS constituiu em ações para a "atualização" (M7, M17) clínica, com "estudo constante" (M3) e a obtenção de mais "conhecimento" (M7 e M3). Podemos inferir que a "educação bancária" apresentada por Freire, restrita à transmissão de conhecimento como atualizações e cursos, é o conceito de EPS presente nas falas. Para eles, o estudo acerca das questões em saúde como atualizações de protocolos, diretrizes e o aprofundar no estudo de determinadas moléstias, foi premente na prática clínica, como expuseram M3 e M4. Na APS e especificamente na ESF, a organização do processo de trabalho individual e em equipe deve priorizar a garantia da universalidade do acesso, integralidade da atenção e melhoria do bem-estar do usuário, além das condições de trabalho da equipe. Necessita-se, assim, de profissionais com uma ampliação do seu núcleo de saberes, que além da competência técnica, como estudos, cursos e capacitações, desenvolvam dimensões políticas e de gestão do trabalho em saúde (GALAVOTE et al., 2016a; MASSUDA et al., 2018).

M12 associou a EPS às práticas de grupos operativos na ESF, ligadas à educação em saúde:

"[...] educação permanente seria tudo o que a gente puder fazer de benéfico para a estratégia de saúde da família e à população. Fazer grupo pra podermos explicar para os pacientes sobre diversos assuntos que eles tenham dúvidas, mas em conjunto [...]”.'. (M12).

A educação em saúde (ES) é um instrumento importante capaz de promover mudanças de comportamento da população e fomentar no indivíduo e no grupo a capacidade de analisar a sua realidade, como também de decidir ações conjuntas com os profissionais de saúde, tecendo uma relação dialética (VILLA-VELEZ, 2020). A principal meta é a prevenção de doenças e agravos, por meio de estimular a população à adesão de hábitos mais saudáveis. Um dos objetivos da ESF é a produção social de saúde, pautada na troca de informações e experiências entre os profissionais e as famílias assistidas (BRASIL, 2017). Os grupos operativos consistem em momentos importantes de educação em saúde e podem também proporcionar EPS para as equipes, já que a aprendizagem significativa por meio da problematização pode ser consolidada e construída em tais oportunidades também, todavia, a EPS deve ser distinguida da ES.

M15 afirmou desconhecer o que seja educação permanente como em sua fala a seguir e embora ratifique ser distinta da educação continuada, a conceituou de forma semelhante: 
"[...] desconheço a definição perfeita de educação permanente, mas sei que é diferente da educação continuada onde há um estudo constante. Eu acredito que seja uma atualização, um conhecimento de forma contínua, onde o médico esteja sempre atualizado no que existe de melhor para produzir trabalho na sua ESF [...]”. (M15).

Retornando ao entendimento da EPS (pág. 23) enquanto "prática de ensino-aprendizagem" embasada na problematização do cotidiano de trabalho e produção de conhecimento para solução dos problemas identificados, alguns entrevistados se aproximaram das características da EPS, como se constataram em algumas falas:

"[...] na verdade educação permanente é essa reflexão do trazer da prática e a partir desta, procurar a teoria e vice-versa, um ajudando ao outro [...], aprendendo a melhorar as condutas do trabalho em equipe[...]". (M9).

"[...] o que eu aprendi sobre educação permanente é que ela é aquela educação continuada aplicada ao trabalho e estar se atualizando sempre, mas com um objetivo de aplicar aquilo no desenvolvimento do seu trabalho em sua prática diária. Pouco adianta eu estudar uma coisa sempre, porém sem usar quase nada pra melhorar o processo de trabalho [...]". (M11).

M5 abordou a EPS introduzindo características da educação em saúde e educação continuada:

"[...] a educação permanente seria aquela educação entre os profissionais que abordamos a partir de palestras aqui e fazemos bastante, principalmente a conscientização ao explicar aos agentes comunitários de saúde como chegar ao paciente, como tratar o paciente e a forma de abordar um problema aqui. Fazemos os grupos de HIPERDIA, grupo de gestante, de puericultura e saúde mental. Fazemos educação permanente com algumas palestras com as meninas mesmo [...]”. (M5).

Dessa forma, a maioria dos médicos participantes da pesquisa entendeu a EPS como EC, ou seja, associaram à EPS somente à prática de estudo constante, atualização e aprimoramento de conhecimento, como fortalecimento e resolutividade em suas ações assistenciais na ESF. Mas podese perceber algumas aproximações com o entendimento da EPS como na fala de M11: é "aplicada ao trabalho" e a necessidade de retornar para a atuação deles. Compreende-se que a EPS emerge no cenário das práticas como necessidade do processo de trabalho e como objeto de transformação, partindo da reflexão crítica dos profissionais a respeito do que está acontecendo no cotidiano dos serviços e buscando soluções em conjunto com a equipe para os problemas encontrados (FERREIRA L. et al., 2019). 
Embora tenham conceituado a EPS anteriormente à pergunta, responderam com razões aplicadas ao trabalho, à equipe de saúde e à realidade local:

"[...] educação permanente é importante porque vai modulando seus atendimentos, de acordo com que os diagnósticos que vão surgindo $e$ preparando a sua equipe pra aquela demanda. [...] quando faz educação permanente na sua unidade de saúde você não vai trabalhar somente com o médico. Trabalhará com o enfermeiro, com a recepcionista e o agente comunitário de saúde. A educação permanente vai modulando a sua equipe para a necessidade do local [...]”. (M1).

"[...] educação permanente é muito importante no sentido de cada vez mais ir se aprimorando através dela e aprendemos a melhorar as condutas do trabalho em equipe. É importante que a gente tenha opiniões de diversos profissionais e com isso vai aprendendo e se tornando um profissional melhor". (M9).

“[...] a educação permanente é importante porque sem a equipe se reunir, sem a equipe se atualizar com os pacientes, com a unidade de saúde ou se reunir entre eles mesmos, o serviço daquela unidade de saúde não vai evoluir nunca. A gente vai estar sempre parada, sempre no mesmo lugar. Então, além de estar sempre se atualizando, a educação permanente ajuda a estarmos nos reunindo entre nós e com os pacientes daquela região". (M14).

"[...] a educação permanente é de extrema importância para o meu trabalho na estratégia de saúde da família e para minha atualização [...] a educação permanente ajuda a trazer bons resultados no trabalho médico e na equipe”. (M17).

De acordo com as falas acima, pode-se inferir que, apesar de não se comportar como um conceito com total entendimento, apresenta-se com importante aproximação de que a EPS tem sua origem trabalho e para ele retorna, promovendo as transformações pertinentes.

Ambas possuem grande valor para a construção, pois a EC se baseia na necessidade individual do profissional objetivando a atualização por meio de cursos e capacitações, essa pode não atender as necessidades do processo de trabalho no qual o médico esteja inserido. A EP constrói o aprendizado considerando as particularidades e necessidades dos profissionais em seu meio de trabalho, oportuniza a problematização na equipe dos problemas identificados e a solução coletiva. Espera-se que o objetivo da EP seja promover as práticas transformadoras. O profissional médico precisa estar atualizado em sua prática clínica na ESF, como também engajado com a equipe na solução das adversidades locais apresentadas quanto aos usuários os quais pratica o cuidado.

M5 valorizou a EPS por razões que se assemelham a premissa do "aprender a aprender", em que a educação se desenvolve e se articula com o processo de trabalho, à medida em que as 
necessidades em saúde se apresentam e são solucionadas considerando suas particularidades, mediante a capacidade do profissional e da equipe envolvidos.

"[...] com educação permanente aprendemos muito dentro da unidade de saúde. Ensinamos para as outras meninas da equipe e aprendemos também com a equipe e acredito que a educação permanente que é realizada também entre níveis superiores e agente comunitário de saúde, torna-se muito importante, pois aprendemos muito e corrigimos erros. Creio ser muito importante”. (M5).

A concepção do "aprender a aprender" como um processo dinâmico e ascendente introduz nas práticas dos profissionais a capacidade de serem co-construtores da aprendizagem necessária. A ideia de corresponsabilidade não está relacionada ao estabelecimento de um programa (referindo-se à educação continuada) de aprendizagem que encaminha um diagnóstico de certezas, porém, vinculase estrategicamente, a tirar proveito dos erros para se aperfeiçoar. "Aprender a aprender” dentro da perspectiva da EP é um tipo de aprendizagem orgânica, que comporta correções, modificações, adaptações dinâmicas, sendo essa a base do processo de auto renovação capaz de produzir mudanças profundas nos seres humanos (MORIN, 2003).

A opinião de M5 a respeito de incluir o agente comunitário de saúde (ACS) no processo de ensino e aprendizagem na ESF deve ser valorizada. Nessa perspectiva, Leite et al. (2013) apontam que uma das principais apostas nos ACS é a de que eles possam fazer a articulação e mediação entre os saberes científicos e os populares, com a finalidade de construir projetos de cuidados que atendam às particularidades de um determinado território. Ainda, segundo os autores, por serem membros/moradores da comunidade onde trabalham, potencializam a proximidade entre usuários e profissionais, possibilitando o reconhecimento de recursos do território que estão fora do campo sanitário.

Pode-se inferir que na realidade local, as demandas e necessidades do território, tornam a EPS para esses profissionais um dispositivo capaz de problematizar, no intuito de alcançar a solução de conflitos no trabalho, além de qualificá-los como clínicos na abordagem ao paciente, família e comunidade. A EPS como metodologia de aprendizagem, pode por meio da problematização fornecer subsídios para a dissolução de "nós críticos" advindos da realidade do trabalho médico e em equipe.

Evidenciou-se nesta categoria que o profissional médico deve realizar seu trabalho considerando as especificidades do território, das famílias que o formam, realizando diagnóstico em saúde inserido em um contexto de visão interdisciplinar ou trabalho em equipe, como orientação em suas tomadas de decisão. Apesar de não estruturarem nas falas o conceito e concepções conscientes que definem o dispositivo EPS, reconheceram sua importância para a prática médica e destacaram 
que ele pode ser transformador para resolução de "nós críticos" inerentes ao meio laboral no cotidiano e nas relações do trabalho no território de atuação. 


\subsection{DIRETRIZES PARA UM PROGRAMA DE EDUCAÇÃO PERMANENTE EM SAÚDE NO MUNICÍPIO POLO}

O termo "diretriz" é definido pelo Houaiss e Villar (2001, p. 1.050) como: "1. A linha básica que determina o traçado de uma estrada; 2. Esboço, em linha gerais, de um plano, projeto etc; 3. Norma de procedimento, conduta etc; diretiva". Os sentidos apresentados, dessa forma, permitem compreender como as diretrizes determinam meios e normas para se atingir objetivos e como elas podem apontar rumos e estratégias que estariam aptos a organizarem a EPS para médicos no município deste estudo.

A EPS está vinculada à reconstrução do processo de trabalho, sendo o cenário dos serviços de saúde o principal manancial de conhecimento no qual pode-se proporcionar reflexões e possibilidades de problematização da realidade vivenciada (D'AVILA et al., 2014). Dessa forma, diante da complexidade dos processos de saúde encontrada também na ESF, um dispositivo competente e articulado visa atender às necessidades práticas das equipes de saúde e, especificamente, neste estudo, às necessidades dos médicos da APS, no modelo prioritário de atenção. Esta pesquisa identificou o reconhecimento e a importância da EPS para o desenvolvimento do trabalho dos médicos, apontando, assim, que a implantação desse dispositivo terá a concordância do grupo.

Diante do planejamento e implantação da EPS para médicos da ESF, um importante percurso deve ser construído, sendo de fundamental importância conhecer a população alvo. O perfil desses profissionais quanto aos dados sociodemográficos, educacionais, laborais, relativo aos seus interesses e objetivos com o trabalho no modelo de atenção, além da apresentação das habilidades e competências necessárias, são informações singulares à estruturação do dispositivo e foram identificadas, descritas e analisadas neste trabalho. A finalidade dessas informações está relacionada à organização de um processo de EPS que possa atingir os anseios desses médicos para a efetividade do desenvolvimento da ESF no município. Portanto foi necessário conhecer o entendimento e conhecimento que os médicos possuíam acerca da ESF, seus interesses e intuitos ao se inserirem numa equipe de ESF, que habilidades e competências profissionais seriam necessárias para o desenvolvimento da ESF e se sentiam satisfeitos e valorizados nas equipes de ESF.

De acordo com as diretrizes da ESF almeja-se que um médico ultrapasse as habilidades de confirmar-se não apenas como um clínico qualificado, todavia, que demonstre engajamento com o trabalho, que seja interessado na mais eficaz e resolutiva assistência individual, familiar e comunitária, que seja empático, saiba se relacionar bem em equipe e que tenha sua prática centrada na gestão da clínica e em uma posição de pertencimento à comunidade como um recurso. As características elencadas pelos participantes e desenvolvidas pelos médicos do município do estudo 
foram identificadas como aquelas que podem contribuir para uma EPS sólida e transformadora à APS local.

Outro ponto a ser considerado para uma EPS efetiva é discernir qual seria o conhecimento que os profissionais possuem a respeito da ESF. Uma característica não menos importante ao médico da ESF é entender acerca dos princípios dessa: territorização, programação e planejamento, caráter substitutivo, intersetorialidade e espaço de construção da cidadania. Observa-se que, cônscio dos significados, das características de cada princípio e da importância de desenvolvê-los como agente proativo da equipe em seu território de atuação, contribuirá para o fortalecimento da ESF para o município polo, colaborando para expectativas qualificadoras e promotoras ao desenvolvimento do dispositivo EPS. Porém, detectou-se que há ainda um percurso a se trilhar, já que se demonstraram fragilidades quanto ao conhecimento e desdobramento dos participantes em suas práticas cotidianas: o caráter substitutivo e espaço de construção da cidadania destacaram-se como princípios pouco realizados pelos participantes deste estudo. Dessa forma, são importantes temáticas a serem desenvolvidas na EPS. Ao se desenhar uma EPS, torna-se essencial identificar as necessidades de educação para a população alvo, sendo este um dos objetivos específicos deste trabalho. Para a elaboração da EPS, conhecer tais carências a partir da opinião e percepção dos profissionais, tornouse uma atitude coerente com o processo de formação do dispositivo, já que as resoluções propostas e almejadas, devem originar-se do processo de trabalho desses profissionais.

A escolha de metodologias para o desenvolvimento de uma EPS é fundamental para contribuir com a aprendizagem significativa. As metodologias ativas e participativas devem ser escolhidas como a sugerida neste trabalho: metodologia da problematização, a qual considera um movimento do ensino aprendizado neste movimento de ação - reflexão - ação. O ambiente do trabalho é o cenário onde os atores estão em ação e é onde os problemas originam-se e são identificados. Ao discutirem, refletirem e buscarem os conhecimentos necessários para a solução dos problemas, propiciam-se o aprendizado satisfatório e significativo para a transformação da realidade (ação). Diante do planejamento com tais subsídios, implantar a EPS fará sentido para esses atores e será capaz de transformar suas práticas cotidianas de forma duradoura e qualificada.

Para compor o planejamento de uma futura EPS no município, foram apontados pelos participantes algumas necessidades que devem ser consideradas: as reuniões de equipe precisam utilizar o dispositivo, ou seja, problematizar os conflitos ou "nós críticos" em busca da solução dos problemas e promoção de amadurecimento profissional, interrelacional e social. Acerca da organização do serviço, temas clínicos relacionados às diretrizes nacionais de atenção integral aos diversos grupos: Saúde da Mulher, Saúde do homem, Saúde da Criança e outros conteúdos requerem serem trabalhados na coordenação; e a abordagem aos cuidados integrais a esses grupos na APS, 
discussão em relação ao modelo prioritário, na Estratégia de Saúde da Família. Os atributos essenciais e derivados da APS, devem ser abordados com os profissionais, com ênfase na competência cultural, pouco praticada pelos profissionais do estudo, além do caráter substitutivo e da necessária intersetorialidade, no cumprimento das diretrizes e princípios da ESF e da APS.

Para a qualificação do trabalho médico na ESF são fundamentais à abordagem da temática planejamento em saúde, o desenvolvimento do diagnóstico situacional em saúde e a formação de estratégias que estimulem o engajamento do médico com a equipe e comunidade, incluindo a interação com o conselho local de saúde, matriciamento e reuniões de equipe.

Foram levantados junto aos participantes os desafios para o desenvolvimento da prática profissional na ESF, sendo apontadas a infraestrutura inadequada nas UBS e a falta de medicamentos, assim como, as questões intersetoriais como violência e tráfico de drogas nos territórios. Esses assuntos a serem incorporados na proposta na EPS podem possibilitar aos profissionais a formulação de propostas à gestão e ao poder público vigente quanto aos conflitos e deficiências detectados nas UBS. A insuficiência ou ausência de recursos materiais e humanos na APS interfere, sensivelmente, na construção do trabalho.

O princípio da ESF como espaço de construção da cidadania necessita ser estruturado também nesta futura proposta de EPS, pois a participação da comunidade mais ativa e mais ampliada por meio dos conselhos locais e municipais, escolas e outros setores sociais, carece de ser incorporada às argumentações e necessidades em saúde encontradas, para a promoção de saúde nos territórios. Dessa forma, torna-se pertinente incorporar um plano de capacitação dos médicos que ingressam na ESF, sugerindo que se discuta e se reflita em relação ao modelo da ESF, princípios e diretrizes, funcionamento da equipe da ESF, processo de trabalho, planejamento e programação das atividades da UBS/ESF e organização da UBS/ESF, como a primeira capacitação a ser realizada para o profissional que irá compor uma equipe. Sugere-se grupos polos de educação permanente para médicos e equipes de ESF, com horários protegidos e locais adequados aos pequenos grupos.

O município polo por meio da Secretaria Municipal de Saúde se beneficiaria muito ao implementar sua política municipal de Educação Permanente em Saúde, baseada na política estadual vigente e necessitaria, para tanto, traçar o seu próprio plano local de Educação Permanente em Saúde. 


\section{CONSIDERAÇÕES FINAIS}

Ao realizar este estudo com a contribuição dos médicos da Atenção Primária à Saúde, em seu modelo prioritário, a Estratégia de Saúde da Família, de um município polo de Minas Gerais, verificou-se que há prementes necessidades de educação permanente em saúde e que um importante percurso deve ser desenvolvido para que efetivamente o dispositivo seja utilizado, modificando e qualificando as práticas em saúde na ESF. Apesar de conceitualmente a EPS ser confundida com a EC por alguns participantes, identificou-se que a EPS se apresentou como importante dispositivo para a educação dos profissionais e que as necessidades têm sua origem no trabalho e para ele devem retornar, promovendo as transformações pertinentes.

Ao traçar o perfil dos profissionais, percebeu-se que em seus processos educativos a EC é uma prática importante e que se encontra muito presente no cotidiano deles. Os médicos descreveram seus valores e discorreram acerca da construção de um perfil de competência para o médico na ESF.

O trabalho médico na ESF não é uma prática solitária e engessada, todavia, apresenta interdependência em ações de equipe nos territórios, com comprometimento social, em que as relações de trabalho, amizade e empatia na abordagem aos usuários, podem determinar desfechos favoráveis à promoção de saúde na Atenção Primária e à saúde pública como um todo.

Dentre as habilidades e competências elencadas para ser um médico da ESF, as mais importantes foram: ter conhecimento, estudar, ser empático, conhecer o território de atuação, saber trabalhar em equipe, saber ser paciente e estar disposto a escutar. Identificou-se o quanto a educação médica atualizada é importante para esses profissionais e que mesmo apresentando dificuldade na compreensão do que seja EPS, consideraram os problemas oriundos do meio do trabalho como: moduladores da necessidade de conhecimento e capazes de promover o encontro de caminhos transformadores na solução de conflitos em equipe e no território.

Foram apontadas, na pesquisa, que as potencialidades deveriam ser estimuladas pelos gestores e equipes e dentre as relacionadas, a residência médica em medicina de família deveria ser mais valorizada e expandida para outras unidades e sugere-se a implementação de residências multiprofissionais em saúde da família, para qualificação interdisciplinar da APS no município. Além disso, outras potencialidades reconhecidas pelos médicos foram a importância do bom relacionamento em equipe, fator essencial à abordagem médica assistencial; a presença do NASF e o trabalho em rede quanto à coordenação do cuidado, atributo essencial da APS.

Constatou-se a necessidade de um gerente para cada UBS, haja vista que o trabalho em equipe relativo à assistência se apresenta prejudicado, uma vez que a sobrecarga administrativa fica sob a responsabilidade do enfermeiro, dificultando sua atuação na assistência e pouca atuação do 
médico na gestão administrativa da ESF por concentrar-se no cuidado clínico aos indivíduos e famílias. Desse modo, as equipes se beneficiariam com o envolvimento do médico no planejamento administrativo conjunto, promovendo melhoria da assistência à população adscrita.

Este estudo foi inovador no município até esta data. Espera-se que possa contribuir para projeto de educação permanente dos médicos da ESF e favorecer o fortalecimento do modelo assistencial de saúde da ESF, além de poder colaborar com o fortalecimento do modelo assistencial de saúde da APS/ESF, importante nível de atenção e de promoção à saúde da população. 


\section{REFERÊNCIAS}

ABRAMO, L. O futuro do trabalho - os desafios do século XXI para a saúde dos trabalhadores. Revista Brasileira de Medicina do Trabalho, v. 17, p. 3-5, 2019. Disponível em: https://portalperiodicos.unoesc.edu.br/acsa/article/view/15915/12359. Acesso em: 10 abr. 2021.

ALELUIA, I. R. S. et al. Coordenação do cuidado na atenção primária à saúde: estudo avaliativo em município sede de macrorregião do nordeste brasileiro. Ciênc. Saúde Coletiva, Rio de Janeiro, v. 22, n. 6, p.1845-1856, 2017. Disponível em:

http://www.scielo.br/scielo.php?script=sci_arttext\&pid=S141381232017002601845\&lng=en\&nrm $=$ iso. Acesso em: 12 jan. 2021.

ALFRADIQUE, M. E. et al. Internações por condições sensíveis à atenção primária: a construção da lista brasileira como ferramenta para medir o desempenho do sistema de saúde (Projeto ICSAP Brasil). Cad. Saúde Pública, Rio de Janeiro, v. 25, n. 6, p. 1337-1349, jun. 2009. Disponível em: http://www.scielo.br/scielo.php?script=sci arttext\&pid=S0102-

311X2009000600016\&lng=en\&nrm=iso. Acesso em:18 jun. 2020.

ALMEIDA F. et al. Reconhecer Flexner: inquérito sobre produção de mitos na educação médica no Brasil contemporâneo. Cad. Saúde Pública, Rio de Janeiro, v. 26, n. 12, p. 2234-2249, dez. 2010. Disponível em: http://www.scielo.br/scielo.php?script=sci_arttext\&pid=S0102311X2010001200003\&lng=en\&nrm=iso. Acesso em: 04 set. 2020.

ALMEIDA, J. R. S. et al. Educação Permanente em Saúde: uma estratégia para refletir sobre o processo de trabalho. Revista da ABENO, v. 16, n. 2, p. 7-15, 2016. Disponível em: http://revodonto.bvsalud.org/pdf/abeno/v16n2/a03v16n2.pdf. Acesso em: 10 maio 2021.

ALVES, M. T. G. Reflexões sobre o papel da Atenção Primária à Saúde na pandemia de COVID19. Rev. Bras. Med. Fam. Comunidade. Rio de Janeiro, jan-dez,15 (42): 2496, 2020. Disponível em: https://doi.org/10.5712/rbmfc15(42)2496. Acesso em: 13 mar. 2021.

ANDRADE, E. S. et al. Gestão Integral: Diálogos com Educação Permanente e Continuada nas Organizações. pp. 0716, v. 08, 2018. DOI: 10.5216/teri.v8i1.46544. Disponível em: https://www.revistas.ufg.br/teri/article/view/46544/26352. Acesso em: 28 mar. 2021.

ARAÚJO, R. R. M. et al. Educação permanente em enfermagem na estratégia saúde da família. Rev. pesqui. cuid. Fundam, dez, 5 (6): 64-73, 2013. Disponível em: http://www.redalyc.org/html/5057/505750944008/. Acesso em 10 dez. 2019.

BARBOSA, L. G. et al. Recursos Humanos e Estratégia Saúde da Família no norte de Minas Gerais: avanços e desafios. Cad. Saúde Colet. Rio de Janeiro, v. 27, n. 3, p. 287-294, set. 2019. Disponível em: http://www.scielo.br/scielo.php?script=sci_arttext\&pid=S1414462X2019000300287\&lng=en\&nrm=iso. Acesso em: 08 abr. 2021.

BARBOSA, S. P. et al. Aspectos que Compõem o Perfil dos Profissionais Médicos da Estratégia Saúde da Família: o Caso de um Município Polo de Minas Gerais. Rev. bras. educ. med., Brasília, v. 43, n. 1, supl. 1, p. 395-403, 2019. Disponível em: http://www.scielo.br/scielo.php?script=sci_arttext\&pid=S010055022019000500395\&lng=en\&nrm=iso. Acesso em: 19 jun. 2020; 03 jan. 2021. 
BARBOSA, S. P. et al. A prática da Atenção Primária à Saúde no combate da COVID-19. APS em revista, v. 2, n. 1, p. 17-19, janeiro/abril. 2020. Disponível em:

https://apsemrevista.org/aps/article/view/62. Acesso em: 13 jun. 2020.

BARCELOS, M. R. B. et al. Qualidade do rastreamento do câncer de colo uterino no Brasil: avaliação externa do PMAQ. Rev. Saúde Pública, São Paulo, v. 51, 67, 2017. Disponível em: http://www.scielo.br/scielo.php?script=sci_arttext\&pid=S0034-

89102017000100261\&lng=en\&nrm=iso. Acesso em: 10 maio 2020.

BARRA, S. A. R. et al. A intersetorialidade na Estratégia Saúde da Família em Juiz de Fora/MG. HU Revista, Juiz de Fora, v. 42, n. 2, p. 89-95, jul. /ago. 2016. Disponível em: https://periodicos.ufjf.br/index.php/hurevista/article/view/2382/866. Acesso em: 14 mar. 2021.

BARRETO, M. N. S. de C. et al. Análise do acesso ao tratamento medicamentoso para hipertensão e diabetes na Estratégia de Saúde da Família no Estado de Pernambuco, Brasil. Rev. bras. epidemiol., São Paulo, v. 18, n. 2, p. 413-424, junho. 2015. Disponível em: http://www.scielo.br/scielo.php?script=sci arttext\&pid=S1415790X2015000200413\&lng=en\&nrm=iso. Acesso em: 17 jan. 2021

BARTH, P. O. et al. Educação permanente em saúde: concepções e práticas de enfermeiros de unidades básicas de saúde. Revista Eletrônica de Enfermagem, v. 16, n. 3, 2014. Disponível em: https://www.fen.ufg.br/revista/v16/n3/pdf/v16n3a15.pdf. Acesso em: 25 de nov. 2019.

BRASIL. Constituição da República Federativa do Brasil de 1988. Brasília, DF: Presidência da República. 1988. Disponível em: http://www.planalto.gov.br/ccivil_03/Constituicao.htm. Acesso em: 03 ago. 2019.

BRASIL. 11ª Conferência Nacional de Saúde, Brasília 15 a 19 de dezembro de 2000: o Brasil falando como quer ser tratado: efetivando o SUS: acesso, qualidade e humanização na atenção à saúde com controle social: relatório final / Ministério da Saúde, Conselho Nacional de Saúde. Brasília: Ministério da Saúde, 2001. Disponível em:

http://bvsms.saude.gov.br/bvs/publicacoes/11_cns.pdf. Acesso em: 14 dez. 2020.

BRASIL. Ministério da Saúde. Secretaria-Executiva. Núcleo Técnico da Política Nacional de Humanização. Humaniza SUS: Política Nacional de Humanização: a humanização como eixo norteador das práticas de atenção e gestão em todas as instâncias do SUS / Ministério da Saúde, Secretaria Executiva, Núcleo Técnico da Política Nacional de Humanização. - Brasília: Ministério da Saúde, 2004. Disponível em:

https://bvsms.saude.gov.br/bvs/publicacoes/humanizasus_2004.pdf. Acesso em 15 dez. 2019.

BRASIL. Política Nacional de Educação Permanente, ano 2007. 2007. Disponível em: http://www.bvsms.saude.gov.br/bvs/publicacoes/pacto_saude_volume9.pdf52prt1996_20_08_2007. htmlem/1832.pdf. Acesso em: 22 nov. 2019.

BRASIL. Ministério da Saúde. PORTARIA N 1.996, DE 20 DE AGOSTO DE 2007. 2007a.

Disponível em: https://bvsms.saude.gov.br/bvs/saudelegis/gm/2007/prt1996_

20_08_2007.htmlem/1832.pdf. Acesso em: 22 nov. 2019.

BRASIL. Ministério da Saúde. Pró-Residência Médica: Programa Nacional de Apoio à Formação de Médicos Especialistas em Áreas Estratégicas (Pró-Residência Médica) com o objetivo de apoiar a formação especialistas em regiões e áreas prioritárias para o Sistema Único de Saúde (SUS). 
Brasília, 2009. 2009a. Disponível em: http://www.saude.gov.br/trabalho-educacao-equalificacao/provisao-de-profissionais/pro-residencia-medica. Acesso em: 02 dez. 2020.

BRASIL. Ministério da Saúde. Secretaria-Executiva. Departamento de Apoio à Descentralização. O SUS no seu município: garantindo saúde para todos. 2. ed. Brasília: Ministério da Saúde, 2009. 2009b. Disponível em:

https://bvsms.saude.gov.br/bvs/publicacoes/sus_municipio_garantindo_saude.pdf. Acesso em: 10 abr. 2021.

BRASIL. Ministério da Saúde. Secretaria de Gestão do Trabalho e da Educação na Saúde. Departamento de Gestão da Educação em Saúde. Política Nacional de Educação Permanente em Saúde. Brasília, DF: Ministério da Saúde, 2009. 2009c. 64 p. Série B, Textos Básicos de Saúde, Série Pactos pela Saúde v. 9, 2006. Disponível em:

http://bvsms.saude.gov.br/bvs/publicacoes/pacto_saude_volume9.pdf. Acesso em: 10 ago. 2019.

BRASIL. Ministério da Saúde. Secretaria de Vigilância em Saúde. Secretaria de Atenção à Saúde. Política Nacional de Promoção da Saúde / Ministério da Saúde, Secretaria de Vigilância em Saúde, Secretaria de Atenção à Saúde. 3. ed. Brasília: Ministério da Saúde, 2010. Disponível em: https://bvsms.saude.gov.br/bvs/publicacoes/politica_nacional_promocao_saude_3ed.pdf. Acesso em:15 dez. 2019.

BRASIL. Ministério da Saúde. Programa Nacional de Melhoria do Acesso e da Qualidade da Atenção Básica. Manual Instrutivo: Saúde Mais Perto de Você - Acesso e Qualidade. Brasília, DF: 2011. Disponível em: http://189.28.128.100/dab/docs/ publicacoes/geral/manual_instrutivo_pmaq_site.pdf. Acesso em: 10 maio 2020.

BRASIL. Ministério da Saúde. Conselho Nacional de Saúde. Relatório final da $14^{\text {a }}$ Conferência Nacional de Saúde: todos usam o SUS: SUS na seguridade social: Política pública, patrimônio do povo brasileiro/Ministério da Saúde, Conselho Nacional de Saúde, Brasília: Ministério da Saúde, 232 p., Série C. Projetos, Programas e Relatórios. 2012. Disponível em:

http://conselho.saude.gov.br/images/14_cns_relatorio_final.pdf. Acesso em: 14 dez. 2019.

BRASIL. Casa Civil. Lei N ${ }^{\circ}$ 12.871, de 22 de outubro de 2013. Institui o Programa Mais Médicos, altera as Leis no 8.745, de 9 de dezembro de 1993, e no 6.932, de 7 de julho de 1981, e dá outras providências. Diário Oficial da União, 23 out. 2013. Disponível em: http://www.planalto.gov.br/ccivil_03/_ato2011-2014/2013/lei/112871.htm. Acesso em: 11 abr. 2021.

BRASIL. Lei 12.871/2013. Brasília: Diário Oficial da União, 2013. 2013b. Disponível em: http://www.planalto.gov.br/ccivil_03/_ato2011 -2014/2013/Lei/L12871.htm. Acesso em: 04 dez. 2020.

BRASIL. Ministério da Saúde. PORTARIA No 278, DE 27 DE FEVEREIRO DE 2014. Institui diretrizes para implementação da Política de Educação Permanente em Saúde, no âmbito do Ministério da Saúde (MS), 2014. 2014a. Disponível em: http://bvsms.saude.gov.br/bvs/saudelegis/gm/2014/prt0278_27_02_2014.html. Acesso em: 10 ago. 2019.

BRASIL. Ministério da Saúde. Secretaria de Atenção à Saúde. Departamento de Atenção Básica. Núcleo de Apoio à Saúde da Família. Brasília, DF: Ministério da Saúde, 2014. 2014b. Disponível 
em: https://bvsms.saude.gov.br/bvs/publicacoes/nucleo_apoio_saude_familia_cab39.pdf. Acesso em: 10 abr. 2021.

BRASIL. Ministério da Saúde. Secretaria de Gestão do Trabalho e da Educação na Saúde.

Programa mais médicos - dois anos: mais saúde para os brasileiros / Ministério da Saúde, Secretaria de Gestão do Trabalho e da Educação na Saúde. Brasília: Ministério da Saúde, 2015. 2015a. Disponível em:

http://bvsms.saude.gov.br/bvs/publicacoes/programa_mais_medicos_dois_anos.pdf. Acesso em: 11 nov. 2020.

BRASIL. Ministério da Saúde. Manual instrutivo do Pmaq para as equipes de Atenção Básica (Saúde da Família, Saúde Bucal e Equipes Parametrizadas) e Nasf / Ministério da Saúde, Secretaria de Atenção à Saúde, Departamento de Atenção Básica. 2. ed. Brasília: Ministério da Saúde, 2015. 2015b. Disponível em:

$\mathrm{http}$ //bvsms.saude.gov.br/bvs/publicacoes/manual_instrutivo_pmaq atencao_basica.pdf. Acesso em: 11 abr. 2021.

BRASIL. Ministério da Saúde. Secretaria de Atenção à Saúde. Departamento de Atenção Básica. Requalifica UBS: manual instrutivo / Ministério da Saúde, Secretaria de Atenção à Saúde, Departamento de Atenção Básica. - Brasília: Ministério da Saúde, 2016. Disponível em: http://bvsms.saude.gov.br/bvs/publicacoes/requalifica_ubs_manual_instrutivo.pdf. Acesso em: 12 jan. 2021.

BRASIL. Ministério da Saúde. Política Nacional de Atenção Básica. Portaria No 2436 de 21 de setembro de 2017. 2017a. Disponível em:

https://bvsms.saude.gov.br/bvs/saudelegis/gm/2017/prt2436_22_09_2017.html. Acesso em: 27 mar. 2021.

BRASIL. Ministério da Saúde. Termo de referência para as Oficinas Regionais PNEPS.

SGTES/DEGES/Ministério da Saúde: Brasília, DF, 2017. 2017b. Disponível emhttps://mercosur.observatoriorh.org/sites/mercosur.observatoriorh.org/files/webfiles/fulltext/201 7/workshop_oct/tdr_ep.pdf. Acesso em: 14 nov. 2019.

BRASIL. Ministério da Saúde. Laboratório de Inovação em Educação na Saúde com ênfase em Educação Permanente. Organização Pan-americana da Saúde/Organização Mundial Saúde no Brasil: Brasília, DF; 2018. 2018a. Disponível em: https://iris.paho.org/handle/10665.2/49177. Acesso em: 14 dez. 2019.

BRASIL. Ministério da Saúde. Programa para o Fortalecimento das Práticas de Educação Permanente em Saúde no Sistema Único de Saúde (PRO EPS-SUS), 2018. 2018b. Disponível em: https://www.saude.gov.br/trabalho-educacao-e-qualificacao/gestao-da-educacao/qualificacaoprofissional/44943-programa-para-o-fortalecimento-das-praticas-de-educacao-permanente-emsaude-no-sistema-unico-de-saude-pro-eps-sus. Acesso em: 20 dez. 2019.

BRASIL. Ministério da Saúde. Departamento de Atenção Básica. Histórico e Cobertura da Estratégia Saúde da Família. Brasília, DF: Ministério da Saúde, 2018. 2018c. Disponível em: dabsaudegovbr/portaldab/histórico_cobertura_sfphp. Acesso em: 30 dez. 2020.

BRASIL. Política Nacional de Educação Permanente em Saúde: o que se tem produzido para o seu fortalecimento, 2018. 2018d. Disponível em: 
http://www.bvsms.saude.gov.br/bvs/publicacoes/politica_nacional_educacao_permanente_saude_fo rtalecimento.pdf. Acesso em: 19 dez. 2019.

BRASIL. Ministério da Saúde. Relatório Consolidado Sobre o Processo de Implementação da Política Nacional de Educação Permanente (PNEPS), 2018. 2018e. Disponível em: https://antigo.saude.gov.br/images/pdf/2018/dezembro/12/Relat--rio-Consolidado-sobre-oprocesso-de-implementa----o-da-PNEPS--DEGES---SGTES--MS-2018-.pdf. Acesso em: 19 dez. 2019.

BRASIL. Orientações para Manejo de Pacientes com COVID-19. Ministério as Saúde 2020. Disponível em: https://portalarquivos.saude.gov.br/images/pdf/2020/June/18/Covid19-Orientac--o-esManejoPacientes.pdf. Acesso em: 21 mar. 2021.

BRASIL. Ministério da Saúde. Política Nacional de Atenção Básica. Portaria N$^{\circ}$ 648, de 28 de março de 2006. 2006. Disponível em:

http://bvsms.saude.gov.br/bvs/saudelegis/gm/2006/prt0648_28_03_2006.html. Acesso em: 05 abr. 2021.

BURSZTYNL, I. Diretrizes Curriculares Nacionais de 2014: um novo lugar para a Saúde Coletiva? Cadernos ABEM, v. 11, out. 2015. Rio de Janeiro, RJ, p 8. Disponível em: https://website.abemeducmed.org.br/wp-content/uploads/2019/09/CadernosABEM_Vol11.pdf. Acesso em: 03 jan. 2021.

CAMARGO, B. V. et al. Tutorial para o uso do software IRAMUTEQ (Interface de R pour les Analyses Multidimensionnelles de Textes et de Questionnaires). Laboratório de Psicologia Social da Comunicação e Cognição, UFSC: Brasil, 2016. Disponível em:

http://iramuteq.org/documentation/fichiers/Tutorial\%20IRaMuTeQ\%20em\%20portugues_17.03.20 20.pdf. Acesso em: 30 nov. 2020.

CAMPOS, C. V. de A. et al. Satisfação no trabalho e rotatividade dos médicos do Programa de Saúde da Família. Rev. Adm. Pública, Rio de Janeiro, v. 42, n. 2, p. 347-368, abr. 2008.

Disponível em: http://www.scielo.br/scielo.php?script=sci_arttext\&pid=S0034$76122008000200007 \& \operatorname{lng}=$ en\&nrm=iso. Acesso em: 07 dez. 2020.

CAMPOS, G. W. S. Um método para análise e co-gestão de coletivos. São Paulo: Hucitec. 2000.

CAMPOS, G. W. S. et al. Reflexões sobre atenção básica e a estratégia de Saúde da Família. Manual de práticas de atenção básica: saúde ampliada e compartilhada. São Paulo: Hucitec; 2008. Disponível em: https://www.arca.fiocruz.br/bitstream/icict/42201/2/Cap_Reflex\%C3\%B5es\%20sobre\%20a\%20ate a\%C3\%A7\%C3\%A3o\%20b\%C3\%A1 sica\%20e\%20a\%20estrat\%C3\%A9gia.pdf. Acesso em: 19 abr. 2021.

CAMPOS, K. F. C. et al. Educação permanente nos serviços de saúde. Esc. Anna Nery, Rio de Janeiro, v. 21, n. 4, e20160317, 2017. Disponível em:

http://www.scielo.br/scielo.php?script=sci_arttext\&pid=S1414-

$81452017000400801 \& \operatorname{lng}=$ en\&nrm=iso. Acesso em: 18 fev. 2021.

CARDOSO, I. M. Rodas de educação permanente na atenção básica de saúde: analisando contribuições. Saudesoc. São Paulo, v. 21, supl. 1, p. 18-28, maio, 2012. Disponível em: 
http://www.scielo.br/scielo.php?script=sci_arttext\&pid=S0104-

$12902012000500002 \& \operatorname{lng}=\mathrm{en} \& n r m=$ iso. Acesso em: 30 abr. 2020.

CARDOSO, M. L. de M. et al. A Política Nacional de Educação Permanente em Saúde nas Escolas de Saúde Pública: reflexões a partir da prática. Ciênc. Saúde Coletiva, Rio de Janeiro, v. 22, n. 5, p. 1489-1500, maio, 2017. Disponível em: http://www.scielo.br/scielo.php?script=sci_arttext\&pid=S141381232017002501489\&lng=en\&nrm=iso. Acesso em: 19 abr. 2021.

CECCIM, R. B., et al. O Quadrilátero da Formação para a Área da Saúde: Ensino, Gestão, Atenção e Controle Social. 2004. SCIELO. Disponível em:

http://www.scielo.br/pdf/physis/v14n1/v14n1a04.pdf. Acesso em: 23 dez. 2019.

CECCIM, R. B. et al. Educação e saúde: ensino e cidadania como travessia de fronteiras. Trab. educ. saúde, Rio de Janeiro, v. 6, n. 3, p. 443-456, 2008. Disponível em:

http://www.scielo.br/scielo.php?script=sci arttext\&pid=S1981-

$77462008000300003 \& \operatorname{lng}=$ en\&nrm=iso. Acesso em: 03 ago. 2019.

CECCIM, R. B. et al. Educação permanente em saúde. Dicionário da Educação Profissional em Saúde. Fundação Oswaldo Cruz. Escola Politécnica de Saúde Joaquim Venâncio. 2009. Disponível em: http://www.epsjv.fiocruz.br/dicionario/verbetes/. Acesso em: 23 dez. 2019.

CECCON, R. F. et al. Internações por condições sensíveis à atenção primária e ampliação da Saúde da Família no Brasil: um estudo ecológico. Revista Brasileira de Epidemiologia, v. 17, p. 968977, 2014. Disponível em:http://www.scielo.br/scielo.php?script=sci_arttext\&pid=S1415790X2014000400968\&lng=en\&nrm=iso. Acesso em:10 maio 2020.

CHIARELlA, T. et al. A Pedagogia de Paulo Freire e o Processo Ensino-Aprendizagem na Educação Médica. Rev. bras. educ. med. Rio de Janeiro, v. 39, n. 3, p. 418-425, set. 2015. Disponível em: http://www.scielo.br/scielo.php?script=sci_arttext\&pid=S0100$55022015000300418 \& \operatorname{lng}=$ pt\&nrm=iso. Acesso em 29 abr. 2020.

COELHO, A. C. O. et al. Educação Permanente em Saúde: a experiência do uso da educação à distância na capacitação em ações de controle da hanseníase. Junho, 2017. Em Rede, Revista de Educação à Distância. ISSN 2359-6082, v. 4, n.1. 2017. Disponível em:

https://www.aunirede.org.br/revista/index.php/emrede/article/view/176. Acesso em: 01 mar. 2021.

COLLAR, J. M. et al. Educação permanente e o cuidado em saúde: ensaio sobre o trabalho como produção inventiva. Saúde em Redes, 1(4):53-64. 2015. Disponível em:

http://www.lume.ufrgs.br/handle/10183/140334. Acesso em: 30 abr. 2020.

CONSELHO FEDERAL DE MEDICINA. Portal Médico. O site do Conselho Federal de Medicina. 19 de março de 2018. Disponível em:

https://portal.cfm.org.br/index.php?option=com_content\&view $=$ article\&id=27500:2018-03-19-1909-56\&catid=3. Acesso em: 02 dez. 2020.

\section{CONASS. CONSELHO NACIONAL DOS SECRETÁRIOS DE SAÚDE. Portaria}

Interministerial MS/MEC N. 1.618, de 30 de setembro de 2015. 2015. Disponível em:

https://www.conass.org.br/ci-n-230-publicada-a-portaria-interministerial-n-1618-que-institui-comoeixo-do-mais-medicos-residencia-o plano-nacional-de-formacao-de-preceptores-para-os-programasde-residencia-na modalidademedici/. Acesso em: 02 dez. 2020. 
COSTA, R. R. O. et.al. As rodas de conversas como espaço de cuidado e promoção da saúde mental. Rev Atenção Saúde, 3 (43): 30-6. 2015. Disponível

em: http://seer.uscs.edu.br/index.php/revista_ciencias_saude/article/view/2675/pdf_1. Acesso em:30 abr. 2020.

CRUZ, C. S. S. et.al. Educação permanente em saúde: Programa de Educação Permanente para Médicos da Estratégia de Saúde da Família do Estado de Minas Gerais. Resultados e Rumos. Ministério da Educação - Brasil Universidade Federal dos Vales do Jequitinhonha e Mucuri UFVJM. Revista Vozes dos Vales: Publicações Acadêmicas. Qualis/Capes - Latindex nº. 14, ano VII, 10/2018. Disponível em: http://site.ufvjm.edu.br/revistamultidisciplinar/files/2018/10/Leida0108.pdf. Acesso em: 13 jun. 2020.

CUNHA, A. Z. S. et.al. Implicações da educação permanente no processo de trabalho em saúde. Rev Espaço Saúde, 15 (4): 64-75. 2014. Disponível em: https://online.unisc.br/acadnet/anais/index.php/semic/article/view/12250. Acesso em: 30 abr. 2020.

CUNHA, G. T. et al. Método Paidéia para cogestão de coletivos organizados para o trabalho. ORG \& Demo. 2010 jan.; 11(1):31-46. Disponível em: http://www2.marilia.unesp.br/revistas/index.php/orgdemo/article/view/468. Acesso em: 28 abr. 2020.

CUNHA, I. S. da. Educação permanente em saúde e planejamento estratégico situacional: o caso da Secretaria Estadual de Saúde do Piaú. [dissertação]. Rio de Janeiro: Fundação Oswaldo Cruz; 2009. Disponível em:

https://www.arca.fiocruz.br/bitstream/icict/2447/1/ENSP_Disserta\%c3\%a7\%c3\%a3o_Cunha_Iolete _Soares.pdf. Acesso em: 03 ago.2019.

D’AVILA, L. S. et al. Adesão para o Programa de Educação Permanente para médicos de família de um Estado da região sudeste do Brasil. Ciênc. Saúde Coletiva 19 (02). Fev. 2014. Disponível em: https://doi.org/10.1590/1413-81232014192.01162013. Acesso em: 05 jul. 2021.

DAVINI, M. C. Enfoques, Problemas e Perspectivas na Educação Permanente dos Recursos Humanos de Saúde. In: Brasil. Ministério da Saúde (MD). Secretaria de Gestão do Trabalho e da Educação na Saúde. Departamento de Gestão da Educação em Saúde. Política Nacional de Educação Permanente em Saúde. Brasília (DF): Ministério da Saúde, p. 39-63. 2009. Disponível em: http://bvsms.saude.gov.br/bvs/publicacoes/politica_nacional_educacao_permanente_saude.pdf. Acesso em: 28 dez. 2019.

DEJOURS, C. Entre o desespero e a esperança: como reencantar o trabalho Cult. Revista Cult. ano, 139:49-53, 2015. Disponível em: http://revistacult.uol.com.br/home/2010/03/reencantarottrabalho. Acesso em: 10 abr. 2021.

DEJOURS, C. Christophe Dejours: da psicopatologia à psicodinâmica do trabalho. 3.ed. Rio de Janeiro: Editora Fiocruz, 2011.

DUARTE, M. L. C. et al. O trabalho em equipe na enfermagem e os limites e possibilidades da Estratégia e Saúde da Família. Trabalho, Educação e Saúde, on-line, v. 13, n. 3, p.709-720, 2015. Disponível em: http://www.scielo.br/scielo.php?script=sci_abstract\&pid=S1981774620150003 00709\&lng=pt\&nrm=iso\&tlng=pt. Acesso em: 10 de abr. 2021. 
DUARTE, C. G. et al. Satisfação e sofrimento no trabalho do enfermeiro docente: uma revisão integrativa. Revista Mineira de Enfermagem, v. 20, p.1-8, 2016. Disponível em: http://www.reme.org.br/artigo/detalhes/1073. Acesso em: 10 abr. de 2021.

DUNLOP, C. et al. The coronavirus outbreak: the central role of primary care in emergency preparedness and response. BJGP. jan. 2020. Disponível em:

https://doi.org/10.3399/bjgpopen20X101041. Acesso em: 13 maio 2020.

ERDMANN, A. L. et al. Secondary Health Care: best practices in the health services network. Rev. Latino-Am. Enfermagem, Ribeirão Preto, v. 21, n. spe, p. 131-139, fev. 2013.Disponível em: http://www.scielo.br/scielo.php?script=sci_arttext\&pid=S0104$11692013000700017 \& \operatorname{lng}=\mathrm{en} \& \mathrm{nrm}=$ iso. Acesso em: 01 maio 2020.

ESCOREL, S. et al. O Programa de Saúde da Família e a construção de um novo modelo para a atenção básica no Brasil. Pan American Journal of Public Health, 2007. Disponível em: https://www.scielosp.org/article/rpsp/2007.v21n2-3/164-176/pt/. Acesso em: 01 maio 2020.

FACCHINI, L. A. et al. Qualidade da Atenção Primária à Saúde no Brasil: avanços, desafios e perspectivas. Scielo, 2018. Disponível em:

https://www.scielosp.org/article/sdeb/2018.v42nspe1/208-223/. Acesso em: 19 dez. 2019. Acesso em: 30 dez. 2020.

FARIAS, D. C. et al. Acolhimento e Resolubilidade das Urgências na Estratégia Saúde da Família. Rev. bras. educ. med., Rio de Janeiro, v. 39, n. 1, p. 79-87, mar. 2015. Disponível em: http://www.scielo.br/scielo.php?script=sci_arttext\&pid=S010055022015000100079\&lng=en\&nrm=iso. Acesso em: 21 mar. 2021.

FARIA, M. G. de A. et al. Enfermagem e educação permanente à distância: o exemplo do Projeto Telessaúde. Brasil, Núcleo Rio de Janeiro. Cogitare Enfermagem, 15(4), p. 667-673, 2010. Disponível em: http://dx.doi.org/10.5380/ce.v15i4.20363. Acesso em: 25 jan. 2020.

FERLA, A. A. et al. Educação permanente e a regionalização do Sistema Estadual de Saúde na Bahia: ensino-aprendizagem e política de saúde como composição de tempo. Revista Baiana de Saúde Pública, 33(1), p. 7-21. 2009. Disponível em:

https://brasil.campusvirtualsp.org/sites/default/files/Educao\%20Permanente $\% 20 \mathrm{e} \% 20 \mathrm{Gesto} \% 20 \mathrm{Re}$ gionalizada_BA.pdf. Acesso em: 25 jan. 2020.

FERRAZ, L. et al. Educação permanente na enfermagem: uma revisão integrativa. Revista baiana de enfermagem, 2014. Disponível em:

https://portalseer.ufba.br/index.php/enfermagem/article/view/8366. Acesso em: 25 jan. 2020.

FERREIRA, L. et al. Educação Permanente em Saúde na atenção primária: uma revisão integrativa da literatura. Saúde em Debate, 2019, v. 43, n. 120. p. 223-239. Disponível em: https://doi.org/10.1590/0103-1104201912017. Acesso em: 30 abr. 2020.

FERREIRA, M. J. M. et al. Novas Diretrizes Curriculares Nacionais para os cursos de Medicina: oportunidades para ressignificar a formação. Interface (Botucatu), 23(Supl. 1): e170920. 2019. Disponível em: https://doi.org/10.1590/Interface.170920. Acesso em: 14 dez. 2020. 
FERTONANI, H. P. et al. Modelo assistencial em saúde: conceitos e desafios para a atenção básica brasileira. Ciênc. Saúde Coletiva, Rio de Janeiro, v. 20, n. 6, p. 1869-1878, jun. 2015. Disponível em: http://www.scielo.br/scielo.php?script=sci_arttext\&pid=S1413-

81232015000601869\&lng=en\&nrm=iso. Acesso em: 03 jan. 2021.

FIGUEIREDO, M. D. A construção de práticas ampliadas e compartilhadas em saúde: apoio Paideia e formação. Tese (Doutorado em Saúde Coletiva). Faculdade de Ciências Médicas, Universidade Estadual de Campinas, Campinas, 2012. Disponível em: http://repositorio.unicamp.br/bitstream/REPOSIP/313771/1/Figueiredo_MarianaDorsa_D.pdf. Acesso em: 13 maio 2020.

FREIRE, P. Pedagogia da Autonomia. São Paulo: Editora Paz e Terra; 2011.

FREIRE, P. Pedagogia do Oprimido. 59. ed. Rio de Janeiro: Paz \& Terra; 2015.

FRENK J. F. et al. Health professionals for a new century: transforming Educations treng then health systems in an interdependent world. Lancet, 376(9756):1923-57. 2010. Disponível em: https://www.thelancet.com/journals/lancet/article/PIIS0140-6736(10)618545/fulltext?_eventId=login. Acesso em:14 dez. 2019.

FUZISSAKI, M. A. et al. Consolidação da política nacional de educação permanente: revisão integrativa. Rev de enfermagem UFPE, abr.; 8(4):1011-1020. 2014.Disponível em:

https://periodicos.ufpe.br/ revistas/revista enfermagem/article/view/9773. Acesso em:25 abr. de 2020.

GADOTTI, M. Educação e poder: introdução à pedagogia do conflito. 8. ed. São Paulo: Cortez; 1988. Disponível em: https://docero.com.br/doc/50515s. Acesso em: 14 nov. 2019.

GALAVOTE, H. S. et al. A gestão do trabalho na estratégia saúde da família: (des) potencialidades no cotidiano do trabalho em saúde. Saúde e Sociedade, v. 25, n. 4, p. 988-1002,2016. Disponível em: https://doi.org/10.1590/S0104-12902016158633. Acesso em: 03 jan. 2021.

GALAVOTE, H. S. et al. O trabalho do enfermeiro na atenção primária à saúde. Esc. Anna Nery, Rio de Janeiro, v. 20, n. 1, p. 90-98, mar. 2016a. Disponível em: http://www.scielo.br/scielo.php?script=sci_arttext\&pid=S141481452016000100090\&lng=en\&nrm =iso. Acesso em: 27 mar. 2021.

GARCIA JR, C. A. S. et al. Depressão em médicos da Estratégia de Saúde da Família no município de Itajaí/SC. Rev Bras Med Fam Comunidade. Rio de Janeiro, Jan-Dez; 13 (40): 1-12, 2018. Disponível em: http://dx.doi.org/10.5712/rbmfc13(40)1641. Acesso em: 11 abr. 2021.

GIGANTE, R. L. et al. Política de formação e educação permanente em saúde no Brasil: bases legais e referências teóricas. Trab. educ. saúde, Rio de Janeiro, v. 14, n. 3, p. 747-763, dez. 2016. Disponível em: http://www.scielo.br/scielo.php?script=sci_arttext\&pid=S198177462016000300747\&lng=en\&nrm=iso. Acesso em: 29 abr. 2020.

GIL, A. C. Como Elaborar Projetos de Pesquisa. São Paulo; Atlas; 4. ed., 175 p., 2002. Disponível em: http://www.uece.br/nucleodelinguasitaperi/dmdocuments/gil_como_elaborar_projeto_de_pesquisa. pdf. Acesso em: 3 ago.2019. 
GIL, A. C. Como elaborar projetos de pesquisa. São Paulo: Atlas, 2010. Disponível em: https://ria.ufrn.br/123456789/1236. Acesso em: 21 abr. 2021.

GIOVANELLA, L. et al. Saúde da família: limites e possibilidades para uma abordagem integral de atenção primária à saúde no Brasil. Ciênc Saúde Coletiva., 14 (3): 783-94, 2009. Disponível em: http://www.scielo.br/scielo.php?script=sci_arttext\&pid=S1413-

81232009000300014\&lng=en\&nrm=iso. Ácesso em: 14 nov. 2019.

GIOVAnella, L. Atenção Básica ou Atenção Primária à Saúde? Cad. Saúde Pública, Rio de Janeiro, v. 34, n. 8, e00029818, 2018. Disponível em:

http://www.scielo.br/scielo.php?script=sci_arttext\&pid=S0102-

311X2018000800502\&lng=pt\&nrm=iso. Ácesso: em 07 abr. 2021.

GOMES, M. F. P. et al. Qualidade de vida dos profissionais que trabalham na estratégia de saúde da família. v. 14, n. 49, Rev. Atenção à Saúde, 2016. Disponível em:

https://seer.uscs.edu.br/index.php/revista_ciencias_saude/issue/view/222. Acesso em: 19 abr. 2021.

GOMES, T. L. C. S. et al. Integralidade na Atenção Primária à Saúde: compreensão dos estudantes de medicina e enfermagem. Atas do 6. Congresso Ibero-Americano em Investigação Qualitativa em Educação; 2017 jul. 12-14; Salamanca, Espanha. Salamanca: CIAIQ; 2017. Disponível em: https://proceedings.ciaiq.org/index.php/ciaiq2017/article/view/1355/1313. Acesso em: 03 jan. 2021.

GONÇALVES, C. B. et al. A retomada do processo de implementação da Política Nacional de Educação Permanente em Saúde no Brasil. Saúde debate, Rio de Janeiro, v. 43, n. spe1, p. 12-23, ago. 2019. Disponível em: http://www.scielo.br/scielo.php?script=sci_arttext\&pid=S0103$11042019000500012 \& \operatorname{lng}=$ en\&nrm=iso. Acesso em: 28 abr. 2020.

GONÇALVES, R. B. M. Práticas de saúde: processos de trabalho e necessidades. São Paulo; Cefor, 53 p. ilus. Cadernos Cefor, n.1. BVS- Monografia em Português | MS | ID: mis-11635. 1992.

Disponível em: https://pesquisa.bvsalud.org/portal/resource/pt/mis-11635. Acesso em: 19 abr. 2021.

GONÇALVES, R. J. et al. Ser médico no PSF: formação acadêmica, perspectivas e trabalho cotidiano. Rev. bras. educ. med., Rio de Janeiro, v. 33, n. 3, pág. 382-392, setembro de 2009. Disponível em: http://www.scielo.br/scielo.php?script=sci_arttext\&pid=S0100$55022009000300009 \& \operatorname{lng}=\mathrm{en} \& n r m=$ iso. Acesso em:19 de abr. de 2021.

GONZÁLEZ, A. D. et al. Movimentos de mudança na formação em saúde: da medicina comunitária às diretrizes curriculares. Physis, Rio de Janeiro, v. 20, n. 2, p. 551-570, 2010. Disponível em: http://www.scielo.br/scielo.php?script=sci_arttext\&pid=S0103$73312010000200012 \& \operatorname{lng}=$ en\&nrm=iso. Acesso em: 04 set. 2020.

HEIMANN, L. S., et al. Atenção primária em saúde: um estudo multidimensional sobre os desafios e potencialidades na Região Metropolitana de São Paulo (SP, Brasil). Ciênc. Saúde Coletiva, Rio de Janeiro, v. 16, n. 6, p. 2877-2887, jun. 2011. Disponível em: http://www.scielo.br/scielo.php?script=sci_arttext\&pid=S1413$81232011000600025 \& \operatorname{lng}=$ en\&nrm=iso. Acesso em: 30 abr. 2020.

HIRDES, A. A perspectiva dos profissionais da Atenção Primária à Saúde sobre o apoio matricial em saúde mental. Ciênc. Saúde Coletiva, Rio de Janeiro, v. 20, n. 2, p. 371-382, 2015. Disponível em: http://www.scielo.br/scielo.php?script $=$ sci_arttext\&pid=S141381232015000200371\&lng=en\&nrm=iso. Acesso em: 12 jan. 2021. 
HOUAISS, A.; VILLAR, M. S. Dicionário Houaiss da Língua Portuguesa. Rio de Janeiro: Objetiva, 2001.

IBGE. Instituto Brasileiro de Geografia e Estatística, 2018. Disponível em: https://cidades.ibge.gov.br/brasil/mg/governador-valadares/panorama. Acesso em: 03 ago. 2020.

IZECKSOHN, M. M. V., et al. Preceptoria em Medicina de Família e Comunidade: desafios e realizações em uma Atenção Primária à Saúde em construção. Ciência \& Saúde Coletiva, v. 22, n. 3, pp. 737-746. 2017. Disponível em: https://doi.org/10.1590/1413-81232017223.332372016>. ISSN 1678-4561. Acesso em: 02 dez.2020.

JACOVISKI, M. et al. Trabalho em equipe: percepção dos profissionais da Estratégia de Saúde da Família. Revista Baiana de Enfermagem, Salvador, p. 1-9, abr./jun. 2016. Disponível em: http://dx.doi.org/10.18471/rbe.v30i2.15145. Acesso em: 11 abr. 2021.

JUNQUEIRA, S. R. Competências profissionais na estratégia Saúde da Família e o trabalho em equipe. Módulo Político Gestor. Disponível em: http://www.unasus.unifesp.

br/biblioteca_virtual/esf/1/modulo_politico_gestor/Unidad e_9. pdf, 2008. Acesso em: 10 maio 2021.

JUZWIAK, C. R. et al. $A$ experiência da Oficina Permanente de Educação Alimentar e em Saúde (OPEAS): formação de profissionais para a promoção da alimentação saudável nas escolas. Ciência \& Saúde Coletiva, 18(4), p. 1009-1018, 2013. Disponível em: http://www.scielo.br/scielo.php?script=sci_arttext\&pid=S1413$81232013000400014 \& \operatorname{lng}=$ en\&nrm=iso. Acesso em: 23 dez. 2019.

LAPÃO, L. V. et al. Atenção Primária à Saúde na coordenação das Redes de Atenção à Saúde no Rio de Janeiro, Brasil, e na região de Lisboa, Portugal. Ciência \& Saúde Coletiva., v. 22, n. 3, p. 713-724. 2017. Disponível em: https://doi.org/10.1590/1413-81232017223.33532016. Acesso em: 17 jan. 2021.

LEITE, A. L. S. et al. Atenção Básica e desinstitucionalização da loucura: acionando competências dos Agentes Comunitários de Saúde. In: S. Paulo n \& R. Neves (Org.). Saúde Mental na Atenção Básica: a territorialização do cuidado (pp. 99-112). Porto Alegre: Editora Sulina, 2013.

LEMOS, C. L. S. Educação Permanente em Saúde no Brasil: educação ou gerenciamento permanente? SCIELO. 2016. Disponível em:

http://www.scielo.br/scielo.php?script=sci_arttext\&pid=S1413-

$81232016000300913 \& \operatorname{lng}=$ pt\&tlng=pt. Acesso em: 25 dez. 2019.

LEITE, M. T. S. et al. O Programa de Educação pelo Trabalho para a Saúde na formação profissional. Rev. bras. educ. med., Rio de Janeiro, v. 36, n. 1, supl. 1, p. 111-118, mar. 2012. Disponível em: http://www.scielo.br/scielo.php?script=sci_arttext\&pid=S010055022012000200015\&lng=pt\&nrm=iso. Acesso em: 30 abr. 2020.

LIMA, F. A. et al. Sentidos da participação social na saúde para lideranças comunitárias e profissionais da Estratégia Saúde da Família do território de Vila União, em Sobra 1- CE. Physis:

Revista de Saúde Coletiva, v. 26, n. 1, pp. 157-175. 2016. Disponível em:

https://doi.org/10.1590/S0103-73312016000100010. Acesso em: 09 abr. 2021. 
LINO, M. M. et al. A realidade da Educação Continuada na Enfermagem nos Serviços Públicos de Saúde de Florianópolis. Online Braz J. Nurs Online, 6(0). 2007. Disponível em: http://www.objnursing.uff.br/index.php/nursing/article/view/619/147. Acesso em:20 dez. 2019.

LOPES et al. Potencialidades da educação permanente para a transformação das práticas de saúde. Comum CiencSaude, 18 (2): 147-55. 2007. Disponível em: https://pesquisa.bvsalud.org/portal/resource/pt/lil-484725. Acesso em: 04 dez. 2019.

LOPES J. M. C. et al. A pessoa como centro do cuidado na prática do médico de família. Rev. Bras. Med. Fam. Comunidade, 10 (34): 1-13. 2015. Disponível em: http://dx.doi.org/10.5712/rbmfc10(34)870. Acesso em: 03 jan. 2021.

MACINKO, J. et al. Forte expansão da atenção básica à saúde no Brasil, associada a um declínio da hospitalização desnecessária. Health Affairs, 2010; 29 (12):2149-60.

MAHMUD, I. C. et al. A multidisciplinaridade na visita domiciliar a idosos: o olhar da Enfermagem, Medicina e Psicologia. Pajar, volume 6 n. 2 p. 72-84. 2018. Disponível em: http://dx.doi.org/10.15448/2357-9641.2018.2.31630. Acesso em: 17 jan. 2021.

MASSUDA, A. et al. Remembering Alma-Ata: challenges and innovations in primary health care in a middle-income city in Latin America. Revista Panamericana de Salud Pública, v. 42, 2018. Disponível em: https://doi.org/10.26633/RPSP.2018.157. Acesso em: 27 mar. 2021.

MARIZ, R. S. et al. A força do local na educação da liquidez: a experiência do Projeto Rondon. In: Revista Diálogos, Universidade Católica de Brasília, Brasília, v.21, n.2, nov.2017. Disponível em: https://portalrevistas.ucb.br/index.php/RDL/article/view/9110. Acesso em: 08 abr. 2021.

MELLO, G. A. et al. Médico de família: ser ou não ser? Dilemas envolvidos na escolha desta carreira. SCIELO. Rev. bras. educ. med., Rio de Janeiro, v. 33, n. 3, p. 464-471, set. 2009. Disponível em: http://www.scielo.br/scielo.php?script=sci_arttext\&pid=S010055022009000300017. Acesso em: 25 dez. 2019.

MELO, D. G. et al. Qualificação e provimento de médicos no contexto da Política Nacional de Atenção Integral às Pessoas com Doenças Raras no Sistema Único de Saúde (SUS). Interface Comunicação, Saúde, Educação [online]. 2017, v. 21, n. Suppl 1, pp. 1205-1216. Disponível em: https://doi.org/10.1590/1807-57622016.0211. Acesso em: 26 abr. 2021.

MENDES, E. V. As redes de atenção à saúde. / Eugênio Vilaça Mendes. Brasília: Organização Pan-Americana da Saúde, 549 p.: il. ISBN: 978-85-7967-075-6. 2011. Disponível em: http://20098-146-

54.clouduol.com.br/bitstream/123456789/1314/1/as\%20Redes\%20de\%20Atencao\%20a\%20Saude EugeniE_2ed.PDF. Acesso em: 26 dez. 2019.

MERHY, E. E. Saúde: a cartografia do trabalho vivo. São Paulo: Hucitec, 2007.

MESSINA, L. A. et al. Impactos da rede universitária de telemedicina: ações de educação contínua, pesquisa colaborativa e assistência remota: Fase I (2006-2009). 2013. Rio de Janeiro. Disponível em:

http://bases.bireme.br/cgibin/wxislind.exe/iah/online/?IsisScript=iah/iah.xis\&src=google\&base=LI LACS\&lang=p\&nextAction=lnk\&exprSearch=696420\&indexSearch=ID. Acesso em: 14 nov. 2019. 
MICCAS, et al. Educação permanente em saúde: metassíntese. SCIELO, 2014. Disponível em: http://www.scielo.br/scielo.php?pid=S0034-89102014000100170\&script=sci_abstract\&tlng=pt. Acesso em: 26 dez. 2019.

MILANEZ, T. C. M. et al. Satisfação e insatisfação na Estratégia Saúde da Família: potencialidades a serem exploradas, fragilidades a serem dirimidas. Cad. Saúde Colet. Rio de Janeiro, v. 26, n. 2, p. 184-190, jun. 2018. Disponível em:

http://www.scielo.br/scielo.php?script $=$ sci_arttext\&pid=S1414-

462X2018000200184\&lng=en\&nrm=iso. Acesso em: 03 jan. 2021.

MINAS GERAIS. Secretaria de Estado da Saúde. Resolução SES/MG 322918 de abril de 2012. Dispõe sobre as normas gerais do Programa de Educação Permanente/PEP para médicos de família e dá outras providências. Belo Horizonte, 2012. Imprensa Oficial do Estado de Minas Gerais. Belo Horizonte, MG, 19 abr. 2012. Disponível em:

https://www.saude.mg.gov.br/images/documentos/resolucao_3229.pdf. Acesso em: 13 de jun. 2020.

MINAYO, M. C. de S. O desafio do conhecimento: pesquisa qualitativa em saúde. 13 ed., São Paulo: Hucitec, 2013.

MISHIMA, S. M. et al. Perspectiva dos gestores de uma região do estado de São Paulo sobre educação permanente em saúde. Rev. Esc. Enfermagem. USP, São Paulo, v. 49, n. 4, p. 0665 0673, ago. 2015. Disponível em: http://www.scielo.br/scielo.php?script=sci_arttext\&pid=S008062342015000400665\&lng=en\&nrm=iso. Acesso em: 01 maio 2020.

MORAES, K. G. Análise do Processo de Implementação da Política de Educação Permanente em Saúde no Distrito Federal. Dissertação (Mestrado) - Universidade de Brasília, Brasília, 2012. Disponível em: https://repositorio.unb.br/handle/10482/12736. Acesso em: 04 dez. 2020.

MOREIRA, J. et al. Educação permanente em saúde na estratégia saúde da família: reflexões a partir do existencialismo e da educação libertadora. Revista Da FAEEBA - Educação E Contemporaneidade, 26 (50), 255-272. Ano 2017. Disponível em: https://doi.org/10.21879/faeeba2358-0194.2017.v26.n50.p255-272. Acesso em: 05 jan. 2021.

MORIN, E.A cabeça bem-feita: repensar a reforma, reformar o pensamento / Edgar Morin; tradução: Eloá Jacobina, 8 ed. Rio de Janeiro: Bertrand Brasil, 2003. Disponível em: http://abdet.com.br/site/wp-content/uploads/2015/04/A-cabe\%C3\%A7a-bem-feita.pdf. Acesso em: 20 abr. 2021.

MOTA, R. G. B, et al. O Programa Mais Médicos no Estado de Mato Grosso, Brasil: uma análise de implementação. Ciência \& Saúde Coletiva, v. 21, n. 09, p. 2879-2888. 2016. Disponível em: https://doi.org/10.1590/1413-81232015219.14582016. Acesso em: 11 abr. 2021.

MOTTA, L. C. S. et al. Estratégia Saúde da Família: Clínica e Crítica. Rev. bras. educ. med., Rio de Janeiro, v. 39, n. 2, p. 196-207, jun. 2015. Disponível em:

http://www.scielo.br/scielo.php?script=sci_arttext\&pid=S0100-

55022015000200196\&lng=en\&nrm=iso. Acesso em: 10 abr. 2021.

NESPOLI G. et al. Discursos que formam saberes: uma análise das concepções teóricas e metodológicas que orientam o material educativo de formação de facilitadores de Educação 
Permanente em Saúde. Interface - Comunic. Saúde, Educ., v. 15 n. 39, p. 985-996, 2011.

Disponível em: https://www.ead.fiocruz.br/curso.index.cfm?cursoid=612. Acesso em: 08 jan. 2020.

NEVES, D. R. et al. Sentido e significado do trabalho: uma análise dos artigos publicados em periódicos associados à Scientific Periodicals Electronic Library. Cadernos Ebape.br, [s.1.], v. 16, n. 2, p.318-330, 2018. Disponível em: http://www.scielo.br/scielo.php?pid=S1679-

9512018000200318\&script=sci_arttext. Acesso em:10 abr. de 2021.

NOVAK, et al. A teoria subjacente aos mapas conceituais e como elaborá-los e usá-los. Práxis Educativa, Ponta Grossa, n.1, v. 5, p. 9-29, 2010. Disponível: http://www.periodicos.uepg.br. Acesso em: 15 abr.2020.

OLIVEIRA, F. P. et al. Mais Médicos: um programa brasileiro em uma perspectiva internacional. Interface (Botucatu), Botucatu, v. 19, n. 54, p. 623-634, set. 2015. Disponível em: http://www.scielo.br/scielo.php?script=sci arttext\&pid=S1414-

32832015000300623\&lng=en\&nrm=iso. Acesso em: 07 dez. 2020.

OLIVEIRA, H. M. de et al. As relações de poder em equipe multiprofisssional de Saúde da Família segundo um modelo teórico arendtiano. Interface (Botucatu), Botucatu, v. 15, n. 37, p. 539-550, june. 2011. Disponível em: http://www.scielo.br/scielo.php?script=sci_arttext\&pid=S141432832011000200017\&lng=en\&nrm=iso. Acesso em: 19 abr. 2021.

OLIVEIRA J. P. A. et al. O Programa Mais Médicos: provimento de médicos em municípios brasileiros prioritários entre 2013 e 2014. Cienc. Saúde Colet, 21 (9): 2719-27. 2016. Disponível em: https://doi.org/10.1590/1413-81232015219.17702016. Acesso em: 04 dez. 2020.

OLIVEIRA, M. A. N. Educação à Distância como estratégia para a educação permanente em saúde: possibilidades e desafios. Rev. Bras. Enfermagem. Brasília, v. 60, n. 5, p. 585-589, out. 2007. Disponível em: http://www.scielo.br/scielo.php?script=sci arttext\&pid=S003471672007000500019\&lng=en\&nrm=iso. Acesso em: 05 abr. 2021.

OLIVEIRA, M. A. de C. et al. Atributos essenciais da Atenção Primária e a Estratégia Saúde da Família. Rev. Bras. Enferm. Brasília, v. 66, n. spe, p. 158-164, set. 2013. Disponível em: http://www.scielo.br/scielo.php?script=sci_arttext\&pid=S0034$71672013000700020 \& \operatorname{lng}=$ en\&nrm=iso. Acesso em: 07 dez. 2020.

OMS. ORGANIZAÇÃO MUNDIAL DE SAÚDE. Coronavirus disease (COVID-2019). Genebra: World Health Organization, 2020. Disponível em: https:/www.who.int/docs/defaultsource/coronaviruse/situation-reports/20200401-sitrep-72-covid-19.pdf?sfvrsn=3dd8971b_2. Acesso em: 13 maio 2020.

PADILHA, R. Q. et al. Princípios para a gestão da clínica: conectando gestão, atenção à saúde e educação na saúde. Ciência \& Saúde Coletiva. 2018, v. 23, n. 12, pp. 4249-4257. Disponível em: https://doi.org/10.1590/1413-812320182312.32262016. Acesso em: 03 jan. 2021.

PAIM, J. S. Financiamento da Saúde: questão política para além do setor. CREMEB-Vida \&Ética; 5(18):17, ano 2014. Disponível em: http://www.cremeb.org.br/wp-content/uploads/2015/12/PDF18.pdf. Acesso em: 26 dez. 2019.

PEDUZZI, M. et al. Trabalho em Equipe, Prática e Educação Interprofissional. Clínica Médica. 2. ed. Barueri: Manoele, p. 171-9, 2016. Disponível em: 
https://edisciplinas.usp.br/pluginfile.php/3011330/mod_resource/content $/ 1 /$ Trabalho $\% 20 \mathrm{em} \% 20 \mathrm{equ}$ ipe.ppd. Acesso em: 08 abr. 2021.

PEDUZZI, M. et al. Trabalho em equipe: uma revisita ao conceito e a seus desdobramentos no trabalho interprofissional. Trabalho, Educação e Saúde, 18 (Supl. 1), e0024678, ano 2020. Disponível em: http://www.scielo.br/scielo.php?script=sci_arttext\&pid=S1981$77462020000400401 \& \operatorname{lng}=$ en\&nrm=iso. Acesso em: 08 abrr. 2021.

PENDLETON, D. et al. A nova consulta: desenvolvendo a comunicação entre médico e paciente. Porto Alegre; Artmed; 2011. 160 p.

PEREIRA, J. G. et al. Integração Academia, Serviço e Comunidade: um relato de experiência do curso de graduação em medicina na atenção básica no município de São Paulo. O Mundo da Saúde São Paulo, 33(1): 99-107, 2009. Disponível em: http://www.saocamilosp.br/pdf/mundo_saude/66/99a107.pdf. Acesso em: 11 abr. 2021.

PESSOA, L. R. et al. A Educação permanente e a cooperação internacional em saúde: um olhar sobre a experiência de fortalecimento da Rede haitiana de vigilância, pesquisa e educação em saúde, no âmbito do projeto Tripartite. Brasil-Haiti-Cuba. Divulgação Saúde em Debate, 49, p. 165-171, 2013. Disponível em: http://informe.ensp.fiocruz.br/assets/anexos/63802503ec0a8c6a0118ff263102e43216771f9f.PDF Acesso em: 03 ago. 2019.

PINHEIRO, G. E. W. et al. Facilidades e dificuldades vivenciadas na Educação Permanente em Saúde, na Estratégia Saúde da Família. Saúde em Debate, 2018, v. 42, n. spe 4., p. 187-197. Disponível em: https://doi.org/10.1590/0103-11042018S415. Acesso em: 27 mar. 2021.

PINTO, H. A et al. Política Nacional de Educação Permanente em Saúde: aprender para transformar. A educação permanente em saúde e as redes colaborativas: conexões para a produção de saberes e práticas. Porto Alegre: Rede UNIDA, p. 23-65. 2016. Disponível em:https:/historico.redeunida.org.br/editora/biblioteca-digital/serie-atencao-basica-e-educacao-nasaude/a-educacao-permanente-em-saude-e-as-redes-colaborativas-conexoes-para-a-producao-desaberes-e-praticas. Acesso em: 26 dez. 2020.

PINTO, L. F et al. Do Programa à Estratégia Saúde da Família: expansão do acesso e redução das internações por condições sensíveis à atenção básica (ICSAB). Ciênc. Saúde coletiva, Rio de janeiro, v. 23, n. 6, p. 1903-1914, junho, 2018. Disponível em: http://www.scielo.br/scielo.php?script=sci_arttext\&pid=S1413$81232018000601903 \& \operatorname{lng}=$ en\&nrm=iso. Acesso em: 14 mai. 2020.

POLI, N. et al. Remuneração variável na Atenção Primária à Saúde: relato das experiências de Curitiba e Rio de Janeiro, no Brasil, e de Lisboa, em Portugal. Ciênc. Saúde Coletiva, Rio de janeiro, v. 21, n. 5, p. 1377-1388, maio, 2016. Disponível em:

http://www.scielo.br/scielo.php?script=sci_arttext\&pid=S1413-

81232016000501377\&lng=pt\&nrm=iso. Acesso em: 08 abr. 2021.

PRADO, M. L. do et al. Arco de Charles Maguerez: refletindo estratégias de metodologia ativa na formação de profissionais de saúde. Esc. Anna Nery, Rio de Janeiro, v. 16, n. 1, p. 172 177, mar. 2012. Disponível em: http:/www.scielo.br/scielo.php?script=sci_arttext\&pid=S1414$81452012000100023 \& \operatorname{lng}=\mathrm{en} \& n \mathrm{~mm}=$ iso. Acesso em: $23 \mathrm{dez} .2019$. 
PROCÓPIO, L. C. R. et al. A Atenção Domiciliar no âmbito do Sistema Único de Saúde: desafios e potencialidades. Saúde debate, Rio de Janeiro, v. 43, n. 121, p. 592-604, abr. 2019. Disponível em: http://www.scielo.br/scielo.php?script=sci_arttext\&pid=S010311042019000200592\&lng=en\&nrm=iso. Acesso em: 21 mar. 2021.

RADDATZ, M. Ações de educação permanente em saúde desenvolvidas por equipes de atenção básica em saúde. Rio Grande do Sul. Universidade Federal de Santa Maria, 81 p. 2014. Disponível em:

https://repositorio.ufsm.br/bitstream/handle/1/7405/RADDATZ\%2c\%20MICHELE.pdf?sequence= 1\&isAllowed=y. Acesso em: 01 de mai. 2020.

RAMOS, L. H. Gestão de Serviços de Saúde. Módulo Político Gestor. Especialização em Saúde da Família, 2015. Disponível em: http://www.unasus.unifesp.br/ biblioteca_virtual/ esf/1/modulo_politico_gestor/Unidade11.pdf. Acesso em: 10 mai. 2020.

RANGEL, M. L. et al. Redes de aprendizagem colaborativa: contribuição da educação a distância no processo de qualificação de gestores do Sistema Único de Saúde - SUS, Brasil. Interface Comun Saúde Educ, 41(16): 545-556. 2012. Disponível em: https://www.scielosp.org/article/icse/2012.v16n41/545-556/\#ModalArticles. Acesso em: 05 abr. 2021.

RICARDI, L. M. et al. As Conferências Nacionais de Saúde e o processo de planejamento do Ministério da Saúde. Saúde em Debate, v. 41, spe 3, p. 155-170. 2017. Disponível em: https://doi.org/10.1590/0103-11042017S312. Acesso em: 29 abr. 2020.

ROTTA, M. F. O. N. et al. Perspectivas profissionais e motivações de estudantes de Medicina para atuação na Estratégia Saúde da Família. Interface - Comunicação, Saúde, Educação v. 24, suppl 1, 2020. Disponível em: https://doi.org/10.1590/Interface.190531. Acesso em 14 dez. 2020.

ROVERE, M. R. et al. Gestion estratégica de La educacion permanente em salud. Educación Permanente de Personal de Salud. Washington: Organizacion Panamericana de La Salud; Série Desarrollo de Recursos Humanos, n.100, p. 63-106, 1994. Disponível em: https://pesquisa.bvsalud.org/portal/resource/pt/lil-160630. Acesso em: 29 abr. 2020.

SANT'ANNA, C. F. et al. Comunidade: objeto coletivo do trabalho das enfermeiras da Estratégia Saúde da Família. Acta Paul Enferm, 24 (3): 341-47. 2011. Disponível em: https://www.scielo.br/pdf/ape/v24n3/06.pdf. Acesso em: 11 abr. 2021.

SANTOS, A. M. dos, et al. Desafios à gestão do trabalho e educação permanente em saúde para à produção do cuidado na Estratégia de Saúde da Família. Rev APS., jan/mar;18(1):39-49, 2015. Disponível em: https://periodicos.ufjf.br/index.php/aps/article/view/15469. Acesso em: 19. abr. 2021.

SANTOS, P. F. et al. A Educação Permanente como ferramenta no trabalho interprofissional na Atenção Primária à Saúde. Tempus, Actas de Saúde Colet, Brasília, 10(3), 177-189, set, 2016. Disponível em: http://dx.doi.org/10.18569/tempus.v10i3.1641. Acesso em: 30 abr. 2020.

SANTOS, R. A. B. G, et al. Apoio matricial e ações na atenção primária: experiência de profissionais de ESF e Nasf. Saúde em Debate, v. 41, n. 114, p. 694-706,2017. Disponível em: https://doi.org/10.1590/0103-1104201711402. Acesso em: 12 jan. 2021. 
SARTI, T. D. et al. Qual o papel da Atenção Primária à Saúde diante da pandemia provocada pela COVID-19? Epidemiologia e Serviços de Saúde. v. 29, n. 2, 2020. Disponível em:

https://doi.org/10.5123/S1679-49742020000200024. ISSN 2237-9622. Acesso em: 16 jun. 2020.

SBMFC. SOCIEDADE BRASILEIRA DE MEDICINA DE FAMÍLIA E COMUNIDADE.

Currículo Baseado em Competências, 2015. Disponível em: http://www.sbmfc.org.br/wp-

content/uploads/media/Curriculo\%20Baseado $\% 20 \mathrm{em} \% 20$ Competencias(1).pdf. Acesso em: 21 mar. 2021.

SCHEFFER, M. C. et al. A feminilização da medicina no Brasil. Rev. Bioética, 21 (2): 268-77. 2013. Disponível em:

https://revistabioetica.cfm.org.br/index.php/revista_bioetica/article/view/817/905. Acesso em: 11 nov. 2020.

SCHEFFER, M. C. Demografia Médica no Brasil. São Paulo: Departamento de Medicina Preventiva; Faculdade de Medicina; Universidade de São Paulo, Conselho Regional de Medicina do Estado de São Paulo; Conselho Federal de Medicina; 2015. Disponível em:

http://www.usp.br/agen/wp-content/uploads/DemografiaMedica30nov2015.pdf. Acesso em: 02 dez. 2020.

SCHEFFER, M. C. O capital estrangeiro e a privatização do sistema de saúde brasileiro. Cadernos de Saúde Pública, v. 31, n. 4, p. 663-666; 2015a. Disponível em: https://doi.org/10.1590/0102311XPE010415. Acesso em: 28 abr. 2020.

SCHULTZ T.W. O valor econômico da educação. Rio de Janeiro. Editora: Zahar; 1985

SCHWEICKARDT, J. et al. Educação permanente em gestão regionalizada da saúde: saberes e fazeres no território do Amazonas. Porto Alegre: Rede UNIDA, 2015. Disponível em: http://dx.doi.org/10.18310/9788566659429. Acesso em: 28 abr. 2020.

SEIDL, H. et al. Gestão do trabalho na Atenção Básica em Saúde: uma análise a partir da perspectiva das equipes participantes do PMAQ-AB. Saúde em Debate, v. 38, n. spe, p. 94-108. 2014. Disponível em: https://doi.org/10.5935/0103-1104.2014S008. Acesso em: 07 abr. 2021.

SILVA, A. N. et al. Limites e Possibilidades do Ensino a Distância (EAD) na Educação Permanente em Saúde: revisão integrativa. Revista Ciência e Saúde Coletiva, Rio de Janeiro, v.20, n.4, 2015. 2015a. Disponível em:http://www.scielosp.org/pdf/csc/v20n4/1413-8123-csc-20-04-01099.pdf. Acesso em: 01 mar. 2021.

SILVA, C. S. et al. Atenção Primária à Saúde: conceitos, práticas e pesquisa. Saúde debate, Rio de Janeiro, v. 42, n. spe1, p. 452-456, set. 2018. Disponível em: http://www.scielo.br/scielo.php?script=sci arttext\&pid=S0103$11042018000500452 \& \operatorname{lng}=$ en\&nrm=iso. Acesso em: 10 mai. 2020.

SILVA, C. T. et al. Educação permanente em saúde: percepção de profisssionais de uma residência multidisciplinar. Rev. Enferm. UFSM. 2014. 3:627-635. Disponível em: https://periodicos.ufsm.br/reufsm/article/view/11067/pdf. Acesso em: 26 dez. 2019

SILVA, J. A. M. da et al. Educação no trabalho na atenção primária à saúde: interfaces entre a educação permanente em saúde e o agir comunicativo. Saúde soc. São Paulo, v. 20, n. 4, p. 1018- 
1032, dez. 2011. Disponível em: http://www.scielo.br/scielo.php?script=sci_arttext\&pid=S0104$12902011000400018 \& \operatorname{lng}=$ pt\&nrm=iso. Acesso em: 26 jan. 2020.

SILVA, J. F. A educação permanente em saúde como espaço de produção de saberes na Estratégia de Saúde da Família. 2015. 2015c. 78 f. Dissertação (Mestrado em Saúde Pública). Escola Nacional de Saúde Pública Sergio Arouca, Fundação Oswaldo Cruz, Rio de Janeiro, 2015. Disponível em: https://www.arca.fiocruz.br/handle/icict/13461. Acesso em: 30 abr. 2020.

SILVA, K. D. Análise do Programa Telessaúde Brasil Redes no estado de Pernambuco no período de 2007 a 2011. ARCA, 2013. Disponível em:

https://www.arca.fiocruz.br/handle/icict/10364. Acesso em: 26 dez. 2019.

SILVA, K. M. et al. The nursing processing family health strategy and the care for the elderly. SCIELO, 2015. 2015b. Disponível em: http://www.scielo.br/pdf/tce/v24n1/0104-0707-tce-24-0100105.pdf. Acesso em: 26 dez. 2019.

SILVA, K. L. et al. A construção da educação permanente no processo de trabalho em saúde no estado de Minas Gerais, Brasil. Esc. Anna Nery, Rio de Janeiro, v. 21, n. 4, e20170060, 2017. Disponível em: http://www.scielo.br/scielo.php?script=sci_arttext\&pid=S141481452017000400204\&lng=en\&nrm=iso. Acesso em: 19 ab̄r. 2021.

SILVA, L. A. A. et al. Desafios na construção de um projeto de educação permanente em saúde. Revista de Enfermagem da UFSM, v. 2, n. 3, p. 496 - 506, dez. ISSN 2179-7692. 2012. Disponível em: https://periodicos.ufsm.br/reufsm/article/view/5364. Acesso em: 30 abr. 2020.

SILVA, L. A. A. et al. A educação permanente no processo de trabalho de enfermagem. Rev. Enferm. Cent. - Oeste, 6 (3): 2349-2361. 2016.

Disponívelem: http://www.seer.ufsj.edu.br/index.php/recom/article/view/1027/1168. Acesso em: 01 maio 2020.

SILVA, L. A. A. et al. Educação permanente em saúde na atenção básica: percepção dos gestores municipais de saúde. Revista gaúcha enfermagem, mar., 38 (1): 1-8,2017. Disponível em: http://www.scielo.br/pdf/rgenf/v38n1/0102-6933-rgenf-1983-144720170158779.pdf. Acesso em: 01 maio 2020.

SILVA, R. M. et al. Contexto de trabalho e custo humano no trabalho: um estudo com trabalhadores portuários de transporte. Barborói-Revista do Departamento de Ciências Humanas, on-line, n. 46, p. 98-118, 2016. Disponível em: https://on-line.unisc.br/seer/index.php/barbaroi/article/view/6410. Acesso em: 11 abr. de 2021.

SILVÉRIO, J. B. Programa de educação permanente para médicos de família. Ver Med Minas Gerais, 18 (Supl. 4): S60-S66.2008. Disponível em: http://rmmg.org/artigo/detalhes/1270. Acesso em: 26 dez. 2019.

SORATTO, J. et al. Insatisfação no trabalho de profissionais da saúde na Estratégia de Saúde a Família. Texto Contexto - Enferm., Florianópolis, v. 26, n. 3, e2500016, 2017. Disponível em: http://www.scielo.br/scielo.php?script=sci_arttext\&pid=S0104-

$07072017000300325 \& \operatorname{lng}=$ en\&nrm=iso. Acesso em: 03 jan. 2021.

SORATTO, J. et al. Satisfação dos profissionais da Estratégia de Saúde da Família no Brasil: um estudo qualitativo. Texto contexto - enferm., Florianópolis, v. 29, e 20180104, 2020. Disponível 
em: http://www.scielo.br/scielo.php?script=sci_arttext\&pid=S010407072020000100340\&lng=en\&nrm=iso. Acesso em: 07 abr. 2021.

STARFIELD, B. Atenção primária: equilíbrio entre necessidades de saúde, serviços e tecnologia. Brasília: Unesco, Ministério da Saúde (MS), 2002. Disponível em: https://www.nescon.medicina.ufmg.br/biblioteca/imagem/0253.pdf. Acesso em: 14 nov. 2019.

STORTI, M. M. T. et al. A expansão de vagas de residência de Medicina de Família e Comunidade por municípios e o Programa Mais Médicos. Interface - Comunicação, Saúde, Educação. 2017, v. 21, n. Suppl 1, pp. 1301-1314. Disponível em: https://doi.org/10.1590/1807-57622016.0511. Acesso em: 03 jan. 2021.

TESSER, C. D. et al. Estratégia saúde da família e análise da realidade social: subsídios para políticas de promoção da saúde e educação permanente, nov. SCIELO. 2011. Disponível em: http://www.scielo.br/scielo.php?pid=S1413-81232011001200002\&script $=$ sci_abstract\&tlng $=$ pt. Acesso em: 10 jan. 2020.

TOMASI, E. et al. Qualidade da atenção pré-natal na rede básica de saúde do Brasil: indicadores e desigualdades sociais. Cad. Saúde Pública, Rio de Janeiro, v. 33, n. 3, e00195815, 2017. Disponível em: http://www.scielo.br/scielo.php?script=sci_arttext\&pid=S0102311X2017000305001\&lng=en\&nrm=iso. Acesso em: 10 mai. 2020.

TOMASI, E. et al. Diabetes Care in Brazil. Journal of Ambulatory Care Management. Ovid Technologies (WoltersKluwer Health), 40: S12-S23. 2017a. Disponível em: http://dx.doi.org/10.1097/JAC.0000000000000184. Acesso em: 10 mai. 2020.

THUMÉ, E. et al. Reflexões dos médicos sobre o processo pessoal de aprendizagem e os significados da especialização à distância em saúde da família. Ciência \& Saúde Coletiva, v. 21, n. 09, p. 2807-2814. 2016. Disponível em: https://doi.org/10.1590/1413-81232015219.14632016. Acesso em: 01 mar. 2021.

VARGAS, F. M. A. et al. A educação à distância na qualificação de profissionais para o Sistema Único De Saúde: meta estudo. Trab. educ. saúde, Rio de Janeiro, v. 14, n. 3, p. 849870, dez. 2016. Disponível em: http://www.scielo.br/scielo.php?script=sci_arttext\&pid=S1981 77462016000300849\&lng=en\&nrm=iso. Acesso em: 08 abr. 2021.

VASCONCELOS, et al. Dificuldades do trabalho médico no PSF. SCIELO. 2011. Disponível em: http://www.scielo.br/scielo.php?pid=S1413-81232011000700085\&script=sci_abstract\&tlng=pt. Acesso em: 10 jan. 2020.

VASCONCELOS, R. C. et al. Formação de Médicos para o SUS: a Integração Ensino e Saúde da Família - Revisão Integrativa. Rev. bras. educ. med., Rio de Janeiro, v. 39, n. 4, p. 630-638, Dec. 2015. Disponível em: http://www.scielo.br/scielo.php?script=sci_arttext\&pid=S010055022015000400630\&lng=en\&nrm=iso. Acesso em: 17 mar. 2021.

VENTURELLI, J. Educación médica y enciencias dela salud; inminencia y necesidad del cambio. [S.1.]: Facultad de Ciencias de la Salud, Universidad de Macmaster, (s.d.), 2006. Disponível em: http://www.educabrasil.com.br/eb/exe/texto. Acesso em: 03 ago. 2019.

VIEIRA, N. P. Gestão do trabalho em saúde: planos de carreira, cargos e salários como demanda histórica na saúde pública e características de sua implantação em municípios paulistas. Ano 2014, 
112f. Tese (Doutorado) - Escola Paulista de Medicina, Universidade Federal de São Paulo (UNIFESP), São Paulo, 2014. Disponível em:

https:/sucupira.capes.gov.br/sucupira/public/consultas/coleta/trabalhoConclusao/viewTrabalhoCon clusao.jsf?popup=true\&id_trabalho=1618550. Acesso em: 07 abr. 2021.

VILLARDI, M. L. et al. A metodologia da problematização no ensino em saúde: suas etapas e possibilidades. In: A problematização em educação em saúde: percepções dos professores tutores e alunos. São Paulo: Editora UNESP. Cultura Acadêmica, p. 45-52. ISBN 978-85-7983-662-6. 2015. Disponível em: http://www.books.ciello.org. Acesso em: 8 mai. 2020.

VILLA-VELEZ, L. Educación para la salud y justicia social basada em el enfoque de las capacidades: Una oportunidad para el desarrollo de la salud pública. Ciênc. Saúde Coletiva, v. 25, n.4, p.1539-1546. 2020. Disponível em: https://doi.org/10.1590/1413-81232020254.19052018.

Acesso em: 27 mar. 2021.

YAKAMOTO, T. S. et al. Educação Permanente em Saúde como prática avaliativa amistosa à integralidade em Teresópolis, Rio de janeiro. Trab. educ. saúde, Rio de Janeiro, v. 13, n. 3, p. 617638, dez. 2015. Disponível em: http://www.scielo.br/scielo.php?script=sci_arttext\&pid=S198177462015000300617\&lng=en\&nrm=iso. Acesso em: 08 mai. 2020. 


\section{APÊNDICE A - TERMO DE CONSENTIMENTO LIVRE E ESCLARECIDO}

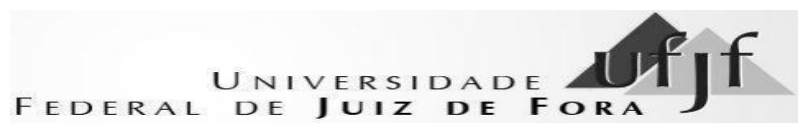

Gostaríamos de convidar você a participar como voluntário (a) da pesquisa "educação permanente para médicos da estratégia de saúde da família de um município polo de Minas Gerais". O motivo que nos leva a realizar esta pesquisa deve-se a necessidade de implantar no município, projeto de educação permanente para os médicos da estratégia de saúde da família. Acredita-se que seja uma ação importante para organizar e qualificar o trabalho médico nas equipes, tendo como finalidade a melhoria da qualidade da assistência prestada aos usuários.

Nesta pesquisa pretendemos analisar as necessidades de educação permanente em saúde dos médicos da estratégia de saúde da família no município. Caso você concorde em participar, vamos fazer a seguinte atividade com você: aplicaremos questionário composto de questões fechadas e abertas para caracterizar o perfil dos participantes e a identificação das necessidades de educação permanente.

Esta pesquisa tem alguns riscos que são considerados mínimos, como sentir cansaço, aborrecimento ou desconforto durante o preenchimento dos dados. Mas, para diminuir a chance desses riscos acontecerem, a pesquisadora estará atenta para que estas situações não ocorram, aplicando perguntas objetivas, não extensas e sendo respondido em ambiente reservado para que haja conforto. A pesquisa poderá ajudar a traçar diretrizes para um processo de educação permanente para médicos das equipes da estratégia de saúde da família do município.

Para participar deste estudo você não vai ter nenhum custo, nem receberá qualquer vantagem financeira. Apesar disso, se você tiver algum dano por causadas atividades que fizermos com você nesta pesquisa, você tem direito a indenização. Você terá todas as informações que quiser sobre esta pesquisa e estará livre para participar ou recusar-se a participar. Mesmo que você queira participar agora, você pode voltar atrás ou parar de participar a qualquer momento. A sua participação é voluntária e o fato de não querer participar não vai trazer qualquer penalidade ou mudança na forma em que você é atendido (a). O pesquisador não vai divulgar seu nome. Os resultados da pesquisa estarão à sua disposição quando finalizada. Seu nome ou o material que indique sua participação não será liberado sem a sua permissão. Você não será identificado (a) em nenhuma publicação que possa resultar.

Este termo de consentimento encontra-se impresso em duas vias originais, sendo que uma será arquivada pelo pesquisador responsável e a outra será fornecida a você. Os dados coletados na pesquisa ficarão arquivados com o pesquisador responsável por um período de 5 (cinco) anos. Decorrido este tempo, o pesquisador avaliará os documentos para a sua destinação final, de acordo com a legislação vigente. Os pesquisadores tratarão a sua identidade com padrões profissionais de sigilo, atendendo a legislação brasileira (Resolução No 466/12 do Conselho Nacional de Saúde), utilizando as informações somente para os fins acadêmicos e científicos.

Declaro que concordo em participar da pesquisa e que me foi dada à oportunidade de ler e esclarecer as minhas dúvidas.

Governador Valadares, de de 2020.

Assinatura do Participante

Assinatura do (a) Pesquisador (a)

Ana Paula Vilas Boas Wheberth

Campus Univ.da UFJF/Faculdade de Medicina/Dep.de Saúde Coletiva/NATES - CEP: 36036-900

E-mail:dravilasboas@hotmail.com- Fone:(33)99916-5847 


\section{APÊNDICE B - TERMO DE CONSENTIMENTO LIVRE E ESCLARECIDO}

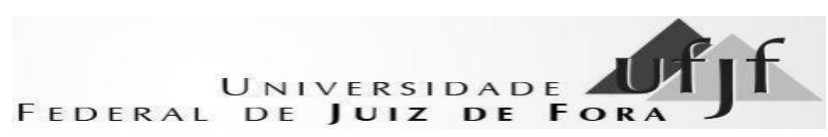

Gostaríamos de convidar você a participar como voluntário (a) da pesquisa "educação permanente para médicos da estratégia de saúde da família de um município polo de Minas Gerais". O motivo que nos leva a realizar esta pesquisa deve-se a necessidade de implantar no município, projeto de educação permanente para os médicos da estratégia de saúde da família. Acredita-se que seja uma ação importante para organizar e qualificar o trabalho médico nas equipes, tendo como finalidade a melhoria da qualidade da assistência prestada aos usuários.

Nesta pesquisa pretendemos analisar as necessidades de educação permanente em saúde dos médicos da estratégia de saúde da família, no município. Caso você concorde em participar, vamos fazer a seguinte atividade com você: será realizada entrevista com base em um roteiro semiestruturado, e a mesma será gravada.

Esta pesquisa tem alguns riscos, que são considerados mínimos, como sentir cansaço, aborrecimento ou desconforto durante gravações de áudio e preenchimento de dados. Mas, para diminuir a chance desses riscos acontecerem, a pesquisadora estará atenta para que estas situações não ocorram interrompendo a entrevista e solicitando que o participante descanse, aplicando perguntas objetivas, não extensas e sendo respondido em ambiente reservado para que haja conforto. O participante também poderá desistir da pesquisa caso esteja incomodado com a mesma. A pesquisa poderá ajudar traçar diretrizes para um processo de educação permanente para médicos das equipes da estratégia de saúde da família do município.

Para participar deste estudo você não vai ter nenhum custo, nem receberá qualquer vantagem financeira. Apesar disso, se você tiver algum dano por causa das atividades que fizermos com você nesta pesquisa, você tem direito a indenização. Você terá todas as informações que quiser sobre esta pesquisa e estará livre para participar ou recusar-se a participar. Mesmo que você queira participar agora, você pode voltar atrás ou parar de participar a qualquer momento. A sua participação é voluntária e o fato de não querer participar não vai trazer qualquer penalidade ou mudança na forma em que você é atendido (a). O pesquisador não vai divulgar seu nome. Os resultados da pesquisa estarão à sua disposição quando finalizada. Seu nome ou o material que indique sua participação não será liberado sem a sua permissão. Você não será identificado (a) em nenhuma publicação que possa resultar.

Este termo de consentimento encontra-se impresso em duas vias originais, sendo que uma será arquivada pelo pesquisador responsável e a outra será fornecida a você. Os dados coletados na pesquisa ficarão arquivados com o pesquisador responsável por um período de 5 (cinco) anos. Decorrido este tempo, o pesquisador avaliará os documentos para a sua destinação final, de acordo com a legislação vigente. Os pesquisadores tratarão a sua identidade com padrões profissionais de sigilo, atendendo a legislação brasileira (Resolução No 466/12 do Conselho Nacional de Saúde), utilizando as informações somente para os fins acadêmicos e científicos.

Declaro que concordo em participar da pesquisa e que me foi dada à oportunidade de ler e esclarecer as minhas dúvidas.

Governador Valadares, de de 2020.

Assinatura do Participante

Assinatura do (a) Pesquisador (a)

Ana Paula Vilas Boas Wheberth

Campus Universitário da UFJF

Faculdade de Medicina/Departamento de Saúde Coletiva/NATES - CEP: 36036-900 Fone:(33)99916-5847E mail:dravilasboas@hotmail.com 


\section{APÊNDICE C - QUESTIONÁRIO}

\section{UNIVERSIDADE FEDERAL DE JUIZ DE FORA \\ FACULDADE DE MEDICINA \\ PROGRAMA DE PÓS GRADUAÇÃO - MESTRADO EM SAÚDE DA FAMÍLIA}

Pesquisadora Responsável: Ana Paula Vilas Boas Wheberth

Orientadora: Prof. ${ }^{a}$ Dr. ${ }^{a}$ Beatriz Francisco Farah

Título da pesquisa: "Educação permanente para médicos da Estratégia de Saúde da Família de um município polo de Minas Gerais".

\section{QUESTIONÁRIO}

\section{Parte I - IDENTIFICAÇÃO DO SUJEITO}

\section{A. Dados gerais}

Nome:

CÓDIGO:

UBS:

Sexo: () Fem. ( ) Masc. Idade: ___ Ano de formação:

Formação profissional:

( ) somente graduação 


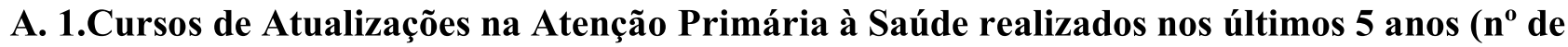
cursos):

Você recebeu capacitação para atuar na ESF? ( ) Sim （ ) Não

Você participa de atividades de educação permanente? ( ) Sim （ ) Não

Que modalidade de educação permanente participa?

( ) promovidas pela coordenação da ESF ( ) educação à distância （ ) na equipe （ ) Outras:

A. 2. Qual a ferramenta que utiliza para sua atualização:

( ) Livro ( ) Artigos científicos ( ) Congressos ( ) Seminários ( ) Cursos presenciais

( ) Educação à distância - EAD ( ) Internet （ ) Web palestras ( ) Telessaúde

B. Trabalho Profissional

Tempo de atuação na APS:

Tempo de serviço nesta UBS:

Tempo de serviço na ESF:

Carga Horária de trabalho nesta UBS: ( ) 20h $\quad$ ( ) 30h $\quad$ ( ) 40h

Modalidade contratual: ( ) Estatutário ( ) CLT ( ) Terceirizado ( ) RPA ( ) Bolsista Mais

Médicos ( ) Médicos pelo Brasil

( ) Outros:

B. 1. Marque em ordem crescente ( 1 a 5$)$ as atividades que mais você realiza cotidianamente:

( ) Assistenciais ( ) Administrativas e gerenciais ( ) Educativas

( ) Pesquisa ( ) Controle Social 
Você recebe algum incentivo no exercício de seu vínculo com a Prefeitura? Marque quais.

( ) Função gratificada ( ) Incentivo Produtividade ( ) Incentivo ESF ( ) Plano de Carreiras Cargos Salários ( ) Insalubridade ( ) Outros. Quais:

\section{Trabalho na ESF \\ C. 1. Que atributos da Atenção Primária à Saúde são desenvolvidos na sua UBS? \\ ( ) Primeiro contato ( ) equidade ( ) longitudinalidade ( ) universalidade \\ ( ) encaminhamento ( ) coordenação do cuidado ( ) competência cultural \\ ( ) abordagem comunitária ( ) conselho local ( ) integralidade}

C.2. Quais os princípios da Estratégia da Saúde da Família que são desenvolvidos na sua UBS?

( ) caráter substitutivo ( ) territorização ( ) planejamento e programação

( )intersetorialidade ( ) espaço de construção da cidadania

\section{3. Quais ações você realiza no cotidiano de seu trabalho?}

( ) consulta individuais ( ) grupos educativos ( ) preventivo ca colo uterino e de mama

( ) pré-natal ( ) puericultura ( ) reuniões com local ( ) consultas compartilhadas

( ) atendimento aos diabéticos e hipertensos ( ) Matriciamento com NASF ( ) reunião com a equipe ( ) salas de espera ( ) atividades em escolas ( ) reunião com a comunidade

( ) Visita domiciliares ( ) cadastramento ( ) mapa da área de abrangência ( ) planejamento das ações da equipe

( ) diagnóstico de saúde local ( ) ferramentas de abordagem familiar como genograma, ecomapa, etc ( ) Notificação compulsória de agravos e doenças ( ) Busca ativa 
C. 4. Você está satisfeito com seu trabalho na ESF?

( ) $\operatorname{Sim}$ ( ) Não

Justifique sua resposta informando os motivos:

C. 5. Você é reconhecido pela gestão pelo seu trabalho desenvolvido na ESF?

( ) $\operatorname{Sim}$ ( ) Não

Justifique sua resposta informando os motivos:

C. 6. Você se sente valorizado pelo seu trabalho desenvolvido na ESF?

( ) Sim ( ) Não

Justifique sua resposta informando os motivos: 


\section{Educação Profissional}

D.1Quais atividades para o aprimoramento do processo de trabalho na ESF você costuma participar?

( ) reuniões

( ) cursos

( ) capacitações

( ) palestras

( ) treinamentos ou oficinas

( ) especialização

\section{D.2Quais são os temas que você necessita revisar ou se aprimorar para atuar na ESF?}

- Revisão de temas relativos ao serviço: ( ) organização do serviço ( ) registro prontuário eletrônico ( ) trabalho em equipe e com outros prestadores ( ) gestão do serviço ( ) sistemas de informação

( ) Outros, cite:

- Revisão do processo de prestação do cuidado: ( ) performance clínica (exame clínico, encaminhamento, prescrições, tomada de decisão médica)

( ) performance interpessoal (comunicação, trabalho em equipe, educação de pacientes, visita domiciliar, grupos operativos)

( ) performance gerencial (flexibilidade, tomada de decisão, liderança, continuidade) ( ) Saúde da Mulher ( ) Saúde do Homem ( ) Saúde da Criança ( ) Saúde do Idoso ( ) Saúde do Adolescente ( ) Saúde do Adolescente ( ) Abordagem individual ( ) Abordagem familiar

( ) Outros, cite: 


\section{APÊNDICE D - ENTREVISTA}

UNIVERSIDADE FEDERAL DE JUIZ DE FORA

FACULDADE DE MEDICINA

PROGRAMA DE PÓS GRADUAÇÃO - MESTRADO EM SAÚDE DA FAMÍLIA

Pesquisadora Responsável: Ana Paula Vilas Boas Wheberth

Orientadora: Prof. ${ }^{a}$ Dr. ${ }^{a}$ Beatriz Francisco Farah

Título da pesquisa: "Educação permanente para médicos da Estratégia de Saúde da Família de um município polo de Minas Gerais".

\section{ENTREVISTA}

\section{ROTEIRO DE ENTREVISTA SEMIESTRUTURADA}

\section{Parte II - PERGUNTAS}

1. Em sua opinião quais são as competências e habilidades necessárias ao médico integrante da equipe de Saúde da Família?

2. Quais as potencialidades e desafios para realizar o modelo assistencial de saúde preconizado pela ESF no cotidiano do seu trabalho?

3. Fale-me sobre seu entendimento do que é educação permanente?

4. Qual a sua opinião sobre a importância ou não da educação permanente na sua vida profissional na ESF? 


\section{ANEXO A - DADOS DO PROJETO DE PESQUISA}

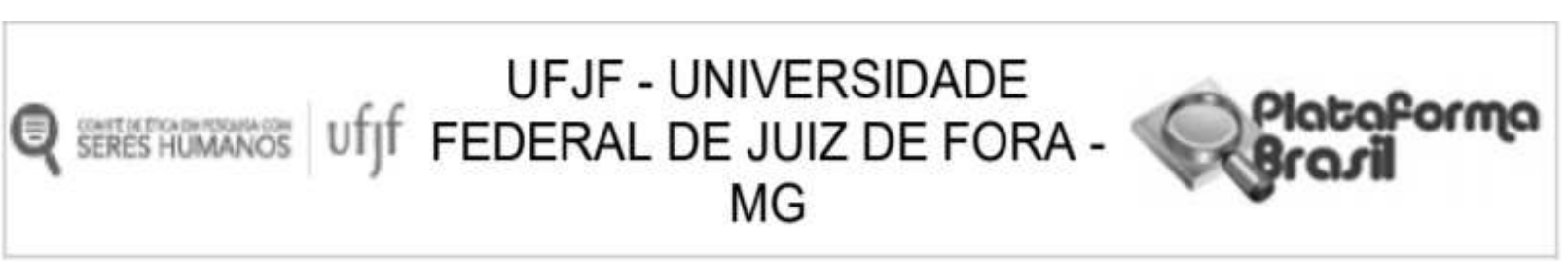

Título da Pesquisa: EDUCAÇÃO PERMANENTE PARA MÉDICOS DE UM MUNICÍPIO POLO - MG

Pesquisador: ANA PAULA VILAS BOAS WHEBERTH

Área Temática:

Versão: 2

CAAE: 27682920.5 .0000 .5147

Instituição Proponente: NATES - NÚCLEO DE ASSESSORIA, TREINAMENTO E ESTUDOS EM SAÚDE

Patrocinador Principal: Financiamento Próprio

\section{DADOS DO PARECER}

Número do Parecer: 3.824 .788

\section{Apresentação do Projeto:}

As informações elencadas nos campos "Apresentação do Projeto", "Objetivo da Pesquisa" e "Avaliação dos Riscos e Benefícios" foram retiradas do arquivo Informações Básicas da Pesquisa. Pesquisa qualitativa, descritiva e exploratória. Os dados serão colhidos em duas etapas: será aplicado questionário com questões fechadas e abertas aos médicos da Estratégia de Saúde da Família de Governador Valadares-MG (61 médicos), e se realizará entrevista semiestruturada com os médicos da ESF. A análise dos dados será por meio da análise de conteúdo, do tipo temática, utilizando-se de software Iramuteq para auxiliar na análise. Apresentação do projeto está clara, detalhada de forma objetiva, descreve as bases científicas que justificam o estudo, estando de acordo com as atribuições definidas na Resolução CNS 466/12 de 2012, item III.

\section{Objetivo da Pesquisa:}

Objetivo Primário:

Analisar as necessidades de educação permanente em saúde dos médicos da Estratégia de Saúde da Família de um município polo de Minas Gerais.

Objetivo Secundário:

1. Conhecer a percepção dos médicos das equipes de Saúde da Família sobre educação permanente em saúde; 
2. Compreender a percepção dos médicos das equipes de Saúde da Família sobre a importância do desenvolvimento da educação permanente;

3. Identificar quais são as necessidades de educação permanente dos médicos que atuam nas equipes de Saúde da Família e município polo de Minas Gerais;

4. Descrever qual é o modelo assistencial de saúde que os médicos das equipes de Saúde da Família desejam viabilizar com a educação permanente de saúde;

5. Traçar diretrizes para um processo de educação permanente para médicos das equipes da Estratégia de Saúde da Família de um município de Minas Gerais. Os Objetivos da pesquisa estão claros bem delineados, apresenta clareza e compatibilidade com a proposta, tendo adequação da metodologia aos objetivos pretendido, de acordo com as atribuições definidas na Norma Operacional CNS 001 de 2013, item 3.4.1 -4.

\section{Avaliação dos Riscos e Benefícios:}

Esta pesquisa tem alguns riscos, que são considerados mínimos, como sentir cansaço, aborrecimento ou desconforto durante gravações de áudio, questionário e preenchimento de dados. Mas, para diminuir a chance desses riscos acontecerem, a pesquisadora estará atenta para que estas situações não ocorram interrompendo a entrevista e solicitando que o participante descanse, aplicando perguntas objetivas, não extensas e sendo respondido em ambiente reservado para que haja conforto. O participante também poderá desistir da pesquisa caso esteja incomodado com a mesma. A pesquisa poderá ajudar traçar diretrizes para um processo de educação permanente para médicos das equipes da estratégia de saúde da família de Governador Valadares. Riscos e benefícios descritos em conformidade com a natureza e propósitos da pesquisa. O risco que o projeto apresenta é caracterizado como risco mínimo e benefícios esperados estão adequadamente descritos. A avaliação dos Riscos e Benefícios está de acordo com as atribuições definidas na Resolução CNS 466/12 de 2012, itens III; III.2 e V.

\section{Comentários e Considerações sobre a Pesquisa:}

O projeto está bem estruturado, delineado e fundamentado, sustenta os objetivos do estudo em sua metodologia de forma clara e objetiva, e se apresenta em consonância com os princípios éticos norteadores da ética na pesquisa científica envolvendo seres humanos elencados na resolução 466/12 do CNS e com a Norma Operacional No 001/2013 CNS.

\section{Considerações sobre os Termos de apresentação obrigatória:}

O protocolo de pesquisa está em configuração adequada, apresenta FOLHA DE ROSTO

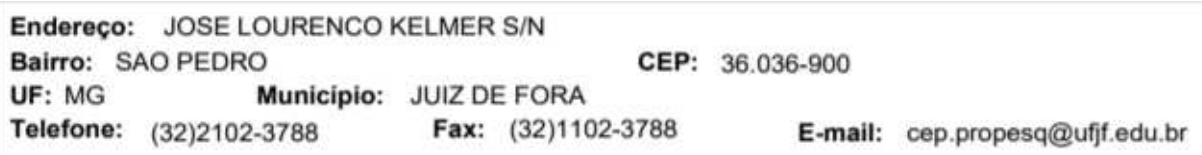

devidamente preenchida, com o título em português, identifica o patrocinador pela pesquisa, estando de acordo com as atribuições definidas na Norma Operacional CNS 001 de 2013 item

3.3letra a; e 3.4.1 item 16. Apresenta o TERMO DE CONSENTIMENTO LIVRE ESCLARECIDO em linguagem clara para compreensão dos participantes, apresenta justificativa e objetivo, campo para identificação do participante, descreve de forma suficiente os procedimentos, informa que uma das vias do TCLE será entregue aos participantes, assegura a liberdade do participante recusar ou retirar o consentimento sem penalidades, garante sigilo e anonimato, explicita riscos e desconfortos esperados, indenização diante de eventuais danos decorrentes da pesquisa, contato do pesquisador e do CEP e informa que os dados da pesquisa 
ficarão arquivados com o pesquisador pelo período de cinco anos, de acordo com as atribuições definidas na Resolução CNS 466 de 2012, itens: IV letra b; IV.3 letras a, b, d, e, f, g e h; IV. 5 letra de XI.2 letra

f. Apresenta o INSTRUMENTO DE COLETA DE DADOS de forma pertinente aos objetivos delineados e preserva os participantes da pesquisa. O Pesquisador apresenta titulação e experiência compatível com o projeto de pesquisa, estando de acordo com as atribuições definidas no Manual Operacional para CPEs. Apresenta DECLARAÇÃO de infraestrutura e de concordância com a realização da pesquisa de acordo com as atribuições definidas na Norma Operacional CNS 001 de 2013 item 3.3 letra h.

\section{Conclusões ou Pendências e Lista de Inadequações:}

Diante do exposto, o projeto está aprovado, pois está de acordo com os princípios éticos norteadores da ética em pesquisa estabelecido na Res. 466/12 CNS e com a Norma Operacional No 001/2013 CNS. Data prevista para o término da pesquisa: abril de 2021.

\section{Considerações Finais a critério do CEP:}

Diante do exposto, o Comitê de Ética em Pesquisa CEP/UFJF, de acordo com as atribuições definidas na Res. CNS 466/12 e com a Norma Operacional No001/2013 CNS, manifesta-se pela APROVAÇÃO do protocolo de pesquisa proposto. Vale lembrar ao pesquisador responsável pelo projeto, o compromisso de envio ao CEP de relatórios parciais e/ou total de sua pesquisa informando o andamento da mesma, comunicando também eventos adversos e eventuais modificações no protocolo.

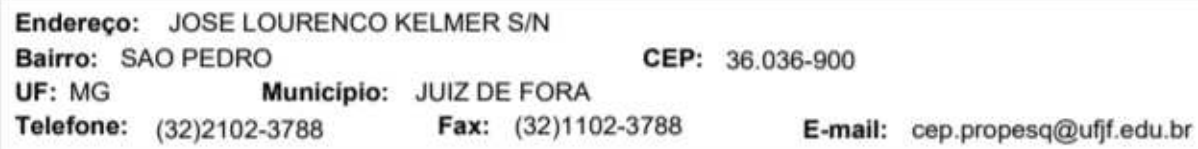

\begin{tabular}{|c|c|c|c|c|}
\hline Tipo Documento & & Postagem & $\begin{array}{l}\mathrm{A} \\
\mathrm{u} \\
\mathrm{t} \\
\mathrm{o} \\
\mathrm{r}\end{array}$ & Situação \\
\hline $\begin{array}{l}\text { Informações Básicas } \\
\text { do Projeto }\end{array}$ & $\begin{array}{l}\text { PB_INFORM } \\
\text { AÇÕES_BÁ } \\
\text { SICAS_DO_ } \\
\text { P } \\
\text { ROJETO_14 } \\
\text { 95202.pdf }\end{array}$ & $\begin{array}{c}05 / 02 / 2020 \\
20: 51: 10\end{array}$ & & Aceito \\
\hline Outros & ent.docx & $\begin{array}{c}05 / 02 / 2020 \\
20: 41: 07\end{array}$ & $\begin{array}{l}\text { ANA PAULA } \\
\text { VILAS } \\
\text { BOAS } \\
\text { WHEBERTH }\end{array}$ & Aceito \\
\hline
\end{tabular}




\begin{tabular}{|c|c|c|c|c|}
\hline Outros & que.docx & $\begin{array}{c}05 / 02 / 2020 \\
20: 39: 11\end{array}$ & $\begin{array}{l}\text { ANA PAULA } \\
\text { VILAS } \\
\text { BOAS } \\
\text { WHEBERTH }\end{array}$ & Aceito \\
\hline $\begin{array}{l}\text { Projeto Detalhado / } \\
\text { Brochura Investigador }\end{array}$ & pro.docx & $\begin{array}{c}05 / 02 / 2020 \\
20: 38: 54\end{array}$ & $\begin{array}{l}\text { ANA } \\
\text { PAULA } \\
\text { VILAS } \\
\text { BOAS } \\
\text { WHEBERT } \\
\text { H }\end{array}$ & Aceito \\
\hline $\begin{array}{l}\text { TCLE / Termos de } \\
\text { Assentimento } \\
\text { Justificativa de Ausência }\end{array}$ & TCLE.docx & $\begin{array}{c}05 / 02 / 2020 \\
20: 37: 18\end{array}$ & $\begin{array}{l}\text { ANA PAULA } \\
\text { VILAS } \\
\text { BOAS } \\
\text { WHEBERTH }\end{array}$ & Aceito \\
\hline $\begin{array}{l}\text { Declaração de } \\
\text { Instituição e } \\
\text { Infraestrutura }\end{array}$ & dec.docx & $\begin{array}{c}06 / 01 / 2020 \\
17: 56: 24\end{array}$ & $\begin{array}{l}\text { ANA PAULA } \\
\text { VILAS } \\
\text { BOAS } \\
\text { WHEBERTH }\end{array}$ & Aceito \\
\hline $\begin{array}{l}\text { Declaração de } \\
\text { Instituição e } \\
\text { Infraestrutura }\end{array}$ & dec.pdf & $\begin{array}{c}06 / 01 / 2020 \\
17: 54: 18\end{array}$ & $\begin{array}{l}\text { ANA PAULA } \\
\text { VILAS } \\
\text { BOAS } \\
\text { WHEBERTH }\end{array}$ & Aceito \\
\hline Folha de Rosto & $\begin{array}{l}\text { folha_de_rost } \\
\text { o.pdf }\end{array}$ & $\begin{array}{c}06 / 01 / 2020 \\
17: 46: 29\end{array}$ & $\begin{array}{l}\text { ANA PAULA } \\
\text { VILAS } \\
\text { BOAS } \\
\text { WHEBERTH }\end{array}$ & Aceito \\
\hline
\end{tabular}

Este parecer foi elaborado baseado nos documentos abaixo relacionados:

\section{Situação do Parecer:}

Aprovado

\section{Necessita Apreciação da CONEP:}

Não

JUIZ DE FORA, 06 de fevereiro de 2020. 


\section{ANEXO B - DADOS DO QUESTIONÁRIO DA PESQUISA COMPILADOS NO PROGRAMA EXCEL}

1-Você recebeu capacitação para atuar na ESF?

\begin{tabular}{|c|c|}
\hline Sim & Não \\
\hline 38 & 14 \\
\hline
\end{tabular}

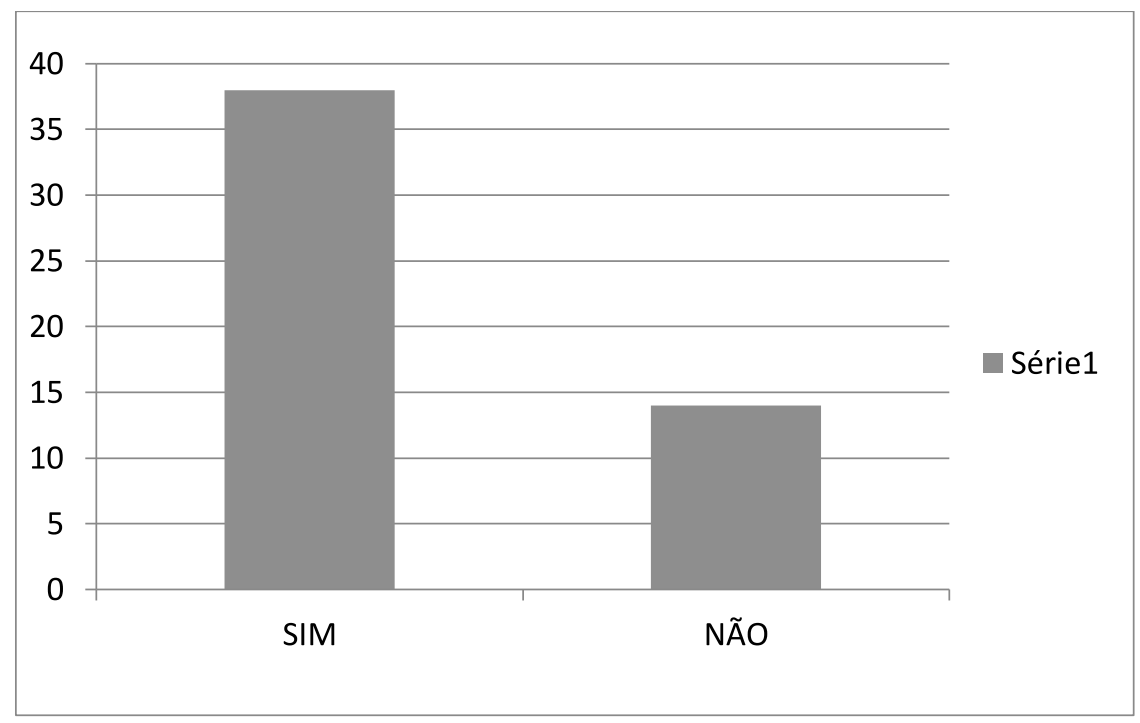

2-Você participa de atividades de educação permanente?

\begin{tabular}{|c|c|}
\hline Sim & Não \\
\hline 51 & 01 \\
\hline
\end{tabular}

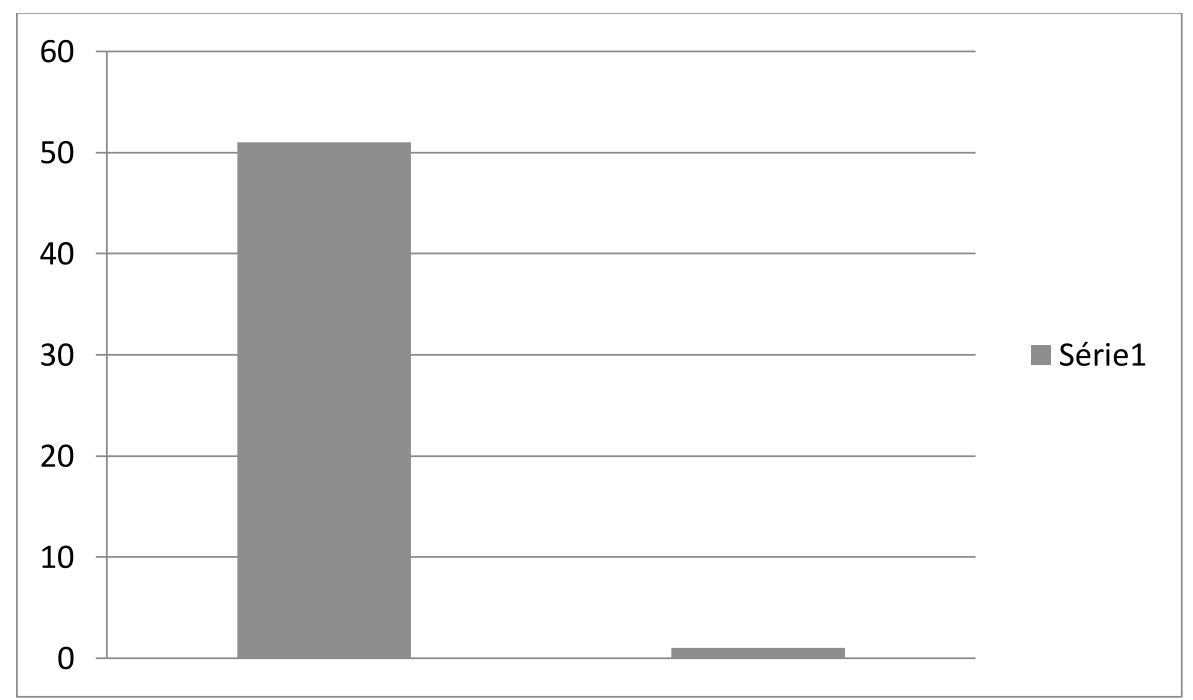


3- Que modalidade de educação permanente participa?

\begin{tabular}{|l|c|}
\hline $\begin{array}{l}\text { Promovidas } \\
\text { pela gestão }\end{array}$ & 41 \\
\hline EaD & 43 \\
\hline Na equipe & 11 \\
\hline outras & 02 \\
\hline
\end{tabular}

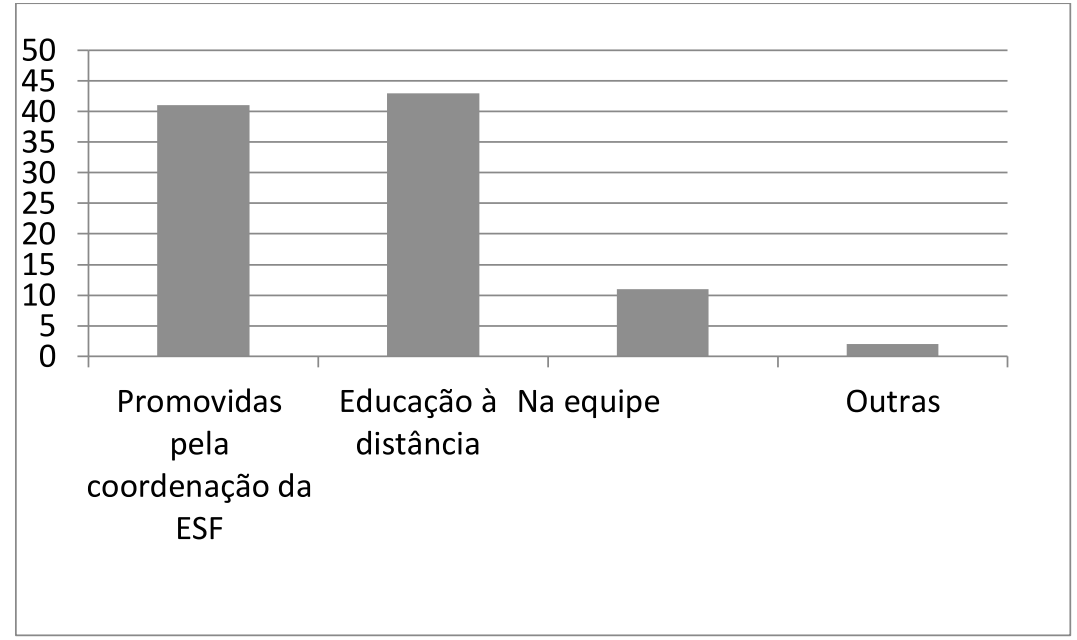

4 - Qual a ferramenta que utiliza para sua atualização?

\begin{tabular}{|l|c|}
\hline Livros & 33 \\
\hline Artigos científicos & 32 \\
\hline Congressos & 17 \\
\hline Seminários & 14 \\
\hline Cursos presenciais & 26 \\
\hline EaD & 39 \\
\hline Internet & 28 \\
\hline Webpalestras & 23 \\
\hline Telessaúde & 17 \\
\hline
\end{tabular}




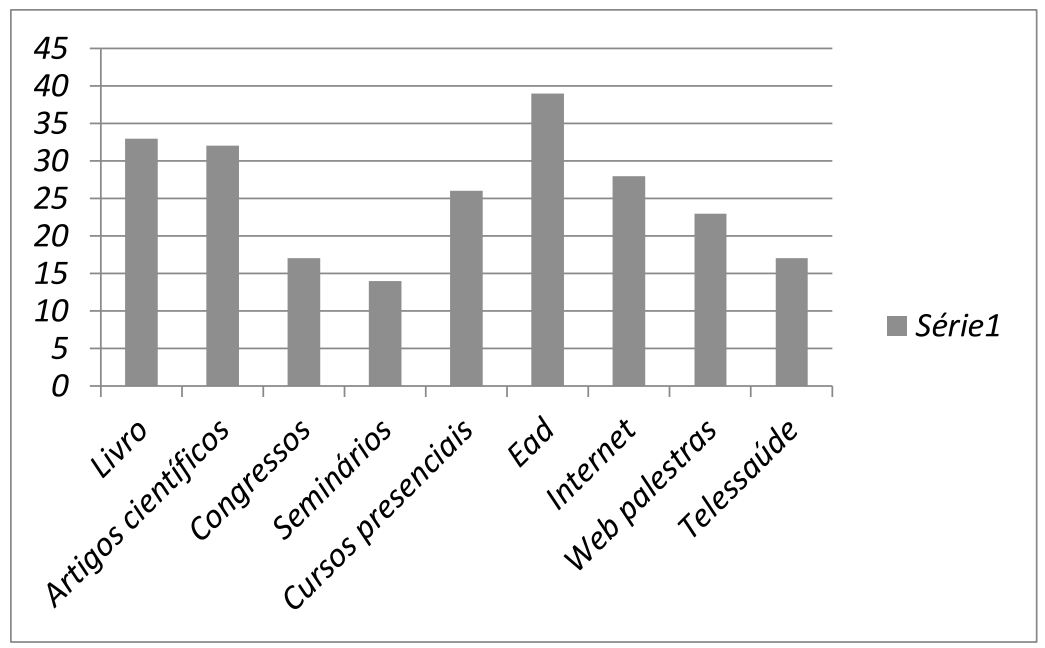

5- Carga horária de trabalho semanal nesta UBS:

\begin{tabular}{|l|c|}
\hline 20h & 03 \\
\hline 30h & 12 \\
\hline 40h & 37 \\
\hline
\end{tabular}

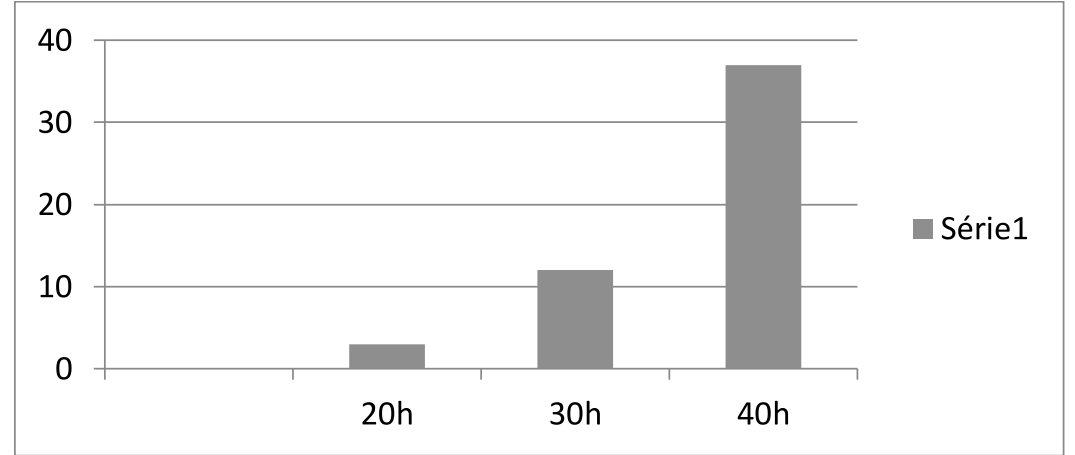

6 - Modalidade contratual

\begin{tabular}{|l|c|}
\hline Estatutário & 01 \\
\hline CLT & 10 \\
\hline Terceirizado & 0 \\
\hline RPA & 0 \\
\hline Bolsista do mais médicos & 30 \\
\hline $\begin{array}{l}\text { Bolsista médicos pelo } \\
\text { Brasil }\end{array}$ & 0 \\
\hline $\begin{array}{l}\text { Bolsista preceptor da } \\
\text { residência de MFC }\end{array}$ & 11 \\
\hline
\end{tabular}




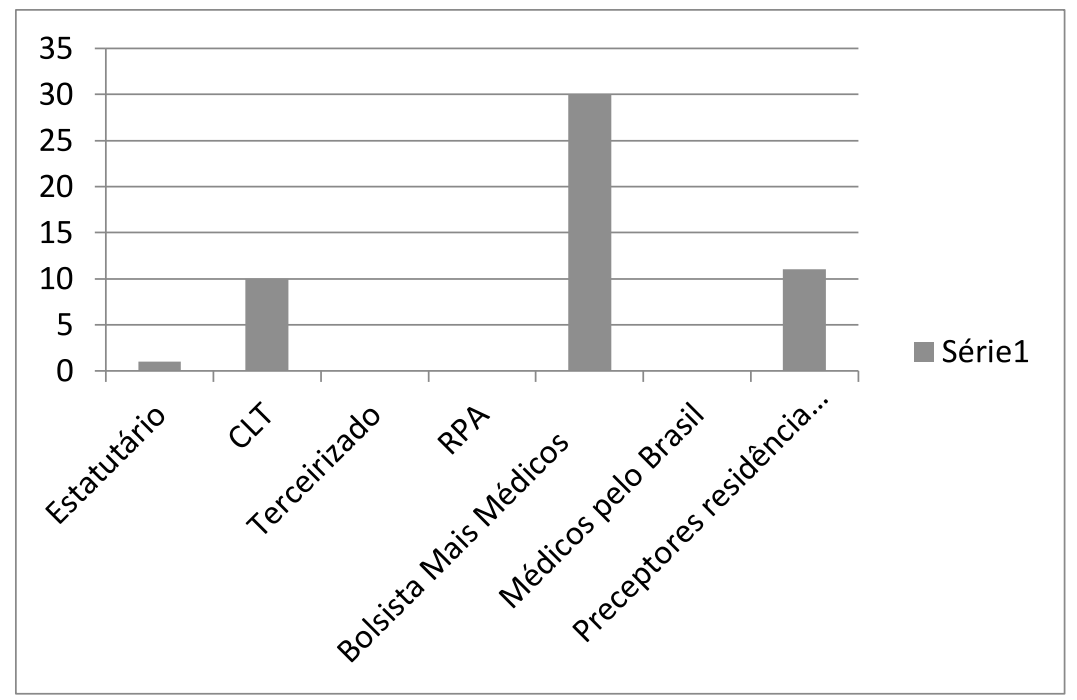

7- Você recebe algum incentivo no exercício de seu vínculo com a Prefeitura?

\begin{tabular}{|l|c|}
\hline Função gratificada & 09 \\
\hline Incentivo produtividade & 0 \\
\hline Incentivo ESF & 07 \\
\hline $\begin{array}{l}\text { Plano de carreira de } \\
\text { cargos e salários }\end{array}$ & 01 \\
\hline Insalubridade & 10 \\
\hline Outros & 34 \\
\hline
\end{tabular}

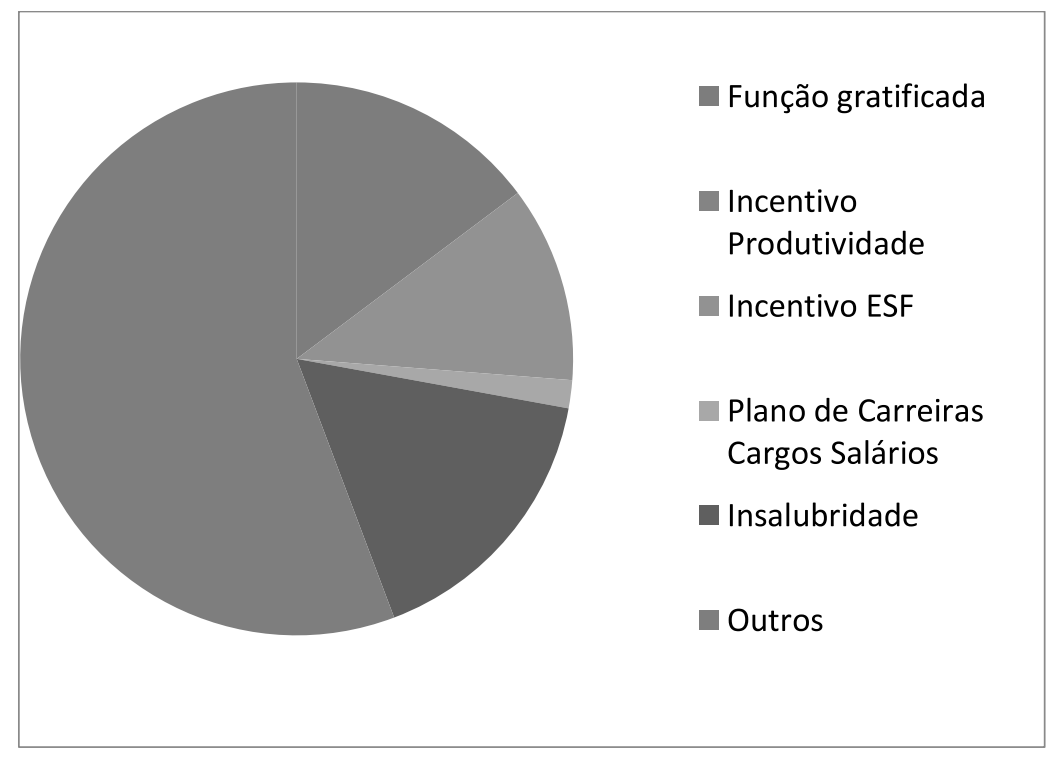


8- Trabalho na ESF

Que atributos da Atenção Primária à Saúde são desenvolvidos na sua UBS?

\begin{tabular}{|l|c|}
\hline Primeiro contato & 44 \\
\hline Equidade & 44 \\
\hline Longitudinalidade & 36 \\
\hline Universalidade & 40 \\
\hline Encaminhamentos & 42 \\
\hline Coordenação do cuidado & 33 \\
\hline Competência cultural & 13 \\
\hline Abordagem comunitária & 32 \\
\hline Conselho local & 32 \\
\hline Integralidade & 34 \\
\hline
\end{tabular}

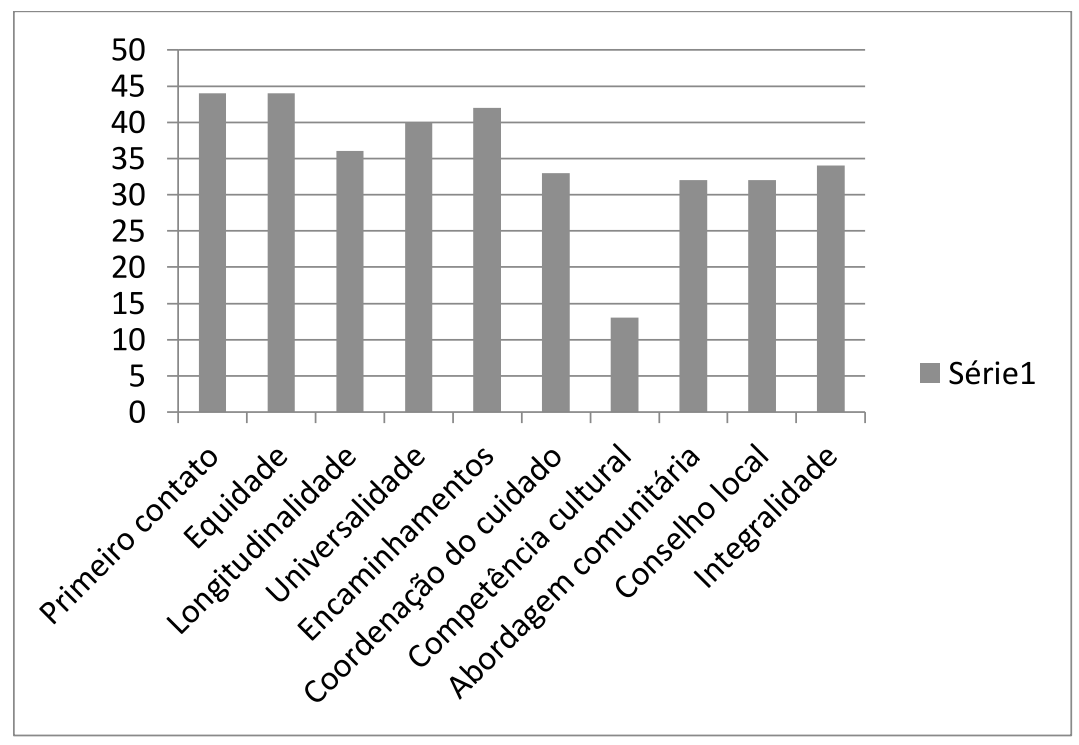

9 - Quais os princípios da Estratégia da Saúde da Família que são desenvolvidos na sua UBS?

\begin{tabular}{|l|c|}
\hline Caráter substitutivo & 04 \\
\hline Territorização & 40 \\
\hline $\begin{array}{l}\text { Planejamento e } \\
\text { programação }\end{array}$ & 41 \\
\hline Intersetorialidade & 27 \\
\hline
\end{tabular}




\begin{tabular}{|l|l|}
\hline $\begin{array}{l}\text { Espaço de construção da } \\
\text { cidadania }\end{array}$ & 22 \\
\hline
\end{tabular}

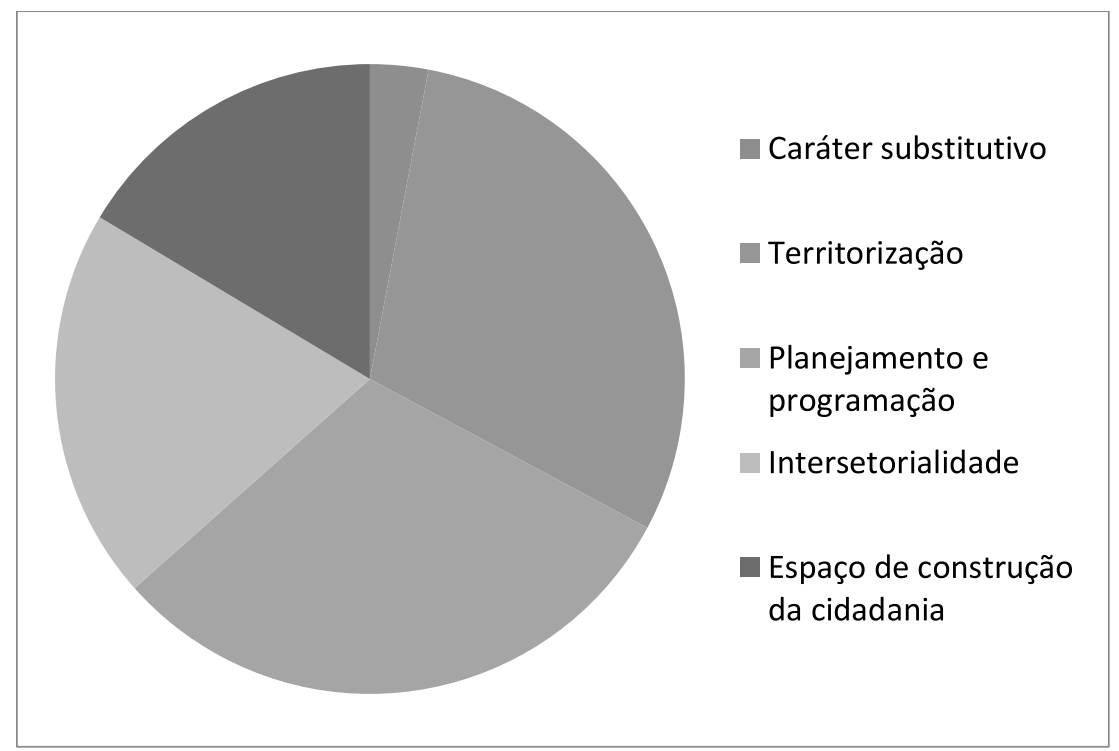

10 - Quais ações você realiza no cotidiano de seu trabalho?

\begin{tabular}{|l|c|}
\hline Consultas individuais & 52 \\
\hline Grupos educativos & 46 \\
\hline $\begin{array}{l}\text { Preventivo câncer colo uterino e } \\
\text { mama }\end{array}$ & 21 \\
\hline Pré-natal & 49 \\
\hline Puericultura & 41 \\
\hline Reuniões conselho local & 35 \\
\hline Consultas compartilhadas & 48 \\
\hline $\begin{array}{l}\text { Atendimento hipertensos e } \\
\text { diabéticos }\end{array}$ & 41 \\
\hline Matriciamento com o NASF & 48 \\
\hline Reuniões de equipe & 45 \\
\hline Salas de espera & 26 \\
\hline Atividades em escolas & 25 \\
\hline Reuniões com a comunidade & 28 \\
\hline Visitas domiciliares & 51 \\
\hline Cadastramento & 15 \\
\hline Mapa da área de abrangência & \\
\hline
\end{tabular}




\begin{tabular}{|l|c|}
\hline Planejamento das ações em equipe & 32 \\
\hline Diagnóstico situacional em saúde & 29 \\
\hline $\begin{array}{l}\text { Ferramentas de abordagem } \\
\text { familiar como ecomapa, } \\
\text { genograma, etc. }\end{array}$ & 14 \\
\hline $\begin{array}{l}\text { Notificação compulsória de } \\
\text { agravos e doenças }\end{array}$ & 41 \\
\hline Busca ativa & 39 \\
\hline
\end{tabular}

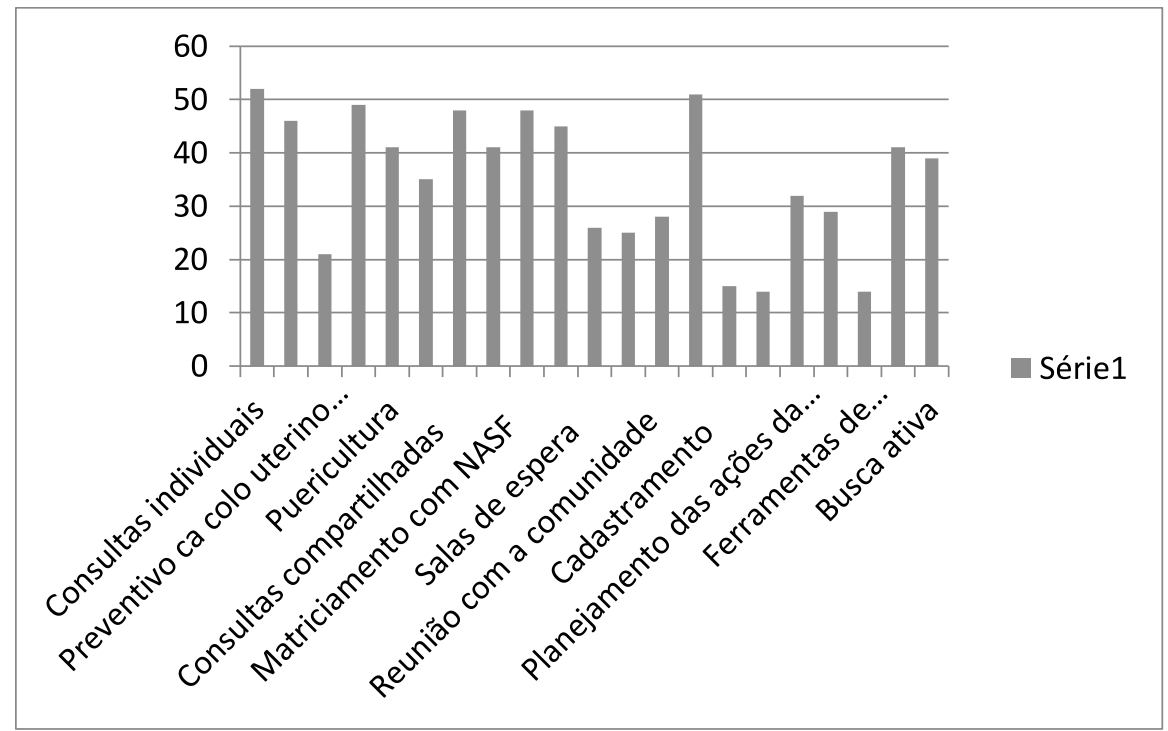

11 - Você está satisfeito com seu trabalho na ESF?

\begin{tabular}{|c|c|}
\hline Sim & Não \\
\hline 47 & 05 \\
\hline
\end{tabular}

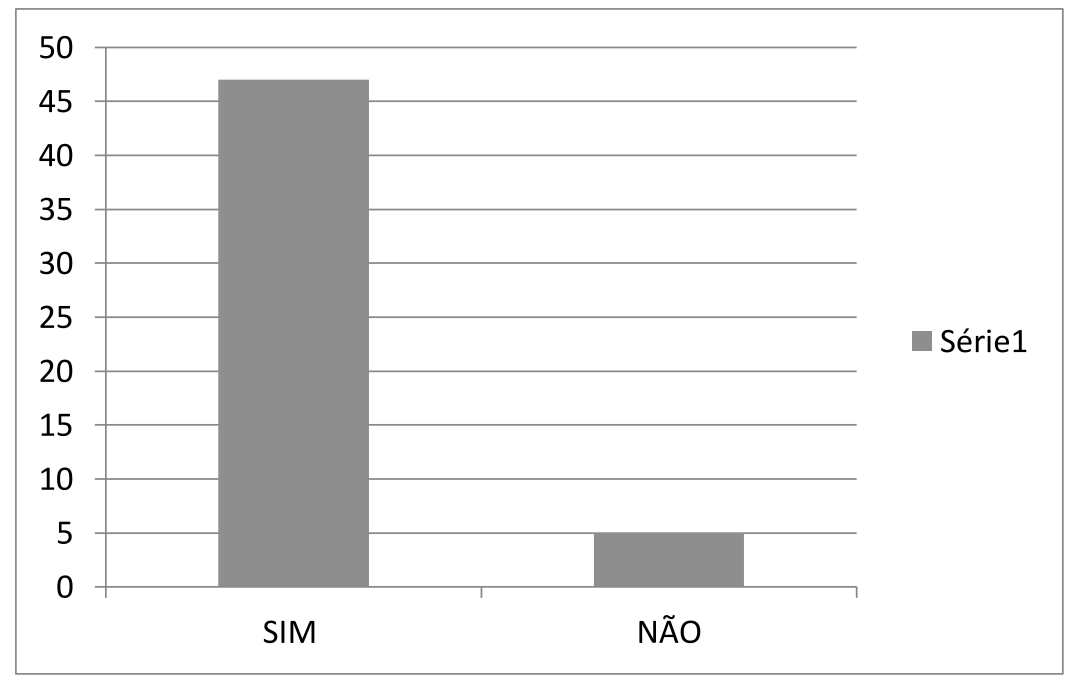


12 - Você é reconhecido pela gestão, pelo seu trabalho desenvolvido na ESF?

\begin{tabular}{|c|c|}
\hline Sim & Não \\
\hline 39 & 13 \\
\hline
\end{tabular}

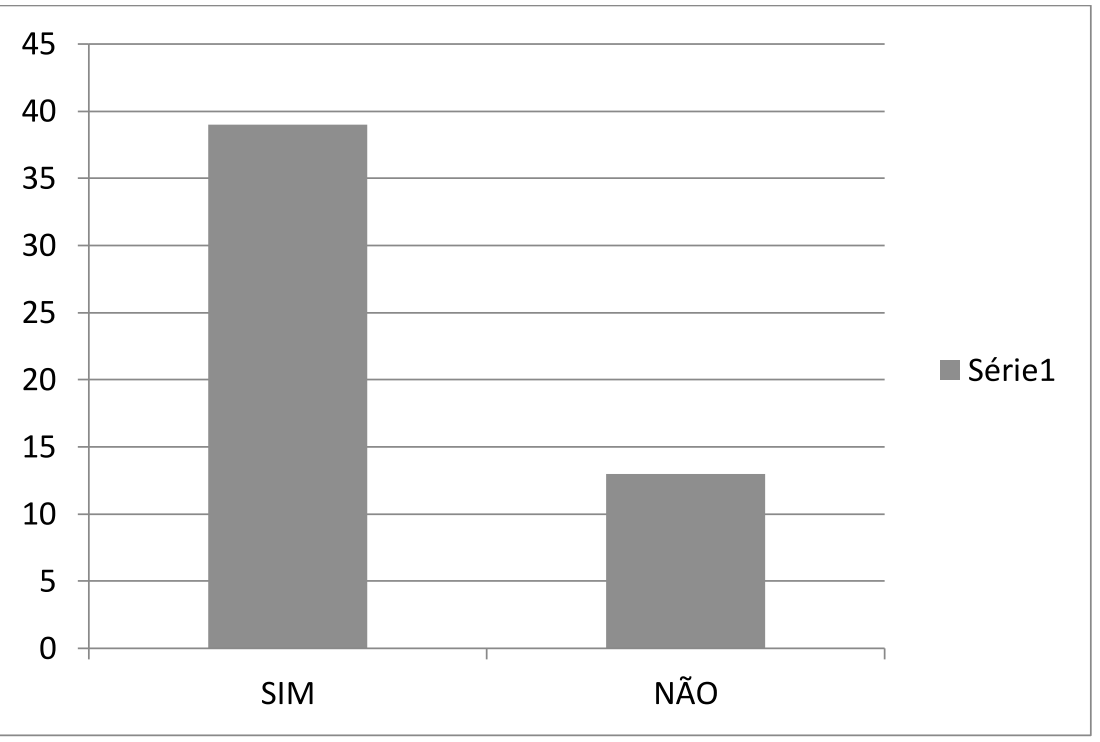

13 - Você se sente valorizado pelo seu trabalho desenvolvido na ESF?

\begin{tabular}{|c|c|}
\hline Sim & Não \\
\hline 42 & 10 \\
\hline
\end{tabular}

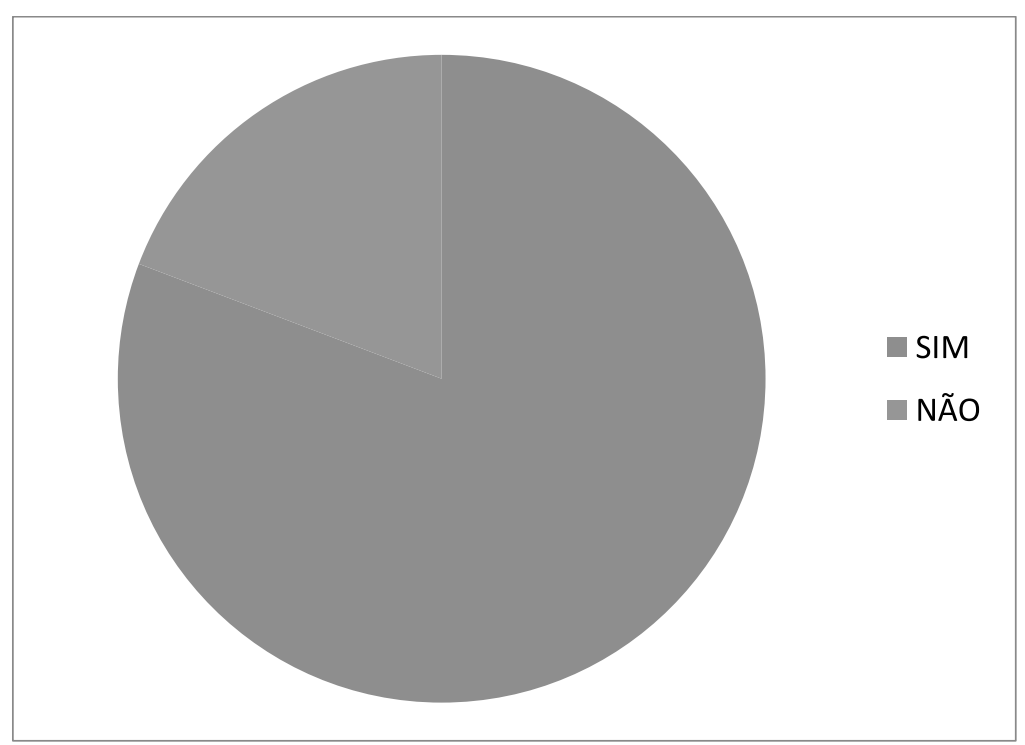


14 - Educação Profissional

14.1 - Quais atividades para o aprimoramento do processo de trabalho na ESF você costuma participar?

\begin{tabular}{|l|c|}
\hline Reuniões & 46 \\
\hline Cursos & 33 \\
\hline Capacitações & 47 \\
\hline Palestras & 38 \\
\hline Treinamentos & 27 \\
\hline Oficinas & 33 \\
\hline
\end{tabular}

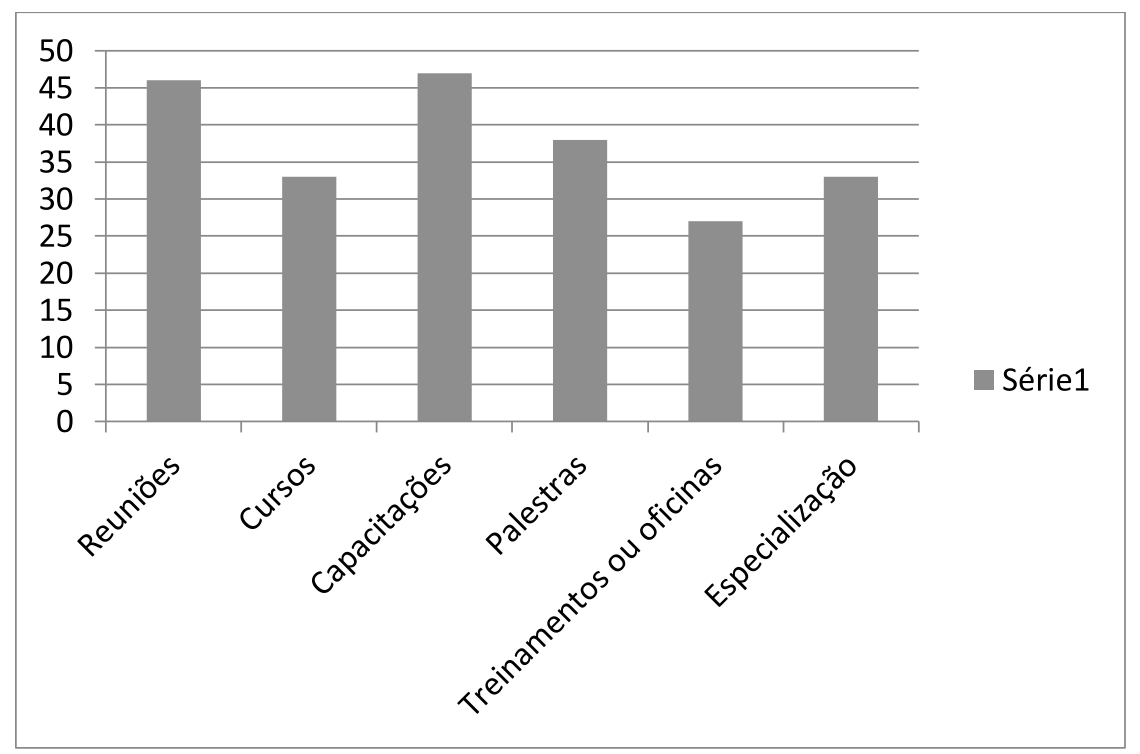

15 - Quais são os temas que você necessita revisar ou se aprimorar para atuar na ESF? Revisão de temas relativos ao serviço

\begin{tabular}{|l|c|}
\hline Organização serviço & 24 \\
\hline $\begin{array}{l}\text { Registro em prontuário } \\
\text { eletrônico }\end{array}$ & 13 \\
\hline $\begin{array}{l}\text { Trabalho em equipe e com } \\
\text { outros prestadores }\end{array}$ & 14 \\
\hline Gestão do serviço & 19 \\
\hline Sistema de informação & 17 \\
\hline Outros & 04 \\
\hline
\end{tabular}




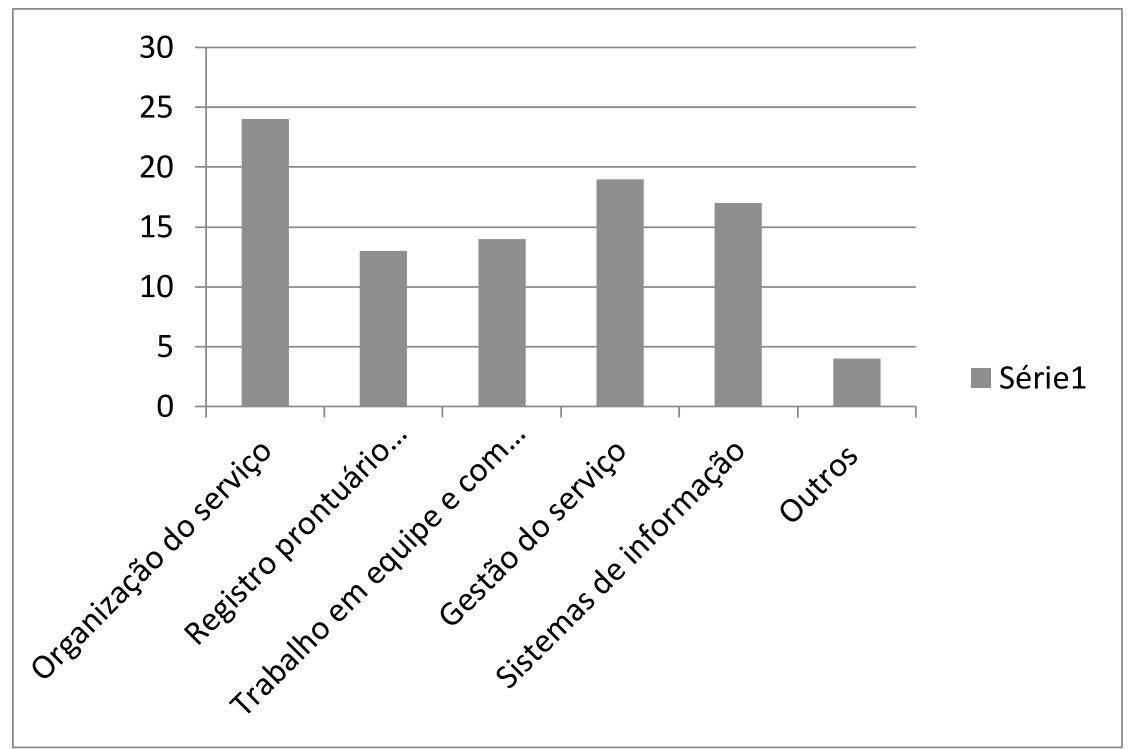

16 - Revisão do processo de prestação do cuidado:

\begin{tabular}{|l|l|}
\hline $\begin{array}{l}\text { Performance clínica (exame clínico, } \\
\text { encaminhamento, prescrições, } \\
\text { tomada de decisão médica) }\end{array}$ & 28 \\
\hline $\begin{array}{l}\text { Performance interpessoal } \\
\text { (comunicação, trabalho em equipe, } \\
\text { educação de pacientes, visita } \\
\text { domiciliar, grupos operativos) }\end{array}$ & 18 \\
\hline $\begin{array}{l}\text { Performance gerencial } \\
\text { (flexibilidade, tomada de decisão, } \\
\text { liderança, continuidade) }\end{array}$ & 19 \\
\hline Saúde da mulher & 16 \\
\hline Saúde do homem & 17 \\
\hline Saúde da criança & 18 \\
\hline Saúde do idoso & 16 \\
\hline Saúde do adolescente & 24 \\
\hline Abordagem individual & 11 \\
\hline Abordagem comunitária & 23 \\
\hline Outros & 02 \\
\hline
\end{tabular}




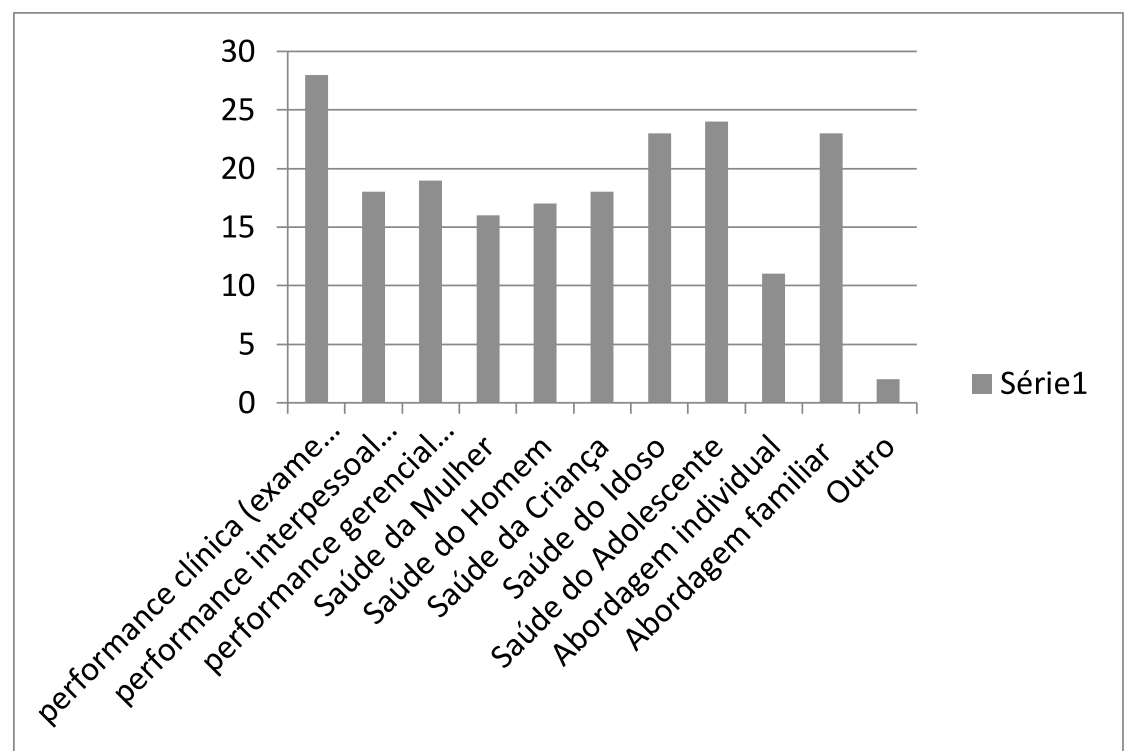

17 - Ano de formatura:

\begin{tabular}{|l|c|}
\hline $\mathbf{1 9 7 2}$ & 01 \\
\hline $\mathbf{1 9 7 4}$ & 01 \\
\hline $\mathbf{1 9 7 6}$ & 01 \\
\hline $\mathbf{1 9 8 7}$ & 01 \\
\hline $\mathbf{1 9 8 9}$ & 01 \\
\hline $\mathbf{1 9 9 6}$ & 01 \\
\hline $\mathbf{2 0 0 3}$ & 04 \\
\hline $\mathbf{2 0 0 7}$ & 01 \\
\hline $\mathbf{2 0 0 8}$ & 02 \\
\hline $\mathbf{2 0 0 9}$ & 01 \\
\hline $\mathbf{2 0 1 0}$ & 02 \\
\hline $\mathbf{2 0 1 1}$ & 03 \\
\hline $\mathbf{2 0 1 2}$ & 02 \\
\hline $\mathbf{2 0 1 3}$ & 02 \\
\hline $\mathbf{2 0 1 4}$ & 03 \\
\hline $\mathbf{2 0 1 5}$ & 03 \\
\hline $\mathbf{2 0 1 6}$ & 13 \\
\hline $\mathbf{2 0 1 7}$ & 02 \\
\hline $\mathbf{2 0 1 8}$ & 05 \\
\hline $\mathbf{2 0 1 9}$ & 03 \\
\hline
\end{tabular}


Título do Gráfico

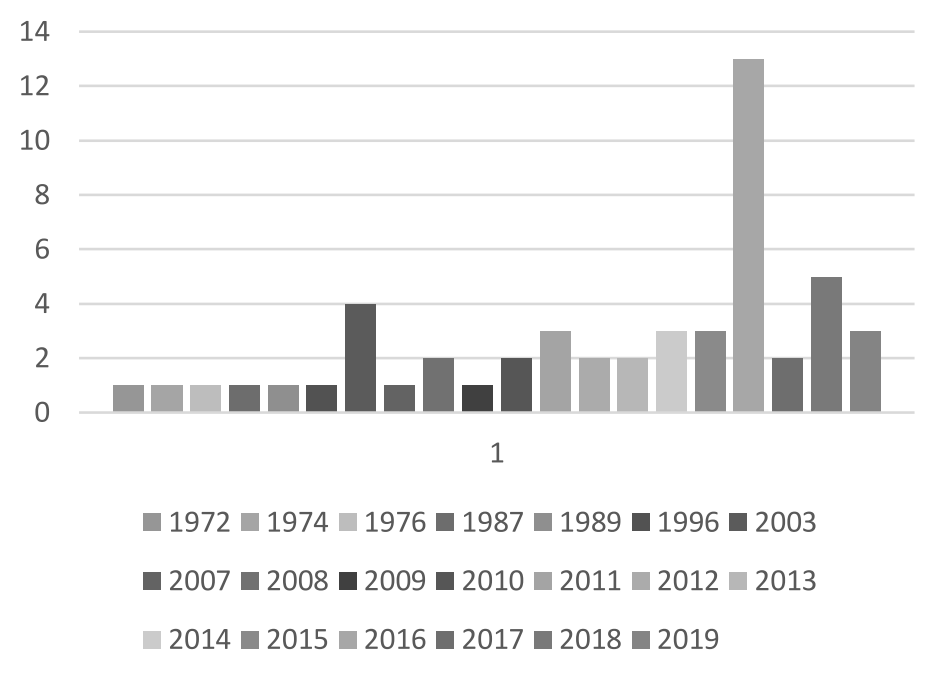

18 - Formação Profissional

\begin{tabular}{|l|l|}
\hline Graduação & 09 \\
\hline Residência & 10 \\
\hline Especialização & 35 \\
\hline Mestrado & 01 \\
\hline Doutorado & 00 \\
\hline
\end{tabular}

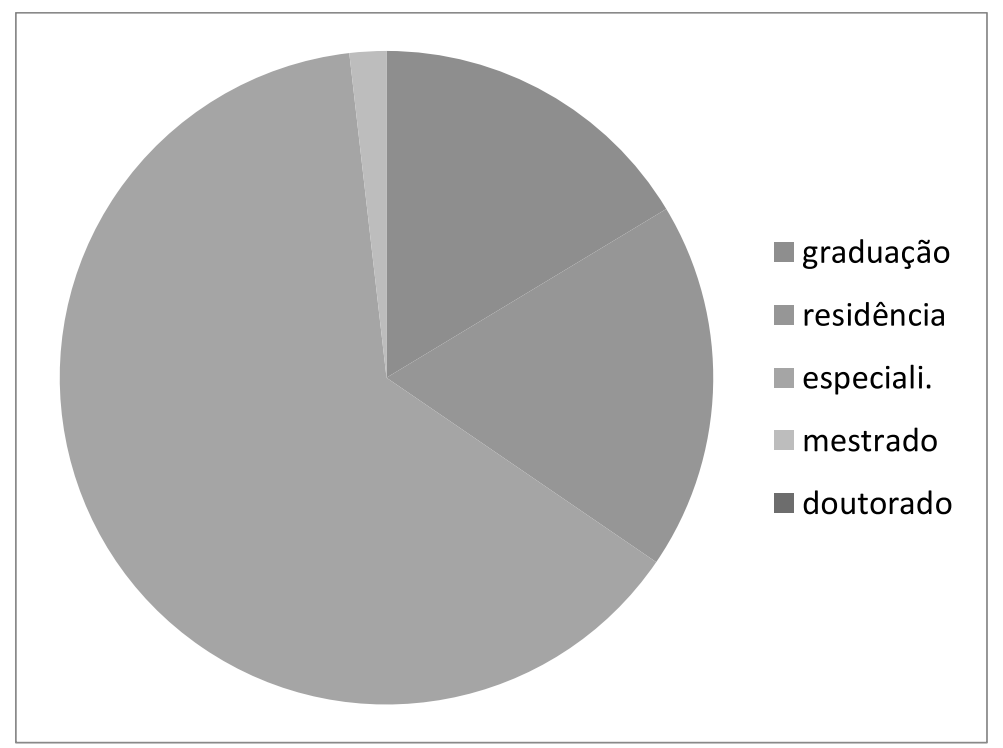


19 - Cursos de atualização na Atenção Primária à Saúde realizados nos últimos 5 anos $\left(n^{\circ}\right.$ de cursos):

\begin{tabular}{|c|c|}
\hline Número & Médicos \\
\hline 0 & 11 \\
\hline 1 & 08 \\
\hline 2 & 06 \\
\hline 3 & 05 \\
\hline 4 & 04 \\
\hline 5 & 07 \\
\hline 6 & 02 \\
\hline 8 & 01 \\
\hline 10 & 04 \\
\hline 11 & 01 \\
\hline 15 & 02 \\
\hline 20 & 01 \\
\hline
\end{tabular}

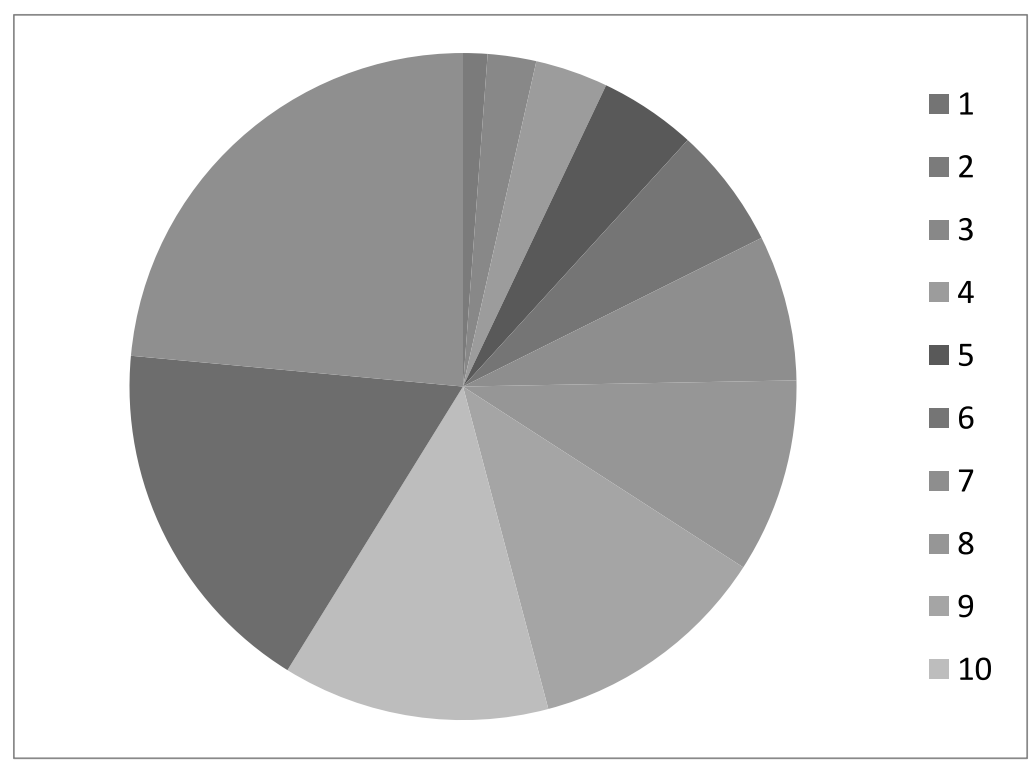


20- Formação profissional

\begin{tabular}{|l|l|}
\hline gestão do cuidado em saúde da família & 02 \\
\hline saúde da família & 14 \\
\hline dermatologia & 05 \\
\hline endoscopia/gastroenterologia & 01 \\
\hline Atenção básica & 02 \\
\hline Urologia & 01 \\
\hline Medicina do trabalho & 01 \\
\hline Pediatria & 01 \\
\hline Psiquiatria & 03 \\
\hline Terapia intensiva & 02 \\
\hline Fisiologia do exercício & 01 \\
\hline Preceptoria em medicina de família & 09 \\
\hline Endocrinologia & 01 \\
\hline Medicina do tráfego & 01 \\
\hline
\end{tabular}

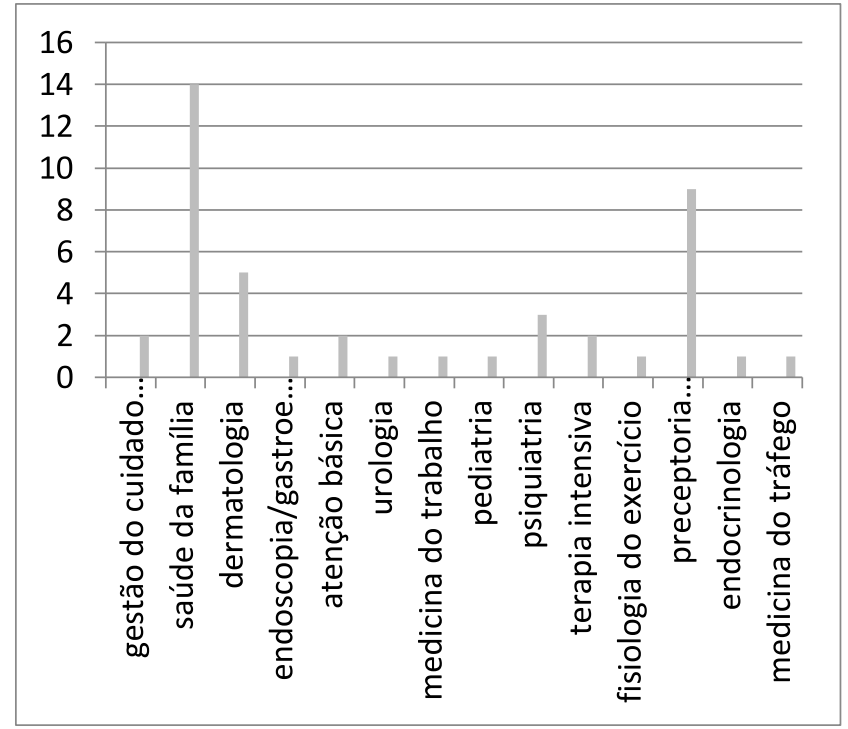


21- Tempo de serviço na ESF

\begin{tabular}{|l|c|}
\hline \multicolumn{1}{|c|}{ Ano } & Número \\
\hline$<1 \mathrm{a}$ & 05 \\
\hline 1 & 07 \\
\hline 2 & 08 \\
\hline 3 & 07 \\
\hline 4 & 06 \\
\hline 5 a 10 & 08 \\
\hline 11 a 15 & 06 \\
\hline 16 a 20 & 02 \\
\hline 21 a 25 & 02 \\
\hline Mais 25 & 01 \\
\hline
\end{tabular}

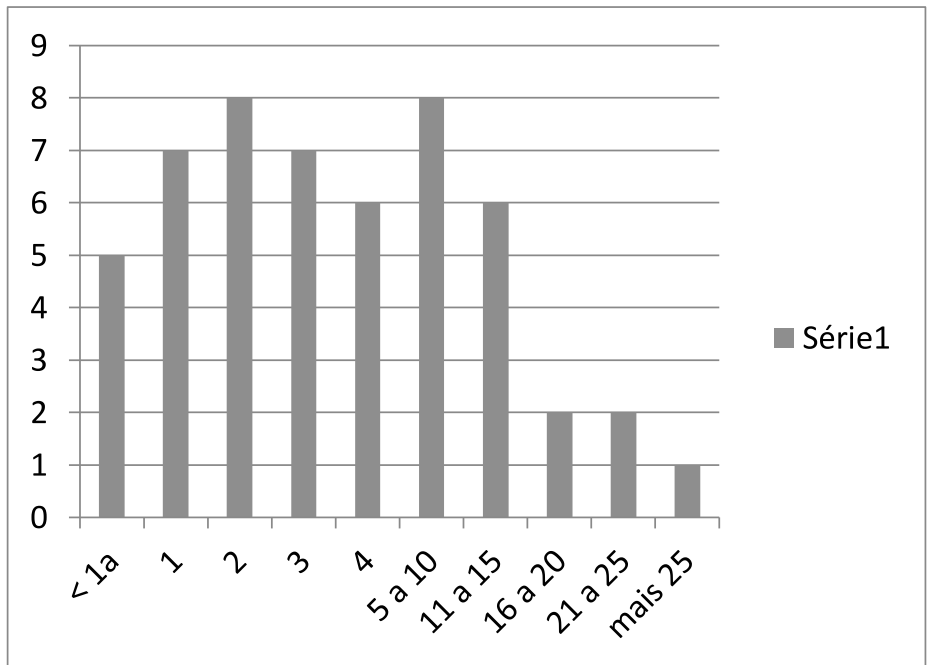

22- Tempo de serviço nesta UBS

\begin{tabular}{|l|c|}
\hline \multicolumn{1}{|c|}{ Ano } & Número \\
\hline$<1 \mathrm{a}$ & 07 \\
\hline 1 & 11 \\
\hline 2 & 10 \\
\hline 3 & 10 \\
\hline 4 & 06 \\
\hline 5 a 10 & 03 \\
\hline 11 a 15 & 01 \\
\hline 16 a 20 & 02 \\
\hline 21 a 25 & 02 \\
\hline Mais 25 & 00 \\
\hline
\end{tabular}




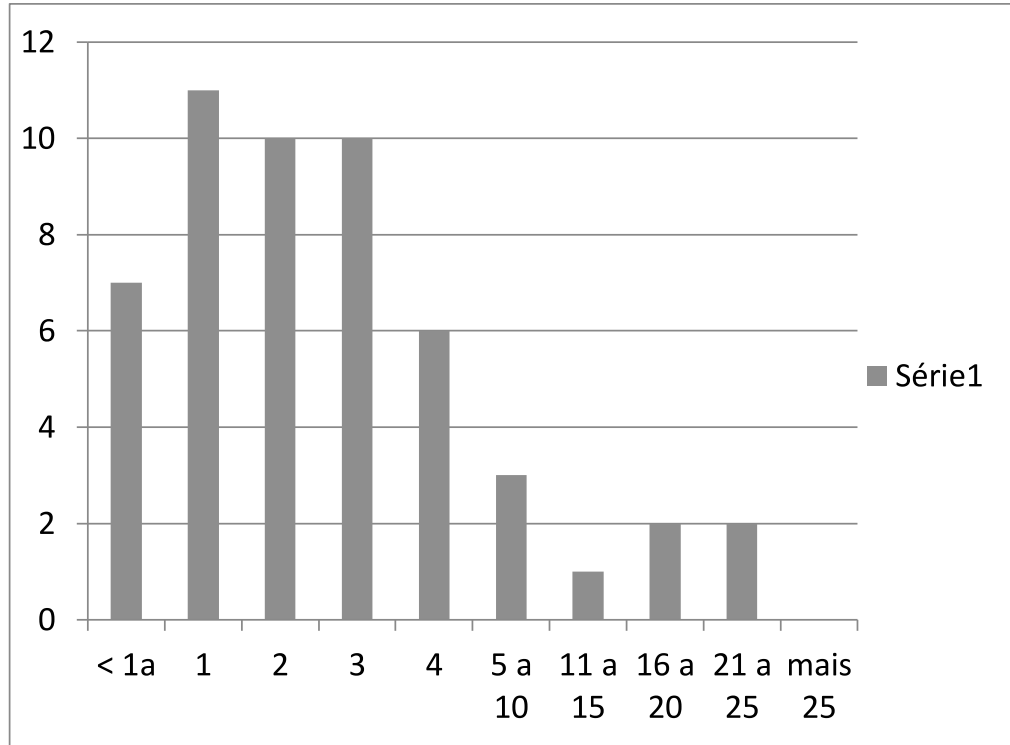

23- Tempo de serviço na APS

\begin{tabular}{|l|c|}
\hline \multicolumn{1}{|c|}{ Ano } & Número \\
\hline$<1 \mathrm{a}$ & 05 \\
\hline 1 & 05 \\
\hline 2 & 08 \\
\hline 3 & 11 \\
\hline 4 & 06 \\
\hline 5 a 10 & 07 \\
\hline 11 a 15 & 05 \\
\hline 16 a 20 & 01 \\
\hline 21 a 25 & 03 \\
\hline Mais 25 & 01 \\
\hline
\end{tabular}

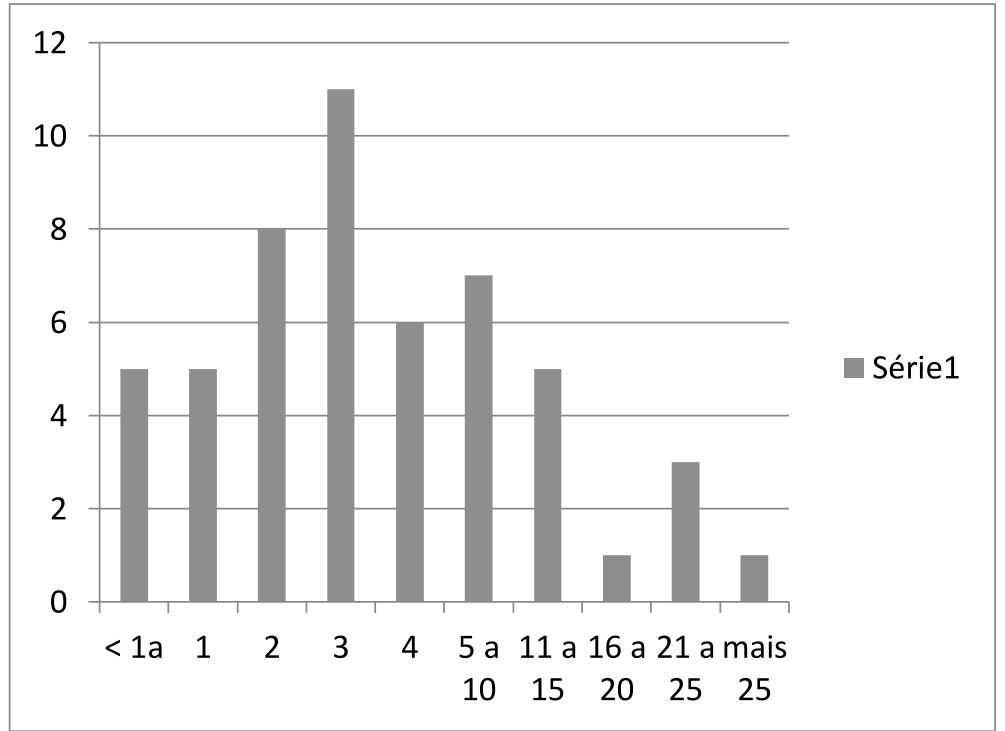

